UNIVERSIDADE DE SÃO PAULO

FACULDADE DE FILOSOFIA, LETRAS E CIÊNCIAS HUMANAS DEPARTAMENTO DE LETRAS MODERNAS

PROGRAMA DE PÓS-GRADUAÇÃo EM ESTUDOS DA TRADUÇÃO

\title{
Práticas Integrativas e Complementares: análise de corpora e glossário bilíngue português/inglês para tradutores
}

Versão corrigida

Luana Mara Almeida Teixeira 


\title{
Práticas Integrativas e Complementares: análise de corpora e glossário bilíngue português/inglês para tradutores
}

\author{
Versão corrigida
}

\begin{abstract}
Dissertação de Mestrado apresentada ao Programa de Pós-Graduação em Estudos da Tradução da Faculdade de Filosofia, Letras e Ciências Humanas da Universidade de São Paulo, parte das exigências para obtenção do título de Mestre em Estudos da Tradução.
\end{abstract}

Orientadora: Profa. Dra. Angela Maria Tenório Zucchi Linha de Pesquisa: Tradução e Corpora 
Autorizo a reprodução e divulgação total ou parcial deste trabalho, por qualquer meio convencional ou eletrônico, para fins de estudo e pesquisa, desde que citada a fonte.

Catalogação na Publicação

Serviço de Biblioteca e Documentação

Faculdade de Filosofia, Letras e Ciências Humanas da Universidade de São Paulo

Teixeira, Luana Mara Almeida

T266p Práticas Integrativas e Complementares: análise de corpora e glossário bilíngue português/inglês para tradutores / Luana Mara Almeida Teixeira ; orientadora Angela Maria Tenório Zucchi. - São Paulo, 2018 .

$192 \mathrm{f}$.

Dissertação (Mestrado) - Faculdade de Filosofia, Letras e Ciências Humanas da Universidade de São Paulo. Departamento de Letras Modernas. Área de concentração: Estudos da Tradução.

1. Tradução. 2. Linguística de corpus. 3 . Terminologia bilíngue. 4. Práticas Integrativas e Complementares. 5. Florais. I. Zucchi, Angela Maria Tenório, orient. II. Título. 
A minha filha Verônika (in memoriam).

A minha filha Iris Bibiana, gestada durante o desenvolvimento desse trabalho. 


\section{Agradecimentos}

A minha família, por ser a raiz de minha trajetória.

Ao meu marido Alexsandro, por me incentivar a trilhar essa jornada.

A minha orientadora Angela, por ter acolhido meu projeto.

A todos os mestres que me fizeram acreditar na possibilidade da união entre ciência e espiritualidade, compreender um pouco mais nosso papel como seres humanos, e a despertar para meu próprio mestre interior. 
A nossa tendência natural é ver as coisas como diferentes, e a tarefa do cientista é descobrir o fio que une, que entretece as muitas flores numa grinalda única e harmoniosa.

Amit Goswami 
TEIXEIRA, L. M. A. Práticas Integrativas e Complementares: análise de corpora e glossário bilíngue português/inglês para tradutores. Dissertação (mestrado) Departamento de Letras Modernas, Faculdade de Filosofia, Letras e Ciências Humanas, Universidade de São Paulo, 2017.

\section{RESUMO}

A busca por saúde e bem-estar é intrínseca ao ser humano. Além da medicina convencional ou alopática, existem numerosas modalidades terapêuticas consideradas parte da Medicina Complementar e Alternativa (MCA). No Brasil, essas terapias foram chamadas Práticas Integrativas e Complementares (PIC), definidas pela Portaria no 971, de 3 de maio de 2006 do Ministério da Saúde. Embora sejam amplamente utilizadas com apoio da Organização Mundial da Saúde, faltam materiais de suporte aos tradutores sobre esse tema. Dessa forma, procuramos desenvolver um glossário bilíngue português brasileiro/inglês britânico dessa área de especialidade, por meio da compilação de corpora comparáveis nos dois idiomas, escolhendo textos representativos sobre essa temática. Para a realização desse trabalho, utilizamos como referenciais teóricos a Linguística de Corpus e a Terminologia Bilíngue. Como ferramenta computacional usamos o WordSmith Tools. Após a compilação dos corpora, utilizando artigos acadêmicos, livros, textos de sites institucionais e legislação, examinamos a linguagem utilizada na área de PIC e extraímos os termos pertinentes à pesquisa por meio de uma análise quantitativa e qualitativa. Verificamos a ocorrência de termos simples, compostos, complexos e siglas. Em seguida, buscamos os equivalentes em língua inglesa para os termos selecionados. Nem todos os equivalentes foram encontrados no corpus em inglês, portanto, realizamos nova busca usando a web como corpus. Explicitamos a macroestrutura e a microestrutura propostas e apresentamos a primeira versão do glossário, com exemplos de contextos de uso autêntico em ambos os idiomas. Propusemo-nos também a buscar os equivalentes em inglês para uma terapia desenvolvida no Brasil cuja terminologia ainda não tivesse sido vertida para o inglês. Foi escolhida a terapia floral baseada na alquimia, da qual elaboramos um corpus, extraímos os termos mais representativos e buscamos os equivalentes em inglês por meio de pesquisas pontuais. Elaboramos um glossário ilustrado de plantas utilizadas na produção das essências florais utilizadas nessa terapia. Esperamos contribuir com um material de apoio inicial aos tradutores da área de PIC, além de incentivar o desenvolvimento de novas pesquisas sobre essa lingua de especialidade.

Palavras-chave: Linguística de Corpus; Terminologia Bilíngue; Práticas Integrativas e Complementares; Medicina Complementar e Alternativa; florais. 
TEIXEIRA, L. M. A. Complementary and Integrative Practices: corpora analysis and bilingual glossary Portuguese/English for translators. Dissertação (mestrado) Departamento de Letras Modernas, Faculdade de Filosofia, Letras e Ciências Humanas, Universidade de São Paulo, 2017.

\begin{abstract}
The search for health and well-being is intrinsic to the human being. In addition to conventional or allopathic medicine, there are numerous therapeutic modalities considered part of Complementary and Alternative Medicine (CAM). In Brazil, these therapies are called Complementary and Integrative Practices (CIP), defined by Ministry of Health Ordinance No. 971 of May 3, 2006. Although widely used with support from the World Health Organization, there is a lack of reference terminological materials for translators on this topic. Thus, we seek to develop a Brazilian Portuguese/British English bilingual glossary of this area of expertise, by compiling comparable corpora in both languages, choosing representative texts on this topic. In order to carry out this work, we used as theoretical references Corpus Linguistics and Bilingual Terminology. As a computational tool we used WordSmith Tools. After the compilation of corpora, using academic articles, books, texts of institutional websites and legislation, we examined the language used in the area of CIP and extracted the related terms to the research through a quantitative and qualitative analysis. We verified the occurrence of simple terms, compound terms, complex terms and acronyms. Next, we searched for English equivalents of the selected terms. Not all of the equivalents were found in the English corpus, so we performed a new search using the web as a corpus. Then, we explained the proposed macrostructure and microstructure and presented the first version of the glossary, with examples of contexts of authentic use in both languages. We also proposed to seek equivalents in English for a therapy developed in Brazil whose terminology had not yet been translated into English. Alchemy based flower essences therapy was chosen, from which we developed a corpus, extracted the most representative terms and searched for equivalents in English through a one-on-one research. We developed an illustrated glossary of plants used in the production of the flower essences used in this therapy. We hope to contribute an initial reference material to translators in the area of CIP, as well as encouraging the development of new research on this specialized language.
\end{abstract}

Keywords: Corpus Linguistics; Bilingual Terminology; Complementary and Integrative Practices; Complementary and Alternative Medicine; flower essences. 
TEIXEIRA, L. M. A. Pratiche integrative e complementari: analisi di corpora e glossario bilingue portoghese/inglese per i traduttori. Dissertação (mestrado) - Departamento de Letras Modernas, Faculdade de Filosofia, Letras e Ciências Humanas, Universidade de São Paulo, 2017.

\section{RIASSUNTO}

La ricerca della salute e del benessere è intrinseca all'essere umano. Oltre alla medicina convenzionale o allopatica, ci sono numerose modalità terapeutiche considerate parte della Medicina Complementare e Alternativa (MCA). In Brasile, queste terapie vengono chiamati Pratiche Integrativa e Complementari (PIC), definite dalla ordinanza n 971, del 3 maggio 2006, dal Ministero della Salute. Anche se ampiamente utilizzate, come sostiene l'Organizzazione Mondiale della Sanità, c'è una mancanza di strumenti ausiliari ai traduttori su questo argomento. Quindi, abbiamo cercato di sviluppare un glossario bilingue portoghese brasiliano / inglese britannico su questo campo di specialità, in base alla ricerca a partire dalla compilazione di corpora paragonabile in entrambe le lingue, con testi rappresentativi su questo argomento. Per eseguire questo lavoro, abbiamo usato come riferimenti teorici e metodologici la Corpus Linguistics e la Terminologia Bilingue. Come strumento di calcolo abbiamo usato WordSmith Tools. Dopo la compilazione dei corpora, utilizzando articoli accademici, libri, testi di siti istituzionali e legislazione, abbiamo esaminato il linguaggio utilizzato nel settore dei PIC ed estratto i termini pertinenti alla ricerca attraverso un'analisi quantitativa e qualitativa. Abbiamo verificato la presenza di termini semplici, composti, complessi e acronimi. Successivamente, abbiamo cercato gli equivalenti inglesi per i termini selezionati. Non tutti gli equivalenti sono stati trovati nel corpus in inglese, così abbiamo effettuato una nuova ricerca utilizzando la web come corpus. Reso esplicito le proposte di macrostruttura e microstruttura e presentato la prima versione del glossario con esempi di contesti di utilizzo autentici in entrambe le lingue. Abbiamo anche proposto di cercare equivalenti in inglese per una terapia sviluppata in Brasile la cui terminologia non era ancora stata tradotta in inglese. Si è scelto la floriterapia basata su alchimia, da cui abbiamo elaborato un corpus, estratto i termini più rappresentativi e cercato equivalenti in inglese attraverso una ricerca uno-a-uno. Abbiamo sviluppato un glossario illustrato di piante utilizzate nella produzione di essenze floreali utilizzate in questa terapia. Speriamo di contribuire nel fornire un materiale di supporto iniziale ai traduttori nel settore dei PIC e incoraggiare lo sviluppo di nuove ricerche in questa lingua di specialità.

Parole chiave: Linguistica di corpus; Terminologia Bilíngue; Pratiche Integrative e Complementari; Medicina Complementare e Alternativa; floriterapia. 


\section{LISTA DE FIGURAS}

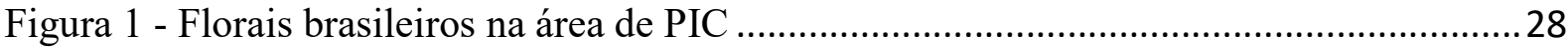

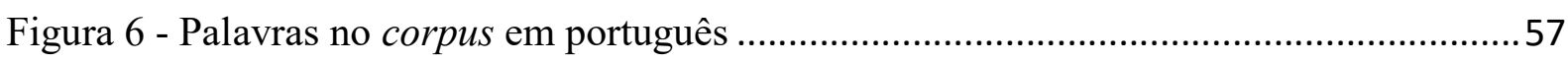

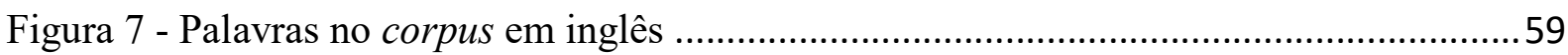

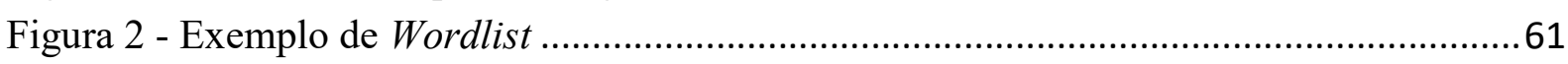

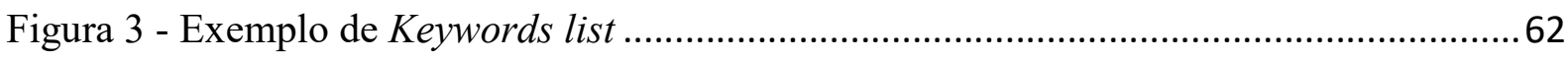

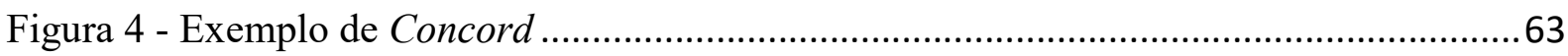

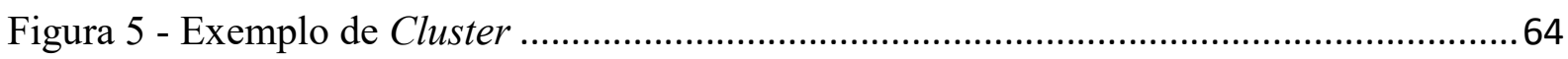

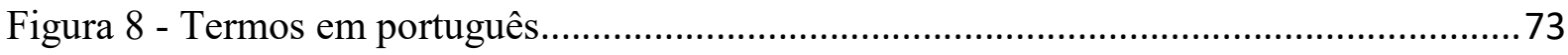

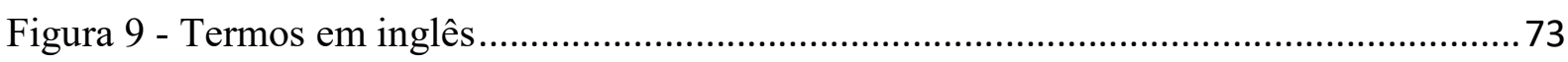




\section{LISTA DE QUADROS}

Quadro 1 - Árvore de conceitos de PIC 51

Quadro 3 - Keywords corpus de florais 67

Quadro 4 - Lista de termos e equivalentes .72

Quadro 5 - Exemplos de traços conceptuais. 85

Quadro 6 - Glossário português/inglês de PIC . .93

Quadro 7 - Glossário inglês/português de PIC 1187

Quadro 8-Glossário português/inglês de florais brasileiros. 121

Quadro 9 - Glossário inglês/português de florais brasileiros. 138 


\section{LISTA DE SIGLAS}

BNC - British National Corpus

BVS - Biblioteca Virtual da Saúde

CAM - Complementary and Alternative Medicine

DT - Definição Terminológica

ETBC - Estudos da Tradução Baseados em Corpus

FHT - Federation of Holistic Therapists

LC - Linguística de Corpus

MC - Medicina Complementar

MAC - Medicina Alternativa e Complementar

MCA - Medicina Complementar e Alternativa

MI - Medicina Integrativa

MT - Medicina Tradicional

MT\&C - Medicina Tradicional e Complementar

OCR - Optical Characters Recognition

OMS - Organização Mundial da Saúde

PIC - Práticas Integrativas e Complementares

PNPIC - Política Nacional de Práticas Integrativas e Complementares

SINTE - Sociedade Internacional de Terapia

SUS - Sistema Único de Saúde

$\mathrm{T} \& \mathrm{CM}$ - Traditional and Complementary Medicine

TCT - Teoria Comunicativa da Terminologia

TGT - Teoria Geral da Terminologia

TM - Traditional Medicine

WHO - World Health Organization

WST - WordSmith Tools 


\section{SUMÁRIO}

Introdução 14

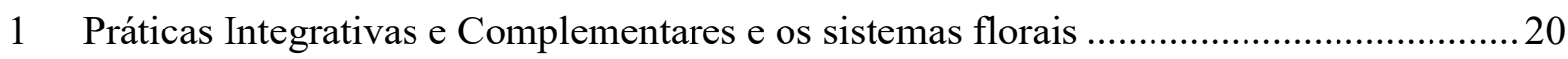

1.1 Breve panorama sobre a utilização de PIC .............................................................20

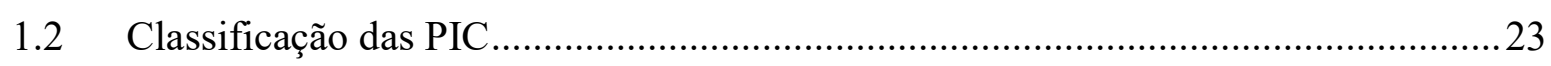

1.3 Sistemas florais e a escolha de uma terapia criada no Brasil..................................24

1.3.1 A escolha dos florais brasileiros baseados na alquimia ...................................2

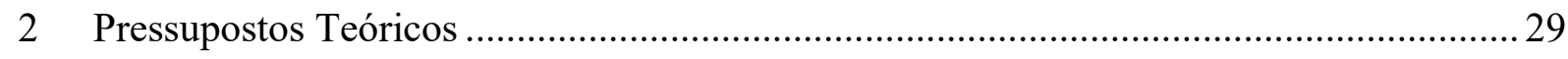

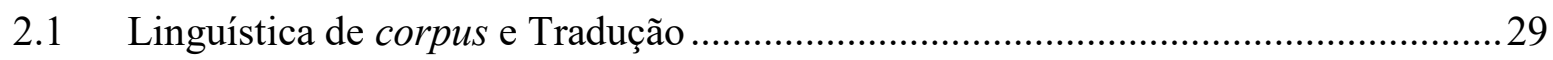

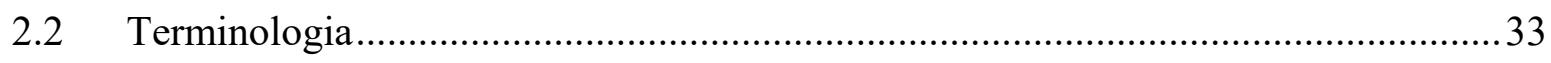

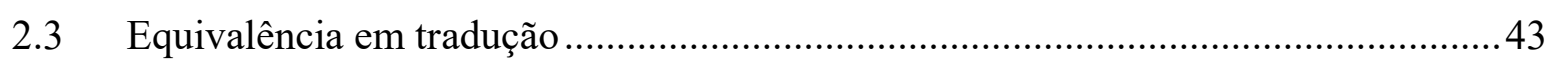

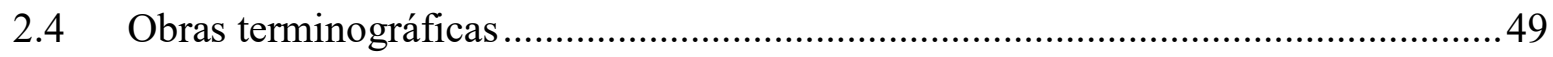

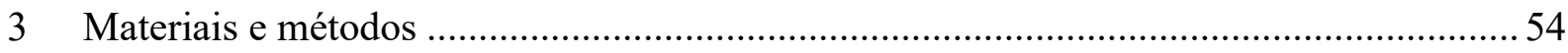

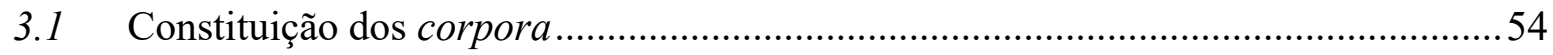

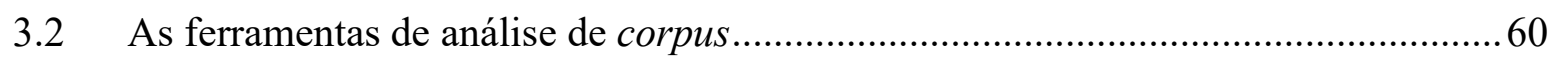

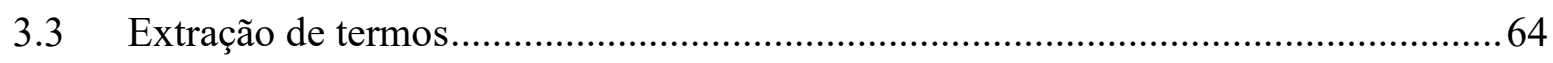

4 Apresentação e discussão dos resultados ................................................................... 68

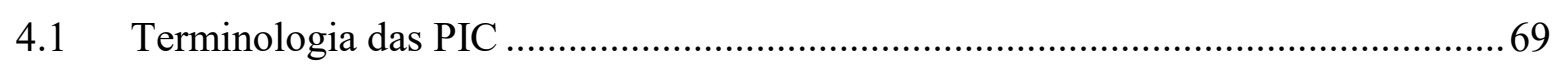

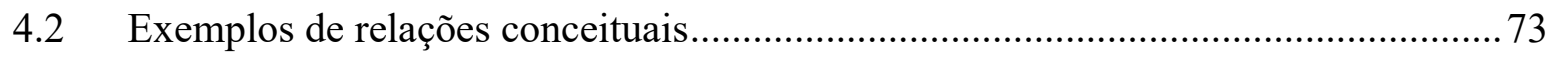

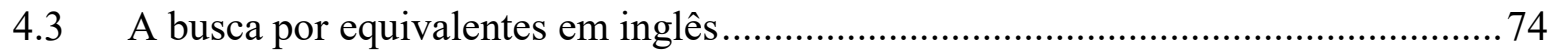

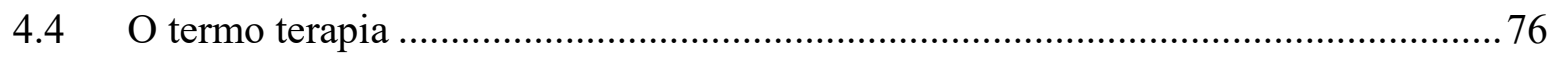

4.5 Exemplos de contextos definitórios, explicativos e associativos ..............................77

4.6 Exemplos de traços conceptuais encontrados na busca por equivalentes ................. 79

4.7 Termos do corpus de florais brasileiros baseados na alquimia ............................... 85

5 O glossário de PIC e o glossário de florais ................................................................ 91

5.1 Glossário português/inglês de PIC ......................................................................92

5.1.1 Glossário inglês/português de PIC …......................................................... 116

5.2 O glossário bilíngue de plantas utilizadas nos florais brasileiros baseados na alquimia

5.2.1 Glossário ilustrado português/inglês de plantas usadas nos florais brasileiros 120

5.2.2 Glossário inglês-português de plantas usadas nos florais brasileiros ............... 137

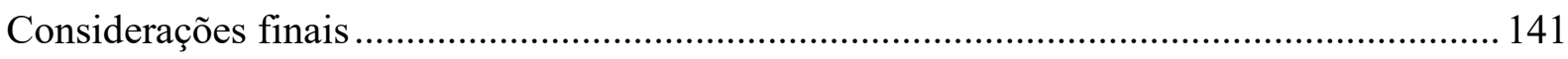




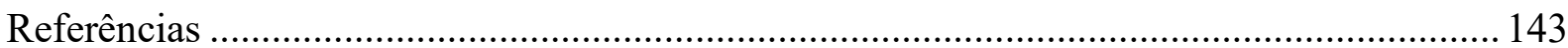

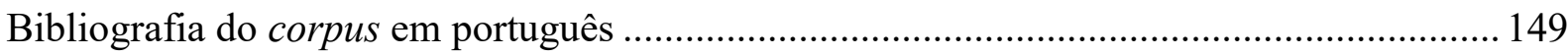

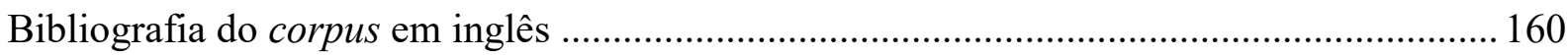

Apêndice I - Lista de palavras-chave do corpus em português ................................................ 171

Apêndice II - 500 primeiras palavras-chave do corpus em inglês............................................ 183 


\section{INTRODUÇÃO}

A busca pelo bem-estar é uma característica intrínseca ao ser humano, e esse bemestar, que contempla as dimensões física, emocional, mental, social e espiritual do indivíduo, pode ser sintetizado pela palavra "saúde".

É notório o grande avanço tecnológico que a medicina alopática ou convencional tem conquistado ao longo dos anos, salvando a vida de inúmeras pessoas, porém, este não é o único tipo de medicina buscado e utilizado por grande parcela da população.

Há também a Medicina Tradicional (MT), que aplica saberes ancestrais, mantidos de geração em geração por culturas atávicas; a Medicina Complementar e Alternativa (MCA), que abrange uma vasta gama de terapias que usam técnicas naturais, holísticas, tradicionais ou não convencionais amplamente difundidas entre os mais diversos povos; e a Medicina Integrativa (MI), que busca conciliar a medicina alopática com terapias complementares.

De acordo com a Organização Mundial da Saúde (2014), em alguns países, a Medicina Tradicional é a principal fonte de cuidados de saúde ou serve como um complemento a ela. Em outros países, a Medicina Tradicional ou não convencional é denominada Medicina Complementar (MC).

A maneira de se relacionar com a saúde e com a falta dela nos dá indícios da idiossincrasia de uma comunidade e mesmo de sua cosmovisão, pois nos trazem elementos de sua maneira de perceber, sentir e agir em relação às coisas. A fatores econômicos e de acesso, somam-se aspectos culturais e subjetivos na escolha de um tipo de tratamento que refletem crenças e a própria narrativa ontológica do ser.

Existem diversas formas de denominar essas modalidades de terapias, como: terapias complementares, alternativas, integrativas, holísticas, tradicionais ou não convencionais. Parece haver, entretanto, um consenso no sentido de levar em consideração o indivíduo em sua totalidade. A parte imaterial do ser, sua alma (emoções, sentimentos e pensamentos) é vista como indissociável da parte física (corpo), sendo que os processos físicos e doenças relacionam-se a estados mentais e emocionais. 
No que concerne à denominação, apresentamos a seguir algumas definições difundidas pela Organização Mundial da Saúde (OMS, 2014, tradução nossa) :

Medicina Tradicional (MT): A medicina tradicional tem uma longa história. É a soma dos conhecimentos, habilidades, práticas baseadas nas teorias, crenças e experiências intrínsecas a diferentes culturas, explicáveis ou não, utilizadas na manutenção da saúde, bem como na prevenção, diagnóstico, melhoria ou tratamento de doença física e mental. ${ }^{1}$

Medicina complementar (MC): Os termos "medicina complementar" ou "medicina alternativa" referem-se a um amplo conjunto de práticas de cuidados de saúde que não fazem parte da medicina tradicional ou convencional do país e não estão totalmente integrados no sistema de saúde dominante. Eles são usados em conjunto com a medicina tradicional em alguns países. $^{2}$

Medicina tradicional e complementar (MT\&C): MT\&C funde os termos MT e MC, englobando produtos, práticas e profissionais. ${ }^{3}$

Para Medicina Integrativa (MI), consideramos uma definição de Andrew Weil, médico norte-americano, pioneiro na difusão desse termo:

\begin{abstract}
Medicina Integrativa é uma abordagem médica orientada para a cura (healing), tendo como foco o cuidado do paciente como um todo - mente, corpo, espírito e estilo de vida. Além disso, enfatiza o relacionamento terapêutico e emprega todas as terapias adequadas para cada caso, tanto as convencionais como as complementares. No entanto, medicina integrativa não é sinônimo de medicina alternativa ou complementar, pois não rejeita a medicina convencional e tampouco aceita tratamentos complementares sem um olhar crítico (Weil, 2009). ${ }^{4}$
\end{abstract}

\footnotetext{
${ }^{1}$ Original: Traditional medicine (TM): Traditional medicine has a long history. It is the sum of the knowledge, skill, practices based on the theories, beliefs, and experiences indigenous to different cultures, whether explicable or not, used in the maintanence of health as well in the prevention, diagnosis, improvement or treatment of physical and mental illness (WHO, 2014, p. 15).

2Original: Complementary medicine (CM): The terms "complementary medicine" or "alternative medicine" refer to a broad set of health care practices that are not part of that country's own traditional or conventional medicine and are not fully integrated into the dominant health-care system. They are used interchangeably with traditional medicine in some countries (WHO, 2014, p. 15).

${ }^{3}$ Original: Traditional and Complementary Medicine (T\&CM): T\&CM merges the terms TM and CM, encompassing products, practices and practioners (WHO, 2014, p. 15).

${ }^{4}$ Andrew Weil, fundador e diretor do Centro de Medicina Integrativa da Universidade do Arizona.
} 
No Brasil, essas técnicas terapêuticas foram chamadas de Práticas Integrativas e Complementares (PIC), definidas pela Portaria de $\mathrm{n}^{\circ}$ 971, de 3 de maio de 2006 do Ministério da Saúde / Gabinete do Ministro, que aprova a Política Nacional de Práticas Integrativas e Complementares (PNPIC) no Sistema Único Saúde. São regidas pelo decreto $n^{\circ}$ 5813 de 22 de junho de 2006 que aprova a Política Nacional de Plantas Medicinais e Fitoterápicos e dá outras providências. A Portaria de $n^{0} 971$ dispõe sobre as práticas Medicina Tradicional Chinesa - Acupuntura, Homeopatia, Plantas Medicinais e Fitoterapia e Termalismo Social/Crenoterapia.

Posteriormente, foi publicada a Portaria nº 849, de 27 de março de 2017 do Ministério da Saúde, que: "Inclui a Arteterapia, Ayurveda, Biodança, Dança Circular, Meditação, Musicoterapia, Naturopatia, Osteopatia, Quiropraxia, Reflexoterapia, Reiki, Shantala, Terapia Comunitária Integrativa e Yoga à Política Nacional de Práticas Integrativas e Complementares". 5 No entanto, há muitos outros tipos de terapias não contempladas nesse documento, que se encontram descritas, por exemplo, no site da Sociedade Internacional de Terapias. ${ }^{6}$

Feitas essas considerações, esclarecemos que no escopo deste trabalho, utilizaremos Práticas Integrativas e Complementares (PIC) para nos referirmos tanto às técnicas terapêuticas utilizadas em Medicina Tradicional, Medicina Complementar e Alternativa quanto àquelas utilizadas em Medicina Integrativa, que muitas vezes são as mesmas, mudando apenas a forma de abordagem. No entanto, destacamos que essa terminologia faz parte de uma política governamental nacional, e nesta dissertação abrangemos técnicas terapêuticas não abordadas pela presente legislação brasileira.

É pertinente ressaltar que o foco desta pesquisa é unicamente relacionado à terminologia utilizada na área de Práticas Integrativas e Complementares, especificamente no que tange às questões terminológicas e de tradução, independentemente de sua eficácia, riscos ou comprovação científica, pois este trabalho está inserido no âmbito dos Estudos da Tradução.

\footnotetext{
${ }^{5}$ Em tempo: após a defesa desta dissertação, o Ministério da Saúde anunciou a inclusão de mais 10 modalidades de PIC no SUS, conforme notícia disponível em: https://www1.folha.uol.com.br/cotidiano/2018/03/sus-incluidez-novas-terapias-alternativas-como-a-de-

florais.shtml?utm_source=twitter\&utm_medium=social\&utm_campaign=twfolha, acesso em 12/03/2018. Foram incorporadas na rede pública as seguintes terapias: apiterapia, aromaterapia, constelação familiar, cromoterapia, geoterapia, bioenergética, hipnoterapia, imposição de mãos, ozonioterapia e terapia de florais.

${ }^{6} \mathrm{http}: / / \mathrm{www} \cdot$ sinte.com.br/
} 
Partindo da direção português-inglês, deparamos com a questão de pesquisa: como encontrar equivalentes em inglês para as principais Práticas Integrativas e Complementares utilizadas no Brasil para a construção de um glossário bilíngue?

Também deve-se levar em conta o surgimento e assimilação de novas modalidades terapêuticas. A OMS alerta que as autoridades nacionais de saúde, "reconhecendo o fato de que a MT\&C é verdadeiramente global, devem estar preparadas para lidar com novas formas de MT\&C sendo introduzidas de outros países” (OMS, 2014, p. 32). Nesse caso, considerando uma terapia criada e desenvolvida no Brasil e que ainda não tenha sido traduzida, será possível encontrar equivalentes em inglês para seus principais termos?

Diante do exposto, temos como objetivo principal deste trabalho a elaboração de uma proposta de glossário bilíngue na direção português brasileiro/inglês britânico da terminologia de Práticas Integrativas e Complementares. Para atingir esse escopo, acreditamos que a Linguística de Corpus (LC) seja de grande auxílio para a elaboração de um glossário, com o par linguístico português brasileiro/inglês britânico.

Dessa forma, o primeiro passo para a realização deste trabalho é a compilação de corpora originais em português e inglês, com textos específicos sobre a área a ser estudada, para utilizar ferramentas computacionais de análise de corpus, e assim extrair palavras-chave e possíveis candidatos a termo.

Assim , temos as seguintes objetivos específicos:

- compilar corpora comparáveis bilíngues, com textos originais em português e inglês, da área de Práticas Integrativas e Complementares.

- Extrair os termos do corpus em português e buscar os equivalentes no corpus em inglês.

- Extrair contextos de uso real dos termos nos dois idiomas para a composição do glossário.

- Selecionar um tipo de terapia criada e desenvolvida do Brasil que não tenha sido traduzida, compilar um corpus dessa área para a seleção de termos e buscar os equivalentes em inglês para elaboração de um glossário. 
Para atestar a relevância deste trabalho, consideramos o seguinte item entre as ações estratégicas recomendadas pela OMS para seus Estados-membros: "Incentivar a geração, tradução e disseminação de conhecimento, estabelecendo uma abordagem abrangente e inclusiva da pesquisa e desenvolvimento da MT\&C, inclusive em qualidade e custoefetividade" (WHO 2014, p. 47). ${ }^{7}$

Conforme será explicitado no Capítulo 1, as modalidades terapêuticas utilizadas em PIC e MCA já estão integradas na sociedade, no entanto, até o momento de realização dessa pesquisa, não localizamos trabalhos publicados sobre esse tema para tradutores. Não encontramos disponível nenhum glossário bilíngue com o par linguístico português-inglês sobre Práticas Integrativas e Complementares, portanto, justifica-se o desenvolvimento de um material de apoio ao tradutor desta abrangente área de conhecimento.

A presente dissertação está organizada em cinco capítulos, além desta Introdução, das Considerações Finais e Referências. A seguir, apresentamos brevemente o que será desenvolvido em cada parte.

No Capítulo 1, demonstramos a abrangência de utilização das PIC, portanto, corrobora-se a escolha dessa temática como objeto de estudos linguísticos. Trata-se de um campo de conhecimento que vem se desenvolvendo desde o início da civilização no ensejo de manter ou restaurar a saúde física e mental de forma integrada. Abordamos também a escolha de uma terapia desenvolvida no Brasil, os florais brasileiros baseados na alquimia.

No Capítulo 2, apresentamos os Pressupostos Teóricos e conceitos utilizados para a realização deste trabalho: a Linguística de Corpus, tipos e critérios para compilação de corpora; a Terminologia, seus objetos de estudo, especialmente o termo, as aplicações em Terminografia e a construção de obras terminográficas; a busca por equivalentes em tradução e as intersecções entre o uso de corpora, Terminologia e Tradução.

No Capítulo 3, explicitamos a metodologia, com a utilização das ferramentas computacionais de apoio à pesquisa, descrevemos a formação dos corpora de estudos, os critérios para compilação dos textos e para a extração dos termos a partir das listas de palavras-chave.

\footnotetext{
${ }^{7}$ Encourage knowledge generation, translation and dissemination by establishing a comprehensive and inclusive approach to T\&CM research and development including into quality and cost-effectiveness. World Health Organization (WHO).
} 
No Capítulo 4, analisamos os resultados, expomos a nomenclatura da proposta de glossário e discutimos as relações entre os termos, exemplificamos os tipos de contextos encontrados nos corpora e os traços conceptuais comuns em português e inglês na busca por equivalentes tradutórios.

Finalmente, no Capítulo 5, apresentamos a primeira versão de nosso glossário bilíngue português/inglês de Práticas Integrativas e Complementares e o de plantas utilizadas na produção dos florais brasileiros baseados na alquimia.

Concluímos esta dissertação com as Considerações Finais, Referências citadas ao longo do trabalho, a Bibliografia do corpus em português, a Bibliografia do corpus em inglês e ainda dois Apêndices: o primeiro com a lista completa de palavras-chave gerada a partir do corpus em português e o segundo com uma amostra das palavras-chave do corpus em inglês.

Esta pesquisa poderá auxiliar o trabalho de tradutores, redatores, terapeutas que pesquisem novas técnicas ou atuem em países diferentes do seu de origem e até mesmo usuários e pacientes desses tratamentos que queiram ter clareza sobre o método ao qual serão submetidos, seja um estrangeiro no Brasil, ou um brasileiro em consulta no exterior, em um país anglo-falante. 


\section{PRÁTICAS INTEGRATIVAS E COMPLEMENTARES E OS SISTEMAS FLORAIS}

Neste capítulo, abordaremos a utilização de PIC no Brasil e no exterior, a classificação dessas práticas e a inserção dos sistemas florais nessa área. Também vamos apresentar a terapia desenvolvida no Brasil escolhida para estudo: os florais brasileiros baseados na alquimia.

\subsection{Breve panorama sobre a utilização de PIC}

Em 2002, quando foi publicada a Traditional Medicine Strategy 2002-2005, a OMS já reconhecia a ampla difusão da Medicina Complementar e Alternativa (MCA) ao redor do mundo e seu rápido crescimento nos sistemas de saúde e em sua importância econômica.

Em 2014 foi publicado um segundo documento norteador dessa área para os Estadosmembros da OMS, a Traditional Medicine Strategy 2014-2023, com dois objetivos principais: “apoiar os Estados-Membros no aproveitamento da contribuição potencial da MT\&C para a saúde, o bem-estar e os cuidados de saúde centrados nas pessoas e promover a utilização segura e eficaz da MT\&C através da regulamentação de produtos, práticas e profissionais" (OMS, 2014, p. 8). ${ }^{8}$

De acordo com esse documento, muito mudou desde que a estratégia global anterior foi publicada em 2002:

\footnotetext{
Mais países aceitaram gradualmente a contribuição que a MT\&C pode fazer para a saúde e o bem-estar dos indivíduos e para a abrangência de seus sistemas de saúde. Os governos e os consumidores estão interessados em mais do que medicamentos à base de plantas, e estão começando a considerar aspectos das práticas e profissionais de MT\&C e se eles devem ser integrados à prestação de serviços de saúde (WHO, 2014, p. 7). ${ }^{9}$
}

\footnotetext{
${ }^{8}$ To support Member States in harnessing the potential contribution of T\&CM to health, wellness and peoplecentred health care and to promote the safe and effective use of T\&CM through the regulation of products, practice and practitioners.

${ }_{9}^{9}$ More countries have gradually come to accept the contribution that T\&CM can make to the health and wellbeing of individuals and to the comprehensiveness of their health-care systems. Governments and consumers are interested in more than herbal medicines, and are now beginning to consider aspects of T\&CM practices and practitioners and whether they should be integrated into health service delivery.
} 
Ainda de acordo com a OMS (2014), a utilização de Medicina Complementar ou Alternativa tem sido cada vez mais alvo de estudos para sua regulamentação em diversos países, além de ter aumentado sua inserção em cursos de nível superior nas últimas décadas.

Sobre a prevalência desse tipo de cuidado de saúde, "mais de 100 milhões de europeus são atualmente usuários da $\mathrm{MT} \& \mathrm{C}$, com um quinto usando regularmente $\mathrm{MT} \& \mathrm{C}$ e o mesmo número preferindo cuidados de saúde que incluam MT\&C. Há muito mais usuários de MT\&C na África, Ásia, Austrália e América do Norte" (WHO, 2014, p. 25). ${ }^{10}$

Especificamente em nosso continente, a Medicina Integrativa está se tornando cada vez mais aceita. "Nos Estados Unidos, 44 das 125 faculdades de medicina já adotam esse modelo, executando-o tanto na prática clínica como nas áreas de educação e pesquisa" (Frenkel. M., 2009). ${ }^{11}$

No Brasil, com a integração de diversas práticas terapêuticas integrativas e complementares ao Sistema Único de Saúde (SUS), também houve expansão na área. "Dados do Ministério da Saúde mostram que o SUS faz, em média, 385 mil procedimentos de acupuntura e mais de 300 mil de homeopatia por ano. Esses serviços estão disponíveis em cerca de 1200 municípios" (Lima, 2009, p. 25-26).

De acordo com Lima (2009), a Universidade Federal de São Paulo (Unifesp) pesquisa há anos a influência da meditação e das técnicas de biofeedback em transtornos de ansiedade e distúrbios alimentares e o Hospital Albert Einstein tem levado a Medicina Integrativa a pacientes que convivem com o câncer.

Em junho de 2017, a Faculdade de Saúde Pública da Universidade de São Paulo realizou seu $1^{\mathrm{o}}$ Seminário de Práticas Integrativas e Complementares ${ }^{12}$, no qual foram abordados temas como iridologia, self-healing, meditação, calatonia e toques sutis, plantas medicinais e fitoterápicos, yoga, antroposofia, entre outros.

\footnotetext{
${ }^{10}$ Over 100 million Europeans are currently T\&CM users, with one fifth regularly using T\&CM and the same number preferring health care which includes T\&CM. There are many more T\&CM users in Africa, Asia, Australia and North America.

${ }^{11}$ Dr. Moshe Frenkel, professor associado - diretor médico do Programa de Medicina Integrativa do MD Anderson Cancer Center, da Universidade do Texas

${ }^{12} \mathrm{http}: / /$ www.fsp.usp.br/site/eventos/mostrar/6507
} 
Técnicas como essas são utilizadas em consultórios, spas, resorts, centros terapêuticos, instituições religiosas e também em hospitais como, por exemplo, no Hospital Sírio Libanês, em São Paulo/SP em que:

A exemplo do que acontece nos maiores centros internacionais de oncologia, o Sírio-Libanês oferece a seus pacientes uma série de terapias complementares que contribuem efetivamente para o seu bem-estar ao longo de todo o tratamento. Fazem parte dos cuidados integrativos práticas como a meditação, a acupuntura, técnicas de relaxamento e respiração, musicoterapia, arteterapia, reiki, tai chi chuan e yoga. (Hospital Sírio-Libanês, [s.d] $)^{13}$

Já no Hospital Sofia Feldman, em Belo Horizonte/MG, existe o núcleo de Terapias Integrativas e Complementares, onde:

No Centro de Parto Normal é oferecido às parturientes escalda pés, homeopatia, aromaterapia, musicoterapia, método Rességuier e massagem, favorecendo a humanização do parto e nascimento, através de qualificação da vivência do trabalho de parto, relaxamento e alívio à dor. (Hospital Sofia Feldman, [s.d.]) $)^{14}$

Podemos citar ainda o Hospital da Divina Providência, em Porto Alegre/RS, que comporta o Ambulatório de Terapias Naturais e Complementares; e o Centro de Especialidades em Práticas Integrativas e Complementares (CREMIC), antigo Hospital de Medicina Alternativa, de Goiânia/GO, que oferece esse tipo de tratamento à população pelo SUS.

Os profissionais dessa área de atuação buscam formação em cursos livres disponibilizados pelos mais diversos institutos e afins, além de cursos de graduação e pósgraduação ofertados em universidades ou faculdades. Há profissionais atuantes pertencentes a área da saúde e outros que não possuem formação regular.

Segundo a OMS (2014), resultados do Projecto CAMbrella ${ }^{15}$ indicam que a provisão da MT\&C na União Europeia provém de aproximadamente 160.000 profissionais não médicos e 145.000 médicos.

No Brasil, há cursos de graduação na área reconhecidos pelo Ministério da Educação (MEC), como Naturologia, da Universidade do Sul de Santa Catarina (Unisul); Naturologia

\footnotetext{
${ }^{13} \mathrm{http}$ ://www.hospitalsiriolibanes.org.br/hospital/especialidades/centro-oncologia

${ }^{14} \mathrm{http}: / /$ www.sofiafeldman.org.br/atencao-a-mulher/nt-integrativas

${ }^{15} \mathrm{CAMbrella}$ is a European research network for complementary and alternative medicine (CAM) that conducted a research program into the situation of CAM in Europe between 2010 and 2012. The group consisted of 16 partner institutions from 12 European countries. The CAMbrella project focussed on academic research into, but not the advocacy for any CAM treatment. http://www.cambrella.eu/home.php
} 
Aplicada, da Universidade Anhembi Morumbi, em São Paulo/SP; e Musicoterapia, curso oferecido pelas Faculdades Metropolitanas Unidas (FMU),em São Paulo/SP.

Também no Reino Unido, as PIC estão presentes nos currículos das universidades, como por exemplo, o curso de "Equine Sports Therapy and Rehabilitation", da University of Greenwich, no País de Gales, e o curso de "Complementary Healthcare" da Cardiff Metropolitan University - UK, que proporciona formação em "massage therapy, reflexology and aromatherapy".

Além do mais, no site da Federation of Holistic Therapists (FHT, [s.d.]), declarada "a maior e principal associação profissional de terapeutas do Reino Unido e da Irlanda"16, encontramos grande diversidade de terapias em seu Directory ${ }^{17}$, que é uma espécie de glossário de PIC.

Em pesquisas em periódicos para a construção dos corpora de estudo que abordaremos posteriormente, observamos que houve aumento da pesquisa científica na área ao longo dos anos.

\subsection{Classificação das PIC}

A OMS (2002) divide as PIC em basicamente dois grandes grupos de terapias:

Dependendo das terapias envolvidas, as terapias de MT / MAC podem ser tratadas como terapias de medicação - se usam medicamentos à base de plantas, partes de animais e / ou minerais - ou terapias não medicamentosas - se forem realizadas principalmente sem usar medicação, como no caso da acupuntura, terapias manuais, qigong, taiji, terapia termal, ioga e outras terapias físicas, mentais e espirituais corpo-mente (tradução nossa). ${ }^{18}$

Diversos autores também buscam uma categorização dessas terapias. De acordo com Kramlich (2014), as terapias usadas em CAM podem ser divididas em: Natural products and mind-and-body practices (produtos naturais e práticas mente-corpo).

\footnotetext{
16 "the largest and leading professional association for therapists in the UK and Ireland"

${ }^{17} \mathrm{http}$ ://findatherapist.fht.org.uk/d

${ }^{18}$ Depending on the therapies involved, TM/CAM therapies can be catergorized as medication therapies - if they use herbal medicines, animal parts and/or minerals - or non-medication therapies - if carried out primarily without using medication, as in the case of acupunture, manual therapies, qigong, taiji, termal therapy, yoga, and other physical, mental and spiritual mind-body therapies.
} 
Por sua vez, esses dois grandes grupos podem ser subdivididos em Biologically Based Therapies, (terapias baseadas biologicamente), Mind-Body Therapies, (terapias mente-corpo), Manipulative and Body-Based Therapies (terapias manipulativas e baseadas no corpo), Energy Therapies (terapias energéticas) and Systems of care (sistemas de cuidado), porém, há várias nuances entre eles, e modalidades terapêuticas que se enquadram em mais de um grupo.

Também Braz (2015) aponta uma possibilidade de classificação das terapias utilizadas:

\begin{abstract}
O National Institute of Health $(\mathrm{NIH})^{19}$ classifica este tipo de prática médica em cinco grupos: 1) medicina alternativa: medicina tradicional chinesa (incluindo acupuntura), medicina naturopática, ayurvedica ou homeopatia; 2) terapias com bases biológicas, incluindo fitoterapia, suplementação dietética e tratamento biológico individual (...) 3) terapias energéticas, como Reiki, toque terapêutico e terapia magnética, entre outros; 4) sistemas baseados em manipulação corporal: quiropraxia, osteopatia e massagens; 5) intervenções corpo-mente, como meditação, relaxamento, biofeedback e hipnoterapia.
\end{abstract}

Todas essas tentativas de classificação nos dão uma ideia mais ampla da diversidade de possibilidades terapêuticas encontradas nas PIC.

\title{
1.3 Sistemas florais e a escolha de uma terapia criada no Brasil
}

Ao analisar nosso corpus em português (sua formação será detalhada no capítulo Materiais e Métodos), na busca por alguma terapia que tenha sido desenvolvida no Brasil, observamos pela lista de palavras-chave que, dentre os termos referentes a modalidades de PIC, florais foi o segundo mais frequente, atrás apenas de acupuntura. Como acupuntura provém da Medicina Chinesa, decidimos analisar as concordâncias com o termo "florais" e mostrou-se proeminente a profusão de sistemas florais existentes.

Há indícios de que muitos povos já utilizavam flores como forma de tratamento humano desde a antiguidade, e isso foi se desenvolvendo ao longo dos anos. Hoje em dia, essência floral é uma denominação comum para um preparado natural, geralmente elaborado a partir de flores ou plantas conservados em brandy ou álcool natural. No entanto, a maneira de preparar as flores para extrair sua essência pode variar, e também as flores e plantas utilizadas podem ser muito diferentes, dependendo do ecossistema utilizado. Dessa forma, podemos dizer que existem numerosos sistemas florais, que apresentam características distintas.

\footnotetext{
${ }^{19}$ Instituto Nacional de Saúde do Reino Unido, equivalente ao SUS no Brasil.
} 
Podemos fazer uma analogia com a dança: existem características que permitem denominar "dança" várias formas de movimentação rítmica do corpo, no entanto, são inúmeros os tipos/ritmos de dança, como ballet, salsa, forró, dança contemporânea, samba, bolero, sapateado, tango, e assim por diante. Quem observa e quem executa os movimentos sabe que há vários fatores que permitem identificar um tipo específico de dança e diferenciálo dos outros, embora, genericamente, todos sejam danças. "Dança" é um hiperônimo ${ }^{20}$ das várias modalidades de dança existentes, que são os hipônimos.

Analogamente, um sistema floral é um hiperônimo, pois é um modo geral de se referir a uma terapia que utiliza essências florais. Existem diferentes tipos de sistemas florais, que possuem características distintas dos outros, seja pelo modo de preparo, seja pela escolha das flores e plantas utilizadas. Estes são os hipônimos.

O primeiro grupo de florais sistematizado foi desenvolvido pelo médico inglês Dr. Edward Bach, entre 1928 a 1936. Ele criou uma forma de terapia usando 38 flores, com as quais criou 38 remédios, chamados Florais de Bach. Esses 38 florais, conhecidos com Bach Flower Remedies, compõem o sistema floral de Bach, hoje difundido pelo mundo.

Entretanto, vários outros tipos de florais foram desenvolvidos em diversos países, inclusive no Brasil. Vamos, a seguir, exemplificar a abundância de sistemas florais disponíveis, sem, no entanto, ter a intenção de abordar todos os tipos existentes. Os exemplos seguintes foram apontados por Costeira (2015):

\section{Essências florais brasileiras:}

Florais Acquântica

Florais Agnes

Florais do Agreste

Florais Água Azul

Florais de Aiuruoca ou Dharidhana

Florais da Amazônia

Florais Angels

Florais Ararêtama

Florais Arco-lris

Florais Aura Luz

Florais Brasileiros (Joel Aleixo)
Florais Filhas de Gaia

Florais Florescência

Florais Flores do Vento

Florais de Gabriel

Florais dos Golfinhos

Florais Kahena

Florais Mãe Terra

Florais Mata da Estiva

Florais de Minas

Florais do Nordeste

Florais do Planalto Central

\footnotetext{
${ }^{20}$ Hiperônimo: conceito mais genérico que abrange outros termos, seus hipônimos.
} 
Florais do Cerrado

Florais da Chapada Diamantina

Florais Essências Cristais de $\mathrm{Oz}$

Florais da Deusa

Florais Dharma Essências Vibracionais

Florais do Dr. Edward

Florais Essências do Butiazal

Florais Essências Vibracionais D'Água

\section{Essências florais do resto do mundo:}

Florais da África do Sul (África do Sul)

Florais Anaflora (USA)

Florais Ancient Forest (USA)

Florais Angelic (USA - Peru)

Florais da Antártica (Antártica)

Florais do Alaska (USA)

Florais AUM Himalaia (Índia)

Florais Australianos (Austrália)

Florais de Bach (Inglaterra)

Florais Bailey (Inglaterra)

Florais da Califórnia (USA)

Florais Delta Gardens (USA)

Florais do Deserto (USA)

Florais DEVA (França)

Florais Essências Cactus (Europa)

Florais Essências Cogumelo (Europa)

Florais Essências do Pacífico (Canadá)

Florais Findhorn (Escócia)

Florais Flores Del Alma (Argentina)

Florais da Floresta Canadense (Canadá)

Florais das Árvores da Floresta Canadense (Canadá)

Florais da Fox Mountain (USA)
Florais de Saint Germain

Florais Solares

Florais Sol Nascente

Florais do Sul

Florais Templo de Ártemis e Arcturus

Florais da Vida

Florais da Vida (Vida Botânica)
Florais Green Man Tree (Inglaterra)

Florais de Gemas Australianos (Austrália)

Florais Harebell (Escócia)

Florais do Havaí (USA)

Florais do Himalaia (Índia)

Florais da Holanda (Holanda)

Florais Hummingbird (USA)

Florais de Kaua'i (USA)

Florais Living Essences (Austrália)

Florais Living Light (Canadá)

Florais Master (USA)

Florais New Millennium (Nova Zelândia)

Florais New Perception (Nova Zelândia)

Florais Orquídeas do Amazonas

(Colômbia)

Florais Orquídeas Dancing Light (USA)

Florais Orquídeas Living Tree (Inglaterra)

Florais de Orquídeas Européias (Europa)

Florais Pegasus (USA)

Florais Perelandra

Florais Petite Fleur (USA)

Florais de Raff (Argentina)

Florais Sylfos (Chile)

Com esses exemplos pode-se ter uma clara ideia da vastidão do universo dos florais, que diferem entre si tanto pelos processos utilizados e princípios seguidos em sua elaboração, quanto em número e características das plantas, variando de região para região, mesmo dentro do mesmo país. 


\subsubsection{A escolha dos florais brasileiros baseados na alquimia}

Dentre as essências florais brasileiras, existe o sistema de florais brasileiros baseados na alquimia, conhecido como Sistema Joel Aleixo, ou Florais Joel Aleixo, nome de seu criador. Esse sistema floral mostrou-se relevante por utilizar plantas nativas brasileiras ou que já tenham se adaptado plenamente ao solo e clima brasileiros, valorizando o ecossistema nacional, além de ser o único baseado na Alquimia, sendo esse um diferencial entre os outros florais desenvolvidos no Brasil.

O paraibano Joel Barbosa Aleixo começou seu trabalho com os florais há mais de 20 anos e fundou a Escola de Alquimia Joel Aleixo ${ }^{21}$ em São Paulo/SP, formando centenas de terapeutas, habilitados a atuar com esses florais, após realização de um curso com duração de oito semestres,

As primeiras essências florais desse sistema foram criadas em 1991 e hoje ele é formado por compostos florais em spray, glóbulos, uma linha cosmética e numerosas essências sutis, com base em 99 plantas selecionadas após ampla pesquisa. Inclusive, esses florais já foram apresentados em eventos internacionais sobre Medicina Complementar e Alternativa, como, por exemplo, a Conferência Internacional de Saúde Quântica (CISQ), ocorrida em Gramado/RS em 2012 e versões posteriores.

Os florais brasileiros baseados na alquimia também possuem a peculiaridade de promover a união de saberes antigos de vários povos sintetizados de forma sincrética, como a Alquimia, a Astrologia e o uso de plantas de forma terapêutica, diferenciando-se de outros sistemas florais. Segundo Costeira (2015, p.202), “o plantio das flores é feito em canteiros na forma de mandalas e as flores são colhidas de acordo com a lunação (...). A partir dessa etapa, cada floral é criado de acordo com fórmulas e procedimentos específicos da Alquimia”.

\footnotetext{
${ }^{21}$ http://www.joelaleixo.com/portal/
} 


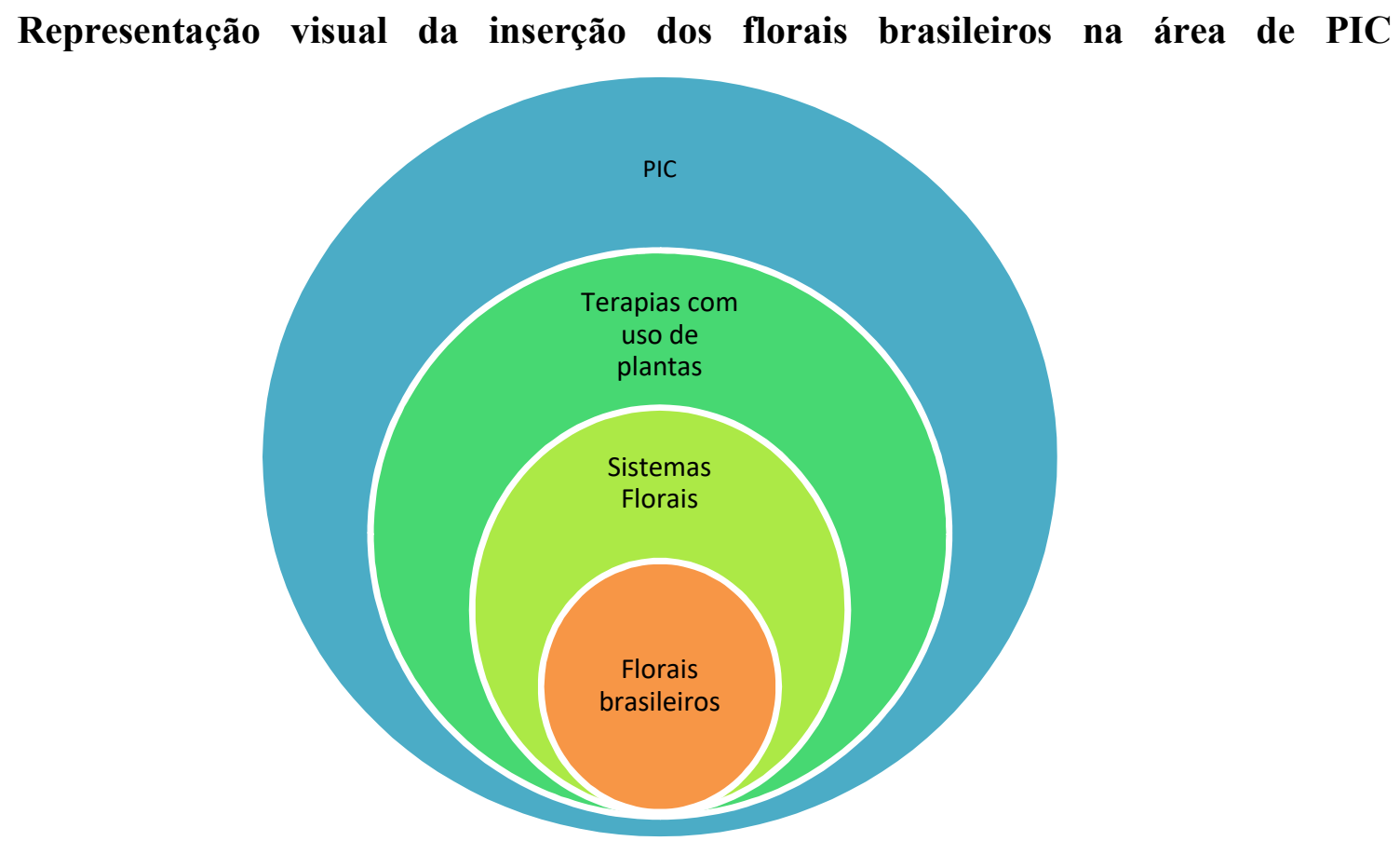

Figura 1 - Florais brasileiros na área de PIC

Assim, por meio da frequencia no corpus, percebendo a grande ocorrência do termo "florais", verificamos a variedade de sistemas florais existentes e com uma investigação aprofundada neste tema, selecionamos os florais brasileiros baseados na alquimia para a elaboração de um corpus e de um glossário específicos de uma modalidade de PIC desenvolvida no Brasil, também considerando a possibilidade de algumas das plantas utilizadas na fabricação desses florais não serem conhecidas pelo público anglo-falante. 


\section{PRESSUPOSTOS TEÓRICOS}

Utilizamos como arcabouço teórico e metodológico a Linguística de Corpus (LC) e a Terminologia, bem como suas aplicações em Tradução. Na primeira parte, abordamos a LC, conceito e tipos de corpus e sua construção (Almeida, Baker, Magalhães, Sinclair, Tagnin, Zanettin). Na segunda parte, tratamos da Terminologia (Barros, Cabré, Krieger \& Finatto), suas intersecções com a Tradução, os tipos de termos, formas de encontrar equivalentes tradutórios, glossários e suas partes principais. Baseando-nos nos conhecimentos dos autores estudados, concluímos com a importância da utilização de corpora em trabalhos terminológicos.

\subsection{Linguística de corpus e Tradução}

A Linguística de Corpus (LC) vem sendo desenvolvida ao longo dos últimos cinquenta anos e aplicada em estudos relacionados à tradução, entre outras áreas. Caracterizase pelo uso do computador na análise de dados e investigação da linguagem em uso. Pode ser de interesse para vários tipos de pesquisadores, como lexicógrafos (na criação de dicionários), terminógrafos (na criação de obras terminográficas), tradutores, no ensino e aprendizagem de línguas, na formação de professores e análise de discurso.

No contexto da LC, "Um corpus é uma coleção de textos em formato eletrônico, selecionados de acordo com critérios externos para representar, na medida do possível, uma linguagem ou variedade de linguagem como fonte de dados para pesquisa linguística" (tradução nossa) ${ }^{22}$ (SINCLAIR, 2005).

De acordo com Magalhães (2014), os estudos descritivos da tradução forneceram a base para que Baker $(1993,1995,1996)$ propusesse a abordagem dos Estudos da Tradução Baseados em Corpora (ETBC). Dentro dos Estudos Descritivos da Tradução, Toury foi um dos primeiros teóricos a abrir o caminho para as pesquisas em tradução baseadas em corpora (MAGALHÃES, 2014, p. 95); Baker (1993) lança a proposta dos ETBC de textos traduzidos a partir de duas correntes: a de Toury (1978), com o conceito de normas na tradução, e

\footnotetext{
${ }^{22}$ No original:"A corpus is a collection of pieces of language text in eletronic form, selected according to external criteria to represent, as far as possible, a language or language variety as a source of data for linguistic research"
} 
Sinclair (1991), que superou as limitações humanas do pesquisador por meio do uso de corpora computadorizados.

Como uma abordagem empírica para o estudo da língua em diversas dimensões, a Linguística de Corpus é especialmente útil no estudo da Tradução. Essa abordagem está atrelada ao desenvolvimento da tecnologia, pois permite a observação de uma grande quantidade de textos em formato eletrônico, passível de análise por meio de ferramentas computacionais (ZANETTIN, 2012).

Assim, dados quantitativos são gerados, permitindo um aprofundamento da investigação além da intuição do pesquisador/tradutor, possibilitando que ele chegue a muitas conclusões por meio da compilação e análise do corpus e "a encontrar, no corpus construído, os equivalentes mais adequados para os termos que procura" (TAGNIN \& TEIXEIRA, 2004, p. 356). Desta forma, o tradutor pode compilar um corpus específico para determinado projeto.

Também Krieger e Finatto atestam a importância dos estudos com corpora: "graças à proliferação dos recursos informatizados, essa prática já alcançou um grau de sofisticação demonstrado na aplicabilidade das ferramentas e na confiabilidade dos resultados" (2004, p. 140). Para a realização da análise, é necessário ter acesso a um software para trabalhar com o corpus, como por exemplo, AntConc ${ }^{23}$, Sketch Engine ${ }^{24}$ e WordSmith Tools ${ }^{25}$ (WST).

Em trabalhos terminológicos bi ou multilíngues, a LC é especialmente útil na extração de termos, busca por equivalentes, seleção de diversos tipos de contextos, observação de fraseologismos, além da busca por denominações que os usuários de uma língua realmente empregam, utilizando corpora comparáveis, bi ou multilíngues, conforme o caso.

Sob essa perspectiva, nosso trabalho se caracteriza por uma análise de corpora, com a tentativa de encontrar os termos equivalentes realmente utilizados na língua de chegada (inglês), com a utilização de textos autênticos. Como produto terminográfico, desenvolvemos uma proposta de glossário para uso especialmente de tradutores, buscando, assim, dar uma contribuição aos Estudos da Tradução.

\footnotetext{
23 http://www.laurenceanthony.net/software/antconc/

24 https://www.sketchengine.co.uk/

25 http://www.lexically.net/wordsmith/
} 
Para que um corpus possa ser utilizado como fonte de dados para algum estudo, ele não pode ser compilado de maneira aleatória, e sim "compilado para um propósito específico e de acordo com critérios de desenho explícitos para garantir que seja representativo da área dada ou amostra do idioma de que pretende dar conta" (tradução nossa) ${ }^{26}$ (BAKER, 1995).

Com relação à forma de análise, os estudos com corpora podem ser: baseados em corpus, "em que o corpus é usado (a) para comprovar (ou não) uma hipótese ou (b) para extrair exemplos" ou direcionados pelo corpus, ou seja, que "se desenvolve conforme dados apresentados pelo corpus, sem pressuposições teóricas” (Tagnin, 2013, p. 217).

Os corpora podem ser de vários tipos, como explicita Tagnin (2013):

- corpus comparável bilíngue ou multilíngue, formado por originais em cada idioma estudado e que permitem analisar a língua da forma como é usada naturalmente;

- corpus comparável monolíngue, composto por textos originais numa língua e traduções para essa mesma língua, permite comparar a linguagem usada por tradutores e a usada por falantes nativos e fluentes;

- corpus paralelo, formado por originais na língua A e suas respectivas traduções na língua $\mathrm{B}$, bastante útil para a análise de traduções.

De acordo com a autora, um corpus pode ser ainda de estudo, aquele em que se baseia a pesquisa; de referência, usado para comparação com o corpus de estudo; monitor, atualizado constantemente para mostrar como uma língua evolui ao longo do tempo; estático, não possibilita acréscimo de novos materiais; dinâmico, possibilita o acréscimo de novos materiais.

À primeira vista, pode-se pensar que os corpora paralelos seriam os mais indicados para a pesquisa em terminologia bilíngue, ao possibilitar encontrar os equivalentes utilizados pelos tradutores. Aubert (2001), porém, pondera o oposto, pois as soluções terminológicas encontradas pelos tradutores e revisores podem não corresponder aos termos realmente usados por falantes nativos, considerando casos em que a pesquisa derive da ausência de descrição e sistematização terminológicas anteriores.

\footnotetext{
${ }^{26}$ No original: “ it is put togetlher for a particular purpose and according to explicit design criteria in order to ensure that it is representative of the given area or sample of language it aims to account for"
} 
Da mesma forma, Philip (2009) questiona se a tradução baseada em corpus deveria estudar necessariamente o texto traduzido, concluindo que os corpora comparáveis são os mais recomendados para esse fim, considerando que: “O papel do corpus comparável é principalmente destinado a identificar - e eliminar - as inconsistências mais evidentes na terminologia, organização textual e fraseologia em textos traduzidos" (tradução nossa) ${ }^{27}$ (PHILIP, 2009, p. 60).

Durante o planejamento do corpus é preciso estabelecer características necessárias para atender os objetivos aos quais ele se destina, como a opção por textos de língua falada ou escrita, e levar em consideração o público-alvo da pesquisa, pois:

Os usuários de determinado vocabulário de especialidade não constituem, com efeito, um grupo homogêneo. $\mathrm{Na}$ área das ciências da saúde, por exemplo, compartilham e se entrecruzam em um espaço nocional já por si multiforme (abordagens alopata, homeopata e práticas naturistas ou alternativas em geral) (...) cada qual com uma determinada apreensão desta realidade, com históricos individuais e coletivos, competências, crenças, níveis socioeconômicos e sócioculturais e, em seu contexto específico de atuação, motivações por vezes bastante distintas (AUBERT, 2001, p. 59-60).

Almeida reforça a necessidade do cumprimento de certos requisitos para garantir a confiabilidade e validade do corpus, reunindo as características levantadas por diversos pesquisadores em: "autenticidade, representatividade, balanceamento, amostragem, diversidade e tamanho" (ALMEIDA, 2006, p. 88).

A autenticidade relaciona-se a verificar se as fontes foram escritas originalmente no idioma em questão. A diversidade manifesta-se pela variação de gêneros textuais. Balanceamento é "o processo pelo qual se garante que um corpus seja compilado de forma a manter um equilíbrio entre os tipos textuais que o compõem” (TAGNIN, 2015, p. 321).

No que concerne à representatividade, Berber Sardinha (2004) levanta três pontos a serem considerados na dimensão da amostragem: número de palavras, de textos e de gêneros textuais. Existe também a questão da "representatividade para quem?", tomando-se o cuidado de não generalizar as descobertas no corpus para uma população inteira. Também costuma ser necessária a monitoração do corpus, em que se corrigem eventuais problemas encontrados, readequando ou aumentando o corpus.

\footnotetext{
${ }^{27}$ No original: "The role of the comparable corpus is principally aimed at identifying - and eliminating - the more glare inconsistencies in terminology, textual organisation and phraseology in translated texts".
} 
Aubert (2001) afirma não ser necessário um volume muito grande de fontes para a pesquisa terminológica monolíngue, no entanto, ressalta que a exigência é maior para e pesquisa bilíngue, para obter uma cobertura maior das noções e termos. E para Zanetin (2012, p. 152) o corpus compilado de uma linguagem de especialidade não precisa necessariamente ser de grande proporção: "Os requisitos de tamanho de corpus podem ser bastante reduzidos se o objetivo é criar um corpus especializado de textos pertencentes a um domínio muito específico, tipo de texto e tópico" (tradução nossa). ${ }^{28}$

$\mathrm{Na}$ sequência, abordaremos a Terminologia e suas implicações no âmbito deste trabalho.

\subsection{Terminologia}

Para Biderman e Almeida (1998, p. 17), “a Terminologia se ocupa de um subconjunto do léxico de uma língua, a saber cada área específica do conhecimento humano" e tem como unidade-padrão o termo.

Cabe ilustrar a distinção entre Terminologia (com T maiúscula) - estudo e descrição dessas linguagens de especialidade - e terminologia (com t minúscula) "conjunto de termos próprios de um domínio, de um grupo de pessoas ou de um indivíduo" (BOUTIN-QUESNEL, 1985, p. 17).

Existem várias teorias que versam sobre a Terminologia. Considerada a primeira grande teoria sobre esta área, a Teoria Geral da Terminologia (TGT) foi desenvolvida pelo engenheiro Eugen Wüster (1898-1977), que "propôs uma metodologia baseada na sistematização dos conceitos para a elaboração de dicionários terminológicos” (BARROS, 2004, p. 54).

De acordo com a teoria de Wüster, não deveria haver termos polissêmicos, sinônimos ou homônimos, devido ao seu caráter normativo e à busca pela univocidade (um único termo para um único conceito). Dessa forma, pretendia-se eliminar ruídos na comunicação especializada.

\footnotetext{
${ }^{28}$ No original: "corpus size requirements may be greatly reduced if the aim is to create a specialized corpus of texts belonging to a very specific domain, text type and topic [...]"
} 
É pertinente levar em consideração que essa teoria foi desenvolvida em uma época em que especialistas de todas as áreas buscavam a normalização dos termos técnicos e científicos, e ela teve um importante papel na consolidação dessa disciplina.

Todavia, com o crescimento da produção de obras terminográficas e o desenvolvimento de tecnologia computacional, aliados a uma visão linguística, ocorreu um grande processo de reflexão sobre a Terminologia, o que levou ao desenvolvimento de novas teorias na busca de sanar as limitações da TGT. Dentre essas teorias, surgiu então um novo paradigma com a Teoria Comunicativa da Terminologia (TCT), apresentada por Maria Teresa Cabré nos anos 1990.

Diferentemente da TGT, a TCT compreende que não há uma distinção rígida entre unidade lexical da língua geral (palavra) e unidade terminológica (termo). “Considera os termos como unidades linguísticas que exprimem conceitos técnicos e científicos, mas que não deixam de ser signos de uma língua natural (geral), com características e propriedades semelhantes" (Barros, 2004, p. 57).

De acordo com essa abordagem, a forma e o conteúdo dos signos terminológicos são indissociáveis e o conceito expresso pelo termo é ativado pela situação, pelo contexto de uso. Para Cabré:

O objetivo da terminologia teórica é descrever formal, semântica e funcionalmente as unidades que podem adquirir valor terminológico, para explicar a forma como o ativam e para explicar suas relações com outros tipos de sinais do mesmo sistema ou diferente, para avançar o conhecimento sobre a comunicação especializada e as unidades que são usadas nela (tradução nossa) ${ }^{29}$ (CABRÉ, 1999, p. 133).

Seguindo os preceitos da TCT, podemos observar, por exemplo, a unidade lexical "agulha", presente em nosso corpus de estudo. Fora de contexto não é nem palavra nem termo, pois não existe termo per se. No entanto, no âmbito das Práticas Integrativas e Complementares, no contexto da acupuntura, "agulha" adquire o estatuto de termo, pois é um instrumento necessário para a aplicação dessa prática terapêutica.

A mesma unidade lexical, que pode ser uma palavra em um contexto de língua geral, assume o valor de termo na situação comunicativa de uma língua de especialidade. "Nessa

\footnotetext{
${ }^{29}$ No original: El objetivo de la terminología teórica es el de describir formal, semántica y funcionalmente las unidades que pueden adquirir valor terminológico, dar cuenta de cómo lo activan y explicar sus relaciones con otros tipos de signos del mismo o distinto sistema, para hacer progresar el conocimiento sobre la comunicación especializada y las unidades que se usan en ella.
} 
passagem, palavras comuns adquirem significados especializados, pertinentes a determinado campo de saber científico ou técnico, tornando-se, então, elementos integrantes de repertórios de termos" (KRIEGER \& FINATTO, 2004, p. 79).

Outra importante característica da TCT é que os termos são usados e ativados em um domínio (CABRÉ, 1999, p. 141), não havendo a ideia de que os termos "pertencem" a um domínio. Por exemplo, vamos analisar a unidade lexical "meridiano". Pode ser usado como palavra em um contexto de língua geral, e tornar-se termo em um contexto de geografia, como um semicírculo que liga dois pólos de um planeta, tal qual o famoso meridiano de Greenwich.

Já no contexto das Práticas Integrativas e Complementares, meridiano assume o valor de termo, porém, com outro significado, embora análogo, referindo-se aos canais energéticos ao longo do corpo que podem ser estimulados/tratados por meio de diversas técnicas terapêuticas, como acupuntura, shiatsu, massagens, entre outras.

Vejamos ainda o exemplo da unidade lexical "rosa", que apresenta caráter polissêmico em contextos de língua geral (pode ser uma cor, uma flor) e é ativada como termo ao considerarmos o contexto específico dos florais brasileiros baseados na alquimia, em que "rosa" é a denominação de um floral elaborado a partir da essência dessa planta. Designa, portanto, um conceito próprio do domínio em questão.

Em um contexto de botânica, esse termo provavelmente tomaria outras conotações, corroborando a proposta de Cabré de que os termos não pertencem a um domínio, e sim são ativados por ele. É uma teoria de caráter descritivo e, além do mais, aceita e trata sob uma perspectiva comunicativa a sinonímia, a homonímia, a polissemia e a variação linguística (léxica).

Como o mais importante sob a perspectiva da TCT são os termos, não os conceitos, "se passou do método onomasiológico, utilizado na perspectiva prescritivista, para o método semasiológico, nas perspectivas textuais e comunicativas" (BEVILACQUA, 2013, p. 11). Dessa forma, em nossa proposta de glossário, utilizamos a disposição no formato semasiológico.

Vários autores discutem a estreita relação da Terminologia Bilíngue e Multilíngue com a Tradução. Embora os caminhos que elas percorrem não sejam iguais, conforme afirma 
Aubert, "no fazer tradutório, bem como no fazer terminológico, esses mesmos caminhos se cruzam e se entrecruzam" (2001, p. 13).

Um dos principais cruzamentos dessas disciplinas é a geração de produtos terminográficos como glossários e dicionários técnicos. Cabe aos estudos terminológicos gerar essa documentação, da qual os tradutores profissionais são um dos principais grupos de usuários, pois necessitam traduzir terminologias de áreas específicas:

"A primeira motivação do encontro que direciona a Tradução para a Terminologia
relaciona-se ao fato de que os termos técnico-científicos são elementos chave,
nódulos cognitivos, dos textos especializados. É em relação a essa tipologia textual
que se efetua a chamada tradução técnica ou especializada" (KRIEGER \&
FINATTO, 2004, p. 66).

O tradutor precisa conhecer e poder acessar repertórios terminológicos utilizados na língua fonte de um texto e estar apto a buscar os termos equivalentes realmente usados na língua alvo, para a qual está traduzindo este texto, e assim é de grande importância o desenvolvimentos de obras de referência bilíngues ou multilíngues.

Também Vega ressalta o papel fundamental da Terminologia na tradução: “O mais importante na educação do futuro tradutor com relação à terminologia é ensiná-lo e habituá-lo a ser usuário, convertê-lo em usuário empedernido de Lexicografia e de documentação terminológica” (VEGA, 1995, p. 69).

Outro cruzamento entre essas duas áreas, é que a Tradução e a Terminologia são ambas campos interdisciplinares, e a atuação de seus profissionais permeia diversas áreas do conhecimento.

A Terminologia e a Tradução Especializada têm uma relação dialética, com contribuições de uma para a outra. "A disciplina de Terminologia mantém uma relação estreita e de longa data com a tradução técnico-científica, por isso a troca de experiências entre ambas é algo quase natural” (KRIEGER \& FINATTO, 2004, p. 177).

Se, por um lado, os terminólogos podem produzir obras bilíngues ou multilíngues para uso de tradutores, por outro, muitos tradutores têm produzido obras terminográficas ao longo da história, como os glossários médicos da antiguidade. Citaremos alguns exemplos. 
Segundo Van Hoof (1998, p. 249), no século I já surgiram glossários médicos gregos, explicando os termos usados por Hipócrates. Outro médico traduzido foi Galeno, e sobre seu trabalho, "estudiosos sírios compilaram verdadeiros dicionários bilíngues de termos médicos".

Posteriormente, foram se desenvolvendo trabalhos em outras áreas de conhecimento, como botânica, e no século XII, “o médico Maimônides (1139-1024), cordovês, escreveu um glossário com 405 nomes de plantas em árabe, grego, siríaco, persa, berbere e andaluz" (VAN HOOF, 1998, p. 249).

$\mathrm{Na}$ Renascença, surgiram os primeiros glossários especializados no Ocidente. "Um exemplo é o glossário árabe-latino que o médico italiano Andrea Alpago de Belluna (falecido em 1520) incluiu na sua tradução do Cânon da medicina, de Avicena" (VAN HOOF, 1998, p. 249).

Muitos médicos que tiveram seus trabalhos traduzidos foram também alquimistas, em uma época em que não havia grandes divisões entre as ciências. Por sua vez, os tratados de Avicena, entre outros alquimistas, inspiraram o desenvolvimento dos florais brasileiros baseados na alquimia.

Com o crescimento científico e tecnológico, surgiram muitos conceitos sem precedentes, e foi necessário um grande trabalho para incorporar esses conceitos ao conhecimento de mundo vigente. "O século XVIII foi uma época de explosão científica e tecnológica, e os lexicógrafos não tardaram a trabalhar ativamente na criação de terminologia para os novos conceitos" (VAN HOOF, 1998, p. 250).

Entre esses e outros exemplos trazidos por DELISLE e WOODSWORTH (1998) no livro "Os tradutores na história", podemos vislumbrar o importante papel dos tradutores na difusão do conhecimento e de novas terminologias. Contribuíram também para a perpetuação e propagação de muitas técnicas de Medicina Tradicional que sobreviveram ao longo de séculos e foram difundidas em grande parte do Oriente para o Ocidente, como a Medicina Tradicional Chinesa e a Medicina Ayurvédica.

Hoje em dia, a explosão de dicionários especializados reflete o desenvolvimento técnico científico, que por sua vez exige um aumento de vocabulário. Com o advento dos computadores, o processamento de dados tornou-se mais ágil, e desde os anos 1960 muitos 
bancos de dados têm sido usados para difundir terminologias multilíngues ou monolíngues. Ainda que esses bancos de dados estejam sob a égide de terminologistas ${ }^{30}$ especializados, muitos foram originados por registro de tradutores. "Na verdade, a profissão de terminologista deriva da profissão de tradutor" (VAN HOOF, 1998, p. 253).

Embora Terminologia e Tradução tenham suas distinções e especificidades de atuação, é clara a relação intrínseca de cooperação entre uma e outra, também com o desenvolvimento da Terminografia.

Segundo Barros (2004), a Terminologia pode ser vista como ciência fundamental (caráter científico) e a Terminografia como ciência aplicada (caráter tecnológico), embora esta última também possibilite a reflexão teórica sobre sua prática.

A Terminografia refere-se ao registro dos dados terminológicos e sua apresentação, "diz respeito ao estudo dos termos de uma dada linguagem com vistas à elaboração de dicionários, glossários e outros repertórios” (BARROS 2004, P. 145). Trata da produção de vocabulários (dicionários especializados), em que aparecem apenas as acepções específicas dos termos naquele domínio.

A investigação linguístico-textual dos textos técnico-científicos beneficia a Tradução e a Terminologia. "Tanto para quem traduz como para quem organiza informações ou busca empreender um reconhecimento de terminologias, importa reconhecer que o texto especializado é, antes de mais nada, um todo de significação dinâmico e mutável, habitat natural das terminologias" (KRIEGER \& FINATTO, 2004, p. 180).

As áreas específicas do conhecimento humano, em que aparece esse texto especializado, utilizam uma língua ou linguagem de especialidade, "sistema de comunicação oral ou escrita usado por uma comunidade de especialistas de uma área particular do conhecimento" (PAVEL\& NOLET, 2002, p. 124). É a língua natural utilizada com objetivos específicos.

O conceito de línguas de especialidade refere-se não apenas ao léxico específico das tecnologias ditas "de ponta", mas a todo domínio do fazer humano (AUBERT, 2001, p. 14), como culinária, esportes e sabedoria popular.

\footnotetext{
${ }^{30} \mathrm{Na}$ tradução do texto aparece assim, não tivemos acesso ao original.
} 
Barros (2004, p. 43) nos traz a reflexão de muitos autores de que o correto não seria uma língua de especialidade, e sim uma linguagem de especialidade, pois "linguagem seria a língua em uso", porém, a própria autora constata que "o termo língua de especialidade já se consagrou nos meios da Terminologia".

Vamos a seguir apresentar brevemente os objetos de estudo da Terminologia: a fraseologia, a definição e o termo, atendo mais a este último, devido ao foco deste trabalho.

A Fraseologia é "uma construção sintagmática nuclear, um nódulo cognitivo que também transmite conhecimento especializado" (KRIEGER \& FINATTO, 2004, p. 75). Para serem consideradas fraseologias especializadas, precisam ser relevantes em um domínio, ter certo grau de fixação (expressões sintagmáticas mais ou menos fixas) e recorrência, e têm uma base terminológica, que é o núcleo dessa unidade. Pode ser chamada também de fraseologismo:

"um fraseologismo é definido como a coocorrência de uma forma ou de um lema de um item lexical e um ou mais elementos linguísticos adicionais de vários tipos, que funcionam como uma unidade semântica em uma oração ou sentença e cuja frequência de coocorrência é maior do que a esperada ao acaso" (GRIES, 2008, p. 6, tradução nossa). ${ }^{31}$

No escopo deste trabalho não efetuamos a análise de fraseologias, portanto, não vamos nos aprofundar nesse tópico.

Com relação às definições, existem alguns tipos: definição terminológica, que trata dos termos técnico-científicos; definição lexicográfica, que se ocupa de palavras; definição lógica, que constitui um valor proposicional de verdade; definições explicativas ou enciclopédicas, que trazem informações variadas, referências, dados históricos, entre outros.

A Definição Terminológica (DT) é "um enunciado-texto que dá conta de significados de termos ou de expressões de uma técnica, tecnologia ou ciência no escopo de uma situação comunicativa profissional, veiculando, assim, conceitos de uma área de conhecimento. Nesse

\footnotetext{
${ }^{31}$ No original: In sum, a phraseologism is defined as the co-ocurrence of a form or a lemma of a lexical item and one or more additional linguistic elements of various kinds which functions as one semantic unit in a clause or sentence and whose frequency of co-ocurrence is larger than expected on the basis of chance.
} 
caso, grosso modo, definir corresponde a expressar um determinado saber, uma porção desse conhecimento especializado (KRIEGER \& FINATTO, 2004, p. 93).

$\mathrm{Na}$ formulação dos enunciados definitórios, há geralmente duas categorias: o gênero próximo e a diferença específica. Para as autoras supracitadas, gênero próximo: "é a porção da definição que expressa a categoria ou classe geral a que pertence o ente definido. A diferença específica é a indicação da(s) particularidade(s) que distingue(m) esse ente em relação em outros de uma mesma classe". Vejamos o exemplo do corpus: cristaloterapia terapia complementar (gênero próximo) com o uso de cristais (diferença específica).

Conforme Krieger e Finatto (2004, p. 93), "a aplicação de maior evidência em Terminologia (da DT) é a produção de glossários e dicionários”. Na proposta de glossário que vamos apresentar, não foram inseridas definições dos termos, no entanto, privilegiamos enunciados definitórios ao selecionar os contextos de uso dos corpora.

O terceiro objeto de estudo da terminologia, e o principal no âmbito deste trabalho, é o termo, o qual abordaremos a seguir.

Barros (2004) define o termo como "uma unidade lexical com um conteúdo específico dentro de um domínio específico", conceito corroborado por Krieger e Finatto (2004, p. 78), para quem "o que faz de um signo linguístico um termo é o seu conteúdo específico, propriedade que o integra a um determinado campo de especialidade."

O conjunto de termos de uma área especializada chama-se terminologia, ou conjunto terminológico. O termo também pode ser denominado unidade terminológica.

Quanto às características formais, os termos podem apresentar diversas configurações, como "palavra (termo simples), grupo de palavras (termo composto), sintagma, símbolo ou fórmula que designam um conceito de uma área específica” (PAVEL \&NOLET, 2002, p. 131). Temos ainda que considerar a possibilidade de haver quase-sinônimos e variantes ortográficas, de acordo com a região. Em geral, a maior parte dos termos de uma língua de especialidade é formada por substantivos. 
Os termos podem ser considerados simples, complexos ou compostos (mais de uma palavra). No âmbito deste estudo, consideramos palavra como "uma unidade léxica (ou unidade lexical)" (BARROS, 2004, p. 40).

De acordo com as definições dos tipos de termos dadas por Barros (2004 p. 100), vejamos alguns exemplos de cada modalidade relacionados ao domínio de estudo, retirados do corpus em português:

- Termo simples: "definido pela norma ISO 1087 como "constituído de um só radical, com ou sem afixos". Exemplo: terapia, agulha, aura. As unidades lexicais compostas por aglutinação e por justaposição sem hífen são também consideradas termos simples. Exemplos: aromaterapia, musicoterapia.

- Termo composto, formado por dois ou mais radicais, porém, utilizando-se o hífen, em situação de não-autonomia. Exemplo: mente-corpo, arco-íris.

- Termo complexo: "constituído de dois ou mais radicais, aos quais podem se acrescentar outros elementos". Exemplo: terapias complementares, acupuntura sistêmica, acupuntura auricular.

O termo complexo também pode ser chamado de termo sintagmático ou sintagma terminológico, e possui como característica principal ser compostos por mais de uma palavra, sendo bastante comum no discurso especializado:

"Há vários estudos que comprovam a prevalência das terminologias instituídas ao modo de sintagmas, num percentual que se situa em torno de $70 \%$ das ocorrências terminológicas. $\mathrm{O}$ alto percentual é recorrente em áreas novas que ainda estão constituindo seus conceitos e termos" (KRIEGER \& FINATTO, 2004, p. 81).

Para se verificar se uma sequência sintagmática é um termo, precisamos nos questionar se essa sequência designa um conceito específico (BARROS, 2004, p. 103). As palavras que compõem um sintagma podem ter um sentido separadamente, porém, o termo sintagmático possui um sentido específico. Exemplo: medicina tradicional chinesa. Uma pessoa pode ter o conhecimento dessas três palavras isoladas, porém, juntas elas ganham um novo sentido.

Outro fator a ser considerando é a frequência de ocorrência da mesma sequência de palavras no domínio em questão, o que pode ser verificado por softwares de análise de corpora, como o WordsmithTools, do qual vamos falar no Capítulo 3 - Materiais e Métodos. 
Feitas essas considerações, doravante, no escopo deste trabalho, adotamos a denominação termo complexo para termos sintagmáticos ou sintagmas terminológicos.

Também há outros elementos que podem ser observados na descrição de um termo, como a origem dos constituintes (grego, latim); se a formação é original, decorrente de empréstimo ou neológica; os processos de formação (derivação, justaposição etc.).

Nas linguagens de especialidade, um processo muito comum de formação de termos é "a produção neonímica com base em oposições distintivas entre unidades terminológicas que têm como base um hiperônimo (termo mais genérico)" (BARROS, 2004, p. 101). Por exemplo, temos o termo simples terapia (hiperônimo) e termos complexos originados a partir dele: terapia complementar e alternativa, terapia holística, terapia vibracional, terapia integrativa.

De acordo com Krieger e Finatto (2004), é característica da terminologia de algumas áreas a presença de componentes de origem grega e latina. Esses componentes atuam nas formações terminológicas, seja na forma de radicais ou afixos agregados a bases lexicais.

Também são utilizadas as formas latinas ou latinizadas para designar cientificamente espécies animais e vegetais, conforme se convencionou pela nomenclatura binomial desenvolvida por Lineu:

\footnotetext{
“O botânico sueco Carolus Linnaeus (Carl Von Linné, 1707-78), o primeiro cientista a introduzir uma classificação sistemática das espécies, a princípio na botânica, depois na zoologia, adotando uma nomenclatura binomial (gênero/espécie), publicou os resultados dessa pesquisa em latim, na Flora lapponica, lançado em Amsterdam em 1737” (SALAMA-CARR et al. p. 134).
}

Segundo essa forma de classificação, animais e plantas pertencem a uma classe, ordem, família, gênero, espécie e, quando houver, subespécie ou variedade. A nomenclatura binomial corresponde ao gênero (primeiro nome) e à espécie (segundo nome), e costuma aparecer em itálico ou escrita diferente do restante do texto, além de seguir alguns padrões: "O primeiro nome corresponde ao gênero, sempre um substantivo iniciado por letra maiúscula, a espécie e a subespécie são em geral adjetivos e iniciam com letra minúscula" (BARROS, 2004, p. 99). 
A expressão latinizada pode ser referência ao local de origem da espécie, a algum naturalista que se queira homenagear, alguma característica física da espécie, porém, seguindo sempre as orientações do Código Internacional da Nomenclatura Zoológica ou Botânica.

Apresentamos alguns exemplos de expressões latinizadas e seus significados, utilizando plantas presentes no corpus de florais brasileiros baseados na alquimia, que será abordado no Capítulo 3:

- Brasiliensis - Do Brasil, como em Begonia brasiliensis (HARRISON, 2012 p.43). Ex: Araucária: Araucaria brasiliensis ou Araucaria angustifolia, Bracatinga, flor-dasalmas: Senecio brasiliensis.

- Luteus, lutea, luteum - Amarelo, como em Calochortus luteus (HARRISON, 2012, p.127). Ex: Camarão (flor): Pachystachys lútea.

- Andraeanus, andraeana, andraeanum - Em homenagem ao explorador francês Édouard François André (1840-1911), como em Gymnocalcyum andreae. Andreanus, andreana, andreanum (HARRISON, 2012, p. 25). Ex: Antúrio: Anthurium andraeanum.

- Tricolor - Com três cores, como em Tropaeolum tricolor (HARRISON, 2012, p. 204). Ex: Amor-perfeito: Viola tricolor.

Após demonstrarmos várias possibilidades relacionadas aos termos, passamos à questão sobre como encontrar termos equivalentes em idiomas distintos.

\subsection{Equivalência em tradução}

Muitos autores discutem a questão da equivalência em tradução. De acordo com Dubuc (1985), pode ocorrer equivalência total ou equivalência parcial (correspondência). Segundo o autor, para haver equivalência total os termos devem possuir o mesmo conteúdo semântico, pertencer ao mesmo nível de língua sociolinguístico e apresentar o mesmo uso por parte dos especialistas consultados nos dois idiomas. Entretanto, o preenchimento de todos esses requisitos para uma equivalência perfeita não ocorre com frequência. 
A equivalência parcial ou correspondência ocorre quando "o termo da língua A só recobre parcialmente o campo de significação do termo da língua B e vice-versa" (tradução nossa) ${ }^{32}$ (DUBUC, 1985, p. 69).

Vários autores consideram os "correspondentes" (equivalentes parciais) como “equivalentes funcionais", como é o caso de Lerat (1995), baseando-se, por sua vez, no trabalho do juiz Pigeon (1982), que visava garantir que o texto traduzido tivesse os mesmos efeitos jurídicos que o texto original.

Tognini-Bonelli (2004, p.295) também adota um conceito pragmático de equivalência, como uma "visão contextual e funcional da equivalência tradutória" (tradução nossa). ${ }^{33} \mathrm{Da}$ mesma forma, Chanut (2012) e Bevilacqua (2013) referem-se à equivalência funcional como a utilização de elementos linguísticos e culturais que expressem a mesma relação semântica e os mesmos efeitos na cultura de chegada.

No escopo deste trabalho, também adotamos a abordagem da equivalência funcional, pois "não se pode deixar de reconhecer a necessidade enfrentada pelo tradutor quando tem de encontrar um termo que "funcione" no texto de chegada como "funciona" no texto de partida" (TAGNIN, 2007. p. 1).

Para oferecer um termo como equivalente, é preciso que ele tenha sido comprovado por alguma referência oral ou escrita, portanto, às vezes é necessário buscar novas fontes além dos corpora de estudo ou consultar um especialista da área. No entanto, temos que levar em consideração que cada cultura faz um recorte da realidade e mesmo a terminologia técnicocientífica está sujeita às "refrações" culturais e de visão-de-mundo (AZENHA, 1994).

Dessa forma, pode acontecer de o conceito de um termo não existir na língua alvo. Nesses casos, quando os termos de línguas diferentes não coincidem, pode haver nãoequivalência. Entretanto, é preciso verificar alguns critérios antes de apontar que um termo não possui equivalente em outra língua, principalmente verificar se a documentação para composição do corpus nessa língua foi suficiente e, se necessário, consultar outras fontes.

\footnotetext{
${ }^{32}$ No original: "Le terme de la langue A ne recouvre que partiellement le champ de signification du terme de la langue $\mathrm{B}$, ou vice versa".

${ }^{33}$ No original: "contextual and functional view of translation equivalence".
} 
Uma forma de descobrir um caso de não-equivalência pode ser pela análise da lista de palavras-chave (uma das ferramentas de análise em LC que será abordada no Capítulo 3), ao observar-se uma grande ocorrência de um termo em uma língua, mas não na outra. "Reconhecemos a não equivalência por falta de correspondência de uma determinada palavra" (tradução nossa) ${ }^{34}$ (TOGNINI-BONELLI, 2004, p. 298). Consideramos falta de correspondência a não existência de termo específico referente a determinado conceito.

Ao verificar-se a falta de equivalência, algumas estratégias podem ser adotadas: podese recorrer a empréstimos (mantendo o termo em sua forma linguística original), à criação de neologismos, ou ainda a "formas alternativas combinando o empréstimo com a paráfrase" (AUBERT, 2001, p. 50). Barros (2004) aponta que nas situações de não-equivalência podem ser usados termos genéricos para suprir a falta de um termo específico, ou vice-versa. A criação de neologismo não costuma ser indicada, pois o novo termo pode não ser aceito na cultura de destino:

\begin{abstract}
"A criação de um neologismo para preencher uma lacuna no sistema é um procedimento de risco e só se deve decidir depois de muitas consultas a especialistas. Na maior parte dos casos não é recomendável. A função do dicionário não é criar palavras, mas registrar as existentes com o maior rigor científico possível" (ALPÍZAR CASTILLHO, 1997, p. 103).
\end{abstract}

Considerando a afirmação acima, nossa posição no escopo deste trabalho é a de não propor neologismos, e sim descrever o que é usado de fato na língua, pesquisando fontes diversas quando o corpus de estudo em inglês não for suficiente para dar as respostas que buscamos, pois o tradutor precisa encontrar uma estratégia que funcione no contexto.

Auger e Rousseau (1978, p. 39) expressam a importância dos contextos na busca por equivalentes em terminologia bilíngue: "A única maneira de garantir a equivalência dos termos ingleses e franceses é comparar os contextos e definições coletadas em ambas as línguas" (tradução nossa) ${ }^{35}$. Os autores assumem que as equivalências fornecidas pela fonte bilíngue são válidas apenas ao se comparar as definições dos contextos coletados.

Também para Aubert (2001, p. 30), não basta apenas confirmar a presença do termo em seu domínio de uso, precisamos encontrar os traços conceptuais relevantes para distinguir

\footnotetext{
${ }^{34}$ No original: "We recognize non-equivalence by the mismatch of a certain word".

${ }^{35}$ No original: "La seule façon de s'assurer de l'equivalence des termes anglais et français est de comparer les contextes et les définitions recueillis dans les deux langues."
} 
o termo em questão dos demais deste domínio. O termo expressa uma realidade específica dentro de uma área de conhecimento, portanto, "é a situação que interessa ao terminólogo". A situação permite encontrar os elementos nocionais e associá-los ao correspondente em outra língua.

Para a terminologia bilíngue a importância dos traços conceptuais ou noções é maior ainda, pois, para legitimar a relação de equivalência entre uma língua e outra, precisa-se confrontar as respectivas noções. "Para compreender um determinado termo (e para encontrar o equivalente justo na língua de chegada), é necessário saber relacioná-lo com o conceito a que faz referência" (HURTADO ALBIR, 2001, p. 61).

Dubuc chama os traços conceptuais de ganchos terminológicos e os considera a chave para referências cruzadas. "Os ganchos terminológicos incluem descritores comuns aos contextos que acompanham os títulos de uma ficha terminológica" (tradução nossa) ${ }^{36}$ (DUBUC, 1985 p. 72).

Esses ganchos terminológicos podem ser explícitos ou implícitos, em que é preciso extrair do sentido completo dos contextos algum descritor que ateste a paridade entre os conceitos. Os descritores "são elementos reveladores de uma característica de um conceito contido em um contexto" (BARROS, 2004, p. 109).

Ainda que a presença de um gancho terminológico seja essencial para relacionar dois termos de linguagem diferentes, na prática, nem sempre é possível encontrar contextos com descritores comuns. "A relação entre os conceitos é então percebida pelo significado geral dos contextos" ${ }^{37}$ (tradução nossa) (DUBUC, 1985 p. 72), o que possibilita considerar um termo como equivalente na língua alvo.

Dessa forma, quando selecionamos material para um estudo terminológico, é importante observar o grau de explicitação dos termos e, se for preciso, substituir ou adicionar textos com mais informações conceituais, como, por exemplo, revistas especializadas, manuais e obras de divulgação.

\footnotetext{
${ }^{36}$ No original: On entend par crochet terminologique les descripteurs communs aux contextes accompagnant les vedettes d'une fiche terminologique.

${ }^{37}$ No original: Les rapport entre les notion en présence est alors perçu par le sens global des contextes.
} 
As fontes de pesquisa devem proporcionar, por meio de definições, explicações ou descrições inseridas no contexto, a identificação dos traços conceptuais (doravante vamos adotar esta denominação) necessários para delimitar o conceito abrangido pelo termo.

Um contexto é "um enunciado que exprime uma ideia completa, no qual o termo estudado encontra-se atualizado" (DUBUC, 1985, p. 62).

A análise do contexto é baseada na identificação dos descritores, "os elementos reveladores de uma característica de um conceito contido em um contexto" (BARROS 2004, p. 109).

Os descritores mais significativos exprimem a natureza, finalidade e forma. Vários autores: Dubuc (1985), Aubert (2001), Barros (2004) classificam os contextos como definitórios, explicativos ou associativos, dependendo do número e qualidade dos descritores presentes. Os contextos podem ainda ser enciclopédicos, e apresentar dados referenciais, históricos sobre um termo, mas sem defini-lo, e são importantes na elaboração de obras enciclopédicas.

Aubert (2001) afirma que a terminologia descritiva bilíngue pode utilizar, quando possível, o contexto definitório, mas é mais comum o contexto explicativo para se identificar o contexto de cada termo. A seguir, vamos apresentar os tipos de contexto.

- O contexto definitório "oferece informações precisas sobre o conceito designado pelo termo estudado" (BARROS, 2004, p. 110). Exemplo de contexto definitório para "fitoterapia" extraído do corpus:

"Etimologicamente, vem das palavras gregas phyton (plantas) e therapeia (tratamento), ou seja, tratamento por meio das plantas. A fitoterapia caracteriza-se pela prática do uso de plantas, ou de suas partes, com a finalidade de prevenir, aliviar ou curar um processo patológico” (BETTEGA, 2011).

- O contexto explicativo "apresenta sucintamente dados a respeito da natureza e de certos aspectos do termo, sem defini-lo claramente" (BARROS, 2004, p. 110). Exemplo de contexto explicativo para "fitoterapia" extraído do corpus:

"Podemos considerar a fitoterapia a única forma de autocura pertencente a todas as culturas e etnias, uma vez que cada povo ou grupo social empregava as ervas - folhas, flores, 
sementes, raizes, cascas - que obtinham ao seu redor para eliminar as enfermidades" (NAIFF, 2016).

- O contexto associativo que, embora não informe características específicas sobre o termo em questão, "veicula, por sua vez, descritores suficientes apenas para determinar, por meio de associações, se o termo pertence a um domínio ou a um grupo de termos que designem conceitos próprios” (BARROS, 2004, p. 110). É o caso, por exemplo, de um termo que figura em uma enumeração. Exemplo de contexto associativo para "fitoterapia" extraído do corpus:

"Essa denominação difundiu-se desde a aprovação da Política Nacional de Práticas Integrativas e Complementares (PNPIC), em 2006, na qual se incluem, em seu escopo: a medicina tradicional chinesa (sobretudo, a acupuntura), homeopática e antroposófica, as plantas medicinais (fitoterapia) e o termalismo social (crenoterapia)” (LIMA, 2009).

Como no glossário proposto não acrescentamos definições dos termos, procuramos selecionar contextos nos corpora que possuem contextos definitórios, sempre que possível. Ao não encontrar contextos definitórios, optamos por contextos explicativos, para possibilitar a melhor compreensão do termo pelo leitor. Para a elaboração do glossário, é importante utilizar os contextos com mais informações, porém, os contextos associativos podem ser utilizados em última instância, na ausência dos anteriores.

Em alguns casos, pode ser necessária a utilização de outra metodologia, como a pesquisa pontual a respeito de um conceito, uma unidade terminológica ou conjunto de termos não encontrados no corpus compilado (Barros, 2004). É comum a pesquisa pontual bilíngue ou multilíngüe na busca por equivalentes. Fontes bibliográficas diversas ou a própria web podem ser utilizadas.

Por exemplo, ao buscar os nomes populares de animais e plantas em outro idioma, pode-se realizar uma busca pontual pelo nome científico, um traço conceitual em comum da espécie em questão no referido idioma.

Também podemos utilizar imagens para facilitar a identificação dos termos e seus equivalentes. "As ilustrações podem, ainda, completar as informações escritas, permitindo uma visão mais clara do objeto descrito" (BARROS, 2004, p. 245). Finalizadas as considerações sobre obras terminográficas, vamos apontar a importância da LC para a realização de trabalhos dessa natureza. 


\subsection{Obras terminográficas}

Segundo Barros (2004) e Zucchi (2010), parece não haver consenso quanto à terminologia designativa e a tipologia de obras lexicográficas e terminográficas, em nível internacional.

Uma das acepções para o termo glossário é apontada por Bevilacqua (2006), segundo a qual é "um conjunto de palavras de determinada área do conhecimento que não tem o objetivo de ser exaustivo."

Para Zucchi (2010, p. 118), diferentemente do caráter polifuncional atribuído aos dicionários, "os glossários são exemplos de obras lexicográficas concebidas com determinados objetivos, com determinada extensão e para um público-alvo conhecido e específico".

Diante dos vários conceitos relacionados aos repertórios, optamos, no âmbito deste estudo, por utilizar as definições propostas por Barros (2004, p. 144):

- dicionário terminológico (termo concorrente: vocabulário): situa-se no nível da(s) norma(s), registrando unidades terminológicas de um ou de vários domínios de especialidade. Apresenta, obrigatoriamente, definições, mas nenhum dado enciclopédico.

- glossário (bilíngue) (termo tolerado: dicionário bilíngue, dicionário multilíngue): pode situar-se tanto no nível do sistema como no da(s) norma(s). Sua principal característica é não apresentar definições, mas tão somente uma lista de unidades lexicais ou terminológicas acompanhadas de seus equivalentes em outras línguas.

- léxico: situa-se no nível de uma norma, uma vez que lista unidades lexicais, terminológicas ou qualquer outro tipo de expressão utilizada pelo autor que se considere de difícil compreensão do público leitor de uma obra. Nesses casos, o léxico figura normalmente como apêndice da obra e apresenta as unidades lexicais seguidas de suas definições.

Almeida (2006, p. 87) ressalta pontos importantes a serem seguidos durante a elaboração de um produto terminográfico seguindo a TCT, considerando como mais importante as unidades terminológicas, e não os conceitos. Para tanto, a autora reforça a necessidade de organização de um corpus, pois "os termos devem ser observados no seu ambiente natural de ocorrência, ou seja, nos discursos especializados". 
Com relação à geração de glossários especializados, Krieger \& Finatto (2004) descrevem várias etapas fundamentais, assim como critérios de confiabilidade e organização. Entre elas está o planejamento do trabalho, em que se deve refletir sobre aspectos como a concepção de uma ficha terminográfica, como será o sistema de remissivas, de que forma serão apresentadas as equivalências em língua estrangeira, entre outros.

As autoras ressaltam também a necessidade de se fazer um reconhecimento terminológico, ponderando sobre a real representatividade dos termos selecionados dentro de uma área de conhecimento. Para isso, é preciso aliar o embasamento teórico e metodológico com familiaridade com a língua de especialidade em questão.

O produto terminográfico deve preencher uma lacuna de informação e, assim, atender a demanda de um público-alvo. Os dados utilizados para a geração do produto devem ser autênticos e originados de fontes confiáveis.

Após fixar critérios previamente determinados, as expressões que se vinculam a uma área de especialidade são coletadas dos corpora. Os termos técnico-científicos costumam ser o foco dos glossários especializados, muito utilizados por tradutores, especialistas e técnicos das áreas afins, e é comum o usuário principal não ser totalmente leigo nem autoridade no assunto, possuindo um conhecimento intermediário sobre o tema.

Muitos elementos são comuns às obras terminográficas e lexicográficas, como os descritos por Zucchi (2010, p. 115), por exemplo, o conjunto de entradas (nomenclatura ou nominata).

Em um glossário, também são aspectos muito importantes a microestrutura, referente à organização dos dados de cada entrada de um repertório, e a macroestrutura, relacionada à concepção geral da obra e o conjunto das partes principais que a compõem, como introdução, anexos (quando houver), bibliografia, organização dos verbetes de forma semasiológica (ordem alfabética) ou onomasiológica (temática).

Há também o sistema de remissivas, em que um termo remete a outro, e que "procura resgatar as relações semântico-conceptuais existentes entre as unidades lexicais ou terminológicas de uma obra lexicográfica ou terminográfica” (BARROS, 2004, p. 174).

Diversos autores, como Dubuc (1985), Aubert (2001), Krieger \& Finatto (2004), Barros (2004) citam ainda a elaboração da árvore de domínio, do francês "arbre de domaine", 
ou mapa conceitual, que permite visualizar as relações entre os conceitos e sua posição nesse conjunto. Trata-se de uma espécie de organograma ou esquema em que se dispõem os termoschave, vinculados à subárea, área e tema de pesquisa.

Podem ser representados por meio de listas sistemáticas, árvores de conceitos, diagramas ou outras formas escolhidas pelo pesquisador, de maneira a facilitar a compreensão das relações entre os conceitos, que podem ser não-hierárquicas ou hierárquicas. Vamos observar um exemplo de árvore de conceitos:

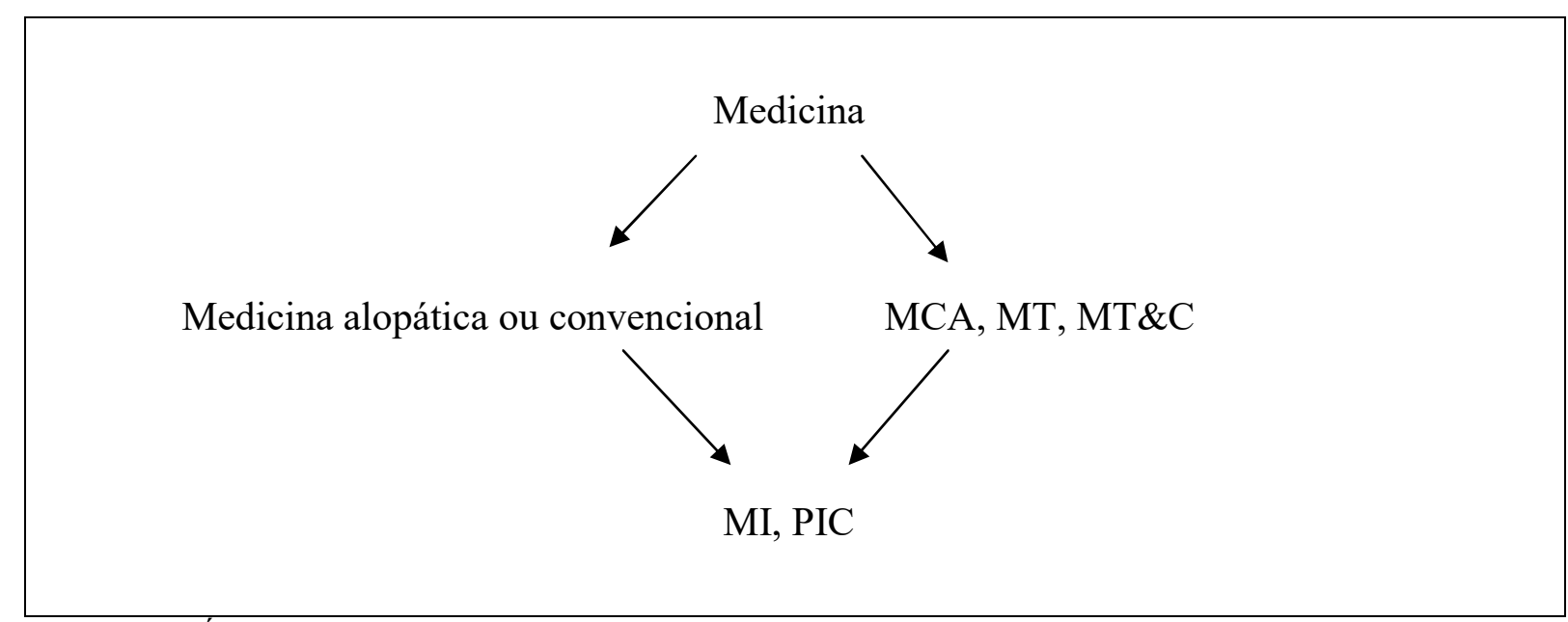

Quadro 1 - Árvore de conceitos de PIC

Dessa forma, fica mais clara a compreensão de que a Medicina Integrativa procura unir a Medicina alopática com a Medicina Alternativa, valendo-se de profissionais de diversas áreas para restabelecer o equilíbrio de bem estar do paciente.

A nomenclatura, conjunto de todas as entradas e verbetes que fazem parte de um dicionário ou glossário é uma parte fundamental da macroestrutura e para sua composição podem ser levados em consideração fatores qualitativos, como a pertinência do termo para a área de conhecimento estudada, e quantitativos, com base na frequência de uso do termo.

Pode acontecer de alguns termos levantados pela frequência não serem pertinentes à pesquisa, então deve-se aliar fatores qualitativos e quantitativos, porém, aplicando os mesmos critérios a todos os termos. Quanto à pertinência do termo, de acordo com Krieger \& Finatto (2004, p. 138), pode haver:

- Pertinência temática "significa a propriedade de um termo pertencer a uma determinada terminologia stricto sensu pelo fato de vincular-se a um conceito que faz parte do campo cognitivo do domínio inventariado." 
- Pertinência pragmática "ao lado de termos cuja presença na lista de termos parece ser indiscutível, aparecem outros termos originados de áreas conexas ou, ainda, de áreas que, de algum maneira, contribuem para a melhor compreensão dos conceitos cobertos pela terminologia especificamente inventariada". A pertinência pragmática relacionase com a multidisciplinaridade de uma área, trazendo conceitos de subáreas que se entrelaçam, facilitando a compreensão de um termo que aparentemente é "alheio à área".

A nomenclatura necessita de revisão contínua durante seu processo de composição, pois será o conteúdo principal de uma obra terminográfica ou lexicográfica.

Ao definir o rol de termos pertinentes a uma obra, é importante observar que eles pode haver relações entre os conceitos que eles abarcam. Elas podem ser relações conceituais nãohierárquicas e relações conceituais hierárquicas (hiponímia, hiperonímia).

As relações conceituais não-hierárquicas podem ser sequenciais ou pragmáticas. As relações sequenciais denotam uma dependência entre "conceitos que se referem a objetos que apresentam uma contigüidade espacial ou temporal” (BARROS, 2004, p. 115).

Exemplo do corpus: iridologia, iridólogo, irisdiagnose. A iridologia busca identificar distúrbios e tendências pelo estudo da iris, enquanto iridólogo(a) é a pessoa que a aplica, e irisdiagnose o método empregado.

As relações pragmáticas são temáticas, como, por exemplo, as práticas integrativas que foram incorporadas em 2017 à PNPICS no Brasil: PIC incluídas na PNPICS pela portaria 849 (Brasil: Ministério da Saúde, 2017) Arteterapia, Ayurveda, Biodança, Dança Circular, Meditação, Musicoterapia, Naturopatia, Osteopatia, Quiropraxia, Reflexoterapia, Reiki, Shantala, Terapia Comunitária Integrativa e Yoga.

Embora cada uma dessas práticas possa ter sua própria racionalidade médica, expressa por diferentes formas de cosmologia, doutrina médica, morfologia, fisiologia ou dinâmica vital humana, sistema de diagnósticos e sistema de intervenções terapêuticas, elas possuem uma relação pragmática por estarem inseridas em um mesmo grupo.

Um dos tipos de relação hierárquica estabelece uma relação de inclusão e pertencimento de conceitos: 
“Em semântica, o conceito mais genérico corresponde ao hiperônimo, enquanto os mais específicos são chamados hipônimos, os quais, quando pertencem ao mesmo nível de abstração dentro de um sistema estruturado, mantém entre si uma relação co-hiponímica (são co-hipônimos)” (BARROS, 2004, p. 117).

Vejamos um exemplo: terapia complementar (hiperônimo) - inclui diversas técnicas terapêuticas, que nesse caso são os hipônimos, como: acupuntura, fitoterapia, shiatsu, florais, entre outras.

Existe também a eponímia, que ocorre quando um nome próprio é usado na formação de um termo, geralmente como uma homenagem a um cientista ou médico. "Em medicina, são ainda muito comuns os epônimos (termos formados em parte por um nome próprio), como, por exemplo, doença de Chagas, mal de Hansen, calcanhar de Aquiles" (BARROS, 2004, p. 98). No corpus de estudo também encontramos casos de epônimos, como florais de Bach.

Enfim, feitas as conceituações necessárias, compreendemos que a Linguística de Corpus é uma abordagem apropriada ao trabalho terminológico, ao permitir a observação da língua em seu uso autêntico por falantes nativos. Para Cabré (1992, p. 246), traduzir implica a compreensão do conteúdo do texto e de seus termos na língua de partida, enquanto:

Fazer terminologia não é, de qualquer modo, traduzir as formas de um idioma para outro com base em nomes supostamente equivalentes, mas retirar os nomes que os usuários de uma língua realmente usam para se referir a um conceito e, em última análise, propor alternativas de denominação a casos mal resolvidos pelos falantes (tradução nossa). ${ }^{38}$

Biderman (2001, p. 81) considera justamente a Lexicologia e a Terminografia como as áreas de conhecimento que mais foram beneficiadas pelos corpora e pelas ferramentas computacionais, por exemplo, para a elaboração de dicionários e glossários. "O corpus veio possibilitar um confronto entre a teoria e os dados empíricos da língua”.

Assim, consideramos a LC a metodologia mais adequada para o estudo desenvolvido, por permitir o exame de uma grande quantidade de ocorrências da língua natural, com a vantagem de observar a linguagem em seu uso autêntico, possibilitando o desenvolvimento de materiais de apoio consistentes para uso dos tradutores.

\footnotetext{
${ }^{38}$ No original: "hacer terminología no es en ningún caso traducir las formas de una lengua a otra sobre la base de unas denominaciones pretendidamente equivalentes, sino recoger las denominaciones que los usuarios de una lengua emplean realmente para referirse a un concepto y, en último término, si cabe, proponer alternativas de denominación a casos mal resueltos por los hablantes".
} 


\section{MATERIAIS E MÉTODOS}

Neste capítulo, vamos apresentar os materiais utilizados para a compilação dos corpora de estudo, as ferramentas computacionais utilizadas nas análises e a metodologia de extração de termos.

O corpus de estudo é aquele em que se baseia a pesquisa e o corpus de referência é usado como comparação na etapa de seleção das palavras-chave. É indicado utilizar um corpus de referência de três a cinco vezes maior que o corpus de estudo, de acordo com Berber Sardinha (2010). Por exemplo, em português, pode ser utilizado o corpus Lácio Web e como corpus de referência em língua inglesa, o British National Corpus (BNC). Foram esses os corpora de referência utilizados nesta pesquisa.

\subsection{Constituição dos corpora}

Para propiciar a variação de gêneros textuais, optamos por selecionar textos de quatro tipos principais: artigos acadêmicos, livros, textos de sites e legislação.

Os artigos acadêmicos foram escolhidos por poderem demonstrar na prática a linguagem utilizada por pesquisadores, provavelmente, em sua maioria, advindos de áreas da saúde e afins. Os artigos também oferecem a vantagem de serem, geralmente, avaliados por seus pares, o que possibilita uma melhor precisão com relação aos termos empregados nessa área de especialidade.

Para realizar esta parte da pesquisa, utilizamos a Biblioteca Virtual da Saúde (BVS $)^{39}$, disponível online, que realiza a busca em diversos repositórios de textos acadêmicos (artigos, monografias, teses e outros) catalogados como da área da saúde. O próprio site da BVS oferece a possibilidade de realizar alguns filtros nas buscas, como por exemplo: idioma principal do artigo, ano de publicação, artigos completos disponíveis, país de afiliação, entre outros.

Primeiramente, vamos explicitar a formação do corpus em português. Com a busca pela palavra-chave "Terapias Complementares", acionamos os filtros para buscar apenas artigos em português, publicados dentro de um período de 20 anos (1995 a 2015), artigos

\footnotetext{
${ }^{39} \mathrm{~A}$ época da pesquisa http://www.bireme.br/php/index.php. Atualmente direciona para http://bvsalud.org/.
} 
completos disponíveis gratuitamente (aqueles que ofereciam apenas o resumo foram desconsiderados) e afiliados ao Brasil. Selecionamos os primeiros 100 artigos que retornaram da busca, número que consideramos suficiente para este gênero textual na pesquisa. As referências completas dos artigos estão presentes na Bibliografia do corpus em português.

Nos casos em que o texto completo do artigo aparecia disponível no corpo do site, foi necessário apenas copiar e colar para Word e depois converter para o formato .txt. Nos casos em que o artigo estava disponível em .pdf, foi preciso extrair o texto por meio de OCR e/ou também copiar e colar.

Com relação aos livros utilizados, os principais critérios foram verificar se os mesmos foram publicados originalmente em português brasileiro (não utilizamos traduções) e se os autores são brasileiros nativos, o que foi possível averiguar por meio de buscas na internet, onde encontramos perfis com resumo da biografia dos autores em questão.

Ao pesquisar pelas palavras-chave Medicina Integrativa, Terapias Alternativas e Complementares, Terapias Holísticas, Medicina Alternativa e Complementar, encontramos uma profusão de livros disponíveis em grandes livrarias do país.

Para limitar a quantidade, decidimos selecionar os livros que se propunham a ser o mais abrangente possível, tratando das terapias e técnicas de forma geral, e não livros que abordassem uma única ou apenas algumas formas de terapias. Esse critério se coaduna com os objetivos de nossa pesquisa, ao ensejar atingir o maior número possível de terapias utilizadas para a elaboração do glossário, ainda que nos livros elas tenham sido tratadas superficialmente. Assim, os cinco livros abaixo foram escolhidos:

- Manual de medicina integrativa: memento fitoterápico.

- Terapias naturais e holísticas: quais são, como foram criadas, para que servem, como são usadas.

- Guia completo das terapias alternativas: métodos terapêticos naturais que proporcionam saúde integral.

- Medicina integrativa: a cura pelo equilíbrio.

- Curso completo de terapia holística \& complementar. 
As referências completas estão disponíveis da Bibliografia do corpus em português. Dentre esses livros, dois estavam em formato digital e três em formato impresso. Foi necessário escanear completamente os livros impressos e posteriormente utilizar o OCR para extração dos caracteres. Essa etapa foi bastante trabalhosa, pois, embora tenhamos contado com o apoio da tecnologia, foi preciso fazer também uma revisão manual, pois muitos caracteres foram reconhecidos erroneamente.

Com relação aos textos de sites utilizados, nos ativemos apenas aos de instituições representativas, como o da Sociedade Internacional de Terapias (SINTE), de hospitais que oferecem atendimentos na área e universidades que oferecem cursos na área, pelo critério da confiabilidade. Utilizamos o conteúdo de páginas que abordassem o tema PIC, e não o conteúdo completo dos sites. Por exemplos, em universidades, apenas textos sobre cursos relacionados às PIC, e não todos oferecidos pela instituição; em hospitais, páginas de centros, núcleos ou outros locais que oferecessem explicações ou divulgassem tratamentos em PIC, e não o conteúdo completo do site do hospital.

No quesito legislação, utilizamos a PORTARIA No 971, DE 03 DE MAIO DE 2006, que aprova a Política Nacional de Práticas Integrativas e Complementares (PNPIC) no Sistema Único de Saúde, e a Política Nacional de Práticas Integrativas e Complementares no SUS, textos do Governo Federal que regulamentam o uso dessas terapias no Brasil. As referências completas dos textos utilizados estão disponíveis na Bibliografia do corpus em português.

Dessa forma, a quantidade de palavras de cada modalidade textual ficou dividida da seguinte maneira:

Artigos acadêmicos: 396.313 palavras

Livros: 268.999 palavras

Legislação: 27.767 palavras

Sites: 11.100 palavras

Total do corpus em português brasileiro: 704.179 palavras

Podemos observar uma representação visual da constituição do corpus no gráfico: 


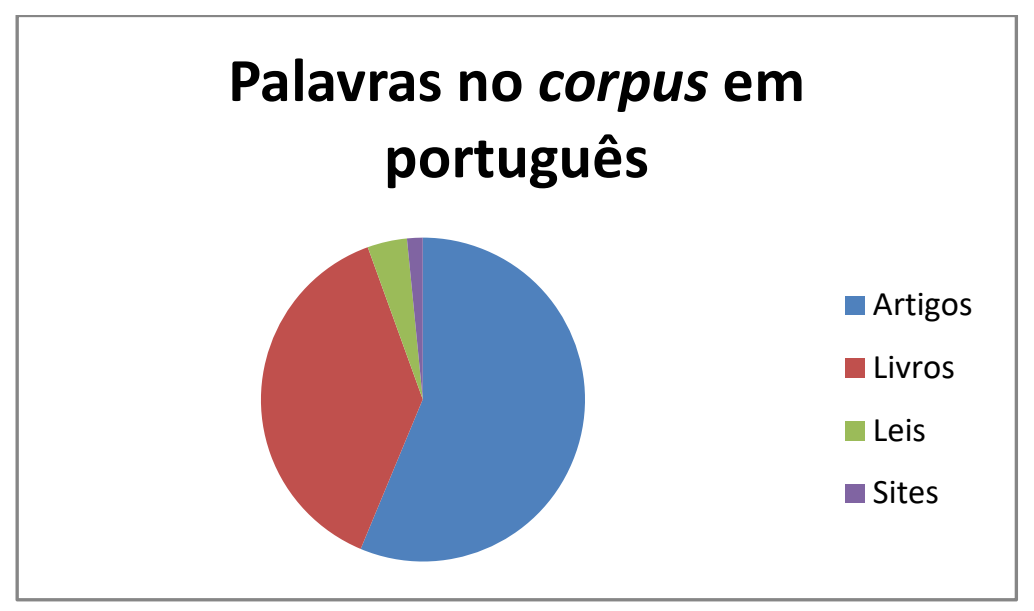

Figura 2 - Palavras no corpus em português

A seguir, abordaremos a formação do corpus em inglês. Para manter o balanceamento dos corpora, optamos por utilizar no corpus em inglês britânico os mesmos gêneros textuais utilizados no corpus em português: artigos acadêmicos, livros, legislação e textos de sites de instituições representativas.

Procuramos manter o balanceamento por gêneros textuais e também por tamanho de corpus. Dessa forma, ao realizar a busca por artigos acadêmicos, embora houvesse maior disponibilidade de artigos escritos em inglês do que em português, decidimos selecionar a mesma quantidade de artigos selecionados em português, ou seja, 100 artigos.

Em busca similar à de português para artigos em inglês do Reino Unido, utilizamos a palavra-chave "Complementary Therapies" e acionamos os filtros de busca por período (1995 a 2015), idioma do texto (inglês) e país de afiliação da revista ou periódico (Reino Unido). As referências completas dos artigos estão disponíveis na Bibliografia do corpus em inglês.

Com relação ao gênero livro, havia muitos disponíveis no mercado, porém, exigiam altos recursos financeiros e longo prazo para importação, além de não ser possível identificar facilmente se os autores eram falantes nativos do inglês britânico. Por esses fatores, selecionamos apenas uma publicação, embora bastante representativa, da Universidade de Oxford:

- Oxford Handbook of Complementary Medicine. 
Com relação ao gênero Legislação, utilizamos os seguintes documentos:

- SIXTH REPORT, 21 NOVEMBER 2000, By the Select Committee appointed to consider Science and Technology. ORDERED TO REPORT COMPLEMENTARY AND ALTERNATIVE MEDICINE. ${ }^{40}$ Documento do Parlamento britânico.

- The General Regulatory Council for Complementary Therapies, The UK Federal Regulator for Complementary Therapies ${ }^{41}$.

No quesito textos de websites, selecionamos textos de hospitais e instituições de ensino que oferecem tratamentos/cursos na área, além de material do site da Federation of Holistic Therapists (FHT). As referências para os textos utilizados podem ser consultadas na Bibliografia do corpus em inglês.

Dessa forma, a quantidade de palavras de cada modalidade textual ficou dividida da seguinte maneira:

Artigos acadêmicos em inglês: 489.139 palavras

Livro: 80.575 palavras

Legislação: 124.767 palavras

Sites: 77.628 palavras

Total do corpus em inglês britânico: 772.109 palavras

Podemos observar uma representação visual da constituição do corpus no gráfico:

\footnotetext{
${ }^{40} \mathrm{https}: / /$ www.publications.parliament.uk/pa/ld199900/ldselect/ldsctech/123/12301.htm

${ }^{41}$ http://www.grcet.org/
} 


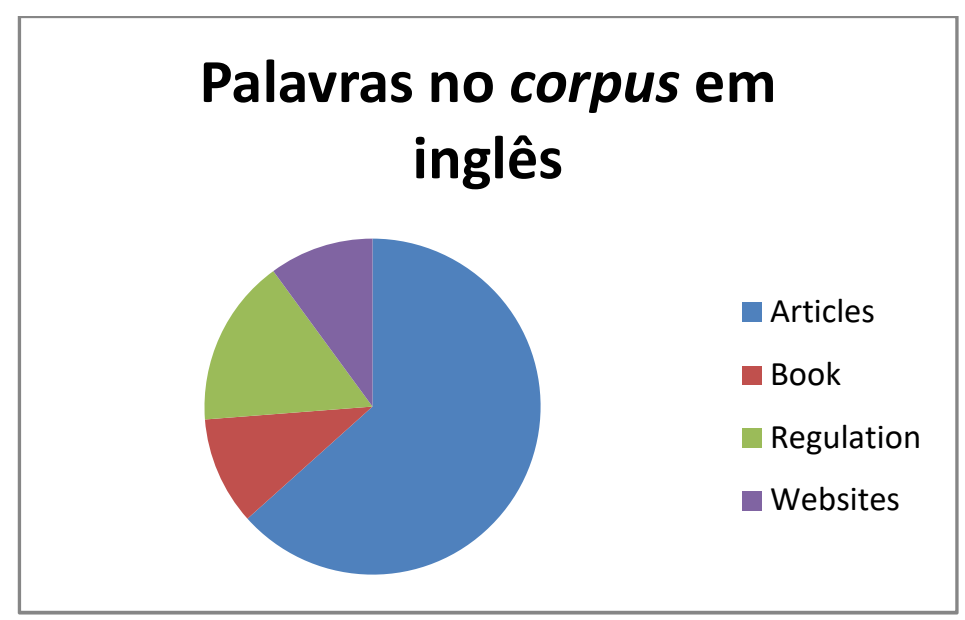

Figura 3 - Palavras no corpus em inglês

Assim, conforme a tipologia proposta por Berber-Sardinha (2004, p. 20-21), os critérios utilizado para a formação desses corpora foram os seguintes:

Língua

Modo

Gêneros

Pesquisa

Seleção

Conteúdo

Uso na pesquisa
Inglês - Português

Escrito

Científico-acadêmicos, livros, legislação e sites de instituições representativas da área.

Sincrônica

Dinâmica

Especializado

Análise Lexical e Terminológica / Tradução

Os textos foram convertidos para o formato .txt para utilização no WST. Aplicamos a ferramenta WordList e em seguida a KeyWords, sendo utilizados como corpora de referência o Lacio Ref para o português, e o British National Corpus (BNC) para o inglês. O Lacio Ref possui textos de língua geral e também de diversas áreas de especialidade. Utilizamos apenas os textos considerados como da área da Saúde, com o objetivo de verificar o que é específico na linguagem de PIC.

Para a formação do corpus de florais brasileiros baseados na alquimia, utilizamos um livro (Essências florais brasileiras) e um texto do gênero instrucional (apostila Introdução ao Sistema Floral Joel Aleixo), utilizado como material didático na formação de terapeutas desse sistema floral. As referências completas desses textos estão disponíveis na Bibliografia do corpus em português. 
Para compilar esse corpus foi necessário escanear o livro e convertê-lo para o formato .txt, juntamente com a apostila, que estava em formato .pdf. Também foi preciso fazer a limpeza do corpus, pois havia muitas imagens no material, o que dificultava o reconhecimento de caracteres.

Após esse processo, o livro forneceu 20.967 palavras e a apostila 23.679 palavras. No total, foram obtidas 44.646 palavras nesse corpus. Após fazer a lista de palavras por frequência, utilizamos a ferramenta KeyWord do WST. Como corpus de referência, utilizamos o próprio corpus em português da área de PIC, para encontrar as especificidades da linguagem dos florais brasileiros em comparação com as terapias integrativas de modo geral.

\subsection{As ferramentas de análise de corpus}

Para realizar a análise de corpus, primeiramente, os textos precisam estar em formato digital, permitindo a análise por ferramentas computacionais. A LC conta hoje com o auxílio de softwares capazes de analisar grandes quantidades de dados linguísticos em corpora autênticos, dando aos estudos de corpora maior confiabilidade e rapidez. Considerando que para a análise dos dados são utilizadas ferramentas computacionais, necessitamos ter como suporte técnico um computador com capacidade suficiente para armazenar os corpora e comportar os softwares utilizados, além de internet banda larga (indispensável para a busca dos textos).

Após a coleta, há vários processos envolvidos na compilação do corpus. Os textos impressos (se houver) precisam ser primeiramente escaneados e convertidos para o formato .txt, que é um dos formatos aceitos pela maioria das ferramentas. Magalhães (2014) descreve alguns processos envolvidos nesta etapa: conversão dos arquivos em formato .pdf com a função Optical Characters Recogtion (OCR) de programas como o ABBYY Fine Reader, por exemplo, e revisão sentença por sentença em toda a extensão do texto para verificar a ocorrência de possíveis erros de OCR e corrigi-los.

A revisão da extensão do documento deve ser bem detalhada, principalmente em materiais que contém imagens ou estão diagramados em colunas, para evitar que a ordem das sentenças seja alterada. Dentre os softwares disponíveis para análise de corpora, utilizamos o 
WordSmith Tools (WST), versão 6.0, criado em 1996 por Mike Scott, da Universidade de Liverpool, Reino Unido.

\section{Exemplos de uso das ferramentas do WordSmith Tools - Versão 6.0}

Vamos a seguir apresentar as ferramentas básicas do WST com as respectivas utilidades, utilizando exemplos elaborados a partir dos corpora de estudo:

Exemplo de Wordlist

\begin{tabular}{|c|c|c|c|c|c|c|c|}
\hline \multicolumn{8}{|c|}{$\begin{array}{l}\text { I corpus-portugues_wordlist.Ist } \\
\text { ile É Edit View Compute SEettings Windows Help }\end{array}$} \\
\hline N & & Word & Freq. & $\%$ & Texts & $\%$ Lemmas & Set \\
\hline 1 & & \# & $43.06_{\iota}^{\prime}$ & 4,99 & 119 & 100,00 & \\
\hline 2 & & $\mathrm{DE}$ & 39.17: & 4,54 & 119 & 100,0 & \\
\hline 3 & & $E$ & $27.36 t$ & 3,17 & 119 & 100,00 & \\
\hline 4 & & A & $26.37 !$ & 3,05 & 119 & 100,00 & \\
\hline 5 & & $\mathrm{O}$ & 16.17 & 1,87 & 119 & 100,00 & \\
\hline 6 & & DA & $12.83^{\circ}$ & 1,49 & 119 & 100,00 & \\
\hline 7 & & QUE & $12.76 !$ & 1,48 & 119 & 100,00 & \\
\hline 8 & & EM & $10.93^{\circ}$ & 1,27 & 119 & 100,0 & \\
\hline 9 & & DO & $10.53 i$ & 1,22 & 119 & 100,00 & \\
\hline 10 & & COM & 8.800 & 1,02 & 119 & 100,00 & \\
\hline 11 & & PARA & 7.113 & 0,82 & 119 & 100,00 & \\
\hline 12 & & OS & 6.542 & 0,76 & 118 & 99,16 & \\
\hline 13 & & SE & 6.460 & 0,75 & 116 & 97,48 & \\
\hline 14 & & NO & 6.291 & 0,73 & 119 & 100,0 & \\
\hline 15 & & AS & 5.727 & 0,66 & 117 & 98,32 & \\
\hline 16 & & UM & 5.435 & 0,63 & 117 & 98,32 & \\
\hline 17 & & NA & 5.417 & 0,63 & 118 & 99,16 & \\
\hline 18 & & UMA & 5.218 & 0,60 & 117 & 98,32 & \\
\hline 19 & & $\dot{E}$ & 4.843 & 0,56 & 117 & 98,32 & \\
\hline 20 & & COMO & 4.739 & 0,55 & 118 & 99,16 & \\
\hline 21 & & DOS & 4.394 & 0,51 & 116 & 97,48 & \\
\hline 22 & & POR & 4.281 & 0,50 & 116 & 97,48 & \\
\hline 23 & & SAÚDE & 4.206 & 0,49 & 111 & 93,28 & \\
\hline 24 & & OU & 3.830 & 0,44 & 111 & 93,28 & \\
\hline 25 & & DAS & 3.782 & 0,44 & 117 & 98,32 & \\
\hline 26 & & NÃO & 3.748 & 0,43 & 111 & 93,28 & \\
\hline 27 & & $\mathrm{AO}$ & 3.060 & 0,35 & 115 & 96,64 & \\
\hline$x$ & & & arer & na & $\ldots$ & anan & \\
\hline
\end{tabular}

Figura 4 - Exemplo de Wordlist

- a WordList produz listas de palavras a partir dos textos selecionados para a composição do corpus contido, podendo ser ordenadas alfabeticamente ou por frequência. 


\section{Exemplo de KeyWords list}

\begin{tabular}{|c|c|c|c|c|c|c|c|c|c|c|c|}
\hline File & Edit & View & Compute & Settings $\underline{W}_{i}$ & Windows $\underline{H}$ & Help & & & & & \\
\hline & $\mathrm{N}$ & & & Key word & Freq. & $\%$ & Texts & $\begin{array}{l}\text { RC. } \\
\text { Freq. }\end{array}$ & RC. \% & ${ }_{6}$ Keyness & $s$ Set \\
\hline & 1 & & & \# & \# 43.06' & 4,99 & 119 & 190.8 & 2,60 & $13.3960,000$ & \\
\hline & 2 & & & LINKS & 2.095 & 0,24 & 71 & 62 & & $8.889,0,000$ & \\
\hline & 3 & & & SAÚDE & $=4.206$ & 0,49 & 111 & 3.732 & 0,05 & $58.807,0,000$ & \\
\hline & 4 & & & BR & 2.070 & 0,24 & 78 & 555 & & $6.739,0,000$ & \\
\hline & 5 & & & MEDICINA & A 2.216 & 0,26 & 100 & 1.185 & 0,02 & $5.848,0,000$ & \\
\hline & 6 & & & WWW & V 1.803 & 0,21 & 40 & 726 & & $5.250,0,000$ & \\
\hline & 7 & & & ED & 1.586 & 0,18 & 63 & 527 & & $4.887,0,000$ & \\
\hline & 8 & & & PRÁTICAS & 1.561 & 0,18 & 93 & 606 & & $4.597,0,000$ & \\
\hline & 9 & & & HTTP & 1.231 & 0,14 & 47 & 454 & & $3.681,0,000$ & \\
\hline & 10 & & & TERAPIAS & 856 & 0,10 & 97 & 32 & & $3.586,0,000$ & \\
\hline & 11 & & $\mathrm{ACU}$ & PUNTURA & A 781 & 0,09 & 59 & 0 & & $3.517,0,000$ & \\
\hline & 12 & & & FLORAIS & 5723 & 0,08 & 33 & 13 & & $3.128,0,000$ & \\
\hline & 13 & & $\mathrm{HON}$ & MEOPATIA & A 680 & 0,08 & 61 & 26 & & $2.845,0,000$ & \\
\hline & 14 & & & TERAPIA & A 858 & 0,10 & 81 & 309 & & $2.583,0,000$ & \\
\hline & 15 & & OMPLEM & IENTARES & 5779 & 0,09 & 81 & 205 & & $2.546,0,000$ & \\
\hline & 16 & & & DIETA & A 677 & 0,08 & 17 & 85 & & $2.534,0,000$ & \\
\hline & 17 & & & MEDICINE & $E \quad 623$ & 0,07 & 74 & 48 & & $2.470,0,000$ & \\
\hline & 18 & & FITC & OTERAPIA & A 522 & 0,06 & 56 & 6 & & $2.286,0,000$ & \\
\hline & 19 & & COMPLE & MENTARY & Y 504 & 0,06 & 62 & 4 & & $2.223,0,000$ & \\
\hline & 20 & & & ACIENTES & 5 1.029 & 0,12 & 87 & 866 & 0,01 & $2.213,0,000$ & \\
\hline & 21 & & & CURA & A 656 & 0,08 & 71 & 171 & & $2.149,0,000$ & \\
\hline & 22 & & TRA & TAMENTO & 1.346 & 0,16 & 101 & 1.827 & 0,02 & $2.142,0,000$ & \\
\hline & 23 & & & EDICINAIS & 568 & 0,07 & 44 & 72 & & $2.123,0,000$ & \\
\hline & 24 & & & CORPO & 1.136 & 0,13 & 75 & 1.362 & 0,02 & $1.976,0,000$ & \\
\hline & 25 & & ALTE & ERNATIVE & $E \quad 457$ & 0,05 & 69 & 19 & & $1.902,0,000$ & \\
\hline & 26 & & TERAF & PÊUTICAS & 478 & 0,06 & 74 & 40 & & $1.879,0,000$ & \\
\hline & 27 & & & CUIDADO & 712 & 0,08 & 70 & 397 & & $1.847,0,000$ & \\
\hline KWs & plo & ot $\quad \mathrm{lin}$ & nks clusters & $\begin{array}{l}\text { nuncunan } \\
\text { filenames }\end{array}$ & $\begin{array}{c}\text { source text } \\
\text { son }\end{array}$ & an & a & $\mathrm{ral}$ & & an anar & \\
\hline
\end{tabular}

Figura 5 - Exemplo de KeyWords list

- Da comparação entre a lista de palavras por frequência dos corpora de estudo e de referência, resulta a KeyWords list (lista de palavras-chave), ou seja, palavras cuja frequência é significativa para a área de especialidade. Dessa forma, em geral, são eliminadas palavras gramaticais (como artigos, pronomes, numerais) e sobressaem palavras de conteúdo, principalmente substantivos, mas também adjetivos e verbos. Quando aparecem palavras-chave que não serão utilizadas na pesquisa que se pretende desenvolver, devido ao recorte feito, pode-se proceder a um filtro manual.

- Embora a LC demonstre a frequência de ocorrência dos termos, conforme BerberSardinha (2004), são também encontradas palavras com uma única ocorrência, conhecidas como hapax legomena. Nesses casos, deve-se analisar a pertinência do termo à pesquisa, associando os critérios quantitativos com qualitativos. 


\section{Exemplo de Concord}

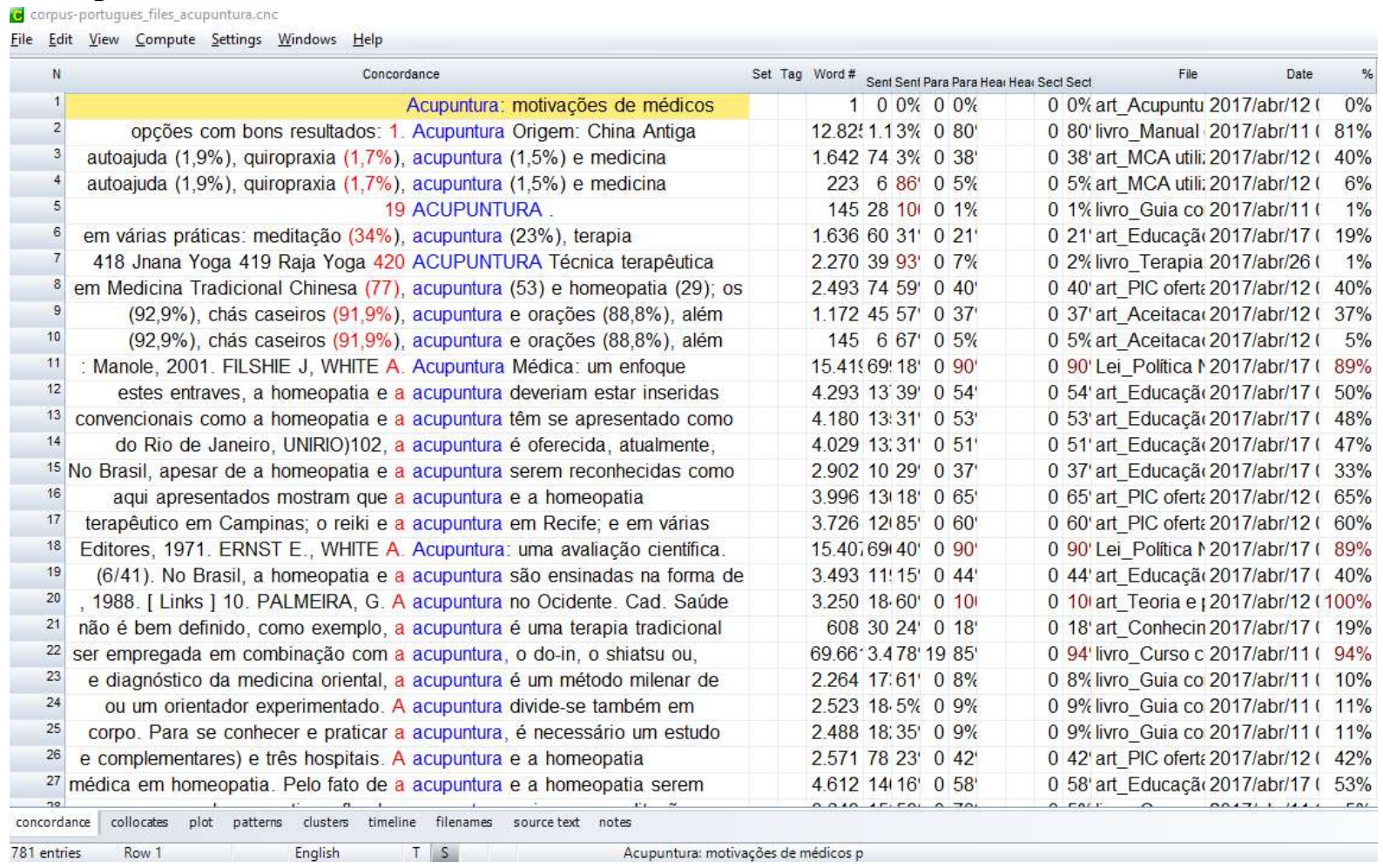

\section{Figura 6 - Exemplo de Concord}

- o Concord produz concordâncias, ou seja, oferece uma listagem com segmentos de texto em que uma palavra específica ocorre. 


\section{Exemplo de Cluster}

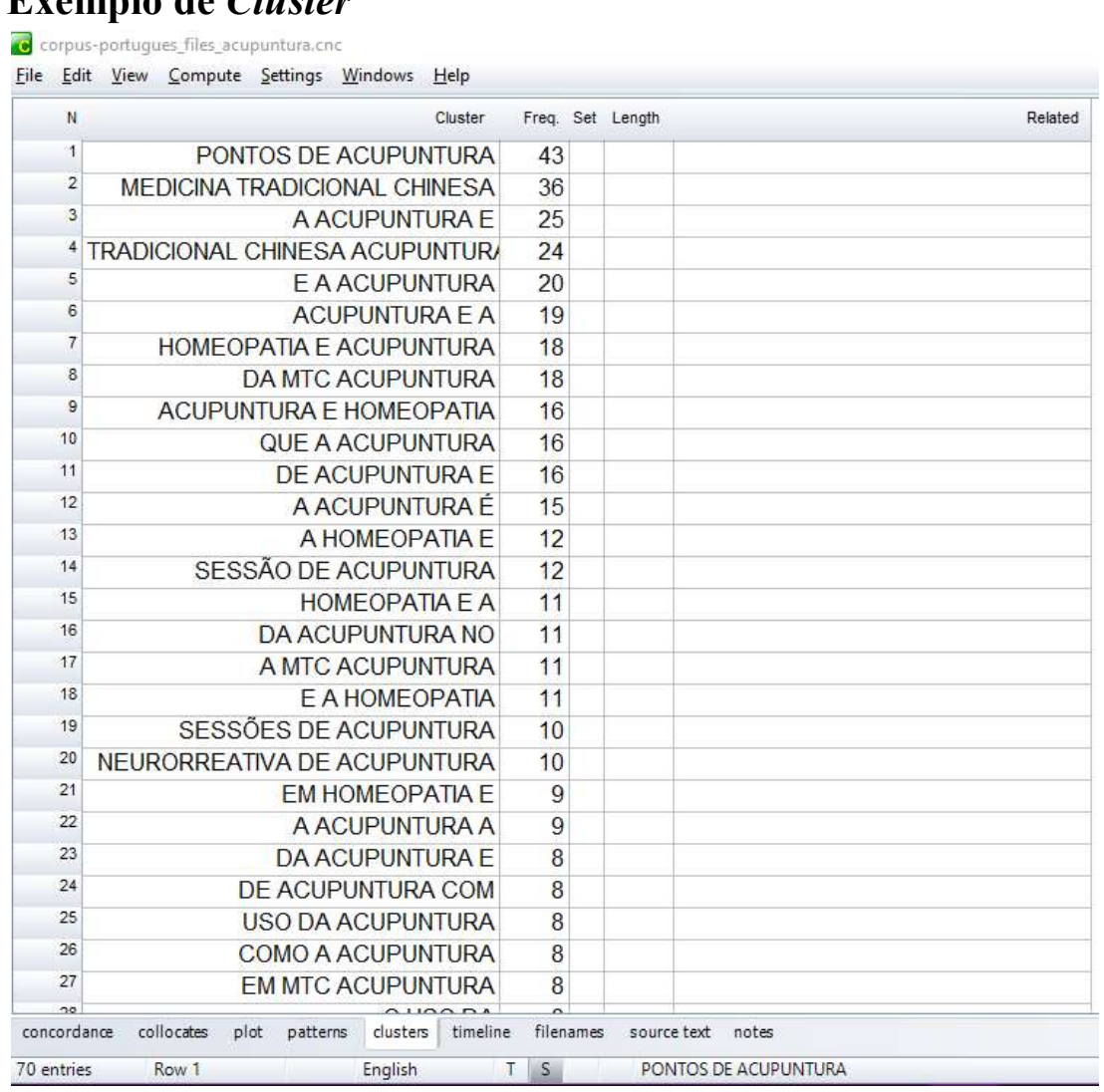

Figura 7 - Exemplo de Cluster

Apresentamos também a ferramenta clusters, que permite analisar agrupamentos de palavras que co-ocorrem frequentemente. Pode-se obter uma lista com duas, três, até oito palavras em cada linha. É por meio dessa ferramenta que podemos observar a ocorrência de fraseologismos.

\subsection{Extração de termos}

Com a lista de palavras-chave, realizamos a extração de candidatos a termo, utilizando critérios quantitativos (pela frequência) e qualitativos (verificando a pertinência para a pesquisa), por meio de leitura atenta de trechos dos textos.

O corpus em português apresentou 584 palavras-chave, disponíveis no Apêndice I. Ao analisar esta lista, podemos observar a terminologia pertinente à área e selecionar os termos para o glossário. 
Alguns conceitos que apareceram na lista de palavras-chave são muito abrangentes, utilizados amplamente na área da saúde em geral ou são interdisciplinares, como os seguintes: práticas, terapias, medicina, plantas, corpo, cura, medicinais, cuidado, energia, profissionais, tratamento, ansiedade, dieta, medicinas, uso, psicologia, chinesa, mente, entrevistados, equilíbrio, saúde, dor, promoção, profissional, mental, científico, emocional, água, campo, folhas, tratamentos, SUS, harmonia, posologia, atenção, paradigma, estresse, indicações, técnicas, ciência, pacientes, eficácia, vida, pensamento, enfermeiro, pontos, gotas, muscular, conhecimento, técnica, enfermagem, dores, exercícios, entre muito outros.

Também foram encontrados termos que mantém entre si relações conceituais nãohierárquicas como: terapias, terapia, terapêuticas, terapêutica, terapêutico, terapêuticos e terapeutas, usados na área da saúde em geral. Dessa forma, percebemos ser necessário realizar a extração de termos de forma híbrida, aliando critérios quantitativos (pela frequência no corpus) a qualitativos, analisando também a pertinência temática e pragmática do termo à área de especialidade.

Dada a abrangência das palavras-chave encontradas, foi necessário efetuar um recorte mais específico para o desenvolvimento do glossário, por isso mantivemos no estudo apenas os termos mais característicos da linguagem de especialidade das Práticas Integrativas e Complementares, com foco nas técnicas terapêuticas usadas em PIC, embora esses mesmos termos possam ser utilizados esporadicamente em qualquer área, já que consideramos não haver conceitos “exclusivos” de um domínio, conforme a TCT.

A partir dessa pesquisa inicial com os corpora, realizamos uma análise mais aprofundada da lista de palavras-chave em português e utilizamos a ferramenta Concord para verificar quais dos resultados encontrados eram realmente termos simples e encontrar os termos complexos ou compostos. Realizamos esse procedimento até o final da lista de palavras-chave e chegamos aos termos mais representativos, aqueles que compõem a nomenclatura do glossário.

Assim, retornaram à pesquisa as palavras-chave plantas e medicinais, originando os sintagmas "plantas medicinais"; terapias, formando "terapias alternativas", entre outros; chinesa, em "medicina chinesa", e assim por diante.

No corpus em inglês obtivemos uma lista com 3442 palavras-chave positivas. Disponibilizamos as primeiras 500 para consulta no Apêndice II. As demais palavras-chave 
poderão ser analisadas em estudos futuros pois, nesse momento, focamos a análise na direção português-inglês.

Buscamos os equivalentes no corpus em inglês, pela lista de KeyWords e também usando a ferramenta Concord. Nem todos os equivalentes foram encontrados no referido corpus, porém, percebemos não se tratar de casos de não equivalência, e sim de uma deficiência do corpus, pois esses equivalentes foram encontrados posteriormente em pesquisas na internet, em sites escritos em língua inglesa.

Com o corpus de florais brasileiros, também realizamos os procedimentos de lista de palavras e lista de palavras-chave. Encontramos 269 palavras-chave, das quais apresentamos, como exemplo, as primeiras 50:

\begin{tabular}{|c|c|c|c|c|c|}
\hline $\mathbf{N}$ & Key word & Freq. & $\%$ & Texts & Keyness \\
\hline 1 & AURA & 182 & 0,41 & 2 & 732,55 \\
\hline 2 & FLORAL & 185 & 0,41 & 2 & 520,74 \\
\hline 3 & INDICADO & 114 & 0,25 & 2 & 351,93 \\
\hline 4 & ÁRVORE & 74 & 0,16 & 2 & 344,58 \\
\hline 5 & CORPO & 247 & 0,55 & 2 & 296,60 \\
\hline 6 & MEMÓRIA & 84 & 0,19 & 2 & 295,52 \\
\hline 7 & ALQUIMIA & 65 & 0,14 & 2 & 290,23 \\
\hline 8 & PRECISAM & 62 & 0,14 & 2 & 240,87 \\
\hline 9 & CORES & 86 & 0,19 & 2 & 233,84 \\
\hline 10 & MIASMAS & 47 & 0,10 & 1 & 225,48 \\
\hline 11 & TERRA & 79 & 0,18 & 2 & 224,09 \\
\hline 12 & NÍVEL & 111 & 0,25 & 2 & 222,64 \\
\hline 13 & ELEMENTOS & 101 & 0,23 & 2 & 221,86 \\
\hline 14 & MUITO & 155 & 0,35 & 2 & 217,75 \\
\hline 15 & MOVIMENTO & 107 & 0,24 & 2 & 215,86 \\
\hline 16 & QUE & 1231 & 2,74 & 2 & 213,07 \\
\hline 17 & TINTURA & 54 & 0,12 & 1 & 210,46 \\
\hline 18 & MERCURIUS & 33 & 0,07 & 1 & 194,72 \\
\hline 19 & FLORAIS & 156 & 0,35 & 2 & 190,98 \\
\hline 20 & MAGNÉTICO & 40 & 0,09 & 2 & 181,14 \\
\hline 21 & COMPOSTOS & 55 & 0,12 & 2 & 179,26 \\
\hline 22 & PLANTA & 82 & 0,18 & 2 & 176,97 \\
\hline 23 & AQUELES & 66 & 0,15 & 2 & 175,32 \\
\hline 24 & GLÓBULOS & 34 & 0,08 & 1 & 171,29 \\
\hline 25 & SULPHUR & 29 & 0,06 & 1 & 171,12 \\
\hline 26 & EMUNCTÓRIOS & 29 & 0,06 & 1 & 162,46 \\
\hline 27 & CHAKRAS & 40 & 0,09 & 2 & 161,80 \\
\hline 28 & JOEL & 36 & 0,08 & 2 & 154,63 \\
\hline 29 & $\mathrm{AR}$ & 53 & 0,12 & 2 & 145,27 \\
\hline 30 & SUBSTÂNCIAS & 64 & 0,14 & 1 & 142,21 \\
\hline 31 & ALEIXO & 35 & 0,08 & 2 & 140,54 \\
\hline 32 & NEURÔNIOS & 30 & 0,07 & 2 & 138,76 \\
\hline 33 & FORTE & 49 & 0,11 & 2 & 135,42 \\
\hline
\end{tabular}




\begin{tabular}{|r|r|r|r|r|r|}
\hline 34 & PARA & 671 & 1,50 & 2 & 131,63 \\
\hline 35 & DICA & 26 & 0,06 & 1 & 130,28 \\
\hline 36 & EMUNCTÓRIO & 22 & 0,05 & 1 & 129,81 \\
\hline 37 & ASSEPSIA & 24 & 0,05 & 1 & 127,72 \\
\hline 38 & SE & 645 & 1,44 & 2 & 123,54 \\
\hline 39 & FOGO & 48 & 0,11 & 2 & 121,65 \\
\hline 40 & LIMPEZA & 48 & 0,11 & 2 & 113,85 \\
\hline 41 & APRESENTA & 57 & 0,13 & 2 & 113,81 \\
\hline 42 & CLIENTE & 48 & 0,11 & 1 & 113,11 \\
\hline 43 & NERVOSO & 50 & 0,11 & 2 & 112,76 \\
\hline 44 & ELEMENTO & 46 & 0,10 & 2 & 108,52 \\
\hline 45 & ALQUIMISTA & 22 & 0,05 & 2 & 107,91 \\
\hline 46 & NATUREZA & 72 & 0,16 & 2 & 106,37 \\
\hline 47 & CONTRAI & 21 & 0,05 & 2 & 106,15 \\
\hline 48 & MATÉRIA & 46 & 0,10 & 2 & 105,65 \\
\hline 49 & DIGESTÓRIO & 24 & 0,05 & 1 & 101,49 \\
\hline 50 & FLORES & 58 & 0,13 & 2 & 100,03 \\
\hline
\end{tabular}

Quadro 2 - KeyWords do corpus de florais

Encontramos assim a lista de palavras-chave específicas dos florais em comparação com o corpus de palavras de PIC, porém, realizamos também uma análise qualitativa, por meio da leitura completa dos textos que compõem o corpus de florais, buscando observar quais os termos mais relevantes para caracterizar este sistema floral e distingui-lo de outros, ainda que não sejam as palavra-chave mais frequentes.

Desta forma, observamos que para a produção dos florais brasileiros baseados na alquimia, são utilizadas 99 plantas, das quais são extraídas as essências para a elaboração destes florais. As plantas utilizadas são o grande diferencial entre os diversos sistemas florais existentes, desde os florais de Bach aos numerosos exemplos citados no Capítulo 1, e são, portanto, termos muito proeminentes desta área de especialidade.

Por essa razão, realizamos este recorte na pesquisa e selecionamos o nome dessas 99 plantas como os termos utilizados para a composição da nomenclatura de uma proposta de glossário dos florais brasileiros baseados na alquimia. 


\section{APRESENTAÇÃO E DISCUSSÃO DOS RESULTADOS}

Passamos agora à apresentação dos resultados da pesquisa. Pela ordem de na lista de palavras-chave nos corpora, selecionamos as 25 modalidades de PIC que mais ocorreram em ambos os idiomas.

25 primeiras PIC pela frequência no corpus em português:

\begin{tabular}{|c|}
\hline acupuntura \\
\hline florais/floral \\
\hline homeopatia \\
\hline fitoterapia \\
\hline meditação \\
\hline relaxamento \\
\hline massagem \\
\hline yoga/ioga \\
\hline aromaterapia \\
\hline naturologia \\
\hline reiki \\
\hline cromoterapia \\
\hline radiestesia \\
\hline antroposófica \\
\hline shiatsu \\
\hline musicoterapia \\
\hline quiropraxia \\
\hline iridologia \\
\hline hipnose/hipnoterapia \\
\hline massoterapia \\
\hline ayurvédica/Ayurveda \\
\hline reflexologia \\
\hline termalismo \\
\hline calatonia \\
\hline equoterapia \\
\hline
\end{tabular}

25 primeiras PIC pela frequência no corpus em inglês: 


\begin{tabular}{|c|}
\hline massage \\
\hline herbal (medicine) \\
\hline acupuncture \\
\hline acupressure \\
\hline homeopathy \\
\hline aromatherapy \\
\hline reflexology \\
\hline relaxation \\
\hline (flower) remedies \\
\hline chiropractic \\
\hline naturopathy \\
\hline osteopathy \\
\hline hypnotherapy/hypnosis \\
\hline reiki \\
\hline shiatsu \\
\hline iridology \\
\hline biofeedback \\
\hline yoga \\
\hline ayurvedic/Ayurveda \\
\hline kinesiology \\
\hline meditation \\
\hline Qigong \\
\hline craniosacral \\
\hline mindfulness \\
\hline hydrotherapy \\
\hline
\end{tabular}

Os termos que correspondem ao mesmo tipo de PIC foram agrupados, como é o caso de florais/(terapia) floral, yoga/ioga (variante), Ayurveda/(terapia) ayurvédica, hypnotherapy/hipnosis.

\subsection{Terminologia das PIC}

Apresentamos a seguir, na primeira coluna a lista com os 109 termos em português selecionados para a composição do glossário e as variantes encontradas no corpus em português. Na segunda coluna apresentamos os equivalentes em inglês. Aqueles que estão marcados com * (asterisco) referem-se aos equivalentes que foram encontrados apenas em outras fontes presentes na $W e b$, e não no corpus compilado. 


\begin{tabular}{|c|c|}
\hline acupuntura & acupuncture \\
\hline agulha(s) & needle(s) \\
\hline Alexander, técnica de & Alexsander technique \\
\hline alquimia & alchemy \\
\hline antroposófica, medicina; Antroposofia & anthroposophical medicine; Anthroposophy \\
\hline apiterapia & apitherapy*; bee therapy* \\
\hline argiloterapia & clay therapy*; mud therapy* \\
\hline aromaterapia & aromatherapy \\
\hline arteterapia & art therapy* \\
\hline aura & aura \\
\hline Aura-soma & Aura-soma* \\
\hline auto-hemoterapia & autohemotherapy*; self-blood therapy* \\
\hline Ayurveda; aiurvédica, medicina & Ayurveda; ayurvedic medicine \\
\hline bambuterapia & bamboo therapy* \\
\hline biodanza; biodança & biodanza* \\
\hline biodinâmica & biodynamics * \\
\hline bioenergética & bioenergetic analysis* \\
\hline biofeedback & biofeedback \\
\hline body talk & BodyTalk \\
\hline calatonia & calatonia* \\
\hline cantoterapia & singing therapy* \\
\hline chacra(s), chakra(s) & chakra(s) \\
\hline chi; ki & $q i ; k i ; c h i$ \\
\hline chi kung; chi gong; qi gong & Qigong; Qi Gung \\
\hline cinesiologia & kinesionlogy \\
\hline colonterapia & colon hydrotherapy; colon cleansing* \\
\hline constelação familiar & family constellation $(s) *$ \\
\hline craniossacral, terapia & craniosacraltherapy \\
\hline crenoterapia; (ver) termalismo & balneotherapy \\
\hline cristaloterapia & crystal therapy \\
\hline cromoterapia & colour therapy; chromotherapy* \\
\hline cura espiritual & spiritual healing \\
\hline cura prânica & pranic healing* \\
\hline dançaterapia; dança-movimento terapia & dance/movement therapy* \\
\hline dietoterapia & diet therapy* \\
\hline do-in & do-in* \\
\hline equoterapia & equine therapy \\
\hline eutonia & eutony* \\
\hline fasciaterapia & fasciatherapy* \\
\hline Feldenkrais & Feldenkrais \\
\hline fitoterapia & herbal medicine, herbalism \\
\hline
\end{tabular}




\begin{tabular}{|c|c|}
\hline $\begin{array}{l}\text { florais; essências florais; terapia floral; } \\
\text { sistemas florais; floralterapia }\end{array}$ & flower essences, flower remedies \\
\hline geoterapia & geothermal therapy*; clay therapy* \\
\hline helioterapia & helio therapy*; sunbathing* \\
\hline hidroterapia & hydrotherapy \\
\hline hirudoterapia & hirudotherapy \\
\hline hipnose; hipnoterapia & hypnotherapy, hypnosis \\
\hline holística, medicina; holismo & holistic medicine; holism \\
\hline homeopatia; homeopática, medicina & homeopathy; homeopathic medicine \\
\hline imagem guiada; imaginação guiada & imagery \\
\hline iridologia & iridology \\
\hline irisdiagnose & iris diagnosis; iris analysis \\
\hline Johrei & Johrei \\
\hline Lian gong & Lian gong* \\
\hline macrobiótica, dieta & macrobiotic diet ${ }^{*}$ \\
\hline magnetoterapia & magnet therapy \\
\hline mantra(s) & mantra $(s)$ \\
\hline massagem & massage \\
\hline massoterapia & massage therapy \\
\hline MCA; medicina complementar e alternativa & $\begin{array}{l}\text { CAM; complementary and alternative } \\
\text { medicine }\end{array}$ \\
\hline medicina integrativa & integrative medicine \\
\hline medicina tradicional & traditional medicine \\
\hline $\begin{array}{l}\begin{array}{l}\text { medicina tradicional chinesa; } \\
\text { chinesa, }\end{array} \\
\end{array}$ & $\begin{array}{l}\text { traditional Chinese medicine; Chinese } \\
\text { medicine }\end{array}$ \\
\hline meditação & meditation \\
\hline meridiano(s) & meridian(s) \\
\hline mindfulness & mindfulness \\
\hline moxabustão; moxa; moxibustão & moxibustion \\
\hline musicoterapia & music therapy \\
\hline naturologia; (ver) naturopatia & naturopathy \\
\hline naturopatia & naturopathy \\
\hline óleos essenciais; óleo essencial & essential oil(s) \\
\hline oligoelementos; oligoterapia & oligoelements $*$; oligotherapy* \\
\hline ortomolecular, medicina & orthomolecular medicine \\
\hline osteopatia & osteopathy \\
\hline ozonioterapia & ozone therapy \\
\hline Pathwork & Pathwork* \\
\hline pêndulo(s) & pendulum* \\
\hline PIC; Práticas Integrativas e Complementares & $\begin{array}{l}\text { CIP*, Complementary and Integrative } \\
\text { Practices* }\end{array}$ \\
\hline plantas medicinais & herbs; medicinal plants \\
\hline PNL, programação neurolinguística & NLP, neuro-linguistic programming \\
\hline
\end{tabular}




\begin{tabular}{|c|c|}
\hline prana & prana \\
\hline pulsologia & $\begin{array}{l}\text { pulsology*; pulse palpation*; pulse } \\
\text { diagnosis* }\end{array}$ \\
\hline quiropraxia; quiroprática & chiropractic \\
\hline radiestesia & dowsing, radiesthesia* \\
\hline radiônica & radionics \\
\hline reflexologia & reflexology \\
\hline reflexoterapia & reflexotherapy* \\
\hline reiki; reike & reiki \\
\hline relaxamento & relaxation \\
\hline Rességuier, método & Rességuier, method* \\
\hline Rolfing & Rolfing \\
\hline sei-tai & seitai $^{*}$ \\
\hline self healing; autocura & self healing \\
\hline shantala; xantala & loving hands*; baby massage \\
\hline shiatsu & shiatsu \\
\hline somaterapia & somatherapy* \\
\hline tai chi chuan, tai-chi-chuan & tai chi \\
\hline talassoterapia & thalassotherapy* \\
\hline $\begin{array}{llll}\text { termalismo; } & \text { termalismo } & \text { social; } & \text { (ver) } \\
\text { crenoterapia } & & & \end{array}$ & balneotherapy \\
\hline tigelas tibetanas; tigelas cantantes & singing bowls; Tibetan singing bowls \\
\hline tintura(s) & tincture $(s)$ \\
\hline toque terapêutico & therapeutic touch \\
\hline tui-na; tui-ná; tuina; tui na & tui-na; tui na \\
\hline urinoterapia & urine therapy \\
\hline vegetoterapia & vegetotherapy* \\
\hline ventosas; ventosaterapia & cupping therapy; Chinese cupping \\
\hline vibracional, medicina; vibracionais, terapias & vibrational medicine; vibrational therapies \\
\hline xamanismo & shamanism* \\
\hline yoga; ioga & $y o g a$ \\
\hline
\end{tabular}

Quadro 3 - Lista de termos e equivalentes

Observamos a presença de siglas (PIC, MCA, PNL), termos compostos (Aura-soma, auto-hemoterapia, do-in, sei-tai, tai-chi-chuan, tui-na), mas na maioria, termos simples e complexos.

Considerando apenas o termo mais frequente, nos casos em que há variantes, chegamos à seguinte representação gráfica: 


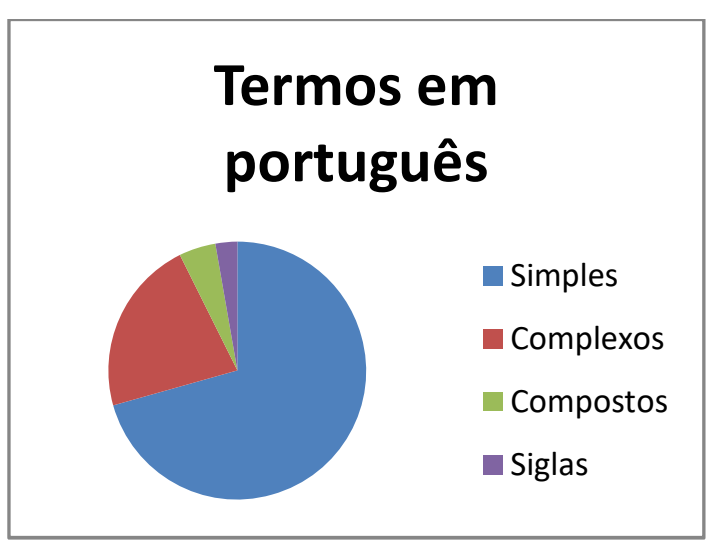

Figura 8 - Termos em português

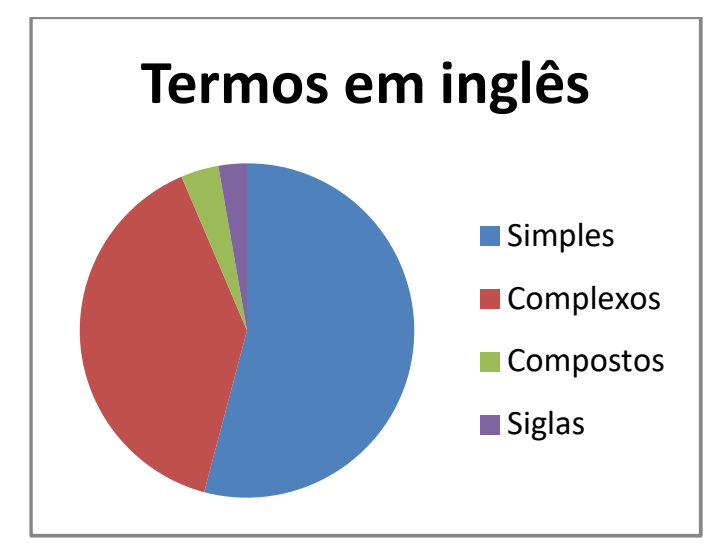

Figura 9 - Termos em inglês

Dessa forma, podemos observar a prevalência dos termos complexos em inglês em relação ao português, embora os termos simples sejam mais abundantes em ambos os idiomas.

\subsection{Exemplos de relações conceituais}

As principais relações conceituais não-hierárquicas encontradas foram do tipo sequenciais, referentes a terapias/modalidades terapêuticas e profissionais/terapeutas que as aplicam, por exemplo:

Homeopatia, homeopata.

Acupuntura, Acupunturista

Quiropraxia, quiroprata.

Fitoterapia, fitoterapeuta.

Massoterapia, massoterapeuta

Radiestesia, radiestesista

Naturologia, naturólogo

Ayurveda, terapeuta aiurvédico

Iridologia, iridólogo

Florais, terapeuta floral

Com relação às relações conceituais hierárquicas, encontramos dois grupos principais de hiperônimos. O primeiro é relacionado à própria maneira de denominar as PIC, que englobam ampla variedade de modalidades terapêuticas. São exemplos: Medicina Complementar e Alternativa (MCA), medicina integrativa, medicina holística, medicina 
natural, medicina vibracional, terapias vibracionais, medicina tradicional. Nesses casos, as mesmas terapias podem ser consideradas hipônimos dos termos acima.

O segundo grupo de hiperônimos é o de racionalidades médicas como:

- Medicina chinesa: engloba fitoterapia, acupuntura, massagem chinesa, ventosas, entre outras técnicas.

- Medicina ayurvédica, ou Ayurveda: engloba fitoterapia, massagem ayurvédica, yoga.

- Medicina Antroposófica ou terapia antroposófica: engloba terapia artística, medicamentos antroposóficos, euritmia, análise biográfica.

- Massoterapia: abrange diversas técnicas de massagem, utilizadas de acordo com a necessidade do cliente, como massagem indiana, tui-na, shiatsu, massagem tailandesa, massagem chinesa, entre outras.

- Naturologia: abrange aromaterapia, cromoterapia, fitoterapia, geoterapia, hidroterapia, massoterapia, talassoterapia.

Houve ocorrência de casos de eponímia - a denominação terminológica embasada na designação de um objeto pelo nome de seu descobridor, ou quem desenvolveu a técnica. Apareceram os seguintes epônimos: Florais de Bach, Técnica de Alexander, Método Feldenkrais, Rolfing, homeopatia hahnemanniana (em referência a Hahnemann), Florais Joel Aleixo, Shantala. ${ }^{42}$

\subsection{A busca por equivalentes em inglês}

Ao buscar os termos equivalentes em ambos os idiomas, observamos a prevalência da utilização do mesmo radical, o que costuma ser bastante comum em linguagens técnicas e científicas. A exceção aplica-se ao termo radiestesia e seu correspondente dowsing, mais frequente do que radiesthesia.

\footnotetext{
${ }^{42} \mathrm{~A}$ técnica foi descoberta pelo médico francês Frédérick Leboyer, ao observar, na Índia, uma mulher de nome Shantala massegeando seu bebê.
} 
Observamos a ocorrência de estrangeirismos, tanto em português quanto em inglês, em casos em que a PIC/terapia é originária de culturas orientais como, por exemplo, reiki/reiki (Japão), shiatsu/shiatsu (China), Ayurveda/Ayurveda e yoga/yoga, da Índia, embora em português também ocorra a variação aportuguesada ioga.

Algumas observações devem ser feitas em relação ao termo "fitoterapia". No corpus em português ele ocorreu 510 vezes, porém, o possível equivalente de mesmo radical, phytotherapy, ocorreu somente 15 vezes no corpus em inglês.

Verificamos então, por meio das linhas de concordância, alta ocorrência de herbal medicine (315 vezes). Ao efetuar a busca por herbal medicine*, que possibilita o retorno da forma no plural, herbal medicines, as ocorrências totalizaram 567, enquanto herbalism ocorreu 44 vezes.

Dessa forma, pela convencionalidade da língua, há indícios no corpus de que herbal medicine seja o equivalente mais adequado para fitoterapia, seguido de herbalism, e phytotherapy seja uma variante utilizada em menor escala.

Para "florais", com o termo no plural, encontramos 674 ocorrências, enquanto a forma no singular, "floral", ocorreu 255 vezes. Destas, 120 ocorrências foram do sintagma terminológico "terapia floral". A variante "floralterapia" apareceu 9 vezes no corpus. Em inglês apareceram as variações "flower essence(s)", 68 vezes, e “(Bach) flower remedies", 36 vezes. É importante ter em mente que os florais de Bach são apenas um dos tipos existentes e disponíveis no mercado. Costeira (2015) cita mais de 80 sistemas florais diferentes, desenvolvidos no Brasil e em diversos outros países, mencionados no Capítulo 1.

Para o termo PIC - Práticas Integrativas e Complementares, foi encontrado o termo CIP - Complementary and Integrative Practices apenas em textos traduzidos para o inglês, sendo a língua de origem o português. Acreditamos que isso se deva ao fato de esse ser um termo cunhado no Brasil.

Utilizando a equivalência funcional, poderíamos considerar mais adequado utilizar CAM - Complementary and Alternative Medicine, porém, em português também aparece MCA - Medicina Complementar e Alternativa com frequência. Portanto, decidimos manter 
no glossário CIP - Complementary and Integrative Practices pois, nos contextos em que são utilizados, referem-se justamente às práticas referidas pela política de saúde instituída no Brasil, e não à utilização de CAM em geral. A denominação PIC também vem sendo utilizada em eventos acadêmicos em geral.

\subsection{O termo terapia}

Ao analisarmos a lista de palavras-chave em português, observamos que o termo simples "terapias" apareceu na quarta posição, com frequência 855. Sua forma no singular, “terapias", ocorreu 811 vezes e ocupa a décima-sétima posição na lista de palavras-chave.

Ao aprofundarmos o estudo do referido termo, verificamos que ele dá origem a numerosos outros termos, formando modalidades de terapia por composição e também termos complexos, com mais de uma palavra.

Excluindo os termos que não são específicos das PIC (como fisioterapia, psicoterapia, quimioterapia e radioterapia), encontramos 63 termos formados por composição por aglutinação ou justaposição, como exemplo, aromaterapia, arteterapia, cristalterapia, cromoterapia, dançaterapia, equoterapia, fitoterapia, floralterapia, hidroterapia, hipnoterapia, magnetoterapia, massoterapia, musicoterapia e reflexoterapia.

Com relação aos termos complexos, verificamos a prevalência de hiperônimos (termos que englobam várias modalidades terapêuticas): terapia alternativa, terapia complementar, terapia complementar e alternativa, terapia energética, terapia holística, terapia integrativa, terapia natural, terapia não convencional, terapia tradicional. Ocorreram ainda, em menor frequência, alguns termos complexos referentes a terapias específicas, por exemplo, terapia antroposófica, terapia floral e terapia ortomolecular.

Em busca similar no corpus em inglês, encontramos 5349 entradas para therap*, com ocorrências na forma singular (therapy) e plural (therapies), além de therapist e therapeutic.

Também realizamos a busca para *therapy, que possibilita o retorno de termos compostos, retornaram 2936 entradas. Excluindo-se aqueles que não são exclusivos da linguagem das PIC, como chemotherapy, physiotherapy, psychotherapy, radiotherapy, 
encontramos apenas sete termos referentes a modalidades terapêuticas específicas: aromatherapy, auriculotherapy, balneotherapy, hirudotherapy, hydrotherapy, hypnotherapye phytotherapy.

Em compensação, os termos complexos foram mais abundantes, também em relação ao português. Houve ocorrência de hiperônimos, como alternative therapy, mind-body therapy, CAM therapy (sigla para complementary and alternative therapy), complementary therapy, energy therapy, holistic therapy, manipulative therapy, manual therapy, natural therapy e unconventional therapy.

Encontramos também 34 termos complexos referentes a modalidades de PIC, por exemplo, anthroposophical therapy, art therapy, colour therapy, crystal therapy, equine therapy, flower essence therapy, herbal therapy, magnet therapy, massage therapy e music therapy.

\subsection{Exemplos de contextos definitórios, explicativos e associativos}

Apresentamos a seguir alguns exemplos de contextos extraídos dos corpora, embora algumas vezes ocorra uma mescla entre os tipos de contextos. As referências para esses exemplos estão disponíveis nas respectivas bibliografias dos corpora.

\section{Contextos definitórios:}

A Crenoterapia consiste na indicação e uso de águas minerais com finalidade terapêutica atuando de maneira complementar aos demais tratamentos de saúde (Brasil: Ministério da Saúde, 2006).

Magnetoterapia - é a técnica na aplicação de ímãs e de aparelhos magnéticos especiais em várias partes do corpo, visando à regularização energética do organismo (Klein; Rodrigues, 2016).

Herbalism - Definition: The medicinal use of preparations that contain exclusively plant material (Boddy, K. et al, 2008).

Craniosacral therapy is a gentle, non-invasive therapy using light touch to help achieve physical and mental balance, and support the body's own ability to self-heal (FHT, 2017).

\section{Contextos explicativos}

Acupuntura - A acupuntura emprega uma faceta da medicina tradicional chinesa e um de seus pilares é a teoria do Yin/Yang, Outro é a teoria dos canais e colaterais (meridianos), que 
em numero de 14 estão de tal forma envolvidos, que constituem uma verdadeira "malha energética" espalhada pelo corpo (Tashiro et al, 2001).

Alquimia - Na Alquimia, incluem-se diversos elementos místicos, filosóficos e metafóricos, além de uma linguagem simbólica e interpretativa (Costeira, 2015).

Spiritual healing - Many different approaches of spiritual healing exist. Typically the healer moves his hands at a distance over the patient's body detecting areas of concern and transmits 'energy' into the patient's body which allegedly enhances self-healing (Boddy, K. et al, 2008).

O exemplo seguinte mescla o contexto definitório com o explicativo:

Balneotherapy - In contrast to hydrotherapy, which generally employs normal tap water, balneotherapy is defined as baths using thermal mineral waters of at least $20^{\circ} \mathrm{C}$ temperature and a mineral content of at least $1 \mathrm{~g} / \mathrm{L}$ water from natural springs (Boddy, K. et al, 2008).

\section{Contextos associativos}

Cura espiritual: Além disso, com base no documento elaborado pela OMS como estratégia para promoção das terapias não convencionais em saúde, foram selecionadas as terapias de acupuntura, chás, fitoterapia, shiatsu, xantala, massoterapia, reflexologia, osteopatia, ioga, ayurveda, homeopatia e cura espiritual (Fontanella, 2007).

Imaginação guiada: Um naturopata pode usar a hipnose, imaginação guiada, ou outros métodos de aconselhamento como parte de um plano de tratamento (Klein; Rodrigues, 2016).

Johrei: Related techniques: Therapeutic touch, Reiki, intercessory prayer, distant healing, Johrei, faith healing, laying on of hands, psychic healing, paranormal healing. (Boddy, K. et al, 2008).

Orthomolecular medicine: Very few midwives were trained in ear acupuncture and orthomolecular medicine (Muñoz-Sellés, 2013).

O exemplo a seguir apresenta um contexto associativo, por meio da enumeração, que permite perceber que se trata de um tipo de terapia, porém, com elementos explicativos entre parênteses:

Rolfing: Examples include chiropractic medicine, osteopathic manipulative medicine, movement therapy, massage, and other body work, such as rolfing (a form of soft-tissue manipulation) (Kramlich, 2014). 


\subsection{Exemplos de traços conceptuais encontrados na busca por equivalentes}

$\mathrm{Na}$ sequência, vamos mostrar exemplos de traços conceptuais comuns nos dois idiomas, embora não necessariamente literais, encontrados nos contextos extraídos dos corpora e usados para a confirmação de equivalentes. As referências estão presentes nas respectivas bibliografias dos corpora.

A tabela apresenta o termo (negrito) e seu contexto em português na primeira coluna, e na segunda coluna o equivalente em inglês (negrito) e seu contexto. Os traços conceptuais analisados em português e inglês também estão em negrito. Muitas vezes esses traços correspondem a alguma característica da modalidade terapêutica, sua forma de aplicação, materiais utilizados, local de origem ou criador.

Nos casos em que o termo e equivalente eram cognatos, os traços conceptuais foram usados para confirmar a equivalências. Nas situações em que não havia cognatos, os traços conceptuais foram decisivos para encontrar a correspondência, como é o caso de crenoterapia - termalismo/balneotherapy, shantala/loving hands - baby massage.

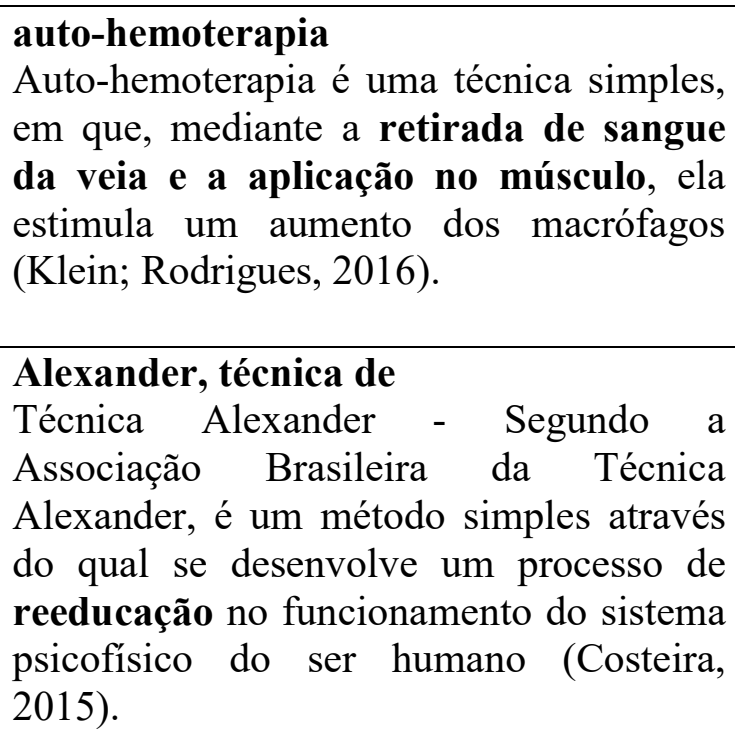

Auto-hemoterapia é uma técnica simples, em que, mediante a retirada de sangue da veia e a aplicação no músculo, ela estimula um aumento dos macrófagos (Klein; Rodrigues, 2016).

Alexander, técnica de

Técnica Alexander - Segundo a Associação Brasileira da Técnica Alexander, é um método simples através do qual se desenvolve um processo de reeducação no funcionamento do sistema psicofísico do ser humano (Costeira, 2015).

\section{autohemotherapy; self-blood therapy}

Autohemotherapy, or self-blood therapy, is a technique that involves the withdrawal of blood from the body and the reinjection of the same blood back into a vein or through the skin or muscle. ${ }^{43}$

\section{Alexsander technique}

The Alexander technique is more a 'learning process' than a therapy, with the teacher offering guidance on how to move and use your body more efficiently, which in turn may improve your posture and general health and well-being (FHT, 2017).

\footnotetext{
${ }^{43} \mathrm{http}: / /$ www.naturallivingcenter.net/ns/DisplayMonograph.asp?StoreID=b571dewxvcs92jj200akhmccqa 7w8v75 \&DocID=bottomline-ungraded-autohemotherapy, acesso em 19/09/2017.
} 


\begin{tabular}{|c|c|}
\hline $\begin{array}{l}\text { acupuntura } \\
\text { Como parte do sistema terapêutico e } \\
\text { diagnóstico da medicina oriental, a } \\
\text { acupuntura é um método milenar de } \\
\text { tratamento através das agulhas (Klein; } \\
\text { Rodrigues, 2016). }\end{array}$ & $\begin{array}{l}\text { acupuncture } \\
\text { Acupuncture aims to restore the balance } \\
\text { of qi in the body, by inserting fine needles } \\
\text { to stimulate specific 'acupoints' that run } \\
\text { along each of the meridians (FHT, 2017). }\end{array}$ \\
\hline $\begin{array}{l}\text { aromaterapia } \\
\text { Aromaterapia é a arte e a ciência que visa } \\
\text { promover a saúde e o bem-estar do corpo, } \\
\text { da mente e das emoções, através do uso } \\
\text { terapêutico do aroma natural das plantas } \\
\text { por meio de seus óleos essenciais (Brito, } \\
\text { 2013). }\end{array}$ & $\begin{array}{l}\text { aromatherapy } \\
\text { Aromatherapy is the systematic use of } \\
\text { essential oils and absolutes in holistic } \\
\text { treatments to improve physical and } \\
\text { emotional well-being (GRCCT, 2017). }\end{array}$ \\
\hline $\begin{array}{l}\text { aura } \\
\text { Podemos conceituar que, sob uma visão } \\
\text { tridimensional, a aura é uma trama } \\
\text { energética em torno e ao redor do } \\
\text { organismo físico, formando uma espécie } \\
\text { de invólucro oval (Naiff, 2016). }\end{array}$ & $\begin{array}{l}\text { aura } \\
\text { Crystals are often placed in patterns } \\
\text { around the patient's body to produce an } \\
\text { energy network to adjust the patient's } \\
\text { energy field or 'aura' (House of Lords, } \\
\text { 2017). }\end{array}$ \\
\hline $\begin{array}{l}\text { Ayurveda; ayurvédica, medicina } \\
\text { Ayurveda trata-se da medicina milenar } \\
\text { indiana, que inclui práticas como } \\
\text { massagem, meditação e uso de alimentos } \\
\text { e plantas (Almeida et al, 2015). }\end{array}$ & $\begin{array}{l}\text { Ayurveda; ayurvedic medicine } \\
\text { Ayurvedic Medicine: an ancient } \\
\text { discipline, originating in India, based } \\
\text { upon the principle of mind- spirit-body } \\
\text { interaction and employing natural herbs, } \\
\text { usually mixtures, in treatment (House of } \\
\text { Lords, 2017). }\end{array}$ \\
\hline $\begin{array}{l}\text { calatonia } \\
\text { Dentre os métodos utilizados destacam-se } \\
\text { a Calatonia, criada pelo médico húngaro } \\
\text { Pëtho Sandor, que se utiliza de toques } \\
\text { corporais para promover a integração } \\
\text { fisicopsíquica (Hospital Sírio-Libanês, } \\
\text { 2017). }\end{array}$ & $\begin{array}{l}\text { calatonia } \\
\text { Dr Sándor developed Calatonia in the } \\
1940 \text { 's when he was working as a } \\
\text { physician in the Red Cross refugee camps } \\
\text { in Europe which emerged following } \\
\text { World War II. Calatonia works through a } \\
\text { series of to delicate touches the feet, } \\
\text { ankles and calves and finally the head. }\end{array}$ \\
\hline $\begin{array}{l}\text { chacra(s), chakra(s) } \\
\text { Os chacras são vórtices energéticos, } \\
\text { como pequenos redemoinhos, localizados } \\
\text { no campo áurico, cuja principal atribuição } \\
\text { é manter a transferência contínua entre as } \\
\text { fontes de energia cósmica (universo } \\
\text { espiritual) e telúrica (mundo natural) com } \\
\text { o plano material (corpo orgânico) (Naiff, }\end{array}$ & $\begin{array}{l}\text { chakra(s) } \\
\text { It works on the principle that energy, also } \\
\text { known as 'ki' or 'chi', flows through the } \\
\text { body via energy centres called 'chakras' } \\
\text { (FHT, 2017). }\end{array}$ \\
\hline
\end{tabular}

\footnotetext{
${ }^{44} \mathrm{https}: / /$ www.oxforddevelopmentcentre.co.uk/a-recent-calatonia-and-subtle-touch-workshop/, $\quad$ acesso 


\begin{tabular}{|c|c|}
\hline 2016). & \\
\hline $\begin{array}{l}\text { Chi; Ki } \\
\text { Essa energia é chamada de Energia CHI } \\
\text { ou Energia Vital (Costeira, 2015). }\end{array}$ & $\begin{array}{l}\text { Qi; ki; chi } \\
\text { The energy is called by various names, } \\
\text { such as ki by the Japanese, prana by the } \\
\text { Hindus, qi or chi by the Chinese, and oki, } \\
\text { orenda, or ton by Native Americans } \\
\text { (Kramlich, 2014). }\end{array}$ \\
\hline $\begin{array}{l}\text { Chi Kung; Chi gong; Qi gong } \\
\text { Chi gong: série de movimentos } \\
\text { harmônicos aliados à respiração, com } \\
\text { foco em determinada parte do corpo, para } \\
\text { desenvolvimento do chi interno e } \\
\text { ampliação da capacidade mental (Brasil: } \\
\text { Ministerio da Saúde, 2006). }\end{array}$ & $\begin{array}{l}\text { Qigong, Qi Gung } \\
\text { Qigong: Practised in China by millions of } \\
\text { people every day, it combines meditation } \\
\text { with a series of stances and slow } \\
\text { movements, all of which are said to help } \\
\text { qi flow freely throughout the body (FHT, } \\
\text { 2017). }\end{array}$ \\
\hline $\begin{array}{l}\text { colonterapia } \\
\text { A colonterapia baseia-se em práticas } \\
\text { milenares de limpeza intestinal (feita } \\
\text { com água morna, purificada e ozonizada) } \\
\text { (Klein; Rodrigues, 2016). }\end{array}$ & $\begin{array}{l}\text { colon hydrotherapy; colon cleansing } \\
\text { Colon cleansing (also known as colon } \\
\text { therapy) encompasses a number of } \\
\text { alternative medical therapies claimed to } \\
\text { remove nonspecific toxins from the colon } \\
\text { and intestinal tract by removing any } \\
\text { accumulations of feces. }{ }^{45}\end{array}$ \\
\hline $\begin{array}{l}\text { crenoterapia; (ver) termalismo } \\
\text { A Crenoterapia consiste na indicação e } \\
\text { uso de águas minerais com finalidade } \\
\text { terapêutica atuando de maneira } \\
\text { complementar aos demais tratamentos de } \\
\text { saúde (Brasil: Ministério da Saúde, 2006). }\end{array}$ & $\begin{array}{l}\text { balneotherapy } \\
\text { Balneotherapy - In contrast to } \\
\text { hydrotherapy, which generally employs } \\
\text { normal tap water, balneotherapy is defined } \\
\text { as baths using thermal mineral waters of } \\
\text { at least } 20^{\circ} \mathrm{C} \text { temperature and a mineral } \\
\text { content of at least } 1 \mathrm{~g} / \mathrm{L} \text { water from natural } \\
\text { springs (Boddy, } \mathrm{K} \text {. et al, 2008). }\end{array}$ \\
\hline $\begin{array}{l}\text { hirudoterapia } \\
\text { Hirudoterapia: a palavra advem do latim } \\
\text { hirudina que significa sanguessuga, além } \\
\text { de terapia, e representa o tratamento com } \\
\text { as sanguessugas, usado para fins } \\
\text { medicinais há mais de mil anos antes de } \\
\text { Cristo (Costeira, 2015). }\end{array}$ & $\begin{array}{l}\text { hirudotherapy } \\
\text { Hirudotherapy is a treatment using } \\
\text { medicinal leeches. } 46\end{array}$ \\
\hline $\begin{array}{l}\text { homeopatia; homeopática, medicina } \\
\text { A homeopatia, sistema médico complexo } \\
\text { de caráter holístico, baseada no princípio } \\
\text { vitalista e no uso da lei dos semelhantes }\end{array}$ & $\begin{array}{l}\text { homeopathy } \\
\text { Therefore, homeopathy is based on the } \\
\text { idea of treating 'like with like' by } \\
\text { administering hugely diluted versions of }\end{array}$ \\
\hline
\end{tabular}




\begin{tabular}{|c|c|}
\hline $\begin{array}{l}\text { foi enunciada por Hipócrates no século IV } \\
\text { a.C. Foi desenvolvida por Samuel } \\
\text { Hahnemann no século XVIII (Brasil: } \\
\text { Ministério da Saúde, 2006). }\end{array}$ & $\begin{array}{l}\text { basically dangerous substances, such that } \\
\text { a dose given to a patient may not contain } \\
\text { even a single molecule of the active } \\
\text { principle (House of Lords, 2017). }\end{array}$ \\
\hline $\begin{array}{l}\text { iridologia } \\
\text { A Iridologia não tem como objetivo dar } \\
\text { nome às patologias e sim após a análise } \\
\text { da íris elaborar um programa de } \\
\text { desintoxicação e reconstrução do } \\
\text { organismo, que é à base do tratamento e } \\
\text { que tem por finalidade de conscientizar e } \\
\text { melhorar as carências nutricionais do } \\
\text { paciente, melhorando, desta forma, sua } \\
\text { qualidade de vida (Klein; Rodrigues, } \\
\text { 2016). }\end{array}$ & $\begin{array}{l}\text { iridology } \\
\text { Iridology: a method of diagnosing } \\
\text { problems and assessing health status that } \\
\text { relies on studying the iris of the eye and } \\
\text { noting marks and changes (House of } \\
\text { Lords, 2017). }\end{array}$ \\
\hline $\begin{array}{l}\text { medicina integrativa } \\
\text { "Medicina integrativa", definida como } \\
\text { uma "medicina que enfatiza a relação } \\
\text { médico-paciente e integra o melhor da } \\
\text { CAM com o melhor da medicina } \\
\text { convencional", englobando aspectos } \\
\text { humanísticos, preventivos e curativos dos } \\
\text { diversos modelos terapêuticos existentes } \\
\text { (Teixeira; Lin, 2013). }\end{array}$ & $\begin{array}{l}\text { integrative medicine } \\
\text { Integrative medicine, the integration of } \\
\text { complementary and alternative } \\
\text { medicine (CAM) with conventional } \\
\text { healthcare, is being increasingly adopted } \\
\text { within mainstream health services (Power; } \\
\text { Hopayian, 2011). }\end{array}$ \\
\hline $\begin{array}{l}\text { meridiano(s) } \\
\text { Meridianos (de Acupuntura) são canais } \\
\text { puramente eletromagnéticos, sem } \\
\text { limitações materiais ( embora, algumas } \\
\text { vezes, coincidam com a musculatura), } \\
\text { pelos quais se transmitem sinais } \\
\text { eletromagnéticos, como os biofótons e } \\
\text { também partículas materiais (SINTE, } \\
\text { 2017). }\end{array}$ & $\begin{array}{l}\text { meridian(s) } \\
\text { Like acupuncture, meridian therapies } \\
\text { work on the principle that energy flows } \\
\text { through the body along channels known } \\
\text { as 'meridians' (FHT, 2017). }\end{array}$ \\
\hline $\begin{array}{l}\text { moxabustão; moxa; moxibustão } \\
\text { A acupuntura divide-se também em vários } \\
\text { ramos, sendo os principais: a acupuntura } \\
\text { propriamente dita, que trata por meio de } \\
\text { agulhas; a moxabustão, que trata por meio } \\
\text { de moxas, ou materiais incandescentes, } \\
\text { feitos com uma erva especial (Klein; } \\
\text { Rodrigues, 2016). }\end{array}$ & $\begin{array}{l}\text { moxibustion } \\
\text { Moxibustion (burning of the herb } \\
\text { Mugwort close to the surface of the skin) } \\
\text { (University College London Hospitals } \\
\text { NHS Foundation Trust, 2017). }\end{array}$ \\
\hline $\begin{array}{l}\text { naturologia } \\
\text { A Naturologia estuda práticas e métodos } \\
\text { naturais, tradicionais e modernos para o } \\
\text { cuidado humano. Visa à expansão, }\end{array}$ & $\begin{array}{l}\text { naturopathy } \\
\text { Naturopathy is a discipline of } \\
\text { accumulated knowledge of effective } \\
\text { natural therapies, diet and lifestyle in }\end{array}$ \\
\hline
\end{tabular}




\begin{tabular}{|c|c|}
\hline $\begin{array}{l}\text { manutenção e recuperação da saúde, bem } \\
\text { como à melhoria da qualidade de vida e ao } \\
\text { equilíbrio do ser humano com o ambiente } \\
\text { e com a sociedade (Universidade do Sul } \\
\text { de SC, 2017). }\end{array}$ & $\begin{array}{l}\text { practice, and does not have a single } \\
\text { originator (School of Natural Medicine } \\
\text { UK, 2017). }\end{array}$ \\
\hline $\begin{array}{l}\text { quiropraxia; quiroprática } \\
\text { Quiropraxia: manipulação da coluna via } \\
\text { toques rápidos e precisos, obtendo-se, } \\
\text { assim, não só a melhoria local, como dos } \\
\text { mais variados distúrbios, em especial, os } \\
\text { de caráter físico (SINTE, 2017). }\end{array}$ & $\begin{array}{l}\text { chiropractic } \\
\text { Chiropractic is a form of healthcare } \\
\text { founded by D. D. Palmer (1845-1913) } \\
\text { that focuses on the relationship between } \\
\text { the body's structure, primarily the spine, } \\
\text { and function. Chiropractors frequently use } \\
\text { vertebral manipulation (Boddy, K. et al, } \\
2008) \text {. }\end{array}$ \\
\hline $\begin{array}{l}\text { reflexologia } \\
\text { Reflexologia: É a ciência que lida com o } \\
\text { princípio de que nos pés e nas mãos } \\
\text { existem áreas de reflexos que } \\
\text { correspondem a todos os órgãos, } \\
\text { glândulas e partes do corpo (Tashiro et } \\
\text { al, 2001). }\end{array}$ & $\begin{array}{l}\text { reflexology } \\
\text { Reflexology is based on the principle that } \\
\text { reflex points on the soles, tops, and sides } \\
\text { of the feet correspond to different areas } \\
\text { of the body (FHT, 2017). }\end{array}$ \\
\hline $\begin{array}{l}\text { reiki; reike } \\
\text { Terapia japonesa que se utiliza da } \\
\text { transmissão da energia ki (universal e } \\
\text { vital) com as palmas das mãos por } \\
\text { intermédio da consciência (Naiff, 2016). }\end{array}$ & $\begin{array}{l}\text { reiki } \\
\text { Those who practise reiki are said to draw } \\
\text { upon universal healing energy, which is } \\
\text { then transferred to the client through } \\
\text { visualisation and by gently placing their } \\
\text { hands on our just above the body (FHT, } \\
\text { 2017). }\end{array}$ \\
\hline $\begin{array}{l}\text { sei-tai } \\
\text { Sei-tai: técnica japonesa de manipulação } \\
\text { passiva da coluna vertebral e } \\
\text { articulações em geral, tem a sua origem há } \\
\text { três séculos entre os guerreiros samurais } \\
\text { que após treinos e batalhas, feridos e com } \\
\text { membros deslocados, precisavam ser } \\
\text { socorridos (Costeira, 2015). }\end{array}$ & $\begin{array}{l}\text { seitai } \\
\text { Seitai is a healing and therapeutic } \\
\text { Japanese massage and is literally } \\
\text { translated from Japanese as 'Bone } \\
\text { Therapy' and so is very effective for } \\
\text { postural, neck and spinal conditions } \\
\text { through non-invasive massage techniques } \\
\text { without using direct manipulation of } \\
\text { the spine. }{ }^{7}\end{array}$ \\
\hline $\begin{array}{l}\text { shantala; xantala } \\
\text { Shantala é a massagem milenar } \\
\text { ayurvédica indicada para os bebês } \\
\text { desde a hora em que nasce, feita pela } \\
\text { própria mãe, trazida para o Ocidente pelo }\end{array}$ & $\begin{array}{l}\text { loving hands; baby massage } \\
\text { In loving hands shows us how, in the } \\
\text { weeks and months following the birth, we } \\
\text { can use the flowing rhythms of the } \\
\text { traditional Indian art of baby massage }\end{array}$ \\
\hline
\end{tabular}

47 http://www.sakuralounge.com.au/Massage/Japanese-Seitai-Massage/0/60/service-product.aspx, acesso em 24/09/2017. 


\begin{tabular}{|c|c|}
\hline $\begin{array}{l}\text { obstetra francês } \\
\text { (Costeira, 2015). }\end{array}$ & $\begin{array}{l}\text { to communicate our love and strength to } \\
\text { our infants in a primal language of touch } \\
\text { and sensation. }\end{array}$ \\
\hline $\begin{array}{l}\text { shiatsu } \\
\text { O shiatsu consiste em pressionar } \\
\text { determinados pontos chamados tsubos } \\
\text { que formam linhas ou canais (meridianos) } \\
\text { de energia pelo corpo (método similar ao } \\
\text { da acupuntura) (Klein; Rodrigues, } \\
2016 \text { ). }\end{array}$ & $\begin{array}{l}\text { shiatsu } \\
\text { shiatsu, like acupuncture - only without } \\
\text { the 'needles' - it involves gently working } \\
\text { specific points on the body, with the aim } \\
\text { of restoring the flow and balance of } \\
\text { energy and promoting health and well- } \\
\text { being (FHT, 2017). }\end{array}$ \\
\hline $\begin{array}{l}\text { somaterapia } \\
\text { Somaterapia, também conhecida como } \\
\text { SOMA, é uma terapia corporal e em grupo } \\
\text { criada pelo psiquiatra, escritor e } \\
\text { terapeuta Roberto Freire, com } \\
\text { fundamento nas teorias de Wilhelm Reich, } \\
\text { no Gestaltismo e no Anarquismo, no } \\
\text { início da década de } 70 \text { do século passado, } \\
\text { em função da implantação do regime } \\
\text { militar ditatorial no Brasil (Costeira, } \\
\text { 2015). }\end{array}$ & $\begin{array}{l}\text { somatherapy } \\
\text { Somatherapy (or Soma) was created by } \\
\text { Freire in the 1970s as a group therapy, } \\
\text { based on the research of the psychoanalyst } \\
\text { Wilhelm Reich. With the objective of } \\
\text { freeing the individual to be more creative, } \\
\text { the exercises in Soma work with the } \\
\text { relationship between the body and } \\
\text { emotions. } 49\end{array}$ \\
\hline $\begin{array}{l}\text { tai chi chuan, tai-chi-chuan } \\
\text { Tai-chi-chuan é a arte marcial chinesa } \\
\text { que alia gestos suaves e respirações } \\
\text { especiais à filosofia oriental e, desse } \\
\text { modo, promover o bem-estar e a } \\
\text { manutenção da saúde (SINTE, 2017). }\end{array}$ & $\begin{array}{l}\text { tai chi } \\
\text { Rooted in ancient Chinese philosophy } \\
\text { and martial arts, Tai chi is a system of } \\
\text { movements and postures used to enhance } \\
\text { mental and physical health (Boddy, K. et } \\
\text { al, 2008). }\end{array}$ \\
\hline $\begin{array}{l}\text { termalismo; termalismo social } \\
\text { O Termalismo compreende as diferentes } \\
\text { maneiras de utilização da água mineral e } \\
\text { sua aplicação em tratamentos de saúde } \\
\text { (Brasil: Ministério da Saúde, 2006). }\end{array}$ & $\begin{array}{l}\text { balneotherapy } \\
\text { Balneotherapy - In contrast to } \\
\text { hydrotherapy, which generally employs } \\
\text { normal tap water, balneotherapy is defined } \\
\text { as baths using thermal mineral waters of } \\
\text { at least } 20^{\circ} \mathrm{C} \text { temperature and a mineral } \\
\text { content of at least } 1 \mathrm{~g} / \mathrm{L} \text { water from natural } \\
\text { springs (Boddy, K. et al, 2008). }\end{array}$ \\
\hline $\begin{array}{l}\text { vegetoterapia } \\
\text { Vegetoterapia carátero-analítica é uma } \\
\text { técnica de psicoterapia criada pelo } \\
\text { psiquiatra Wilhelm Reich, em 1935, }\end{array}$ & $\begin{array}{l}\text { vegetotherapy } \\
\text { Vegetotherapy is a form of Reichian } \\
\text { psychotherapy that involves the physical } \\
\text { manifestations of emotions. } 50\end{array}$ \\
\hline
\end{tabular}

\footnotetext{
48 https://www.amazon.com/Loving-Hands-Traditional-Indian-Massage/dp/0394404696/ref=pd_sim_14_2/1390277804-8325041?_encoding=UTF8\&psc=1\&refRID=RF1YTN5F1VSJP3J1CPZY, acesso em 09/09/2017.

${ }^{49} \mathrm{https}$ ://en.wikipedia.org/wiki/Roberto_Freire_(psychiatrist), acesso em 19/09/2017.

${ }^{50} \mathrm{https} / / /$ en.wikipedia.org/wiki/Vegetotherapy, acesso em 19/09/2017.
} 
conhecida como a proposta corporal primária que originou outras abordagens corporais de terapia hoje existentes (Costeira, 2015).

Quadro 4 - Exemplos de traços conceptuais

\subsection{Termos do corpus de florais brasileiros baseados na alquimia}

Apresentamos a seguir os termos selecionados do corpus de florais brasileiros baseados na alquimia. São as 99 plantas utilizadas para extração dessas essências florais:

\begin{tabular}{|c|c|c|}
\hline abutilom & camomila & jurubeba \\
\hline açucena & cânfora & lantana \\
\hline agapanto & capuchinha & laranjeira \\
\hline aguapé & carqueja & lótus \\
\hline alamanda & cássia & macela \\
\hline alecrim & catinga-de-mulata & magnólia \\
\hline alfazema & cavalinha & manacá \\
\hline amor-perfeito & chapéu-de-couro & mandacaru \\
\hline anis & coentro & manjericão \\
\hline antúrio & confrei & maracujá \\
\hline araucária & cosmos & margarida \\
\hline arnica & cravo & melissa \\
\hline arruda & crisântemo & mentrasto \\
\hline artemísia & dália & mil-folhas \\
\hline assa-peixe & dama-da-noite & orquídea \\
\hline azaleia & dente-de-leão & paineira \\
\hline babosa & espinheira-santa & pata-de-vaca \\
\hline bálsamo & flamboyant & pfáfia \\
\hline begônia & flor-de-lis & picão \\
\hline bela-emília & gerânio & primavera \\
\hline beldroega & gervão & prímula \\
\hline boca-de-leão & girassol & quaresmeira \\
\hline boldo & gloxínia & rosa \\
\hline borragem & guiné & sabugueiro \\
\hline bracatinga & hibisco & sálvia \\
\hline brinco-de-princesa & hortelã & saudade \\
\hline bromélia & hortênsia & serralha \\
\hline buquê-de-noiva & ipê & sete-sangrias \\
\hline cactos & ipomeia & sibipiruna \\
\hline calêndula & jaborandi & suinã \\
\hline camarão & jacarandá & tanchagem \\
\hline camélia & jasmim & trapoeraba \\
\hline
\end{tabular}


Após a seleção dos termos, realizamos uma pesquisa pontual para encontrar os equivalentes em inglês das plantas utilizadas. Para essa busca, utilizamos a nomenclatura binária em latim ou nome científico da planta contido no corpus utilizado nessa parte da pesquisa. Essa pesquisa foi pela busca na $W e b$, principalmente em sites especializados em plantas, como o da Royal Horticultural Society ${ }^{51}$, e outros, como Wikipedia ${ }^{52}$, que tem se mostrado um corpus útil aos estudos terminológicos, como na validação de candidatos a termo. "Apesar dos problemas e inconsistências encontrados na Wikipédia, provamos que

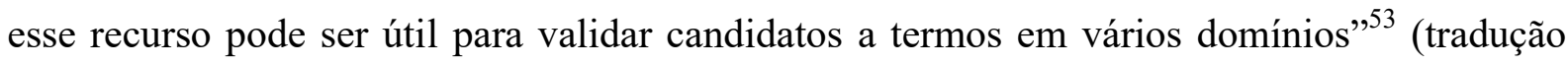
nossa) (Cabrera-Diego, L. A. et al, 2011).

Ao efetuarmos a busca na Web, verificamos a ocorrência de algumas divergências entre os nomes científicos disponíveis em sites especializados e aqueles utilizados no corpus de estudo, sendo que o livro utilizado foi publicado há mais de vinte anos e até o momento desta pesquisa não houve atualização da nomenclatura latina, segundo consulta à Escola de Alquimia. Encontramos também vários sinônimos botânicos, o que não incorreu em prejuízo das buscas. É comum algumas espécies possuírem mais de um nome oficial, pois podem ter sido catalogadas em momentos próximos por diferentes cientistas, ou mesmo seus nomes terem sido atualizados.

Vamos, a seguir, apontar os casos em que houve presença de sinônimos botânicos, além de outras variantes populares encontradas, pois no glossário limitamos a quatro variantes, para não ser exaustivo, utilizando como critério a ordem frequência.

agapanto: encontramos os sinônimos botânicos Agapanthus umbellatus e Agapanthus africanus.

alfazema: encontramos os sinônimos botânicos Lavandula officinalis e Lavandula angustifólia. Como variantes em língua inglesa apareceram true lavender or English lavender, garden lavender, common lavender, narrow-leaved lavender.

\footnotetext{
${ }^{51} \mathrm{https}: / /$ www.rhs.org.uk/plants

${ }^{52} \mathrm{https}: / /$ pt.wikipedia.org/wiki/Wikip\%C3\%A9dia:P\%C3\%A1 gina_principal

${ }^{53}$ No original: In spite of the problems and inconsistencies found in Wikipedia, we have proved that this resource may be useful to validate term candidates in several domains.
} 
amor-perfeito: outras variantes em língua inglesa encontradas: Johnny Jump up (though this name is also applied to similar species such as the yellow pansy), heartsease, heart's ease, heart's delight, tickle-my-fancy, Jack-jump-up-and-kiss-me, come-and-cuddle-me, three faces in a hood, or love-in-idleness.

anis: encontramos as nomenclaturas binárias Indigofera anil (nome antigo) e Indigofera suffruticosa (nome atual). Não se trata do anis culinário, Pimpinella anisum (anise), também conhecido como erva-doce.

araucária: encontramos os sinônimos botânicos Araucaria brasiliensis e Araucaria angustifolia.

arnica: a arnica comum é Arnica Montana (mountain arnica), mas a apontada pelo corpus é a espécie Solidago chilensis - também conhecida como arnica-do-campo, erva-lanceta, arnicabrasileira, arnica-silvestre, equivalente em inglês a Brazilian arnica. O gênero Solidago é comumente chamado de goldenrod.

assa-peixe: o corpus traz Vernonia polyanthes. Encontramos também Vernonia polysphaera.

babosa: embora a espécie Aloe vera seja bastante conhecida, a espécie indicada pelo corpus foi Aloe arborencens.

bálsamo: o nome científico sugerido pelo corpus (balsamina hortensis) não corresponde à ilustração presente no livro. Encontramos outras espéicies também conhecidas popularmente como bálsamo, como a Cotyledon orbiculata. Em pesquisas encontramos a espécie Sedum dendroidum, no Jardim Botânico do Rio de Janeiro, que se assemelha mais, então optamos pela última.

bela-emília: o corpus traz Plumbago capensis. Encontramos também Plumbago auriculata.

boldo: Coleus barbatus (nome antigo), Plectranthus barbatus (nome atual),sinônimo taxonômico Coleus forskohlii.

bracatinga: existe uma árvore chamada bracatinga (Mimosa scabrella), porém, o corpus apresenta a espécie Senecio brasiliensis, uma planta de menor porte conforme a ilustração do livro, também conhecida como flor-das-almas,

bromélia: Bromelia é um gênero botânico da família Bromeliaceae, da qual fazem parte numerosas espécies. A espécie específica apontada pelo corpus é Vriesea guttata. 
buquê-de-noiva: o corpus traz Spiraea $x$ vanhouttei. Encontramos também Spiraea cantoniensis, com o nome comum em inglês Reeve's spiraea.

cactos: "Cactus $L$. era a designação de um género da família Cactaceae, dividido em 3 diferentes géneros: Mammillaria, Melocactus e Opuntia ${ }^{54}$ Cactaceae é uma família botânica de arbustos, árvores, ervas, lianas e subarbustos representada pelos cactos ou catos. São aproximadamente 176 gêneros. No corpus não há indicação de nomenclatura binária, apenas a indicação "vários”, então mantivemos a denominação genérica.

cânfora: o corpus traz Artemísia camphorata, também conhecida como cânfora-de-jardim, cânfora-das-hortas, canforeira, canforinha. Existe também uma árvore chamada cânfora, Cinnamomum camphora, não se trata dessa espécie, conhecida em inglês como camphor tree, camphorwood ou camphor laurel.

cavalinha: Equisetum spp, equivalente em inglês horsetail, com as variantes snake grass, puzzle grass. Aparece no corpus (no livro), mas apenas como tintura, não como floral, por isso essa espécie não foi acrescentada ao glossário.

dama-da-noite: o corpus traz Eichornia, que é um gênero de planta aquática e não parece se tratar da mesma planta retratada na imagem. Há também outra espécie conhecida como damada-noite, a Epiphyllum oxypetalum, similar a um cactos, também muito diferente da ilustração. Enfim encontramos a espécie Cestrum nocturnum, também chamada jasmim-danoite, semelhante à imagem.

flor-de-lis: O corpus traz Iris spp. Existe também a espécie Sprekelia formosissima, conhecida como Aztec lily ou Jacobean lily.

hortelã: O corpus traz Mentha x piperita, conhecida também como hortelã pimenta, e em inglês como peppermint. Há também a espécie Mentha spicata, hortelã verde, hortelã-dashortas, hortelã-comum, em inglês spearmint.

ipê: denominação comum a várias árvores no Brasil. O corpus especifica o gênero Tabebuia spp.

insulina: acrescentada posteriormente ao sistema floral pesquisado, presente na apostila parte do corpus, não no livro Essências Florais Brasileiras. Não há indicação de nome científico e

\footnotetext{
${ }^{54} \mathrm{https} / / /$ pt.wikipedia.org/wiki/Cactus
} 
encontramos na web algumas espécies conhecidas como insulina, como a Myrcia salicifolia, insulina vegetal ou pedra-ume kaá, e a Costus igneus (insulin plant). Pela maior semelhança com a ilustração presente na referida apostila, optamos pela espécie Cissus sicyoides, também chamada cipó-pucá, cortina japonesa, diabetil, uva-do-mato, e em inglês princess vine, millionaire vine e curtain ivy.

jaborandi: o corpus traz Pilocarpus pennatifolius. Encontramos também Pilocarpus jaborandi.

laranjeira: o corpus traz Citrus $x$ sinensis. Encontramos também a laranja-azeda ou laranjaamarga (Citrus aurantium).

lótus: o corpus traz Nymphea spp, as ninféias. Há também a espécie Nelumbo nucifera, conhecida como lótus indiano ou lótus sagrado.

mandacaru: o corpus traz Cereus peruvianus. Encontramos também Cereus jamacaru.

margarida: Chrysanthemum leucanthemum ou Chrysanthemum vulgare (sinônimo botânico).

orquídea: o corpus traz Cattleya labiata. "As Orchidaceae são uma família diversificada e generalizada de plantas com flores (...), comumente conhecida como a família das orquídeas". ${ }^{55}$ Há inúmeros gêneros conhecidos e que vêm aumentando ao longo dos anos, atualmente elevando-se a mais de 800. Cattleya é apenas um desses gêneros.

pfáfia: o corpus traz Pfaffia paniculata. Encontramos também Pfaffia glomerata.

saudade: Há várias espécies conhecidas popularmente dessa forma. O corpus traz Scabiosa atropurpurea. Não confundir com as espécies Solanum rantonnetii e Lycianthes rantonnetii (blue potato bush).

suinã: o corpus traz Erythrina speciosa. Há outra espécie conhecida pelo mesmo nome popular, a Erythrina velutina.

trombeta-de-anjo: o corpus traz Datura pseudostramonium. Encontramos também Brugmansia suaveolens (ou Datura suaveolens), com nomes populares em inglêsBrazil's white angel trumpet e angel's tears. Existe ainda a espécie Datura stramonium, chamada

\footnotetext{
${ }^{55}$ The Orchidaceae are a diverse and widespread family of flowering plants (...), commonly known as the orchid family. https://en.wikipedia.org/wiki/Orchidaceae
} 
como trombeta, trombeteira, estramônio, figueira-do-demo, figueira-do-diabo, figueira-doinferno, figueira brava e zabumba, e conhecida em inglês como jimsonweed or Devil's snare. verbasco: o corpus traz Buddleja brasiliensis, nome popular em inglês butterfly bush. Existe também a Verbascum thapsus, uma espécie de verbasco (ou barbasco, tipo pavio ou vela-debruxa), equivalente em inglês a great mullein ou common mullein.

yuca: não se trata da espécie Manihot esculenta, sinônimo Manihot utilíssima, mandioca, macaxeira ou aipim, em inglês comumente designada yuca, manioc ou cassava (Rebechi, 2013, p. 189). O corpus traz Yucca gloriosa. Nomes comuns em inglês incluem Adam's needle, glorious yucca, lord's candlestick, mound lily, moundlily yucca, palm lily, sea islands yucca, soft-tipped yucca, Spanish bayonet, Spanish-dagger, tree lily. Há diversos variantes em língua portuguesa: iúca, palmeira-lírio, árvore-da-pureza, vela-da-pureza, entre outros. 


\section{O GLOSSÁRIO DE PIC E O GLOSSÁRIO DE FLORAIS}

Apresentamos a seguir a primeira versão do glossário bilíngue de PIC e logo após o glossário bilíngue de plantas utilizadas nos florais brasileiros baseados na alquimia, ambos em ordem alfabética, e também a lista em ordem alfabética dos termos em inglês, para facilitar as buscas.

A microestrutura do Glossário português/inglês de Práticas Integrativas e Complementares oferece, na primeira coluna, o termo-entrada em português (negrito), possíveis variantes (outras denominações em português, quando encontradas) por ordem de frequência no corpus, exemplos do termo inserido ao contexto de uso do corpus de língua original em português, fonte do contexto em português, contexto e fonte das variantes em português, se necessário.

Em seguida, na segunda coluna, disponibilizamos o termo equivalente em inglês (em negrito), variantes em inglês (quando encontradas) por ordem de frequência, exemplo de contexto de uso em inglês, fonte do contexto em inglês, exemplos e fontes do contexto em inglês das variantes, quando necessário para facilitar a compreensão sobre a utilização do termo.

Nos casos em que os equivalentes não foram encontrados no corpus em inglês, disponibilizamos o exemplo de contexto extraído de sites da internet. Também utilizamos contextos da Web em casos nos quais os exemplos do corpus careciam de informações suficientes para a compreensão do termo (falta de contextos definitórios, explicativos e mesmo associativos).

As referências das fontes dos contextos extraídos dos corpora estão disponíveis nas respectivas bibliografias dos corpora e as referências de contextos extraídos da web estão em notas de rodapé.

Após a apresentação do glossário, disponibilizamos uma lista em ordem alfabética na direção inglês-português, para facilitar a busca pelos falantes nativos deste idioma. 


\subsection{Glossário português/inglês de PIC}

\begin{abstract}
acupuntura
A acupuntura emprega uma faceta da medicina tradicional chinesa e um de seus pilares é a teoria do Yin/Yang, Outro é a teoria dos canais e colaterais (meridianos), que em numero de 14 estão de tal forma envolvidos, que constituem uma verdadeira "malha energética" espalhada pelo corpo (Tashiro et al, 2001).
\end{abstract}

agulha(s)

Como parte do sistema terapêutico e diagnóstico da medicina oriental, a acupuntura é um método milenar de tratamento através das agulhas (Klein; Rodrigues, 2016).

\section{Alexander, técnica de}

Técnica Alexander - Segundo a Associação Brasileira da Técnica Alexander, é um método simples através do qual se desenvolve um processo de reeducação no funcionamento do sistema psicofísico do ser humano (Costeira, 2015).

\section{alquimia}

$\mathrm{Na}$ Alquimia, incluem-se diversos elementos místicos, filosóficos e metafóricos, além de uma linguagem simbólica e interpretativa. Assim, podemos defini-la, genericamente, como uma antiga tradição que combina química, física, arte e ocultismo (Costeira, 2015).

\section{antroposófica, medicina; Antroposofia}

A Medicina Antroposófica (MA) foi introduzida no Brasil há aproximadamente 60 anos e apresenta-se como uma abordagem médico-terapêutica complementar, de base vitalista, cujo modelo de atenção está organizado de maneira transdisciplinar, buscando a integralidade do cuidado em saúde (Brasil: Ministério da Saúde, 2006).

A medicina ampliada pela antroposofia trata

\section{acupuncture}

Acupuncture aims to restore the balance of qi in the body, by inserting fine needles to stimulate specific 'acupoints' that run along each of the meridians (FHT, 2017).

\section{needle(s)}

Insertion of one or more needles into the skin and underlying tissues at acupuncture points for therapeutic or preventative purposes (Boddy, K. et al, 2008).

\section{Alexsander technique}

The Alexander technique is more a 'learning process' than a therapy, with the teacher offering guidance on how to move and use your body more efficiently, which in turn may improve your posture and general health and well-being (FHT, 2017).

\section{alchemy}

Alchemy is a philosophical and protoscientific tradition practiced throughout Europe, Africa and Asia. Common aims were (...) the creation of an elixir of immortality; the creation of panaceas able to cure any disease. ${ }^{56}$

\section{anthroposophical Anthroposophy}

medicine;

Anthroposophical medicine aims to stimulate a person's natural healing forces through studying the influence of their soul and spirit on their physical body. House of Lords (2017).

'Anthroposophy' describes people in terms of their physicality, their soul and their spirit. Anthroposophical medicine aims to stimulate a person's natural healing forces through

\footnotetext{
${ }^{56}$ https://en.wikipedia.org/wiki/Alchemy, acesso em 24/09/2017.
} 


\begin{tabular}{|c|c|}
\hline $\begin{array}{l}\text { todos os aspectos do indivíduo, não apenas } \\
\text { seus sintomas físicos, e usa a medicina } \\
\text { ocidental convencional como sua base } \\
\text { (Follador, 2013). }\end{array}$ & $\begin{array}{l}\text { studying the influence of their soul and spirit } \\
\text { on their physical body (House of Lords, } \\
\text { 2017). }\end{array}$ \\
\hline $\begin{array}{l}\text { apiterapia } \\
\text { Apiterapia: uso terapêutico dos produtos da } \\
\text { apicultura (criação de abelhas), tais como } \\
\text { mel, própolis (SINTE, 2017). }\end{array}$ & $\begin{array}{l}\text { apitherapy; bee therapy } \\
\text { Apitherapy is the use of honeybee produced } \\
\text { substances for health and healing. }\end{array}$ \\
\hline $\begin{array}{l}\text { argiloterapia } \\
\text { Argiloterapia: também denominada de } \\
\text { Geoterapia, é uma terapia milenar que } \\
\text { consiste no uso tópico da argila, ou silicato } \\
\text { minimizado, visando um efeito anti- } \\
\text { inflamatório, cicatrizante e antisséptico } \\
(\text { Costeira, 2015). }\end{array}$ & $\begin{array}{l}\text { clay therapy; mud therapy } \\
\text { Clay therapy is a form of therapeutic } \\
\text { treatment. It is realised with the use of mature } \\
\text { therapeutic Clay. }\end{array}$ \\
\hline $\begin{array}{l}\text { aromaterapia } \\
\text { Aromaterapia é a arte e a ciência que visa } \\
\text { promover a saúde e o bem-estar do corpo, da } \\
\text { mente e das emoções, através do uso } \\
\text { terapêutico do aroma natural das plantas por } \\
\text { meio de seus óleos essenciais (Brito, 2013). }\end{array}$ & $\begin{array}{l}\text { aromatherapy } \\
\text { Aromatherapy is the systematic use of } \\
\text { essential oils and absolutes in holistic } \\
\text { treatments to improve physical and emotional } \\
\text { well-being (GRCCT, 2017). }\end{array}$ \\
\hline $\begin{array}{l}\text { arteterapia } \\
\text { Arteterapia - uso de técnicas artísticas como } \\
\text { pintura, dança, música, teatro, dentre outras, } \\
\text { como método terapêutico capaz de promover } \\
\text { saúde, criatividade e todo o potencial interior } \\
\text { (SINTE, 2017). }\end{array}$ & $\begin{array}{l}\text { art therapy } \\
\text { Mind-body interventions - Interventions } \\
\text { using a variety of techniques designed to } \\
\text { enhance the mind's capacity to affect bodily } \\
\text { function and symptoms. Examples include } \\
\text { meditation, prayer, mental healing, and } \\
\text { therapies that use creative outlets such as art, } \\
\text { music, or dance (Boddy, K. et al, 2008). } \\
\text { Art therapy (also known as arts therapy) is a } \\
\text { creative method of expression used as a } \\
\text { therapeutic technique. }\end{array}$ \\
\hline $\begin{array}{l}\text { aura } \\
\text { Podemos conceituar que, sob uma visão } \\
\text { tridimensional, a aura é uma trama energética } \\
\text { em torno e ao redor do organismo físico, } \\
\text { formando uma espécie de invólucro oval } \\
\text { (Naiff, 2016). }\end{array}$ & $\begin{array}{l}\text { aura } \\
\text { Crystals are often placed in patterns around } \\
\text { the patient's body to produce an energy } \\
\text { network to adjust the patient's energy field or } \\
\text { 'aura' (House of Lords, 2017). }\end{array}$ \\
\hline
\end{tabular}

\footnotetext{
${ }^{57} \mathrm{http}: / /$ www.honeybeecentre.com/apitherapy\#.WbRs-siGPcc, acesso em 19/09/2017.

${ }^{58} \mathrm{http}$ ://www.thermalsprings.gr/index.php/en/therapies/clay-therapy/188-clay-therapy, acesso em 24/09/2017.

${ }^{59} \mathrm{https}$ ://en.wikipedia.org/wiki/Art_therapy, acesso em 24/09/2017.
} 


\begin{tabular}{|c|c|}
\hline $\begin{array}{l}\text { Aura-soma } \\
\text { Aura-soma: terapia criada em } 1984 \text { pela } \\
\text { farmacêutica inglesa Vicky Wall (1918/1981) } \\
\text { se baseia, em sendo essencialmente } \\
\text { vibracional e energética, na leitura de quatro } \\
\text { frascos coloridos, previamente escolhidos } \\
\text { pelo paciente de uma coleção de } 101 \text { frascos, } \\
\text { contendo óleo e água das mais variadas } \\
\text { combinações de cores (Costeira, 2015). }\end{array}$ & $\begin{array}{l}\text { Aura-soma } \\
\text { With over } 30 \text { years experience Aura-Soma is } \\
\text { a non-intrusive, self-selective soul system. } \\
\text { Combining the energies of colour, plants, and } \\
\text { crystals, these vibrational tools can support } \\
\text { all levels of our being, bringing harmony and } \\
\text { balance within the subtle fields promoting } \\
\text { wellbeing and a joy for life. } 60\end{array}$ \\
\hline $\begin{array}{l}\text { Auto-hemoterapia é uma técnica simples, em } \\
\text { que, mediante a retirada de sangue da veia e a } \\
\text { aplicação no músculo, ela estimula um } \\
\text { aumento dos macrófagos (Klein; Rodrigues, } \\
\text { 2016). }\end{array}$ & $\begin{array}{l}\text { Autohemotherapy, or self-bloc } \\
\text { technique that involves the } \\
\text { blood from the body and the re } \\
\text { same blood back into a vein } \\
\text { skin or muscle. }\end{array}$ \\
\hline $\begin{array}{l}\text { Ayurveda; ayurvédica, medicina } \\
\text { Ayurveda: trata-se da medicina milenar } \\
\text { indiana, que inclui práticas como massagem, } \\
\text { meditação e uso de alimentos e plantas } \\
\text { (Almeida et al, 2015). } \\
\text { A medicina ayurvédica, ou ciência da vida, } \\
\text { considerada uma racionalidade médica } \\
\text { vitalista (...), tem sido desenvolvida há mais } \\
\text { de cinco mil anos na Índia, sendo o sistema } \\
\text { médico mais antigo conhecido (Navolar et al, } \\
\text { 2012). }\end{array}$ & $\begin{array}{l}\text { Ayurveda;ayurvedic medicine } \\
\text { Ayurvedic Medicine: an ancient discipline, } \\
\text { originating in India, based upon the principle } \\
\text { of mind- spirit-body interaction and } \\
\text { employing natural herbs, usually mixtures, in } \\
\text { treatment (House of Lords, 2017). } \\
\text { Indian head massage comes from Ayurveda, } \\
\text { an ancient method involving natural } \\
\text { therapies, which takes into account mind, } \\
\text { body and spirit (FHT, 2017). }\end{array}$ \\
\hline $\begin{array}{l}\text { bambuterapia } \\
\text { Bambuterapia é uma técnica de origem } \\
\text { francesa que utiliza bambus de diversos } \\
\text { tamanhos como uma espécie de } \\
\text { prolongamento dos dedos (Klein; Rodrigues, } \\
\text { 2016). }\end{array}$ & $\begin{array}{l}\text { therapy } \\
\text { oo Therapy, bamboo is used as a } \\
\text { equipment. }\end{array}$ \\
\hline $\begin{array}{l}\text { biodança; biodanza } \\
\text { Biodança é um sistema de integração afetiva, } \\
\text { renovação orgânica e reeducação das funções } \\
\text { vitais, baseado em vivências geradas pelo } \\
\text { movimento e pela dança (Lima; Silva Neto, } \\
\text { 2011). }\end{array}$ & $\begin{array}{l}\text { Biodanza (neologism from the Greek bio } \\
\text { (life) and the Spanish danza (dance), literally } \\
\text { the dance of life) is a system of self- } \\
\text { development that uses music, movement and } \\
\text { positive feelings to deepen self-awareness. }\end{array}$ \\
\hline
\end{tabular}

\footnotetext{
${ }^{60} \mathrm{http}: / /$ www.aura-soma.net/, acesso em 24/09/2017.

${ }^{61} \mathrm{http} / /$ www.naturallivingcenter.net/ns/DisplayMonograph.asp?StoreID=b571dewxvcs92jj200akhmccqa7w8v75 $\&$ DocID=bottomline-ungraded-autohemotherapy, acesso em 19/09/2017.

${ }^{62} \mathrm{http}: / /$ www.bambootherapy.com/, acesso em 19/09/2017.

${ }^{63} \mathrm{https}$ //en.wikipedia.org/wiki/Biodanza, acesso em 19/09/2017.
} 


\begin{tabular}{|c|c|}
\hline $\begin{array}{l}\text { biodinâmica } \\
\text { Biodinâmica: A técnica engloba um trabalho } \\
\text { verbal, não verbal, emocional, corporal e suas } \\
\text { inter-relações, e se propõe ser uma visão de } \\
\text { mundo em que corpo e mente são elementos } \\
\text { de um mesmo organismo (Costeira, 2015). }\end{array}$ & $\begin{array}{l}\text { biodynamics } \\
\text { Biodynamic Medicine is defined as the art of } \\
\text { healing in accordance with biodynamic } \\
\text { principles. } 64\end{array}$ \\
\hline $\begin{array}{l}\text { bioenergética } \\
\text { Bioenergética: o termo serve para indicar o } \\
\text { sistema terapêutico que associa corpo e } \\
\text { psiquismo, buscando o conhecimento dos } \\
\text { bloqueios energéticos criados por traumas, } \\
\text { conflitos e experiências negativas da infância } \\
\text { e da vida intra-uterina (Klein; Rodrigues, } \\
2016 \text { ). }\end{array}$ & $\begin{array}{l}\text { bioenergetic analysis } \\
\text { Bioenergetic analysis is a form of body } \\
\text { psychotherapy (body-oriented Reichian } \\
\text { psychotherapy), based upon the work of } \\
\text { Wilhelm Reich. }{ }^{65}\end{array}$ \\
\hline $\begin{array}{l}\text { biofeedback } \\
\text { Biofeedback é uma ferramenta terapêutica } \\
\text { que fornece informações com a finalidade de } \\
\text { permitir aos indivíduos, desenvolver a } \\
\text { capacidade auto-regulação. Envolve o retorno } \\
\text { imediato da informação através de aparelhos } \\
\text { sensórios eletrônicos, sobre processos } \\
\text { fisiológicos. } \\
\text { 66 } \\
\text { No Brasil, a Universidade Federal de São } \\
\text { Paulo (Unifesp) pesquisa há anos, com } \\
\text { resultados bastante animadores, a influência } \\
\text { da meditação e das técnicas de biofeedback } \\
\text { em transtornos de ansiedade e distúrbios } \\
\text { alimentares (Lima, 2009). }\end{array}$ & $\begin{array}{l}\text { biofeedback } \\
\text { Biofeedback - What is it? A method using } \\
\text { instruments to perceive body functions in } \\
\text { order to control those functions (Boddy, K. et } \\
\text { al, 2008). }\end{array}$ \\
\hline $\begin{array}{l}\text { body talk } \\
\text { Body talk: técnica de diagnóstico e } \\
\text { tratamento recentemente difundida nos } \\
\text { Estados Unidos da América para buscar o } \\
\text { equilíbrio corporal e o bem-estar físico. A } \\
\text { estratégia usada na sua criação foi a de } \\
\text { unificar a sabedoria de medicinas milenares, } \\
\text { como a Medicina Tradicional Chinesa - } \\
\text { MTC, e a Quiropraxia (medicina feita com as } \\
\text { mãos), com conhecimentos atuais como a } \\
\text { Cinesiologia (ciência que analisa os } \\
\text { movimentos do corpo) e a medicina moderna }\end{array}$ & $\begin{array}{l}\text { BodyTalk } \\
\text { BodyTalk is an energy re-balancing system, } \\
\text { combining the insights of western medical } \\
\text { expertise, acupuncture, applied Kinesiology, } \\
\text { yoga, osteopathic and chiropractic philosophy } \\
\text { (FHT, 2017). }\end{array}$ \\
\hline
\end{tabular}

\footnotetext{
${ }^{64}$ http://www.biodynamic.org/, acesso em 19/09/2017.

${ }^{65}$ https://en.wikipedia.org/wiki/Bioenergetic_analysis, acesso em 19/09/2017.

${ }^{66} \mathrm{https}$ ://pt.wikipedia.org/wiki/Biofeedback, acesso em 11/12/2017.
} 


\begin{tabular}{|c|c|}
\hline osteira, 2015). & \\
\hline $\begin{array}{l}\text { calatonia } \\
\text { Dentre os métodos utilizados destacam-se a } \\
\text { Calatonia, criada pelo médico húngaro Pëtho } \\
\text { Sandor, que se utiliza de toques corporais } \\
\text { para promover a integração fisicopsíquica } \\
\text { (Hospital Sírio-Libanês, 2017). }\end{array}$ & $\begin{array}{l}\text { calatonia } \\
\text { Dr Sándor developed Calatonia in the 1940's } \\
\text { when he was working as a physician in the } \\
\text { Red Cross refugee camps in Europe which } \\
\text { emerged following World War II. Calatonia } \\
\text { works through a series of delicate touches to } \\
\text { the feet, ankles and calves and finally the } \\
\text { head. }{ }^{67}\end{array}$ \\
\hline $\begin{array}{l}\text { cantoterapia } \\
\text { A cantoterapia propõe-se trabalhar a voz } \\
\text { cantada mediante exercícios musicais e } \\
\text { terapêuticos que atuam sobre o corpo e as } \\
\text { emoções (Costeira, 2015). }\end{array}$ & $\begin{array}{l}\text { singing therapy } \\
\text { During a Singing Therapy session you will be } \\
\text { asked to follow a series of exercises for both } \\
\text { body and voice that will help you breathe } \\
\text { more efficiently, helping to calm a number of } \\
\text { stress and anxiety based problems and } \\
\text { disorders whilst having fun. } 68\end{array}$ \\
\hline $\begin{array}{l}\text { chacra(s), chakra(s) } \\
\text { Os chacras são vórtices energéticos, como } \\
\text { pequenos redemoinhos, localizados no campo } \\
\text { áurico, cuja principal atribuição é manter a } \\
\text { transferência contínua entre as fontes de } \\
\text { energia cósmica (universo espiritual) e } \\
\text { telúrica (mundo natural) com o plano material } \\
\text { (corpo orgânico) (Naiff, 2016). }\end{array}$ & $\begin{array}{l}\text { chakra(s) } \\
\text { It works on the principle that energy, also } \\
\text { known as 'ki' or 'chi', flows through the } \\
\text { body via energy centres called 'chakras'. } \\
\text { (FHT, 2017). }\end{array}$ \\
\hline $\begin{array}{l}\text { Chi; Ki } \\
\text { Essa energia é chamada de Energia CHI ou } \\
\text { Energia Vital (Costeira, 2015). }\end{array}$ & $\begin{array}{l}\text { Qi; ki; chi } \\
\text { The energy is called by various names, such } \\
\text { as ki by the Japanese, prana by the Hindus, qi } \\
\text { or chi by the Chinese, and oki, orenda, or ton } \\
\text { by Native Americans (Kramlich, 2014). }\end{array}$ \\
\hline $\begin{array}{l}\text { Chi Kung; Chi gong;Qi gong } \\
\text { Chi gong: série de movimentos harmônicos } \\
\text { aliados à respiração, com foco em } \\
\text { determinada parte do corpo, para } \\
\text { desenvolvimento do chi interno e ampliação } \\
\text { da capacidade mental (Brasil: Ministério da } \\
\text { Saúde, 2006). }\end{array}$ & $\begin{array}{l}\text { Qigong, Qi Gung } \\
\text { Qigong:Practised in China by millions of } \\
\text { people every day, it combines meditation } \\
\text { with a series of stances and slow movements, } \\
\text { all of which are said to help qi flow freely } \\
\text { throughout the body (FHT, 2017). }\end{array}$ \\
\hline $\begin{array}{l}\text { cinesiologia } \\
\text { A Cinesiologia Aplicada é uma terapia que } \\
\text { através de Testes Musculares verifica a }\end{array}$ & $\begin{array}{l}\text { kinesionlogy } \\
\text { Kinesiology - a manipulative therapy by } \\
\text { which a patient's physical, chemical, }\end{array}$ \\
\hline
\end{tabular}

\footnotetext{
${ }^{67} \mathrm{https}: / / \mathrm{www} .0 x f o r d d e v e l o p m e n t c e n t r e . c o . u k / a-r e c e n t-c a l a t o n i a-a n d-s u b t l e-t o u c h-w o r k s h o p /, \quad$ acesso $\quad \mathrm{em}$ 07/09/2017.

${ }^{68} \mathrm{http}: / /$ www.soundrelaxationcentre.com/singing-therapy.html, acesso em 24/09/2017.
} 


\begin{tabular}{|c|c|}
\hline tonicidade desses músculos (Costeira, 2015). & $\begin{array}{l}\text { emotional and nutritional imbalances are } \\
\text { assessed by a system of muscle testing } \\
\text { (House of Lords, 2017). }\end{array}$ \\
\hline $\begin{array}{l}\text { colonterapia } \\
\text { A colonterapia baseia-se em práticas } \\
\text { milenares de limpeza intestinal (feita com } \\
\text { água morna, purificada e ozonizada) (Klein; } \\
\text { Rodrigues, 2016). }\end{array}$ & $\begin{array}{l}\text { colon hydrotherapy; colon cleansing } \\
\text { Colon cleansing (also known as colon } \\
\text { therapy) encompasses a number of alternative } \\
\text { medical therapies claimed to remove } \\
\text { nonspecific toxins from the colon and } \\
\text { intestinal tract by removing any } \\
\text { accumulations of feces. } 69 \\
\text { Institute of Professional Colon Hydrotherapy } \\
\text { (IPCH) (GRCCT, 2017). }\end{array}$ \\
\hline $\begin{array}{l}\text { constelação familiar } \\
\text { A Constelação Familiar pode ajudar em todos } \\
\text { os problemas de origem sistêmica, } \\
\text { compreendendo desde problemas de } \\
\text { relacionamento de casal, com filhos, todos os } \\
\text { tipos de vícios, problemas emocionais, } \\
\text { dificuldades diversas, até problemas de saúde } \\
\text { física que podem ser solucionados, } \\
\text { compreendidos ou amenizados (Costeira, } \\
\text { 2015). }\end{array}$ & $\begin{array}{l}\text { family constellation(s) } \\
\text { Family Constellations, also known as } \\
\text { Systemic Constellations and Systemic Family } \\
\text { Constellations, is an alternative therapeutic } \\
\text { method which draws on elements of family } \\
\text { systems therapy, existential phenomenology } \\
\text { and Zulu attitudes to family. }{ }^{70}\end{array}$ \\
\hline $\begin{array}{l}\text { craniossacral, terapia } \\
\text { Atualmente, os especialistas em TCS vão } \\
\text { mais além, admitindo que a Terapia } \\
\text { Craniossacral seja uma terapia que oferece } \\
\text { um trabalho através do toque, em que a } \\
\text { abordagem corporal, terapêutica e meditativa, } \\
\text { restaura a percepção corpo-mente-espírito } \\
\text { (Costeira, 2015). }\end{array}$ & $\begin{array}{l}\text { craniosacral therapy } \\
\text { Craniosacral therapy is a gentle, non-invasive } \\
\text { therapy using light touch to help achieve } \\
\text { physical and mental balance, and support the } \\
\text { body's own ability to self-heal (FHT, 2017). }\end{array}$ \\
\hline $\begin{array}{l}\text { crenoterapia; (ver) termalismo } \\
\text { A Crenoterapia consiste na indicação e uso de } \\
\text { águas minerais com finalidade terapêutica } \\
\text { atuando de maneira complementar aos } \\
\text { demais tratamentos de saúde (Brasil: } \\
\text { Ministério da Saúde, 2006). }\end{array}$ & $\begin{array}{l}\text { balneotherapy } \\
\text { Balneotherapy - In contrast to hydrotherapy, } \\
\text { which generally employs normal tap water, } \\
\text { balneotherapy is defined as baths using } \\
\text { thermal mineral waters of at least } 20^{\circ} \mathrm{C} \\
\text { temperature and a mineral content of at least } \\
1 \mathrm{~g} / \mathrm{L} \text { water from natural springs (Boddy, K. et } \\
\text { al, 2008). }\end{array}$ \\
\hline $\begin{array}{l}\text { cristaloterapia } \\
\text { Cristaloterapia é o nome dado ao uso }\end{array}$ & $\begin{array}{l}\text { crystal therapy } \\
\text { Crystal therapy - Based on the idea that } \\
\text { crystals can absorb and transmit energy and }\end{array}$ \\
\hline
\end{tabular}

\footnotetext{
${ }^{69}$ https://en.wikipedia.org/wiki/Colon_cleansing, acesso em 19/09/2017.

${ }^{70} \mathrm{https}$ ://en.wikipedia.org/wiki/Family_Constellations, acesso em 23/03/2017.
} 


\begin{tabular}{|c|c|}
\hline $\begin{array}{l}\text { terapêutico dos cristais (Klein; Rodrigues, } \\
\text { 2016). }\end{array}$ & $\begin{array}{l}\text { that the body has a continuing fluctuating } \\
\text { energy which the crystal helps to tune (House } \\
\text { of Lords, 2017). }\end{array}$ \\
\hline $\begin{array}{l}\text { cromoterapia } \\
\text { Cromoterapia é a ciência que utiliza a } \\
\text { vibração das cores do espectro solar para } \\
\text { restaurar o equilíbrio fisico-energético em } \\
\text { áreas do corpo que apresentam alguma } \\
\text { disfunção (Costeira, 2015). }\end{array}$ & $\begin{array}{l}\text { colour therapy; chromotherapy } \\
\text { The therapist may use a number of different } \\
\text { techniques, including; visualisation; spectrum } \\
\text { lamps; coloured crystals and silks; solarized } \\
\text { water; coloured oils; and encouraging the } \\
\text { client to eat foods of a particular colour } \\
\text { (FHT, 2017). }\end{array}$ \\
\hline $\begin{array}{l}\text { cura espiritual } \\
\text { Além disso, com base no documento } \\
\text { elaborado pela OMS como estratégia para } \\
\text { promoção das terapias não convencionais em } \\
\text { saúde, foram selecionadas as terapias de } \\
\text { acupuntura, chás, fitoterapia, shiatsu, xantala, } \\
\text { massoterapia, reflexologia, osteopatia, ioga, } \\
\text { ayurveda, homeopatia e cura espiritual } \\
\text { (Fontanella, 2007). }\end{array}$ & $\begin{array}{l}\text { spiritual healing } \\
\text { Many different approaches of spiritual } \\
\text { healing exist. Typically the healer moves } \\
\text { their hands at a distance over the patient's } \\
\text { body detecting areas of concern and transmits } \\
\text { 'energy' into the patient's body which } \\
\text { allegedly enhances self-healing (Boddy, K. et } \\
\text { al, 2008). }\end{array}$ \\
\hline $\begin{array}{l}\text { cura prânica } \\
\text { Cura prânica, também conhecida como } \\
\text { Terapia Prânica ou Pranic Healing, é um } \\
\text { processo terapêutico que utiliza as mãos sem } \\
\text { tocar no corpo do paciente, em que o foco é a } \\
\text { limpeza de resíduos energéticos negativos } \\
\text { (Costeira, 2015). }\end{array}$ & $\begin{array}{l}\text { pranic healing } \\
\text { Pranic Healing is a highly evolved and tested } \\
\text { system of energy medicine developed by } \\
\text { GrandMaster Choa Kok Sui that utilizes } \\
\text { prana to balance, harmonize and transform } \\
\text { the body's energy processes. }{ }^{71}\end{array}$ \\
\hline $\begin{array}{l}\text { dançaterapia; dança-movimento terapia } \\
\text { Nos estudos sobre a relação das danças e } \\
\text { terapias, percebeu-se uma maior freqüência } \\
\text { de utilização da dançaterapia ou dança- } \\
\text { movimento terapia como técnicas de apoio } \\
\text { para o trabalho corporal em pacientes (Lima; } \\
\text { Silva Neto, 2011). }\end{array}$ & $\begin{array}{l}\text { dance/movement therapy } \\
\text { Based on the empirically supported premise } \\
\text { that the body, mind and spirit are } \\
\text { interconnected, the American Dance Therapy } \\
\text { Association defines dance/movement therapy } \\
\text { as the psychotherapeutic use of movement to } \\
\text { further the emotional, cognitive, physical and } \\
\text { social integration of the individual. }{ }^{72}\end{array}$ \\
\hline $\begin{array}{l}\text { dietoterapia } \\
\text { As práticas complementares em Nutrição } \\
\text { podem ser classificadas em duas categorias: } \\
\text { os "modelos alimentares", que incluem } \\
\text { aquelas vinculadas a práticas tradicionais ou } \\
\text { derivadas de racionalidades médicas, entre }\end{array}$ & $\begin{array}{l}\text { diet therapy } \\
\text { The term "diet therapy" refers to the usage of } \\
\text { food and nutrition in controlling symptoms } \\
\text { and creating the best possible life for yourself } \\
\text { through health and wellness. } 73\end{array}$ \\
\hline
\end{tabular}

\footnotetext{
${ }^{71} \mathrm{https}: / /$ pranichealing.com/what-pranic-healing, acesso em 24/09/2017.

${ }^{72} \mathrm{https} / / /$ adta.org/, acesso em 24/09/2017.

${ }^{73} \mathrm{http}: / / \mathrm{www}$. livestrong.com/article/284796-what-are-the-basic-principles-of-diet-therapy/, acesso em 24/09/2017.
} 


\begin{tabular}{|c|c|}
\hline $\begin{array}{l}\text { elas a alimentação ayurvédica e a dietoterapia } \\
\text { na MTC; e as "correntes alimentares", que } \\
\text { abarcam as tendências estruturadas de } \\
\text { alimentação que não apresentam um vínculo } \\
\text { a alguma religião, sistema tradicional ou } \\
\text { racionalidade médica (Navolar et al, 2012). }\end{array}$ & \\
\hline $\begin{array}{l}\text { do-in } \\
\text { Como a acupuntura, o shiatsu e a } \\
\text { moxabustão, o do-in é um método terapêutico } \\
\text { de estimulação de pontos estratégicos } \\
\text { localizados na pele e diretamente } \\
\text { relacionados ao funcionamento do organismo } \\
\text { (Klein; Rodrigues, 2016). }\end{array}$ & $\begin{array}{l}\text { do-in } \\
\text { Do-In is a combination of meridian stretching } \\
\text { exercises, breathing exercises, chi exercises } \\
\text { and self massage. }{ }^{74}\end{array}$ \\
\hline $\begin{array}{l}\text { equoterapia } \\
\text { A equoterapia é um método terapêutico e } \\
\text { educacional que utiliza o cavalo dentro de } \\
\text { uma abordagem interdisciplinar, nas áreas de } \\
\text { saúde, educação e equitação, buscando o } \\
\text { desenvolvimento biopsicossocial de pessoas } \\
\text { portadoras de deficiência e/ou de } \\
\text { necessidades especiais (Marcelino; Melo, } \\
\text { 2006). }\end{array}$ & $\begin{array}{l}\text { equine therapy } \\
\text { Equine Therapy (also referred to as Horse } \\
\text { Therapy, Equine-Assisted Therapy, and } \\
\text { Equine-Assisted Psychotherapy) is a form of } \\
\text { experiential therapy that involves interactions } \\
\text { between patients and horses. } \\
\text { }{ }^{75} \\
\text { Alternatively a degree in equine therapy } \\
\text { opens up opportunities as a self-employed } \\
\text { complementary practitioner or related career } \\
\text { path (University of Greenwich, 2017). }\end{array}$ \\
\hline $\begin{array}{l}\text { eutonia } \\
\text { A Eutonia é uma terapia que trabalha o corpo } \\
\text { e a mente, fornecendo ao Homem } \\
\text { conhecimento e autonomia para realizar os } \\
\text { movimentos cotidianos (sentar-se e levantar- } \\
\text { se, repousar, empregar força), mas com o } \\
\text { tônus muscular equilibrado, sem gerar } \\
\text { tensões desnecessárias e economizando } \\
\text { energia (Costeira, 2015). }\end{array}$ & $\begin{array}{l}\text { eutony } \\
\text { Eutony is a practice based on sensory } \\
\text { awareness. It was developed by Gerda } \\
\text { Alexander (1908-1994) as a means to balance } \\
\text { tensions in the body, move with ease, and } \\
\text { become more attuned to one's surroundings. } \\
76\end{array}$ \\
\hline $\begin{array}{l}\text { fasciaterapia } \\
\text { Fasciaterapia: método que privilegia o toque } \\
\text { das fascias, tecido conjuntivo do corpo } \\
\text { humano que se situa logo abaixo da } \\
\text { superfície da pele e penetra em vísceras, } \\
\text { músculos, vasos sanguíneos e ossos }\end{array}$ & $\begin{array}{l}\text { fasciatherapy } \\
\text { Fasciatherapy is an innovative treatment for } \\
\text { pain, impaired movement and performance- } \\
\text { related disorders of a physical and/or } \\
\text { psychological nature. } 77\end{array}$ \\
\hline
\end{tabular}

\footnotetext{
${ }^{74} \mathrm{http}: / /$ sylvanstreetsanctuary.com/selfmassage/, acesso em 24/09/2017.

${ }^{75} \mathrm{https}$ ://www.crchealth.com/types-of-therapy/what-is-equine-therapy/, acesso em 11/12/2017.

${ }^{76} \mathrm{https}$ //eutony.co.uk/what-is-eutony/, acesso em 19/09/2017.

${ }^{77} \mathrm{https}: / /$ www.fascia.be/en/fasciatherapy, acesso em 19/09/2017.
} 


\begin{tabular}{|c|c|}
\hline Costeira, 2015). & \\
\hline $\begin{array}{l}\text { Feldenkrais, método } \\
\text { Método sutil de flexibilização dos hábitos de } \\
\text { postura, de movimento e de percepção. Sua } \\
\text { prática retoma o desenvolvimento orgânico- } \\
\text { psicológico aproveitando ao máximo o } \\
\text { potencial das habilidades pessoais. O } \\
\text { autoconhecimento e o autoaproveitamento } \\
\text { são promovidos através da reaproximação da } \\
\text { pessoa à experiência concreta de si mesma e } \\
\text { de seu corpo (Costeira, 2015). }\end{array}$ & $\begin{array}{l}\text { Feldenkrais } \\
\text { Feldenkrais - Definition: a treatment } \\
\text { developed by the physicist Moshe } \\
\text { Feldenkrais (1904-84) based on the belief } \\
\text { that correction of posture and habitual } \\
\text { movements can improve a range of health } \\
\text { problems (Boddy, K. et al, 2008). }\end{array}$ \\
\hline $\begin{array}{l}\text { fitoterapia } \\
\text { Etimologicamente, vem das palavras gregas } \\
\text { phyton (plantas) e therapeia (tratamento), ou } \\
\text { seja, tratamento por meio das plantas. A } \\
\text { fitoterapia caracteriza-se pela prática do uso } \\
\text { de plantas, ou de suas partes, com a } \\
\text { finalidade de prevenir, aliviar ou curar um } \\
\text { processo patológico (Bettega, 2011). }\end{array}$ & $\begin{array}{l}\text { herbal medicine, herbalism, } \\
\text { phythotherapy } \\
\text { Herbal Medicine is the study of the medicinal } \\
\text { qualities of plants, and their practical } \\
\text { applications, to heal the symptoms and cause } \\
\text { of disease (School of Natural Medicine UK, } \\
2017 \text { ). } \\
\text { Herbalism - Definition: The medicinal use of } \\
\text { preparations that contain exclusively plant } \\
\text { material (Boddy, K. et al, 2008). }\end{array}$ \\
\hline $\begin{array}{l}\text { florais; essências florais; terapia floral; } \\
\text { sistemas florais; floralterapia } \\
\text { A eficácia dos florais se encontra na } \\
\text { transformação do paradigma comportamental } \\
\text { por fazer desabrochar todas as qualidades } \\
\text { positivas e efetuar a busca do } \\
\text { autoconhecimento - uma dádiva para a } \\
\text { medicina holística (Naiff, 2016). } \\
\text { Foi essa busca na natureza que acabou } \\
\text { levando Bach a descobrir as propriedades } \\
\text { curativas das essências florais (Costeira, } \\
\text { 2015). } \\
\text { A Terapia Floral utiliza essências de flores, } \\
\text { em extratos líquidos naturais e altamente } \\
\text { diluídos (Costeira, 2015). } \\
\text { A partir dos ensinamentos de Edward Bach } \\
\text { vários novos sistemas florais foram } \\
\text { desenvolvidos em diversas partes do mundo, } \\
\text { preparados com flores diferentes e em } \\
\text { ecossistemas com propriedades peculiares e } \\
\text { diferentes (Costeira, 2015). }\end{array}$ & $\begin{array}{l}\text { flower essences, flower remedies } \\
\text { Flower essences are diluted extracts of } \\
\text { various types of flowers and plants, similar in } \\
\text { many ways to homeopathic remedies (FHT, } \\
\text { 2017). } \\
\text { Bach and other flower remedies: the theory } \\
\text { behind flower remedies is that flowers } \\
\text { contain the life force of the plant and this is } \\
\text { imprinted into water through sun infusion } \\
\text { which is used to make the flower remedy } \\
\text { (House of Lords, 2017). }\end{array}$ \\
\hline
\end{tabular}




\begin{tabular}{|c|c|}
\hline $\begin{array}{l}\text { geoterapia; (ver argiloterapia) } \\
\text { A geoterapia é o sistema de tratamento } \\
\text { através da terra comum, sendo o mais comum } \\
\text { à argila, nas suas mais variadas formas } \\
\text { (Klein; Rodrigues, 2016). } \\
\text { Em sendo a união de técnicas uma prática } \\
\text { comum nas terapias holísticas, a Terapia das } \\
\text { Pedras Quentes une as terapias térmicas, } \\
\text { quente e fria, com a geoterapia que utiliza } \\
\text { pedras basálticas de amidaloide, ou seja, } \\
\text { seixos rolados de rio com formato de } \\
\text { amêndoa, e mais ágatas e mármores } \\
\text { (Costeira, 2015). }\end{array}$ & $\begin{array}{l}\text { geothermal therapy; (see) clay therapy } \\
\text { Geothermal therapy refers to the integration } \\
\text { of heated and/or cooled stones during } \\
\text { bodywork. }\end{array}$ \\
\hline $\begin{array}{l}\text { helioterapia } \\
\text { Helioterapia: utilização da luz solar com fins } \\
\text { terapêuticos ou profiláticos (Costeira, 2015). }\end{array}$ & $\begin{array}{l}\text { helio therapy; sunbathing } \\
\text { Heliotherapy utilizes the beneficial effects of } \\
\text { the sun, air and light to make a person } \\
\text { healthier. }\end{array}$ \\
\hline $\begin{array}{l}\text { hidroterapia } \\
\text { Hidroterapia - uso de banhos e imersões com } \\
\text { recursos que variam entre duchas, hidro- } \\
\text { toques em temperaturas específicas (SINTE, } \\
2017 \text { ). }\end{array}$ & $\begin{array}{l}\text { hydrotherapy } \\
\text { Hydro-/balneotherapy - Definition: external } \\
\text { application of water in any form or } \\
\text { temperature (hot, cold, steam, liquid, ice). A } \\
\text { number of variations are used, such as foot or } \\
\text { lower leg baths, wraps, and rising } \\
\text { temperature baths (Boddy, K. et al, 2008). }\end{array}$ \\
\hline $\begin{array}{l}\text { hirudoterapia } \\
\text { Hirudoterapia: a palavra advem do latim } \\
\text { hirudina que significa sanguessuga, além de } \\
\text { terapia, e representa o tratamento com as } \\
\text { sanguessugas, usado para fins medicinais há } \\
\text { mais de mil anos antes de Cristo (Costeira, } \\
\text { 2015). }\end{array}$ & $\begin{array}{l}\text { Hirudotherapy } \\
\text { Hirudotherapy is a treatment using medicinal } \\
\text { leeches. } \\
\text { British Association of Hirudotherapy (BAH). } \\
\text { The British Association of Hirudotherapy } \\
\text { (BAH).GRCCT (2017). }\end{array}$ \\
\hline $\begin{array}{l}\text { hipnose; hipnoterapia } \\
\text { E a Hipnose é uma técnica natural e eficaz } \\
\text { para acessar o subconsciente, permitindo } \\
\text { fazê-lo de uma forma simples para libertar } \\
\text { velhos padrões, ensamentos, } \\
\text { comportamentos, atitudes e crenças, } \\
\text { reprogramando para o sucesso e o bem-estar. } \\
\text { Costeira (2015). }\end{array}$ & $\begin{array}{l}\text { hypnotherapy, hypnosis } \\
\text { Hypnotherapy - What is it? The induction of } \\
\text { a trance-like state to facilitate relaxation and } \\
\text { make use of enhanced suggestibility to treat } \\
\text { psychological and medical conditions and } \\
\text { affect behavioural changes (Boddy, K. et al, } \\
2008 \text { ). }\end{array}$ \\
\hline
\end{tabular}

\footnotetext{
${ }^{78} \mathrm{https}$ ://holisticri.wordpress.com/information/geothermal-therapy/, acesso em 24/09/2017.

${ }^{79} \mathrm{http}$ ://sunlightenment.com/heliotherapy-benefits-of-sunbathing/, acesso em 24/09/2017.

${ }^{80}$ https://www.ncbi.nlm.nih.gov/pubmed/20920805, acesso em 24/09/2017.
} 


\begin{abstract}
holística, medicina; holismo
$\mathrm{O}$ aspecto principal da Medicina Holística ou Integral é a concepção vitalista do ser humano, segundo a qual, o homem não é composto apenas por um corpo físico, onde tudo funciona como uma rede de "engrenagens" ou sistemas, mas por diversos corpos, entre os quais, um mais sutil, invisível, denominado "corpo vital," mantenedor e responsável por todas as funções físicas, psíquicas e mentais (Klein; Rodrigues, 2016).

O holismo em relação à saúde, ao serem criadas as Terapias Holísticas embutidas na Medicina Vibracional, vê o Homem como um todo - Holos - cujo componente espiritual introduzido ao conhecimento do ser humano redesenhou a sua arquitetura anátomofisiológica sutil, em que o homem passou a ser composto de matéria e espírito; a matéria de corpo e mente, e a mente de emocional e racional (Costeira, 2015).
\end{abstract}

\section{homeopatia; homeopática, medicina}

A homeopatia, sistema médico complexo de caráter holístico, baseada no princípio vitalista e no uso da lei dos semelhantes foi enunciada por Hipócrates no século IV a.C. Foi desenvolvida por Samuel Hahnemann no século XVIII (Brasil: Ministério da Saúde, 2006).

\section{imagem guiada; imaginação guiada}

Imagem guiada - Pacientes eram induzidos a uma viagem imaginária para um lugar especial onde eles poderiam se sentir seguros, confortáveis e amparados, sendo encorajados a lutar e a trabalhar com sentimentos de ansiedade e estresse. Costa; Reis (2014).

Um naturopata pode usar a hipnose, imaginação guiada, ou outros métodos de aconselhamento como parte de um plano de tratamento (Klein; Rodrigues, 2016).

\section{iridologia}

A Iridologia não tem como objetivo dar nome às patologias e sim após a análise da íris elaborar um programa de desintoxicação e reconstrução do organismo, que é à base do

\section{holistic medicine; holism}

'CAM refers to a broad set of health care practices that are not part of a country's own tradition and not integrated into the dominant health care system. Other terms sometimes used to describe these health care practices include "natural medicine", "nonconventional medicine" and "holistic medicine".' World Health Organization (Boddy, K. et al, 2008).

Vitalism and holism are particularly prevalent in complementary medicine (Rampes et al, 1997).

\section{homeopathy; homeopathic medicine}

Therefore, homeopathy is based on the idea of treating 'like with like' by administering hugely diluted versions of basically dangerous substances, such that a dose given to a patient may not contain even a single molecule of the active principle (House of Lords, 2017).

\section{imagery}

Imagery - Definition: a mind-body technique that involves using the imagination and mental images to encourage physical healing, promote relaxation, and bring about a change in attitude or behaviour (Boddy, K. et al, 2008).

\section{iridology}

Iridology: a method of diagnosing problems and assessing health status that relies on studying the iris of the eye and noting marks and changes (House of Lords, 2017). 


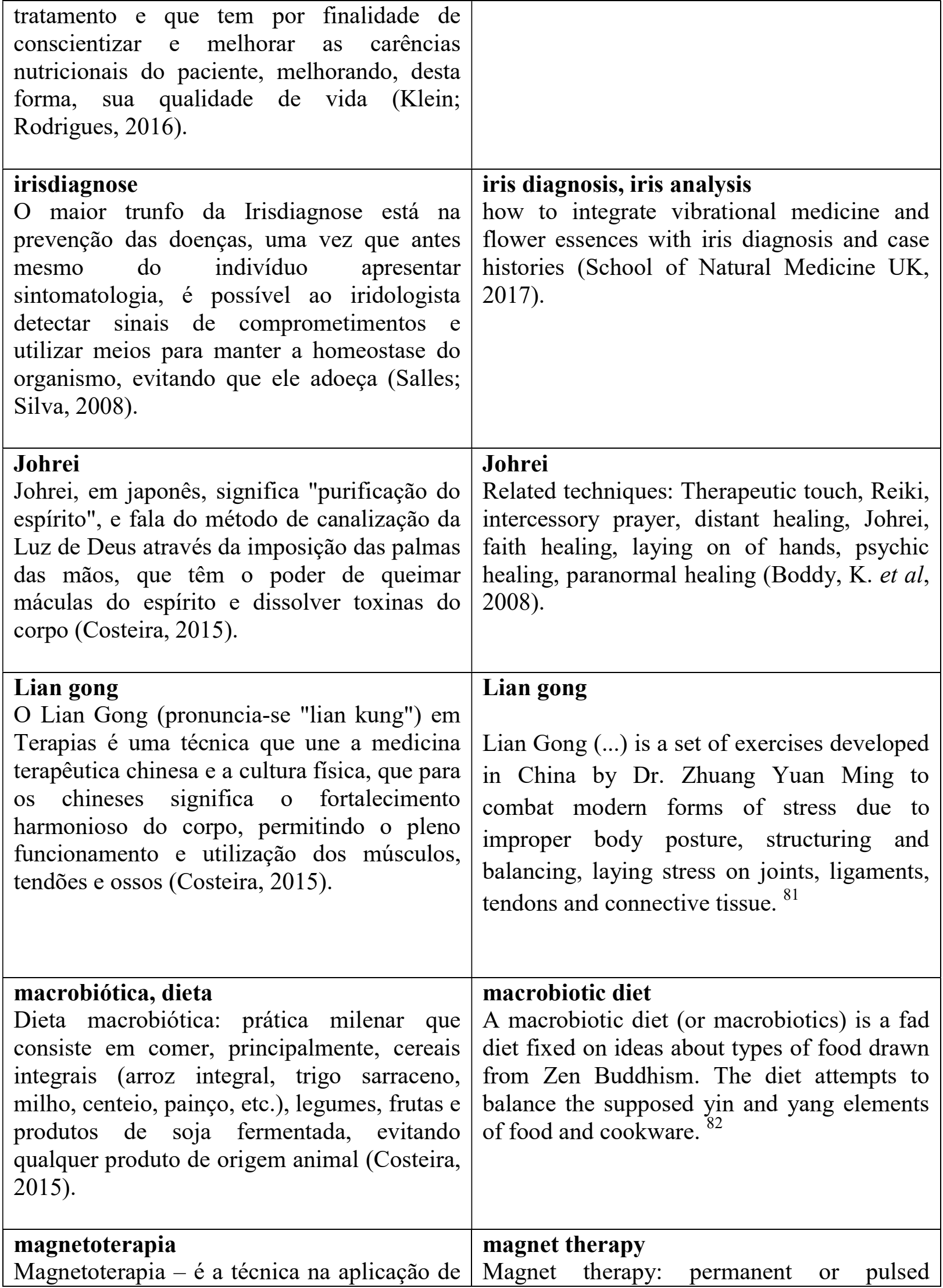

\footnotetext{
${ }^{81}$ http://www.liangong.org/liangong.htm, acesso em 24/09/2017.

${ }^{82} \mathrm{https}$ ://en.wikipedia.org/wiki/Macrobiotic_diet, acesso em 19/09/2017.
} 


\begin{tabular}{|c|c|}
\hline $\begin{array}{l}\text { ímãs e de aparelhos magnéticos especiais em } \\
\text { várias partes do corpo, visando à } \\
\text { regularização energética do organismo } \\
\text { (Klein; Rodrigues, 2016). }\end{array}$ & $\begin{array}{l}\text { magnetic fields applied to head or other parts } \\
\text { of body (Boddy, K. et al, 2008). }\end{array}$ \\
\hline $\begin{array}{l}\text { mantra(s) } \\
\text { A antiga medicina hindu (a medicina } \\
\text { ayurvédica) dispõe até hoje de sons } \\
\text { instrumentais, de cânticos e de mantras } \\
\text { capazes de ativar e de equilibrar os centros de } \\
\text { força psíquica (chakras) do homem, } \\
\text { promovendo a recuperação do organismo, } \\
\text { mesmo diante de problemas sérios (Klein; } \\
\text { Rodrigues, 2016). }\end{array}$ & $\begin{array}{l}\text { mantra(s) } \\
\text { Meditation Diverse range of techniques based } \\
\text { on listening to the breath, repeating a mantra, } \\
\text { focusing attention to bring about a state of } \\
\text { calm (Boddy, K. et al, 2008). }\end{array}$ \\
\hline $\begin{array}{l}\text { massagem } \\
\text { Ninguém duvida do poder relaxante de uma } \\
\text { boa massagem, mas os profissionais da área } \\
\text { ainda lutam para diferenciar uma simples } \\
\text { sessão antiestresse (feita até no shopping) de } \\
\text { uma intervenção capaz de fazer o corpo } \\
\text { reagir a algum desconforto ou problema de } \\
\text { saúde (Almeida et al, 2015). }\end{array}$ & $\begin{array}{l}\text { massage } \\
\text { Massage - definition: a method of } \\
\text { manipulating the soft tissue of whole body } \\
\text { areas(Boddy, K. et al, 2008). } \\
\text { Massage involves working the soft tissue of } \\
\text { the body, to ease day-to-day stresses and } \\
\text { muscular tension, and promote relaxation } \\
\text { (FHT, 2017). }\end{array}$ \\
\hline $\begin{array}{l}\text { massoterapia } \\
\text { A Massoterapia engloba os mais diversos } \\
\text { tipos de massagens, tanto de origem ocidental } \\
\text { como oriental. Algumas das técnicas } \\
\text { utilizadas na Massoterapia são: A Drenagem } \\
\text { Linfática, o Shiatsu, a Reflexologia Podal, o } \\
\text { Do-in, o Tuiná, a Ayurvédica, a Tailandesa, a } \\
\text { Massagem relaxante entre outras (Klein; } \\
\text { Rodrigues, 2016). }\end{array}$ & $\begin{array}{l}\text { massage therapy } \\
\text { Massage Therapy means the systematic use } \\
\text { of classical Massage and soft tissue } \\
\text { techniques, to improve physical and } \\
\text { emotional well being. The Massage } \\
\text { Therapist, or Massage Practitioner, is a } \\
\text { person suitably trained and experienced for } \\
\text { the purpose of applying such therapy } \\
\text { (GRCCT, 2017). }\end{array}$ \\
\hline $\begin{array}{l}\text { MCA, medicina complementar e } \\
\text { alternativa } \\
\text { Paralelamente à medicina oficialmente } \\
\text { reconhecida, coexistem em nosso meio outras } \\
\text { práticas de diagnóstico e de cuidados } \\
\text { relacionados à saúde. A tendência na } \\
\text { literatura é abrigá-las sob o termo medicina } \\
\text { complementar e alternativa (MCA) (Neto et } \\
\text { al, 2009). }\end{array}$ & $\begin{array}{l}\text { CAM, complementary and alternative } \\
\text { medicine } \\
\text { Complementary and alternative medicine } \\
\text { (CAM) has been defined as 'diagnosis, } \\
\text { treatment and/or prevention which } \\
\text { complements mainstream medicine by } \\
\text { contributing to a common whole, satisfying a } \\
\text { demand not met by orthodoxy, or } \\
\text { diversifying the conceptual framework of } \\
\text { medicine' (Posadzki et al, 2013). }\end{array}$ \\
\hline medicina tradicional & traditional Chinese medicine; Chinese \\
\hline
\end{tabular}




\begin{tabular}{|c|c|}
\hline $\begin{array}{l}\text { chinesa } \\
\text { A Medicina Tradicional Chinesa caracteriza- } \\
\text { se por um sistema médico integral, originado } \\
\text { há milhares de anos na China (Brasil: } \\
\text { Ministério da Saúde, 2006). }\end{array}$ & $\begin{array}{l}\text { medicine } \\
\text { Traditional Chinese medicine (TCM) is a } \\
\text { diagnostic and therapeutic system based on } \\
\text { complex (philosophical) theories, e.g. yin and } \\
\text { yang theory and five-element theory. It is } \\
\text { used as an umbrella term for approaches } \\
\text { developed in ancient China, e.g. acupuncture, } \\
\text { herbal medicines, tui-na (massage, } \\
\text { pronounced /twi-na/), tai chi (pronounced } \\
\text { /tie-chee/), diet (Boddy, K. et al, 2008). }\end{array}$ \\
\hline $\begin{array}{l}\text { medicina integrativa } \\
\text { "Medicina integrativa", definida como uma } \\
\text { "medicina que enfatiza a relação médico- } \\
\text { paciente e integra o melhor da CAM com o } \\
\text { melhor da medicina convencional", } \\
\text { englobando aspectos humanísticos, } \\
\text { preventivos e curativos dos diversos modelos } \\
\text { terapêuticos existentes (Teixeira; Lin, 2013). }\end{array}$ & $\begin{array}{l}\text { integrative medicine } \\
\text { Integrative medicine, the integration of } \\
\text { complementary and alternative medicine } \\
\text { (CAM) with conventional healthcare, is being } \\
\text { increasingly adopted within mainstream } \\
\text { health services (Power; Hopayian, 2011). }\end{array}$ \\
\hline $\begin{array}{l}\text { medicina tradicional } \\
\text { A OMS utiliza o termo Medicina Tradicional } \\
\text { para se referir às práticas médicas originárias } \\
\text { da cultura de cada país, como por exemplo, a } \\
\text { medicina tradicional chinesa, a ayurveda } \\
\text { hindu, a medicina unani árabe e a medicina } \\
\text { indígena (Sousa et al, 2012). }\end{array}$ & $\begin{array}{l}\text { traditional medicine } \\
\text { The WHO described 'traditional medicine as } \\
\text { the knowledge, skills and practice of holistic } \\
\text { health care, recognized and accepted for its } \\
\text { role in the maintenance of health and the } \\
\text { treatment of diseases. It is based on } \\
\text { indigenous theories, beliefs and experiences } \\
\text { that are handed down from generation to } \\
\text { generation' (Rüdel et al, 2008). }\end{array}$ \\
\hline $\begin{array}{l}\text { meditação } \\
\text { Dentre essas técnicas, uma das mais } \\
\text { conhecidas e estudadas é a meditação. O } \\
\text { termo refere-se a uma variedade de práticas } \\
\text { que visam focar ou controlar a atenção. } \\
\text { Podem ser praticadas por muitos motivos, } \\
\text { como promover calma e relaxamento físico, } \\
\text { melhorar o equilíbrio psicológico, ajudar a } \\
\text { enfrentar uma doença, ou estimular a saúde e } \\
\text { o bem-estar geral (Hospital Sírio-Libanês, } \\
\text { 2017). }\end{array}$ & $\begin{array}{l}\text { meditation } \\
\text { Meditation: a serie of techniques used to } \\
\text { relax a patient to facilitate deep reflection and } \\
\text { a clearing of the mind (House of Lords, } \\
2017 \text { ). }\end{array}$ \\
\hline $\begin{array}{l}\text { meridiano(s) } \\
\text { Meridianos (de Acupuntura) são canais } \\
\text { puramente eletromagnéticos, sem limitações } \\
\text { materiais ( embora, algumas vezes, } \\
\text { coincidam com a musculatura ), pelos quais } \\
\text { se transmitem sinais eletromagnéticos, como } \\
\text { os biofótons e também partículas materiais }\end{array}$ & $\begin{array}{l}\text { meridian(s) } \\
\text { Like acupuncture, meridian therapies work on } \\
\text { the principle that energy flows through the } \\
\text { body along channels known as 'meridians' } \\
\text { (FHT, 2017). }\end{array}$ \\
\hline
\end{tabular}




\begin{tabular}{|c|c|}
\hline (SINTE, 2017). & \\
\hline $\begin{array}{l}\text { mindfulness } \\
\text { Mindfulness, em inglês, é a capacidade de } \\
\text { estar presente, mantendo intencionalmente a } \\
\text { atenção no que está ocorrendo em nossa vida } \\
\text { (Lima, 2009). }\end{array}$ & $\begin{array}{l}\text { mindfulness } \\
\text { Mindfulness means to be aware of all our } \\
\text { experiences, physical sensations, thoughts } \\
\text { and feelings from moment to moment } \\
\text { (University College London Hospitals NHS } \\
\text { Foundation Trust, 2017). }\end{array}$ \\
\hline $\begin{array}{l}\text { moxabustão; moxa; moxibustão } \\
\text { A acupuntura divide-se também em vários } \\
\text { ramos, sendo os principais: a acupuntura } \\
\text { propriamente dita, que trata por meio de } \\
\text { agulhas; a moxabustão, que trata por meio de } \\
\text { moxas, ou materiais incandescentes, feitos } \\
\text { com uma erva especial (Klein; Rodrigues, } \\
\text { 2016). }\end{array}$ & $\begin{array}{l}\text { moxibustion } \\
\text { Moxibustion (burning of the herb Mugwort } \\
\text { close to the surface of the skin) (University } \\
\text { College London Hospitals NHS Foundation } \\
\text { Trust, 2017). }\end{array}$ \\
\hline $\begin{array}{l}\text { musicoterapia } \\
\text { De acordo com definição da World Music } \\
\text { Therapy Federation, a musicoterapia é a } \\
\text { utilização da música e/ou seus elementos por } \\
\text { um musicoterapeuta qualificado, com um } \\
\text { paciente ou grupo, visando facilitar e } \\
\text { promover a comunicação, relação, } \\
\text { aprendizagem, mobilização, expressão, } \\
\text { organização e outros objetivos terapêuticos } \\
\text { relevantes no sentido de alcançar as } \\
\text { necessidades físicas, emocionais, mentais, } \\
\text { sociais e cognitivas (Hospital Sírio-Libanês, } \\
\text { 2017). }\end{array}$ & $\begin{array}{l}\text { music therapy } \\
\text { Music therapy is one of the expressive } \\
\text { therapies, consisting of a process in which a } \\
\text { music therapist uses music and all of its } \\
\text { facets - physical, emotional, mental, social, } \\
\text { aesthetic, and spiritual - to help clients } \\
\text { improve their physical and mental health. } \\
\text { In pain management, for example, mainly } \\
\text { receptive music therapy is used while active } \\
\text { music therapy is most common in mental } \\
\text { health (Boddy, K. et al, 2008). }\end{array}$ \\
\hline $\begin{array}{l}\text { naturologia (ver naturopatia) } \\
\text { A Naturologia estuda práticas e métodos } \\
\text { naturais, tradicionais e modernos para o } \\
\text { cuidado humano. Visa à expansão, } \\
\text { manutenção e recuperação da saúde, bem } \\
\text { como à melhoria da qualidade de vida e ao } \\
\text { equilíbrio do ser humano com o ambiente e } \\
\text { com a sociedade. Utiliza-se de práticas } \\
\text { integrativas e complementares em saúde } \\
\text { (Universidade do Sul de SC, 2017). }\end{array}$ & $\begin{array}{l}\text { naturopathy } \\
\text { Naturopathy is a discipline of accumulated } \\
\text { knowledge of effective natural therapies, diet } \\
\text { and lifestyle in practice, and does not have a } \\
\text { single originator (School of Natural Medicine } \\
\text { UK, 2017). }\end{array}$ \\
\hline $\begin{array}{l}\text { naturopatia } \\
\text { Naturopatia ou Medicina Naturopata é um } \\
\text { sistema de medicina baseado no poder de }\end{array}$ & $\begin{array}{l}\text { naturopathy } \\
\text { Naturopathy is a discipline of accumu } \\
\text { knowledge of effective natural therapies }\end{array}$ \\
\hline
\end{tabular}

${ }^{83}$ https://en.wikipedia.org/wiki/Music_therapy, acesso em 11/12/2017. 


\begin{tabular}{|c|c|}
\hline natureza (Klein; Rodrig & $\begin{array}{l}\text { d lifestyle in practice, and does not have a } \\
\text { Kle originator (School of Natural Medicine } \\
\text { K, 2017). }\end{array}$ \\
\hline $\begin{array}{l}\text { óleos essenciais; óleo essencial } \\
\text { Óleos essenciais são compostos aromáticos } \\
\text { voláteis extraídos de plantas aromáticas por } \\
\text { processos de destilação, compressão de frutos } \\
\text { ou extração com o uso de solventes. } \\
\text { Aromaterapia é o nome empregado ao } \\
\text { tratamento realizado com a aplicação de óleos } \\
\text { essenciais, os quais são extraídos do reino } \\
\text { vegetal - flores, folhas, frutos, raízes (Naiff, } \\
2016 \text { ). }\end{array}$ & $\begin{array}{l}\text { essential oil(s) } \\
\text { An essential oil is a concentrated } \\
\text { hydrophobic liquid containing volatile } \\
\text { (defined as "the tendency of a substance to } \\
\text { vaporize") aroma compounds from plants. } \\
\text { Aromatherapy is the use of plant essential } \\
\text { oils for therapeutic purposes. Essential oils } \\
\text { have been used in fragrances, flavourings and } \\
\text { medicines for thousands of years (FHT, } \\
2017 \text { ). }\end{array}$ \\
\hline $\begin{array}{l}\text { oligoelementos; oligoterapia } \\
\text { Os oligoelementos são substâncias químicas } \\
\text { que se encontram em pequenas quantidades } \\
\text { no organismo para intervir em seu } \\
\text { metabolismo (Costeira, 2015). } \\
\text { Oligoterapia é a complementação e variação } \\
\text { da Alimentoterapia e da Fitoterapia, que faz } \\
\text { uso dos Oligoelementos (minerais, tais como: } \\
\text { zinco, cobre, etc.), especialmente preparados } \\
\text { para absorção (SINTE, 2017). }\end{array}$ & $\begin{array}{l}\text { oligo elements; oligotherapy } \\
\text { Oligo Elements are designed as nutritional } \\
\text { supplements to be used as an adjunct in } \\
\text { aiding the body help itself. } 86 \\
\text { Oligotherapy is a method of providing the } \\
\text { body with the ions it cannot synthesize and } \\
\text { which are indispensable for cellular } \\
\text { enzymatic functions. }\end{array}$ \\
\hline $\begin{array}{l}\text { ortomolecular, medicina } \\
\text { A medicina ortomolecular é uma terapia da } \\
\text { normalização metabólica e tem como } \\
\text { objetivo principal o restabelecimento do } \\
\text { equilíbrio orgânico através da utilização de } \\
\text { agentes antioxidantes, visando à } \\
\text { neutralização da ação deletéria dos radicais } \\
\text { livres presentes no corpo humano (Klein; } \\
\text { Rodrigues, 2016). }\end{array}$ & $\begin{array}{l}\text { orthomolecular medicine } \\
\text { Orthomolecular medicine is a form of } \\
\text { alternative medicine, aims to maintain human } \\
\text { health through nutritional supplementation. } \\
\text { Very few midwives were trained in ear } \\
\text { acupuncture and orthomolecular medicine } \\
\text { (Muñoz-Sellés, 2013). }\end{array}$ \\
\hline $\begin{array}{l}\text { osteopatia } \\
\text { Forma holística de medicina não } \\
\text { convencional que usa técnicas manuais para } \\
\text { diagnosticar e tratar uma grande variedade de } \\
\text { problemas de saúde. Ela se baseia na filosofia }\end{array}$ & $\begin{array}{l}\text { osteopathy } \\
\text { Osteopathy - A system of diagnosis and } \\
\text { treatment, usually by manipulation, that } \\
\text { mainly focuses on musculo-skeletal } \\
\text { problems, but a few schools claim benefits }\end{array}$ \\
\hline
\end{tabular}

\footnotetext{
${ }^{84}$ https://pt.wikipedia.org/wiki/Óleo_essencial, acesso em 12/12/2017.

${ }^{85} \mathrm{https}$ ://en.wikipedia.org/wiki/Essential_oil, acesso em 12/12/2017.

${ }^{86} \mathrm{http}: / / \mathrm{www}$. stewartchiropracticcenter.com/faq/what-are-oligo-elements, acesso em 19/09/2017.

${ }^{87} \mathrm{https}$ ://innovativemedicine.com/solutions/oligotherapy/, acesso em 19/09/2017.

${ }^{88} \mathrm{https}$ ://en.wikipedia.org/wiki/Orthomolecular_medicine, acesso em 11/12/2017.
} 


\begin{tabular}{|c|c|}
\hline $\begin{array}{l}\text { de que o corpo funciona como uma unidade } \\
\text { composta de diferentes partes móveis, tais } \\
\text { como músculos e articulações, órgãos e } \\
\text { vísceras, circulação sanguínea ou interações } \\
\text { microscópicas entre as células (Costeira, } \\
\text { 2015). }\end{array}$ & $\begin{array}{l}\text { across a wider spectrum of disorders (House } \\
\text { of Lords, 2017). }\end{array}$ \\
\hline $\begin{array}{l}\text { ozonioterapia } \\
\text { Segundo a Associação Brasileira de } \\
\text { Ozonioterapia, é uma técnica que utiliza o } \\
\text { Ozônio como agente terapêutico em um } \\
\text { grande número de patologias (Costeira, } \\
\text { 2015). }\end{array}$ & $\begin{array}{l}\text { ozone therapy } \\
\text { Ozone therapy is a form of alternative } \\
\text { medicine treatment that purports to increase } \\
\text { the amount of oxygen in the body through the } \\
\text { introduction of ozone. }{ }^{89} \\
\text { Ozone therapy: to boost immunological } \\
\text { defence (Boddy, K. et al, 2008). }\end{array}$ \\
\hline $\begin{array}{l}\text { Pathwork } \\
\text { O Pathwork, cuja tradução literal é "Trabalho } \\
\text { do Caminho", é uma metodologia de } \\
\text { autoconhecimento baseada em um conjunto } \\
\text { de ensinamentos apresentados sob a forma de } \\
\text { palestras. }\end{array}$ & $\begin{array}{l}\text { Pathwork } \\
\text { John Pierrakos integrated the Pathwork } \\
\text { concepts such as the Mask, Lower Self and } \\
\text { Higher Self, the Idealized Self, and Life Task } \\
\text { with Bioenergetic physical interventions } \\
\text { which addressed the armoring in the body. }{ }^{91}\end{array}$ \\
\hline $\begin{array}{l}\text { Na década de 70, ao casar-se com Eva Broch, } \\
\text { posteriormente Eva Pierrakos, incorporou à } \\
\text { Análise Bioenergética os ensinamentos } \\
\text { psicografados pela sua mulher, através das } \\
\text { denominadas Palestras do Pathwork } \\
\text { (Costeira, 2015). }\end{array}$ & \\
\hline $\begin{array}{l}\text { pêndulo } \\
\text { Geralmente o radiestesista ao investigar com } \\
\text { seu instrumento (pêndulo, forquilha, } \\
\text { aurameter, dualroad) uma casa ou uma } \\
\text { pessoa, aconselha-a a usar determinados } \\
\text { circuitos para manter ou equilibrar a energia } \\
\text { benéfica (Naiff, 2016). }\end{array}$ & $\begin{array}{l}\text { pendulum } \\
\text { Radionics: this is an umbrella term for } \\
\text { techniques such as dowsing, devining, } \\
\text { pendulum diagnosis and its (most often } \\
\text { electronic) derivatives. The few studies that } \\
\text { are available indicate that radionics is not a } \\
\text { valid diagnostic tool (Boddy, K. et al, 2008). }\end{array}$ \\
\hline $\begin{array}{l}\text { PIC, Práticas Integrativas } \\
\text { Complementares } \\
\text { De acordo com a PNPIC, as práticas } \\
\text { integrativas e complementares são um campo } \\
\text { que contempla tanto sistemas médicos } \\
\text { complexos, quanto os recursos terapêuticos }\end{array}$ & $\begin{array}{l}\text { CIP, Complementary and Integrative } \\
\text { Practices } \\
\text { The use of Complementary and Integrative } \\
\text { Practices (CIP) is on the increase and its }\end{array}$ \\
\hline
\end{tabular}

\footnotetext{
${ }^{89} \mathrm{https}$ ://en.wikipedia.org/wiki/Ozone_therapy, acesso em 11/12/2017.

$90 \mathrm{http}$ ://www.pathworkbrasil.com.br/oque-e-pathworkbrasil.php, acesso em 11/12/2017.

${ }^{91}$ https://en.wikipedia.org/wiki/John_Pierrakos, acesso em 24/09/2017.
} 


\begin{tabular}{|c|c|}
\hline (Lima et al, 2014). & $\begin{array}{l}\text { institutionalization in Primary Health Care } \\
(\mathrm{PHC}) \text { is a challenge. }{ }^{92}\end{array}$ \\
\hline $\begin{array}{l}\text { plantas medicinais } \\
\text { As plantas medicinais são definidas como } \\
\text { aquelas capazes de produzir princípios ativos } \\
\text { que possam alterar o funcionamento de } \\
\text { órgãos e sistemas, restaurando o equilíbrio } \\
\text { orgânico ou a homeostasia nos casos de } \\
\text { enfermidades (Lima et al, 2014). }\end{array}$ & $\begin{array}{l}\text { herbs; medicinal plants } \\
\text { Knowledge of the use of herbs for medicine } \\
\text { predates the knowledge we currently have of } \\
\text { the evolution of humankind (School of } \\
\text { Natural Medicine UK, 2017). } \\
\text { Although rigorous clinical investigations are } \\
\text { lacking at present for many herbs, there is a } \\
\text { vast literature on the phytochemistry, and in } \\
\text { vitro and in vivo pharmacological effects of } \\
\text { medicinal plants (Barnes et al, 2003b). }\end{array}$ \\
\hline $\begin{array}{l}\text { PNL, programação neuro-linguística } \\
\text { No conceito de Bandler, "A PNL é uma } \\
\text { ferramenta educacional, não uma forma de } \\
\text { terapia. Nós ensinamos às pessoas algumas } \\
\text { coisas sobre como os seus cérebros } \\
\text { funcionam, e elas usam esta informação para } \\
\text { mudar" (Costeira, 2015). }\end{array}$ & $\begin{array}{l}\text { NLP, neuro-linguistic programming } \\
\text { NLP: Neuro linguistic programming (FHT, } \\
\text { 2017). } \\
\text { Neuro-linguistic programming (NLP) } \\
\text { creators claim there is a connection between } \\
\text { neurological processes (neuro-), language } \\
\text { (linguistic) and behavioral patterns learned } \\
\text { through experience (programming), and that } \\
\text { these can be changed to achieve specific } \\
\text { goals in life. }\end{array}$ \\
\hline $\begin{array}{l}\text { prana } \\
\text { Essas práticas carregam um saber que leva } \\
\text { em conta o sistema energético do corpo - } \\
\text { chamado de qi pelos chineses, ki pelos } \\
\text { japoneses e prana pelos hindus (Lima, 2009). }\end{array}$ & $\begin{array}{l}\text { prana } \\
\text { The range of techniques is believed to } \\
\text { increase the body's vital energy (prana) } \\
\text { (Boddy, K. et al, 2008). }\end{array}$ \\
\hline $\begin{array}{l}\text { pulsologia } \\
\text { Pulsologia, ou diagnóstico pelo pulso do } \\
\text { paciente (Klein; Rodrigues, 2016). }\end{array}$ & $\begin{array}{l}\text { pulsology; pulse palpation; pulse diagnosis } \\
\text { Chinese Pulsology (Interpretation of pulse). }{ }^{94}\end{array}$ \\
\hline $\begin{array}{l}\text { quiropraxia; quiroprática } \\
\text { Quiropraxia: manipulação da coluna via }\end{array}$ & $\begin{array}{l}\text { chiropractic } \\
\text { Chiropractic is a forr }\end{array}$ \\
\hline
\end{tabular}

\footnotetext{
${ }^{92} \mathrm{http}: / /$ www.scielo.br/scielo.php?script=sci_arttext\&pid=S1413-81232015001003263, acesso em 24/09/2017.

${ }^{93} \mathrm{https} / / /$ en.wikipedia.org/wiki/Neuro-linguistic_programming, acesso em 24/09/2017.

${ }^{94} \mathrm{https}$ ://en.biomanantial.com/pulses-diagnosis-of-health-in-chinese-medicine-a-2404-en.html, acesso em 24/09/2017.
} 


\begin{abstract}
toques rápidos e precisos, obtendo-se, assim, não só a melhoria local, como dos mais variados distúrbios, em especial, os de caráter físico (SINTE, 2017).

Quiroprática (técnica que busca corrigir com as mãos problemas das articulações, dos músculos e, em especial, da coluna) (Manzini et al, 2008).

radiestesia
Termo oriundo do latim radius (radiação) e
do grego aisthesis (sensibilidade),
significando, literalmente, "sensibilidade às
radiações". Numa visão mais ampla, significa
a capacidade de se captar, através de
instrumentos ou não, a energia emanada de
todos os seres vivos e que, direta ou
indiretamente, influencia a nossa vida.
(Costeira, 2015).
\end{abstract}

\section{radiônica}

Radiônica - Ciência que estuda as radiações energéticas emanadas dos seres vivos e sua manipulação à distância para diagnóstico e terapêutica, através de aparelhagem específica e de um "testemunho" que identifique, energeticamente, a fonte emissora da energia (Costeira, 2015).

\section{reflexologia}

Reflexologia: É a ciência que lida com o princípio de que nos pés e nas mãos existem áreas de reflexos que correspondem a todos os órgãos, glândulas e partes do corpo (Tashiro et al, 2001).

\section{reflexoterapia}

Reflexoterapia é a técnica que promove a avaliação do cliente por meio da análise de uma zona corpórea reflexológica (exemplos mais comuns, os pés, as mãos e as orelhas), por via táctil e visual e/ou por aparatos eletrônicos específicos (SINTE, 2017).

\section{reiki; reike}

Terapia japonesa que se utiliza da transmissão da energia ki (universal e vital) by D. D. Palmer (1845-1913) that focuses on the relationship between the body's structure, primarily the spine, and function. Chiropractors frequently use vertebral manipulation (Boddy, K. et al, 2008).

\section{dowsing; radiesthesia}

Dowsing: traditionally used as a way to identify water sources underground. Is not itself a therapy but is used by a range of other disciplines to answer questions through intuitive skills. Often used in conjunction with Radionics (House of Lords, 2017).

\section{radionics}

Radionics: a type of instrument-assisted healing which attempts to detect disease before it has physically manifested itself. It is based on the belief that everyone is surrounded by an invisible energy field which the practitioner tunes into and then attempts to correct problems which have been identified (House of Lords, 2017).

\section{reflexology}

Reflexology is based on the principle that reflex points on the soles, tops, and sides of the feet correspond to different areas of the body (FHT, 2017).

\section{reflexotherapy}

Based on the science of Reflexology, Reflexotherapy is a drug-free, pain-free alternative and complementary method of treatment used to promote healing, relieve stress, tension, aches and pains. ${ }^{95}$

\section{reiki}

Those who practise reiki are said to draw upon universal healing energy, which is then

\footnotetext{
${ }^{95} \mathrm{http}: / / \mathrm{www} . v i t a l i t y l i n k . c o m / m o d a l i t y-R e f l e x o t h e r a p y-177$, acesso em 24/09/2017.
} 


\begin{tabular}{|c|c|}
\hline $\begin{array}{l}\text { com as palmas das mãos por intermédio da } \\
\text { consciência (Naiff, 2016). }\end{array}$ & $\begin{array}{l}\text { transferred to the client through visualisation } \\
\text { and by gently placing their hands on or just } \\
\text { above the body (FHT, 2017). }\end{array}$ \\
\hline $\begin{array}{l}\text { relaxamento } \\
\text { Relaxamento - Técnica corporal } \\
\text { desenvolvida com a finalidade de acalmar o } \\
\text { corpo e a mente quando impregnados de } \\
\text { estresse, tensão muscular e agitação mental, } \\
\text { incompatíveis com o bem-estar e a paz } \\
\text { necessários à vida dos seres humanos } \\
\text { (Costeira, 2015). }\end{array}$ & $\begin{array}{l}\text { relaxation } \\
\text { Relaxation therapy - Definition: Techniques } \\
\text { for eliciting the 'relaxation response' of the } \\
\text { autonomic nervous system (Boddy, K. et al, } \\
\text { 2008). }\end{array}$ \\
\hline $\begin{array}{l}\text { Rességuier, método } \\
\text { É um método terapêutico que busca } \\
\text { harmonizar o corpo sensível em busca da } \\
\text { restauração da fisiologia no diferentes } \\
\text { sistemas orgânicos. Consiste no } \\
\text { desenvolvimento de um estado de atenção no } \\
\text { fluxo interno-externo das sensações. } \\
\text { Dentre as atividades do Núcleo para os } \\
\text { recém-nascidos destacam-se a homeopatia, a } \\
\text { auriculoterapia, a shantala, os florais e o } \\
\text { método Rességuier (Hospital Sofia Feldman, } \\
\text { 2017). }\end{array}$ & $\begin{array}{l}\text { Rességuier, method } \\
\text { Rességuier Method (RM) is a MBT (Mind } \\
\text { Body Therapies) that aims to obtain patient } \\
\text { nonjudgmental awareness and control of } \\
\text { bodily perceptions, which is effective in } \\
\text { reducing physical and mental disorders in } \\
\text { many rheumatic diseases. }\end{array}$ \\
\hline $\begin{array}{l}\text { Rolfing } \\
\text { Rolfing: sistema de educação corporal e } \\
\text { manipulação física desenvolvido por Ida } \\
\text { Rolf, que visa a integração estrutural (SINTE, } \\
\text { 2017). }\end{array}$ & $\begin{array}{l}\text { Rolfing } \\
\text { Examples include chiropractic medicine, } \\
\text { osteopathic manipulative medicine, } \\
\text { movement therapy, massage, and other body } \\
\text { work, such as rolfing (a form of soft-tissue } \\
\text { manipulation) (Kramlich, 2014). }\end{array}$ \\
\hline $\begin{array}{l}\text { sei-tai } \\
\text { Sei-tai: técnica japonesa de manipulação } \\
\text { passiva da coluna vertebral e articulações em } \\
\text { geral, tem a sua origem há três séculos entre } \\
\text { os guerreiros samurais que após treinos e } \\
\text { batalhas, feridos e com membros deslocados, } \\
\text { precisavam ser socorridos (Costeira, 2015). }\end{array}$ & $\begin{array}{l}\text { Seitai } \\
\text { Seitai is a healing and therapeutic Japanese } \\
\text { massage and is literally translated from } \\
\text { Japanese as 'Bone Therapy' and so is very } \\
\text { effective for postural, neck and spinal } \\
\text { conditions through non-invasive massage } \\
\text { techniques without using direct manipulation } \\
\text { of the spine. }\end{array}$ \\
\hline
\end{tabular}

\footnotetext{
${ }^{96} \mathrm{http}: / / \mathrm{www} \cdot$ somostodosum.com.br/clube/eventos.asp?id=15010, acesso em 11/12/2017.

${ }^{97} \mathrm{https} / / / \mathrm{www}$.omicsonline.org/open-access/resseguier-method-reduces-neuromuscular-hyperexcitability-andclinimetricparameters-in-patients-with-fibromyalgia-syndrome-foa-1000108.php?aid=72437, acesso em $24 / 09 / 2017$

${ }^{98} \mathrm{http} / / / \mathrm{www}$. sakuralounge.com.au/Massage/Japanese-Seitai-Massage/0/60/service-product.aspx, $\quad$ acesso em $24 / 09 / 2017$.
} 


\begin{tabular}{|c|c|}
\hline $\begin{array}{l}\text { self healing, autocura } \\
\text { Autocura - self healing: Método terapêutico } \\
\text { criado por Meir Schneider que o define como } \\
\text { um sistema holístico de recuperação da saúde } \\
\text { que desenvolve a inteligência inata do corpo } \\
\text { (Costeira, 2015). }\end{array}$ & $\begin{array}{l}\text { self healing } \\
\text { The Self-Healing method is comprehensive } \\
\text { and integrated, combining movement } \\
\text { education, therapeutic massage, self-massage, } \\
\text { passive movement, gentle movement } \\
\text { exercises, breathing, visualization, and vision } \\
\text { training. } \\
\text { Create nutritious healing foods, receive Iris } \\
\text { Analysis, Self Healing program creation } \\
\text { (Purehealth School of Natural Medicine } \\
\text { International, 2017). }\end{array}$ \\
\hline $\begin{array}{l}\text { shantala; xantala } \\
\text { Shantala é a massagem milenar ayurvédica } \\
\text { indicada para os bebês desde a hora em que } \\
\text { nascem, feita pela própria mãe, trazida para o } \\
\text { Ocidente pelo obstetra francês Frédérick } \\
\text { Leboyer (Costeira, 2015). }\end{array}$ & $\begin{array}{l}\text { loving hands; baby massage } \\
\text { In loving hands shows us how, in the weeks } \\
\text { and months following the birth, we can use } \\
\text { the flowing rhythms of the traditional Indian } \\
\text { art of baby massage to communicate our love } \\
\text { and strength to our infants in a primal } \\
\text { language of touch and sensation. } 100 \\
\text { Prayer, baby massage, simple vitamins, } \\
\text { burning of aromatherapy oils, and over-the- } \\
\text { counter medicines such as cough or anti- } \\
\text { diarrhoeal preparations were discounted due } \\
\text { to the common frequency of use (McCann, } \\
\text { 2005). }\end{array}$ \\
\hline $\begin{array}{l}\text { shiatsu } \\
\text { O shiatsu consiste em pressionar } \\
\text { determinados pontos chamados tsubos que } \\
\text { formam linhas ou canais (meridianos) de } \\
\text { energia pelo corpo (método similar ao da } \\
\text { acupuntura) (Klein; Rodrigues, 2016). }\end{array}$ & $\begin{array}{l}\text { shiatsu } \\
\text { shiatsu, like acupuncture - only without the } \\
\text { 'needles' - it involves gently working specific } \\
\text { points on the body, with the aim of restoring } \\
\text { the flow and balance of energy and } \\
\text { promoting health and well-being (FHT, } \\
2017 \text { ). }\end{array}$ \\
\hline $\begin{array}{l}\text { somaterapia } \\
\text { Somaterapia, também conhecida como } \\
\text { SOMA, é uma terapia corporal e em grupo } \\
\text { criada pelo psiquiatra, escritor e terapeuta } \\
\text { Roberto Freire, com fundamento nas teorias } \\
\text { de Wilhelm Reich, no Gestaltismo e no } \\
\text { Anarquismo, no início da década de } 70 \text { do } \\
\text { século passado, em função da implantação do } \\
\text { regime militar ditatorial no Brasil (Costeira, } \\
\text { 2015). }\end{array}$ & $\begin{array}{l}\text { somatherapy } \\
\text { Somatherapy (or Soma) was created by the } \\
\text { Freire in the 1970s as a group therapy, based } \\
\text { on the research of the psychoanalyst Wilhelm } \\
\text { Reich. With the objective of freeing the } \\
\text { individual to be more creative, the exercises } \\
\text { in Soma work with the relationship between } \\
\text { the body and emotions. }\end{array}$ \\
\hline
\end{tabular}

\footnotetext{
${ }^{99} \mathrm{http}$ ://self-healing.org/, aceso em 12/12/2017.

${ }^{100} \mathrm{https} / / /$ www.amazon.com/Loving-Hands-Traditional-Indian-Massage/dp/0394404696/ref=pd_sim_14_2/1390277804-8325041?_encoding=UTF8\&psc=1\&refRID=RF1YTN5F1VSJP3J1CPZY, acesso em 09/09/2017. ${ }^{101}$ https://en.wikipedia.org/wiki/Roberto_Freire_(psychiatrist), acesso em 19/09/2017.
} 


\begin{tabular}{|c|c|}
\hline $\begin{array}{l}\text { tai chi chuan, tai-chi-chuan } \\
\text { Tai-chi-chuan é a arte marcial chinesa que } \\
\text { alia gestos suaves e respirações especiais à } \\
\text { filosofia oriental e, desse modo, promover o } \\
\text { bem-estar e a manutenção da saúde (SINTE, } \\
\text { 2017). }\end{array}$ & $\begin{array}{l}\text { tai chi } \\
\text { Rooted in ancient Chinese philosophy and } \\
\text { martial arts, Tai chi is a system of movements } \\
\text { and postures used to enhance mental and } \\
\text { physical health (Boddy, K. et al, 2008). }\end{array}$ \\
\hline $\begin{array}{l}\text { talassoterapia } \\
\text { Talassoterapia é a técnica de tratamento } \\
\text { através da aplicação do sal marinho, da água } \\
\text { do mar, dos minerais contidos no mar e de } \\
\text { recursos similares. Pode ser tanto externa } \\
\text { como interna (Klein; Rodrigues, 2016). }\end{array}$ & $\begin{array}{l}\text { thalassotherapy } \\
\text { Thalassotherapy (from the Greek word } \\
\text { thalassa, meaning "sea") is the medical use of } \\
\text { seawater as a form of therapy. It is based on } \\
\text { the systematic use of seawater, sea products, } \\
\text { and shore climate. } 102\end{array}$ \\
\hline $\begin{array}{l}\text { termalismo; termalismo social; (ver) } \\
\text { crenoterapia } \\
\text { O Termalismo compreende as diferentes } \\
\text { maneiras de utilização da água mineral e sua } \\
\text { aplicação em tratamentos de saúde (Brasil: } \\
\text { Ministério da Saúde, 2006). }\end{array}$ & $\begin{array}{l}\text { balneotherapy } \\
\text { Balneotherapy - In contrast to hydrotherapy, } \\
\text { which generally employs normal tap water, } \\
\text { balneotherapy is defined as baths using } \\
\text { thermal mineral waters of at least } 20^{\circ} \mathrm{C} \\
\text { temperature and a mineral content of at least } \\
1 \mathrm{~g} / \mathrm{L} \text { water from natural springs (Boddy, K. et } \\
\text { al, 2008). }\end{array}$ \\
\hline $\begin{array}{l}\text { tigelas tibetanas; tigelas cantantes } \\
\text { Tigelas Tibetanas: forma terapêutica da } \\
\text { utilização do som, cada vez mais usada no } \\
\text { Ocidente, principalmente nas Américas } \\
\text { (Costeira, 2015). }\end{array}$ & $\begin{array}{l}\text { singing bowls; Tibetan singing bowls } \\
\text { Sound therapists use sound specific pitches } \\
\text { with various equipment including 'singing } \\
\text { bowls' (FHT, 2017). }\end{array}$ \\
\hline $\begin{array}{l}\text { tintura(s) } \\
\text { Tintura - maceração especial que consiste em } \\
\text { plantas misturadas que ficam macerando, à } \\
\text { temperatura ambiente, ao abrigo da luz, } \\
\text { durante períodos variáveis (Almeida et al, } \\
\text { 2015). }\end{array}$ & $\begin{array}{l}\text { tincture(s) } \\
\text { The starting point for most homeopathic } \\
\text { medicines is the Mother Tincture, an } \\
\text { alcoholic extract of the original substance } \\
\text { which can be plant, mineral or zoological } \\
\text { (Thompson, 2010). }\end{array}$ \\
\hline $\begin{array}{l}\text { toque terapêutico } \\
\text { Embora o Toque Terapêutico represente uma } \\
\text { nova técnica no nosso atual sistema de } \\
\text { cuidados à saúde, ele se originou da prática } \\
\text { milenar da imposição de mãos, e consiste na } \\
\text { prática de harmonização do campo energético } \\
\text { humano (CEH) através do uso consciente das } \\
\text { mãos, com o intuito de restabelecer pessoas } \\
\text { enfermas (Gomes et al, 2008). }\end{array}$ & $\begin{array}{l}\text { therapeutic touch } \\
\text { The idea of therapeutic touch is to influence } \\
\text { an individual's vital energy field (Soundy et } \\
\text { al, 2015). }\end{array}$ \\
\hline
\end{tabular}

${ }^{102}$ https://en.wikipedia.org/wiki/Thalassotherapy, acesso em 19/09/2017. 


\begin{tabular}{|c|c|}
\hline $\begin{array}{l}\text { tui-na, tui-ná, tuina, tui na } \\
\text { A massagem Tui-Na teve sua origem na } \\
\text { China, sendo parte integrante da Medicina } \\
\text { Tradicional Chinesa-MTC (Costeira, 2015). } \\
\text { Tui-ná: massagem realizada por meio de } \\
\text { movimentos ritmados de sedação e } \\
\text { tonificação (pressão e beliscão) para propiciar } \\
\text { a união e o equilíbrio das energias yin e yang } \\
\text { (Brasil: Ministério da Saúde, 2006). }\end{array}$ & $\begin{array}{l}\text { tui-na, tui na } \\
\text { Traditional Chinese medicine (...)is used as } \\
\text { an umbrella term for approaches developed in } \\
\text { ancient China, e.g. acupuncture, herbal } \\
\text { medicines, tui-na (massage, pronounced /twi- } \\
\text { na/), tai chi (pronounced /tie-chee/), diet } \\
\text { (Boddy, K. et al, 2008). }\end{array}$ \\
\hline $\begin{array}{l}\text { urinoterapia } \\
\text { Urinoterapia: técnica terapêutica que consiste } \\
\text { na ingestão da própria urina, ou em sua } \\
\text { aplicação na pele por meio de compressas, } \\
\text { fricção ou banhos de imersão (Costeira, } \\
\text { 2015). }\end{array}$ & $\begin{array}{l}\text { urine therapy } \\
\text { In alternative medicine, the term urine } \\
\text { therapy or urotherapy refers to various } \\
\text { applications of human urine for medicinal or } \\
\text { cosmetic purposes, including drinking of } \\
\text { one's own urine and massaging one's skin, or } \\
\text { gums, with one's own urine. } 103 \\
\text { Complementary treatment approaches include } \\
\text { herbal medicine and urine therapy (Boddy, K. } \\
\text { et al, 2008). }\end{array}$ \\
\hline $\begin{array}{l}\text { vegetoterapia } \\
\text { Vegetoterapia carátero-analítica é uma } \\
\text { técnica de psicoterapia criada pelo psiquiatra } \\
\text { Wilhelm Reich, em 1935, conhecida como a } \\
\text { proposta corporal primária que originou } \\
\text { outras abordagens corporais de terapia hoje } \\
\text { existentes (Costeira, 2015). }\end{array}$ & $\begin{array}{l}\text { vegetotherapy } \\
\text { Vegetotherapy is a form of Reichian } \\
\text { psychotherapy that involves the physical } \\
\text { manifestations of emotions. } 104\end{array}$ \\
\hline $\begin{array}{l}\text { ventosas; ventosaterapia } \\
\text { Aplicação de ventosas consiste em aplicar } \\
\text { recipiente de vidro ou plástico, onde se gera } \\
\text { vácuo, com a finalidade de estimular zonas } \\
\text { neurorreativas (pontos de acupuntura) (Brasil: } \\
\text { Ministério da Saúde, 2006). } \\
\text { Ventosaterapia: a terapia consiste } \\
\text { basicamente na colocação de uma campânula } \\
\text { de vidro ou outras formas de inspiradores } \\
\text { semelhantes aos copos de ventosas sobre a } \\
\text { pele, após produzir vácuo pela queima do ar } \\
\text { em seu interior, gerando uma sucção no local } \\
\text { (Costeira, 2015). }\end{array}$ & $\begin{array}{l}\text { cupping therapy; Chinese cupping } \\
\text { Cupping therapy (to create local suction on } \\
\text { the skin).University College London } \\
\text { Hospitals NHS Foundation Trust (2017). } \\
\text { Chinese cupping is a traditional Chinese } \\
\text { medicine technique where the therapists } \\
\text { places warm glass, metal, wood or bamboo } \\
\text { cups in an up-turned position on specific } \\
\text { acupoints (FHT, 2017). }\end{array}$ \\
\hline
\end{tabular}

\footnotetext{
${ }^{103} \mathrm{https}$ ://en.wikipedia.org/wiki/Urine_therapy, acesso em 24/09/2017.

${ }^{104}$ https://en.wikipedia.org/wiki/Vegetotherapy, acesso em 19/09/2017.
} 


\begin{tabular}{|c|c|}
\hline $\begin{array}{l}\text { vibracional, medicina; terapias, } \\
\text { vibracionais } \\
\text { A partir desse momento, em que se entende a } \\
\text { matéria como uma manifestação da energia, } \\
\text { nasce a Medicina Vibracional em que os } \\
\text { médicos se preocupam, principalmente, com } \\
\text { a energia existente no ser humano e em todas } \\
\text { as formas de vida. Costeira (2015). }\end{array}$ & $\begin{array}{l}\text { vibrational medicine; vibrational therapies } \\
\text { The work of vibrational medicine pioneers, } \\
\text { Samuel Hahnemann and Edward Bach, are } \\
\text { considered in light of both current research } \\
\text { and ancient understanding of the energetics of } \\
\text { health, disease and the healing properties of } \\
\text { plants (School of Natural Medicine UK, } \\
\text { 2017). }\end{array}$ \\
\hline $\begin{array}{l}\text { xamanismo } \\
\text { No Brasil, para as diversas etnias indígenas, o } \\
\text { Xamanismo se apresenta através da } \\
\text { Pajelança, cujo termo advém do tupi pajé, } \\
\text { com o mesmo significado de curador e de } \\
\text { xamã (Costeira, 2015). }\end{array}$ & $\begin{array}{l}\text { shamanism } \\
\text { Shamanism is a practice that involves a } \\
\text { practitioner reaching altered states of } \\
\text { consciousness in order to perceive and } \\
\text { interact with a spirit world and channel these } \\
\text { transcendental energies into this world. }{ }^{105}\end{array}$ \\
\hline $\begin{array}{l}\text { yoga, ioga } \\
\text { Ioga é um sistema filosófico-prático que } \\
\text { conta com metodologias para a unificação } \\
\text { dos diferentes elementos do psiquismo } \\
\text { humano. Em todas as técnicas deste sistema o } \\
\text { praticante busca eliminar sua agitação e ter } \\
\text { um domínio harmônico de si mesmo (Silva; } \\
\text { Lage, 2006). }\end{array}$ & $\begin{array}{l}\text { yoga } \\
\text { Yoga is a series of poses and breathing } \\
\text { exercises to work the body and relax the mind } \\
\text { (FHT, 2017). }\end{array}$ \\
\hline
\end{tabular}

Quadro 5 - Glossário português/inglês de PIC

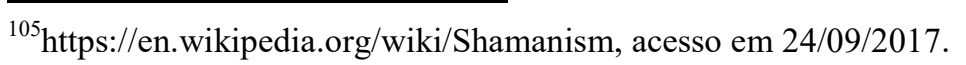




\subsubsection{Glossário inglês/português de PIC}

\begin{tabular}{|c|c|}
\hline acupuncture & acupuntura \\
\hline Ayurveda; ayurvedic medicine & Ayurveda; aiurvédica, medicina \\
\hline alchemy & alquimia \\
\hline Alexsander technique & Alexander, técnica de \\
\hline anthoposophical medicine; Anthroposophy & antroposófica, medicina; Antroposofia \\
\hline apitherapy; bee therapy & apiterapia \\
\hline aromatherapy & aromaterapia \\
\hline art therapy & arteterapia \\
\hline aura & aura \\
\hline Aura-soma & Aura-soma \\
\hline autohemotherapy; self-blood therapy & auto-hemoterapia \\
\hline balneotherapy & crenoterapia; (ver) termalismo \\
\hline balneotherapy & $\begin{array}{llll}\text { termalismo; } & \text { termalismo } & \text { social; } & \text { (ver) } \\
\text { crenoterapia }\end{array}$ \\
\hline bamboo therapy & bambuterapia \\
\hline biodanza & biodanza; biodança \\
\hline biodynamics & biodinâmica \\
\hline bioenergetic analysis & bioenergética \\
\hline biofeedback & biofeedback \\
\hline BodyTalk & body talk \\
\hline calatonia & calatonia \\
\hline $\begin{array}{l}\text { CAM; complementary and alternative } \\
\text { medicine }\end{array}$ & $\begin{array}{lll}\begin{array}{l}\text { MCA; medicina complementar } \\
\text { alternativa }\end{array} & \text { e } \\
\end{array}$ \\
\hline chakra(s) & chacra(s), chakra(s) \\
\hline chiropractic & quiropraxia; quiroprática \\
\hline $\begin{array}{l}\text { CIP, Complementary and Integrative } \\
\text { Practices }\end{array}$ & \begin{tabular}{|lll} 
PIC; $\quad$ Práticas & Integrativas & $\mathrm{e}$ \\
Complementares & & \\
\end{tabular} \\
\hline clay therapy; mud therapy & argiloterapia \\
\hline colon hydrotherapy; colon cleansing & colonterapia \\
\hline colour therapy; chromotherapy & cromoterapia \\
\hline craniosacral therapy & craniossacral, terapia \\
\hline crystal therapy & cristaloterapia \\
\hline cupping therapy; Chinese cupping & ventosas; ventosaterapia \\
\hline dance/movement therapy & dançaterapia; dança-movimento terapia \\
\hline diet therapy & dietoterapia \\
\hline do-in & do-in \\
\hline dowsing, radiesthesia & radiestesia \\
\hline equine therapy & equoterapia \\
\hline essential oil(s) & óleos essenciais; óleo essencial \\
\hline eutony & eutonia \\
\hline family constellation(s) & constelação familiar \\
\hline
\end{tabular}




\begin{tabular}{|c|c|}
\hline fasciatherapy & fasciaterapia \\
\hline Feldenkrais & Feldenkrais \\
\hline flower essences, flower remedies & $\begin{array}{l}\text { florais; essências florais; terapia floral; } \\
\text { sistemas florais; floralterapia }\end{array}$ \\
\hline geothermal therapy; clay therapy & geoterapia \\
\hline helio therapy; sunbathing & helioterapia \\
\hline herbal medicine, herbalism & fitoterapia, fitoterápicos \\
\hline herbs; medicinal plants & plantas medicinais \\
\hline hirudotherapy & hirudoterapia \\
\hline holistic medicine; holism & holística, medicina; holismo \\
\hline homeopathy; homeopathic medicine & homeopatia; medicina homeopática \\
\hline hydrotherapy & hidroterapia \\
\hline hypnotherapy & hipnose; hipnoterapia \\
\hline imagery & imagem guiada; imaginação guiada \\
\hline integrative medicine & medicina integrativa \\
\hline iridology & iridologia \\
\hline iris diagnosis; iris analysis & irisdiagnose \\
\hline Johrei & Johrei \\
\hline kinesionlogy & cinesiologia \\
\hline Lian gong & Lian gong \\
\hline loving hands; baby massage & shantala; xantala \\
\hline macrobiotic diet & macrobiótica, dieta \\
\hline magnet therapy & magnetoterapia \\
\hline mantras & mantra(s) \\
\hline massage & massagem \\
\hline massage therapy & massoterapia \\
\hline meditation & meditação \\
\hline meridian(s) & meridiano(s) \\
\hline mindfulness & mindfulness \\
\hline moxibustion & moxabustão; moxa; moxibustão \\
\hline music therapy & musicoterapia \\
\hline naturopathy & naturologia; (ver) naturopatia \\
\hline naturopathy & naturopatia \\
\hline needle(s) & agulha(s) \\
\hline NLP, neuro-linguistic programming & PNL, programação neurolinguística \\
\hline oligoelements; oligotherapy & oligoelementos; oligoterapia \\
\hline orthomolecular medicine & ortomolecular, medicina \\
\hline osteopathy & osteopatia \\
\hline ozone therapy & ozonioterapia \\
\hline Pathwork & Pathwork \\
\hline pendulum & pêndulo(s) \\
\hline prana & prana \\
\hline
\end{tabular}




\begin{tabular}{|l|l|} 
pranic healing & cura prânica \\
\hline pulsology; pulse palpation; pulse diagnosis & pulsologia \\
\hline qi; ki; chi & chi; ki \\
\hline Qigong; Qi Gung & chi kung; chi gong; qi gong \\
\hline radionics & radiônica \\
\hline reflexology & reflexologia \\
\hline reflexotherapy & reflexoterapia \\
\hline reiki & reiki; reike \\
\hline relaxation & relaxamento \\
\hline Rességuier, method & Rességuier, método \\
\hline Rolfing & Rolfing \\
\hline seitai & sei-tai \\
\hline self healing & self healing; autocura \\
\hline shamanism & xamanismo \\
\hline shiatsu & shiatsu \\
\hline singing bowls; Tibetan singing bowls & tigelas tibetanas; tigelas cantantes \\
\hline singing therapy & cantoterapia \\
\hline somatherapy & somaterapia \\
\hline spiritual healing & cura espiritual \\
\hline tai chi & tai chi chuan, tai-chi-chuan \\
\hline thalassotherapy & talassoterapia \\
\hline therapeutic touch & toque terapêutico \\
\hline tinctures & tintura(s) \\
\hline traditional Chinese medicine; Chinese \\
medicine & $\begin{array}{l}\text { medicina tradicional chinesa; medicina } \\
\text { chinesa, }\end{array}$ \\
\hline traditional medicine & medicina tradicional \\
\hline tui-na; tui na & tui-na; tui-ná; tuina; tui na \\
\hline urine therapy & urinoterapia \\
\hline vegetotherapy & vegetoterapia \\
\hline vibrational medicine; vibrational therapies & $\begin{array}{l}\text { vibracional, medicina; } \\
\text { terapias }\end{array}$ \\
\hline yoga & yoga; ioga \\
\hline Qubracionais, \\
\hline
\end{tabular}

Quadro 6 - Glossário inglês/português de Práticas Integrativas e Complementares 


\subsection{O glossário bilíngue de plantas utilizadas nos florais brasileiros baseados na alquimia}

$\mathrm{Na}$ microestrutura deste glossário, apresentamos em negrito o nome da planta em português da forma como é designado pelo sistema floral, e não outras variantes possíveis em língua portuguesa. Em seguida oferecemos os equivalentes em língua inglesa, do mais frequente para o menos frequente, limitados a quatro variantes.

Disponibilizamos o nome científico (nomenclatura binária em latim) trazido pelo corpus, exceto ressalvas descritas anteriormente, nas quais percebemos, por meio de ampla pesquisa, a necessidade de atualização de alguns nomes científicos por especialista em botânica, para não haver dúvida quanto às espécies realmente utilizadas.

Por fim, ilustramos o glossário com imagens disponíveis no Google, com direitos de uso "marcadas para reutilização", para tornar mais clara a identificação das espécies abordadas, ${ }^{106}$ com exceção para “jasmim”, para a qual foi utilizada imagem própria.

Após a apresentação deste glossário, disponibilizamos uma lista em ordem alfabética na direção inglês/português, para facilitar a busca do leitor anglófono.

\footnotetext{
${ }^{106}$ Em 28 de maio de 2016, realizei uma visita ao Jardim Botânico do Rio de Janeiro/RJ, onde há exemplares da maioria das plantas citadas no glossário com indicação da nomenclatura botânica, para conhecer as espécies visualmente e me certificar das correspondências nome-planta in natura.
} 
5.2.1 Glossário ilustrado de plantas utilizadas nos florais brasileiros

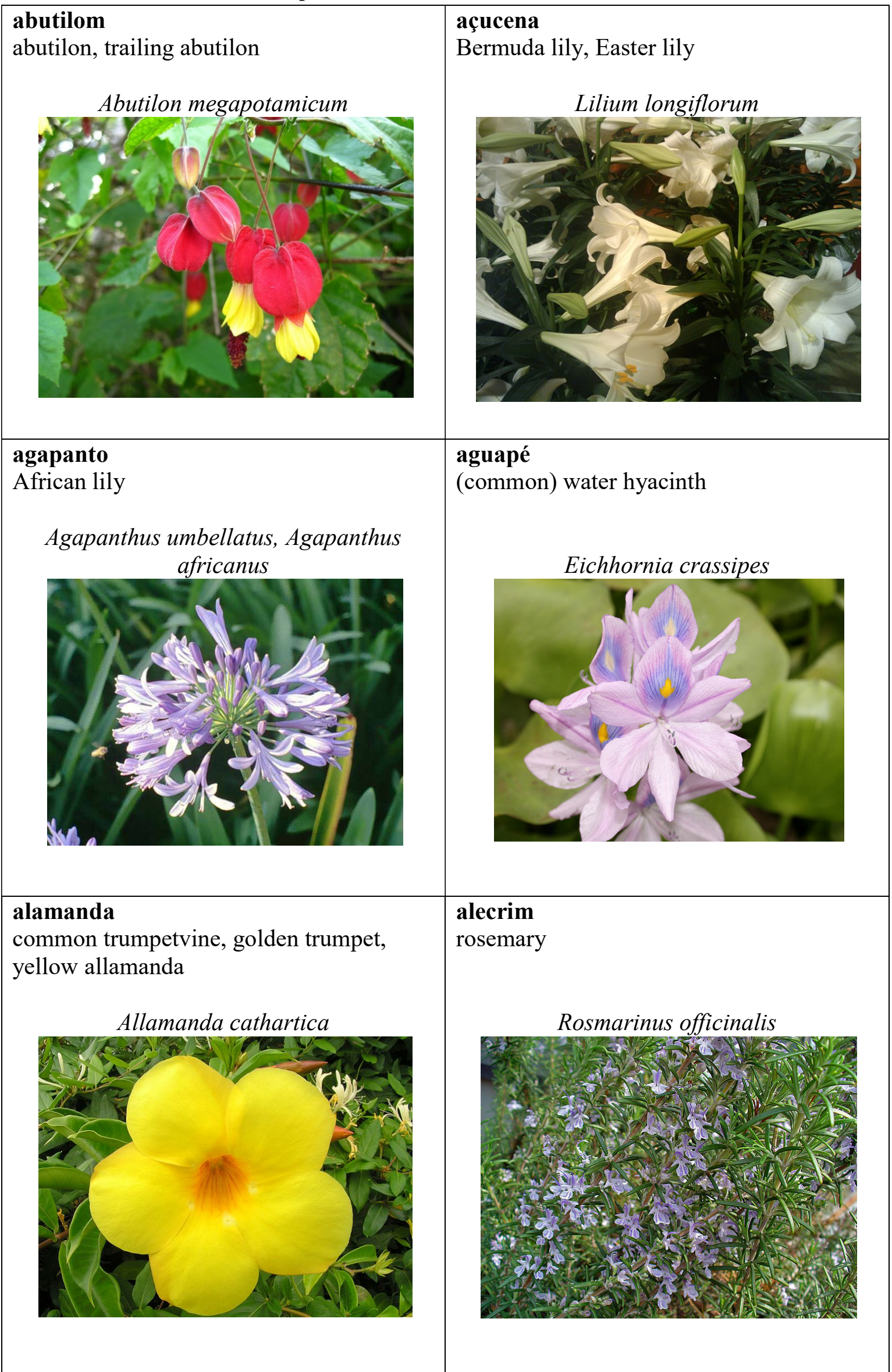




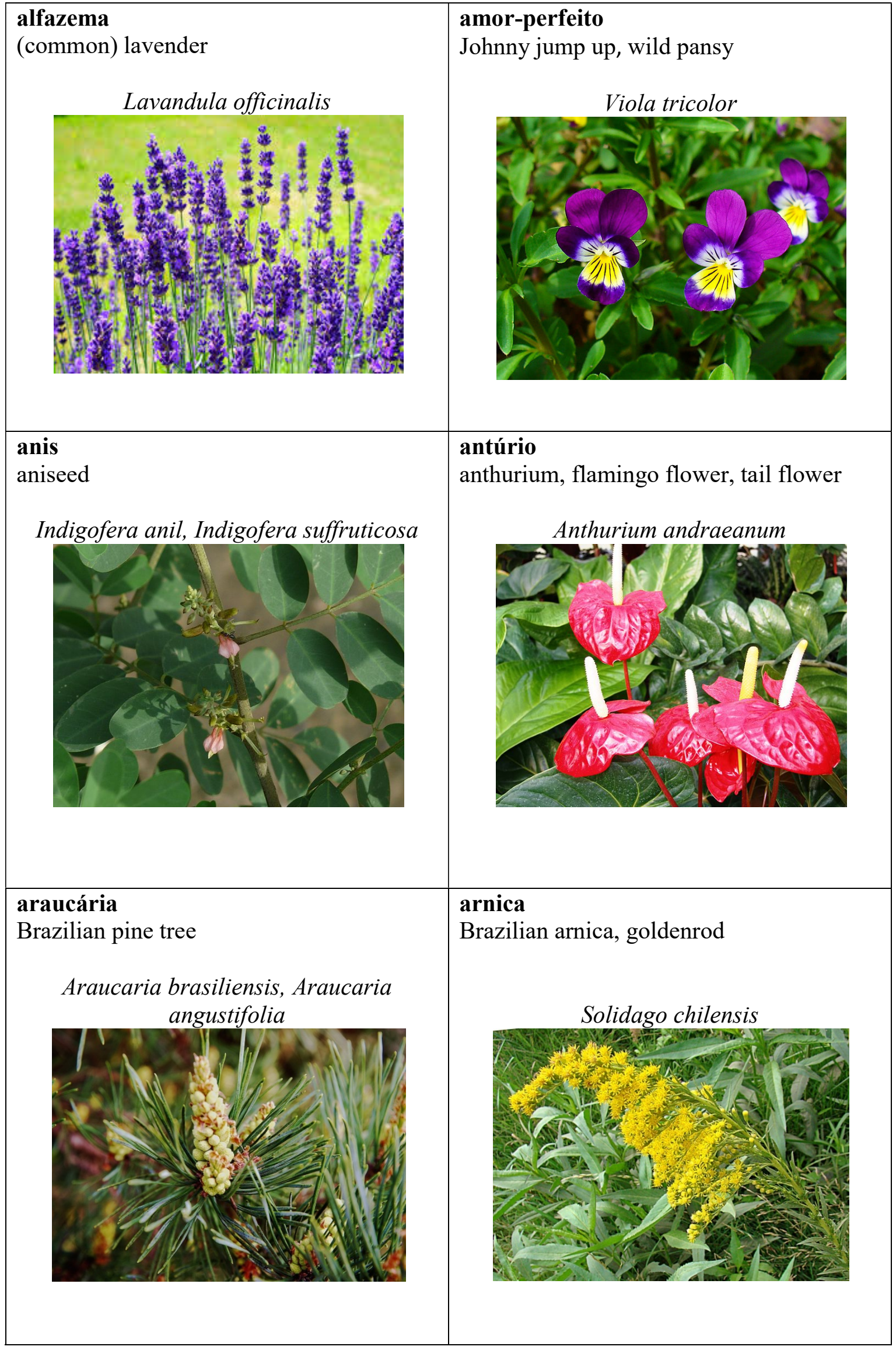




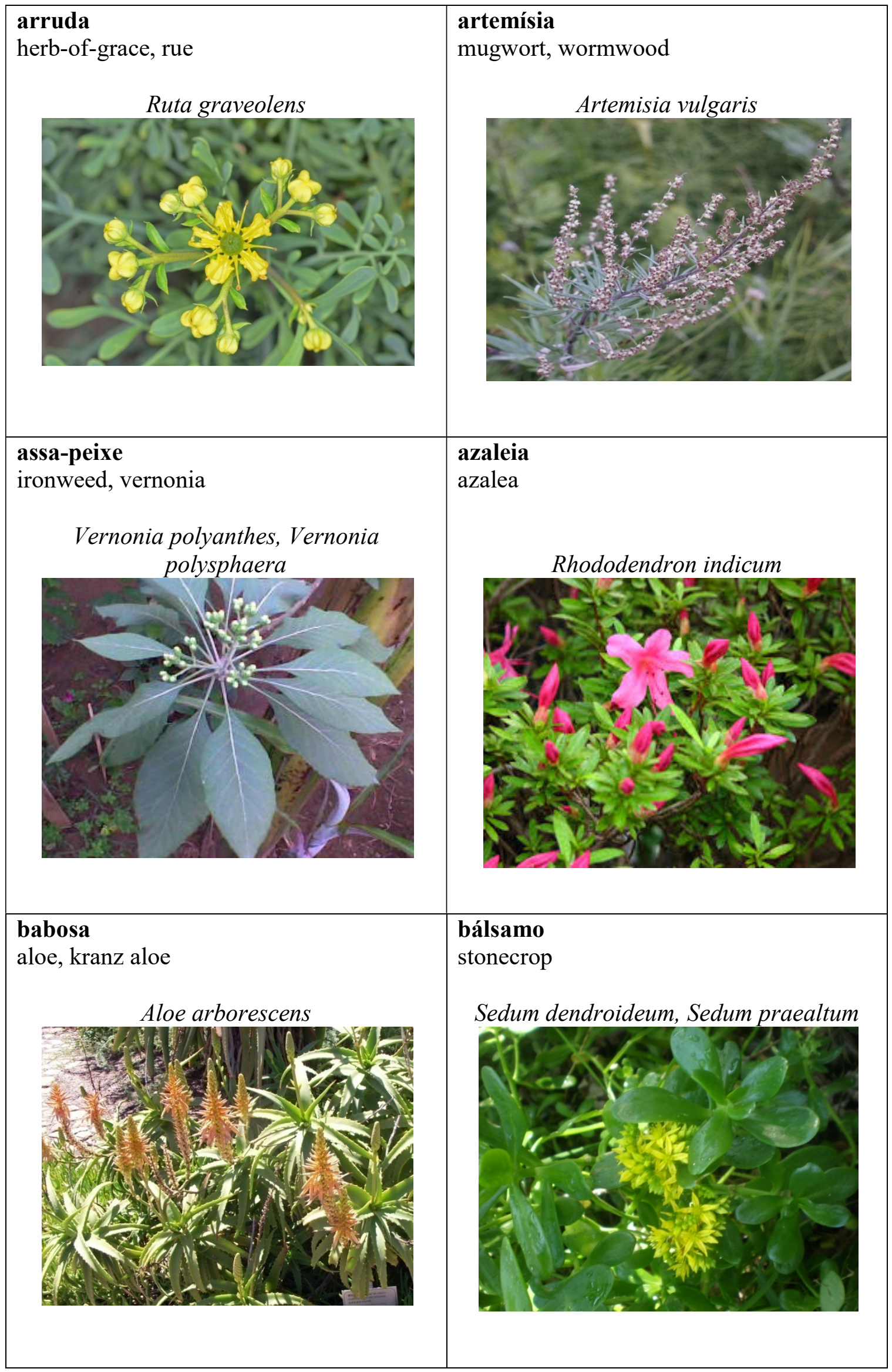




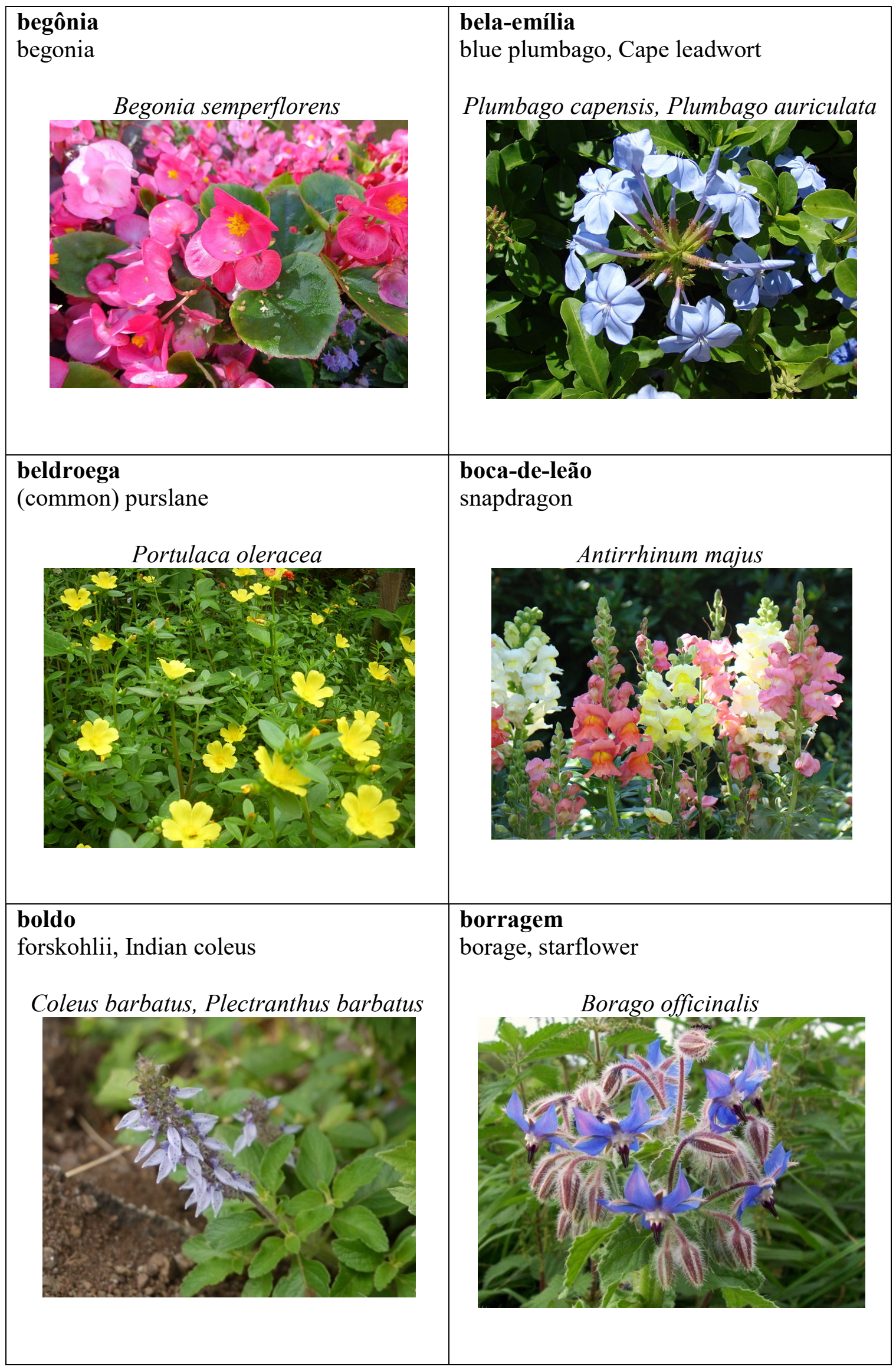




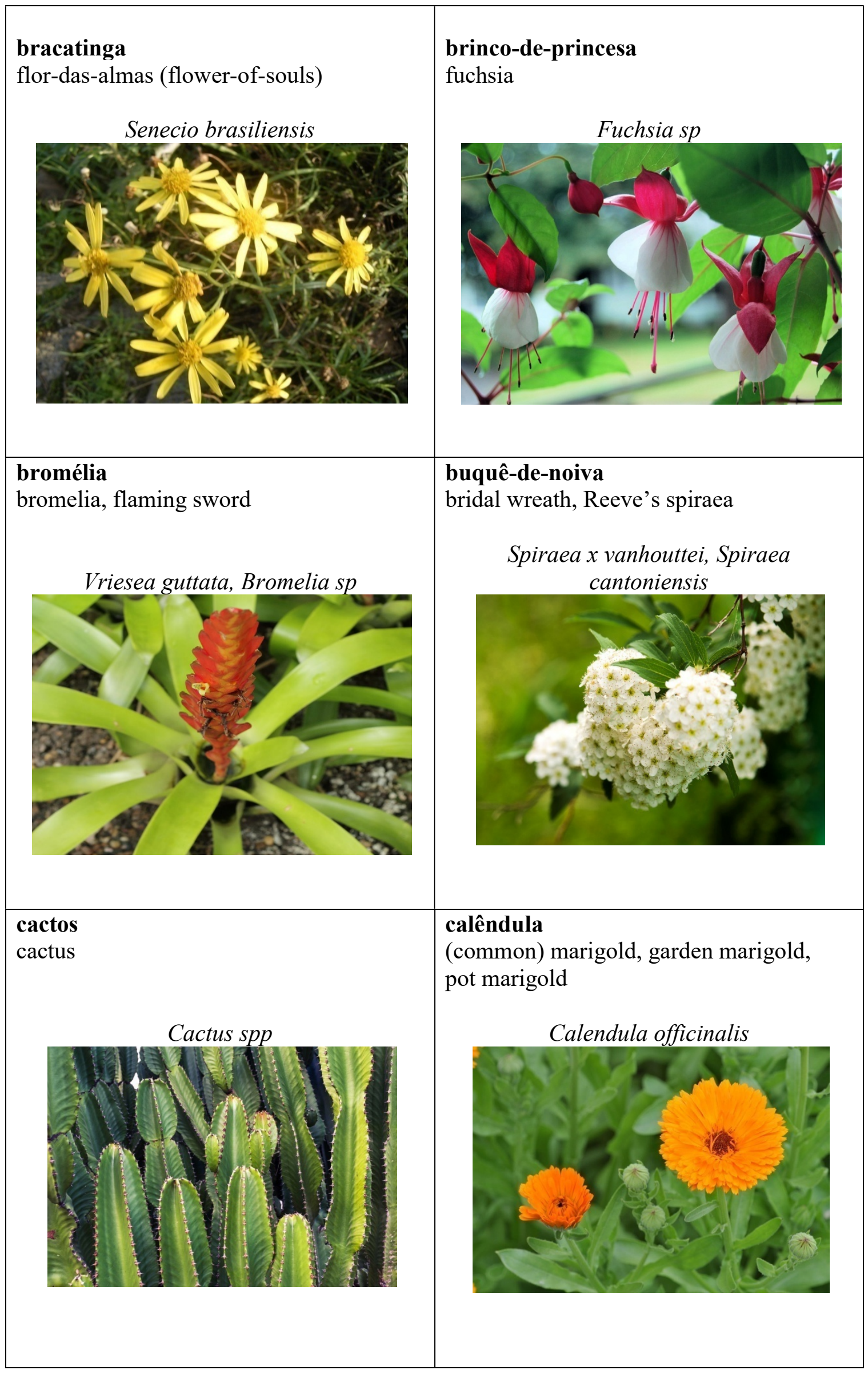




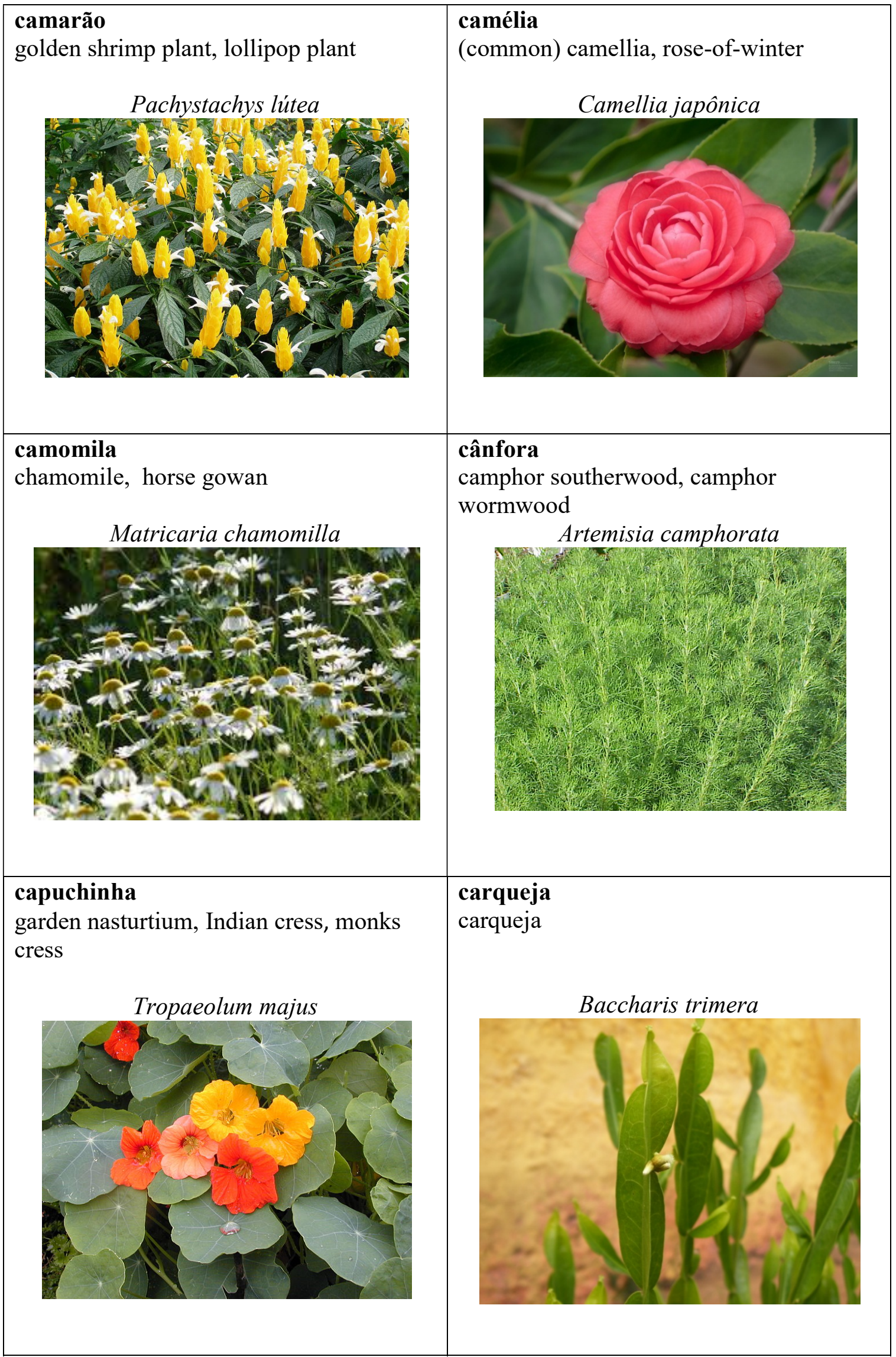




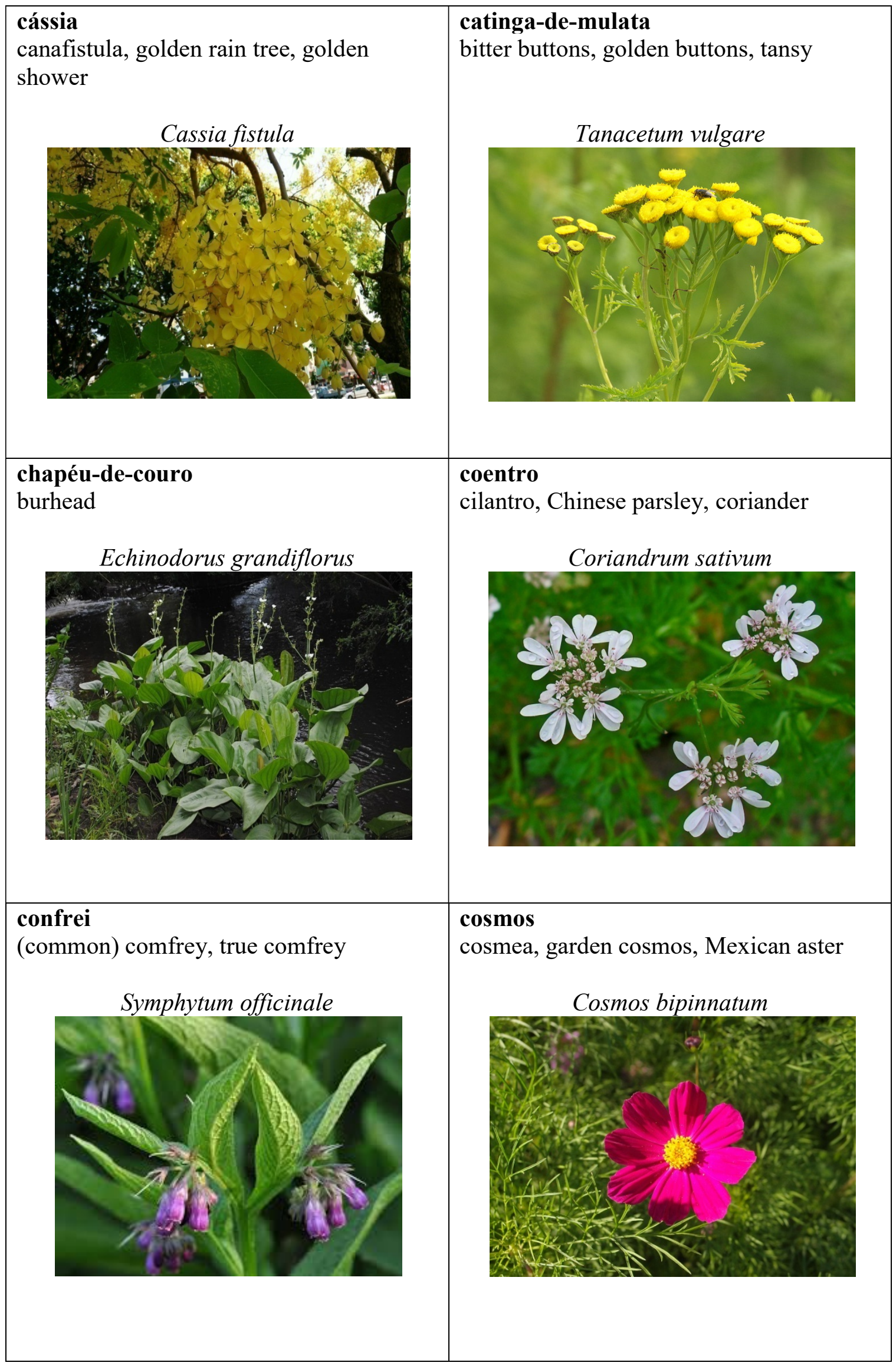




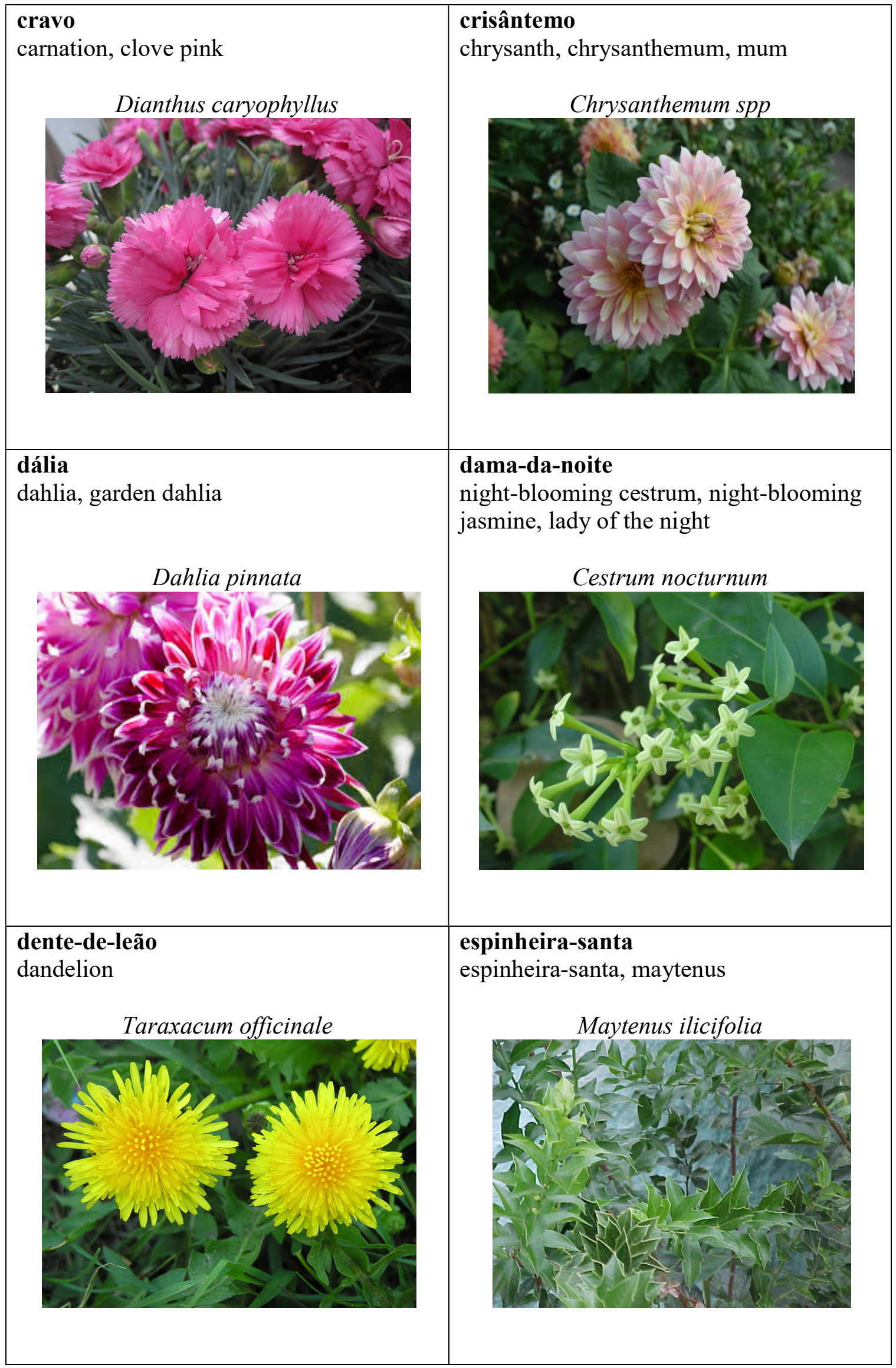




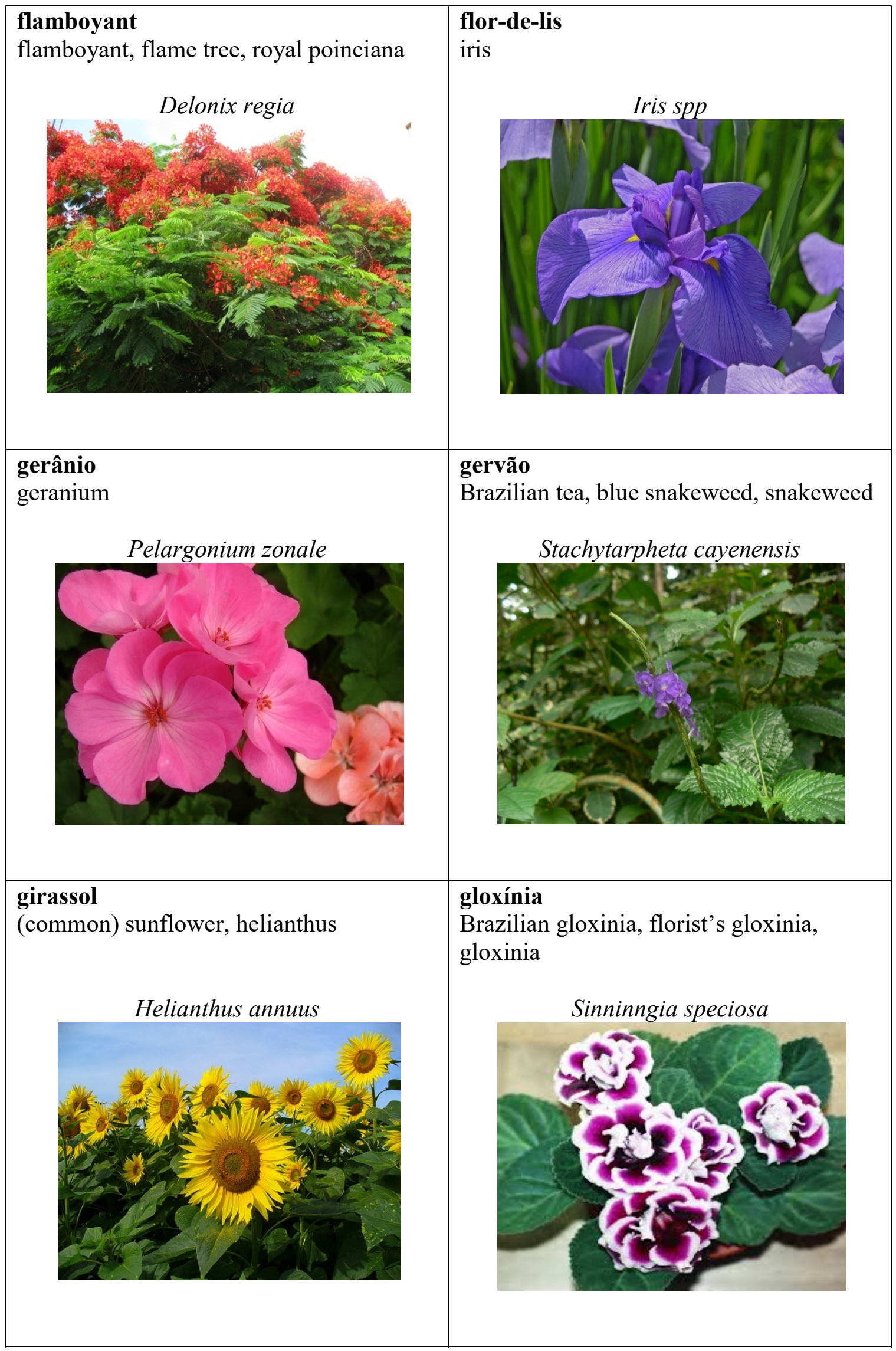




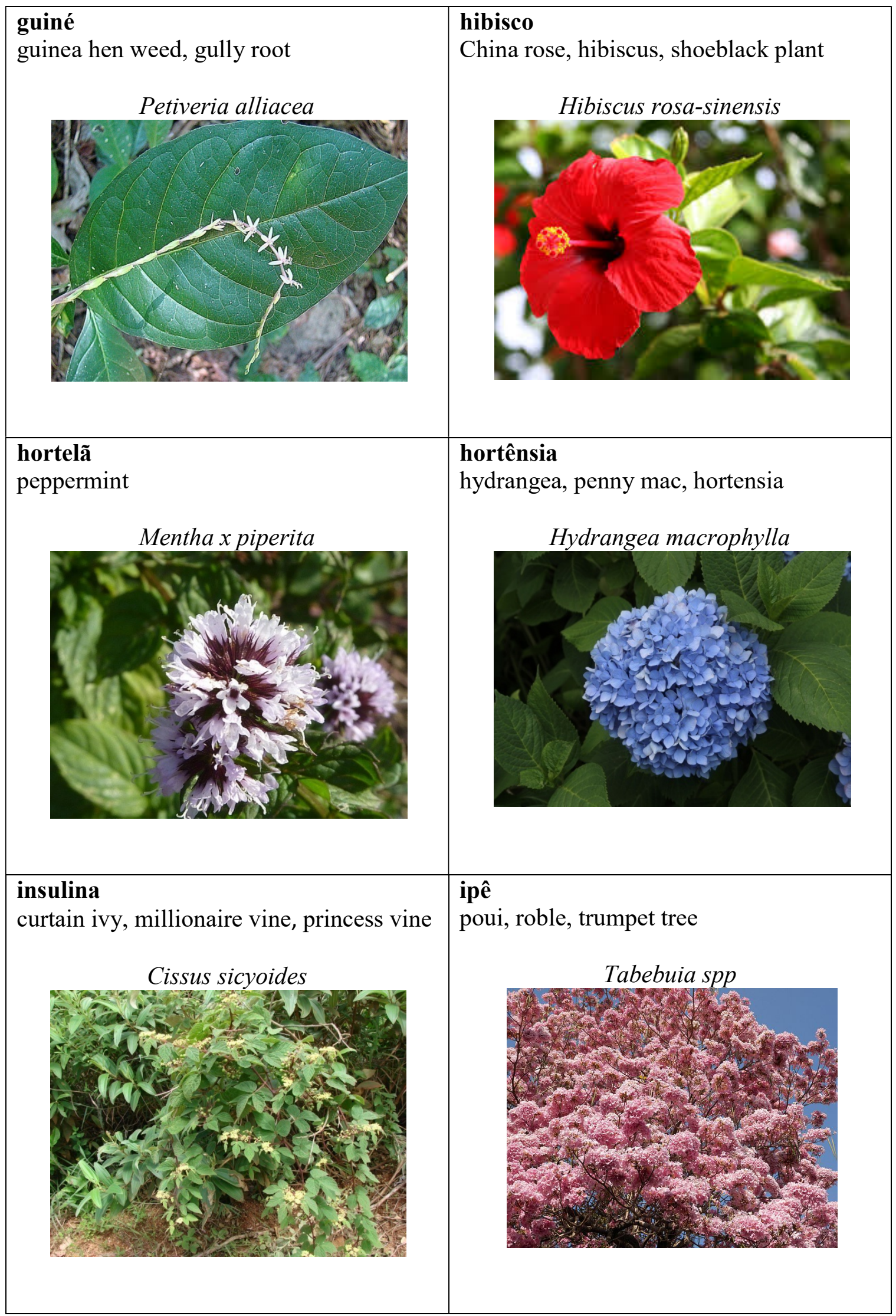




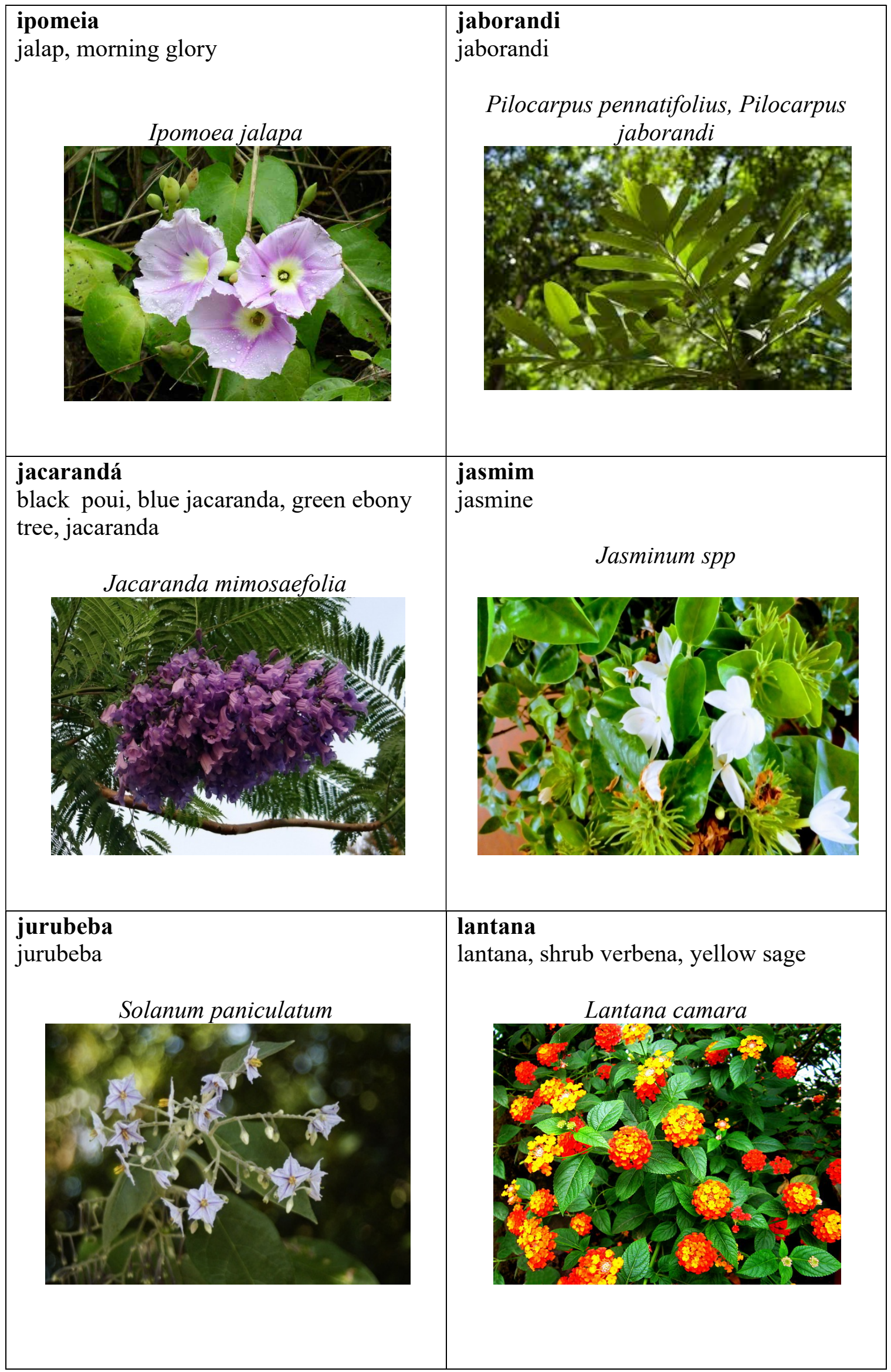




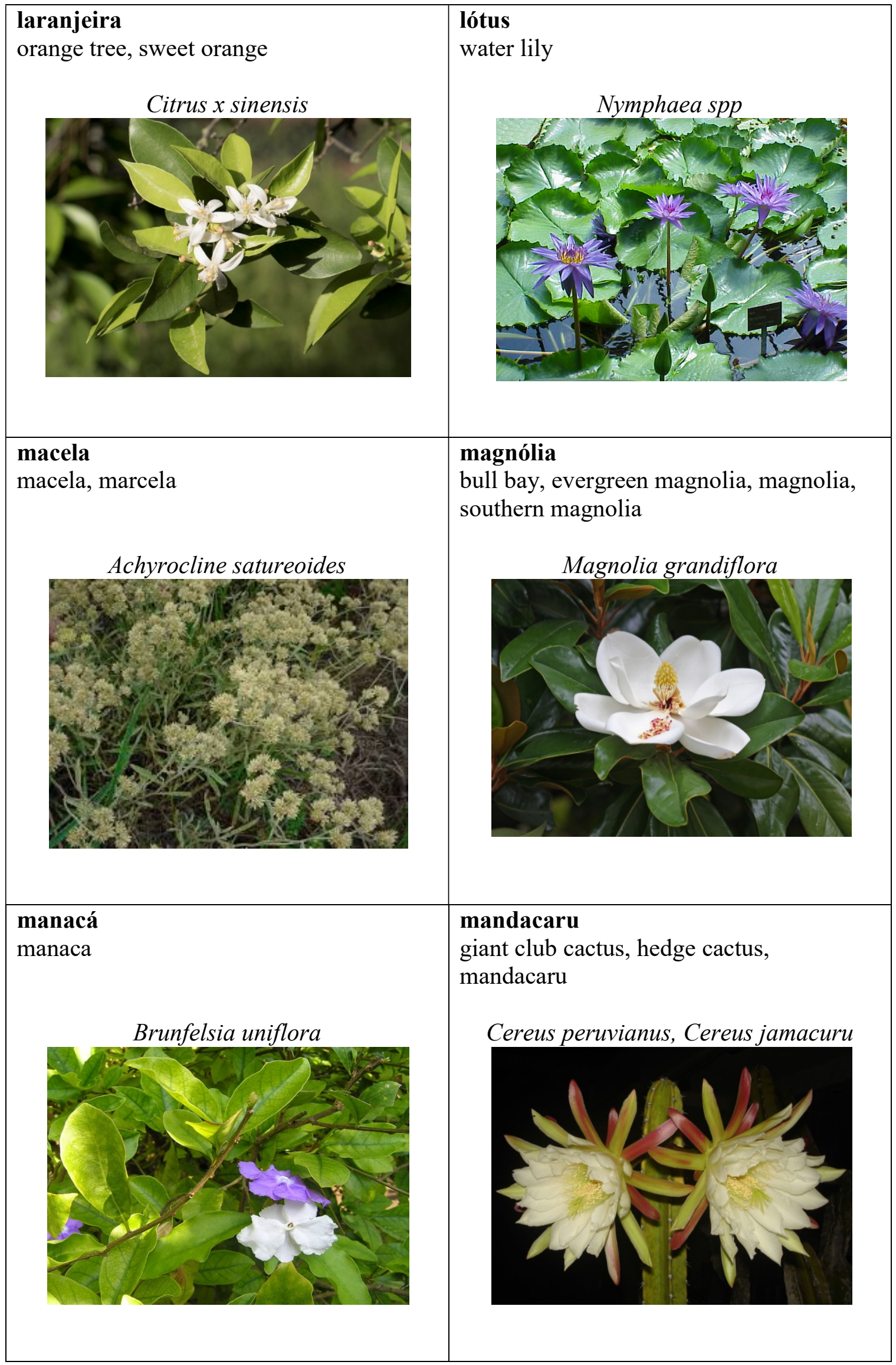




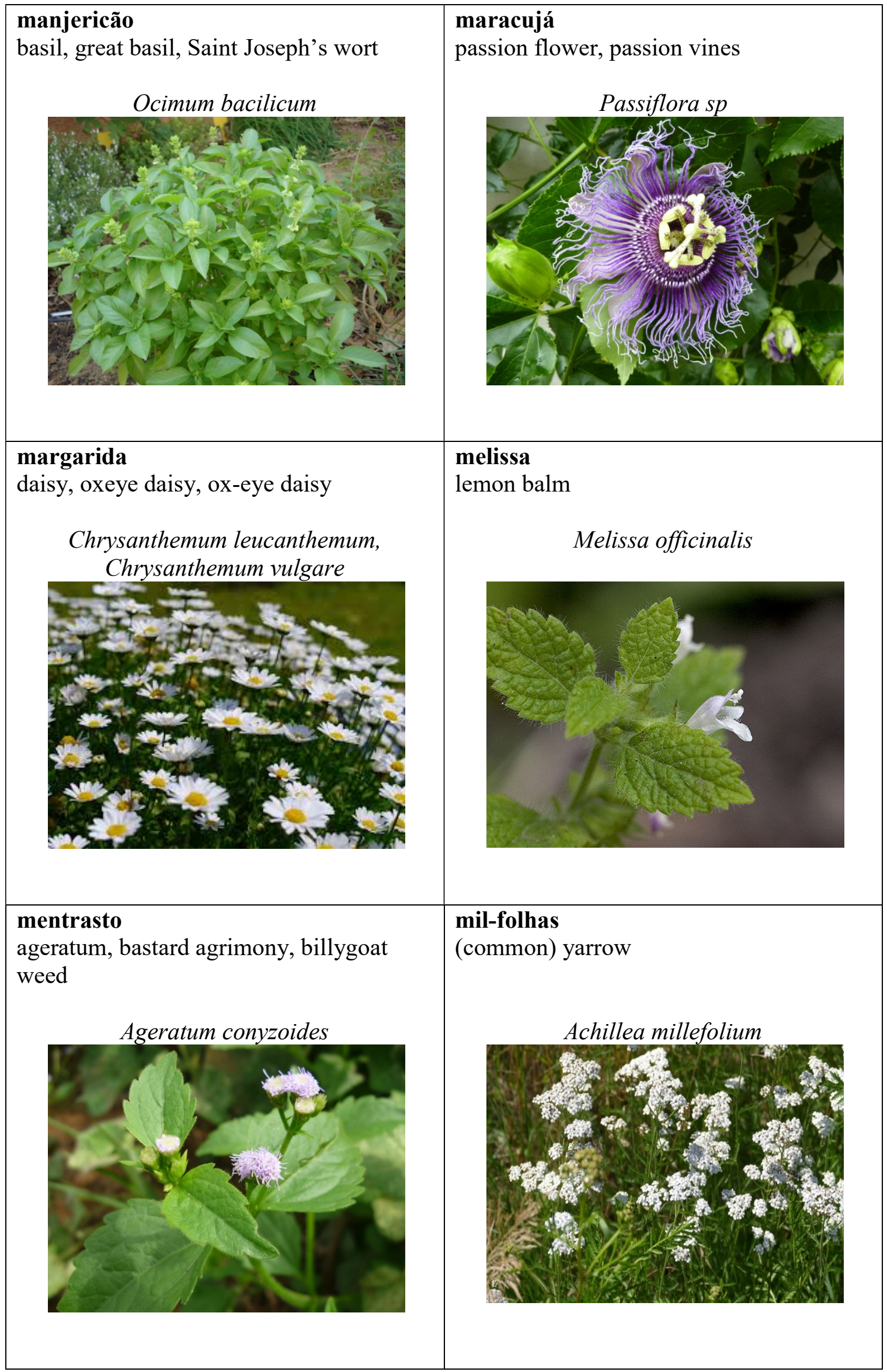




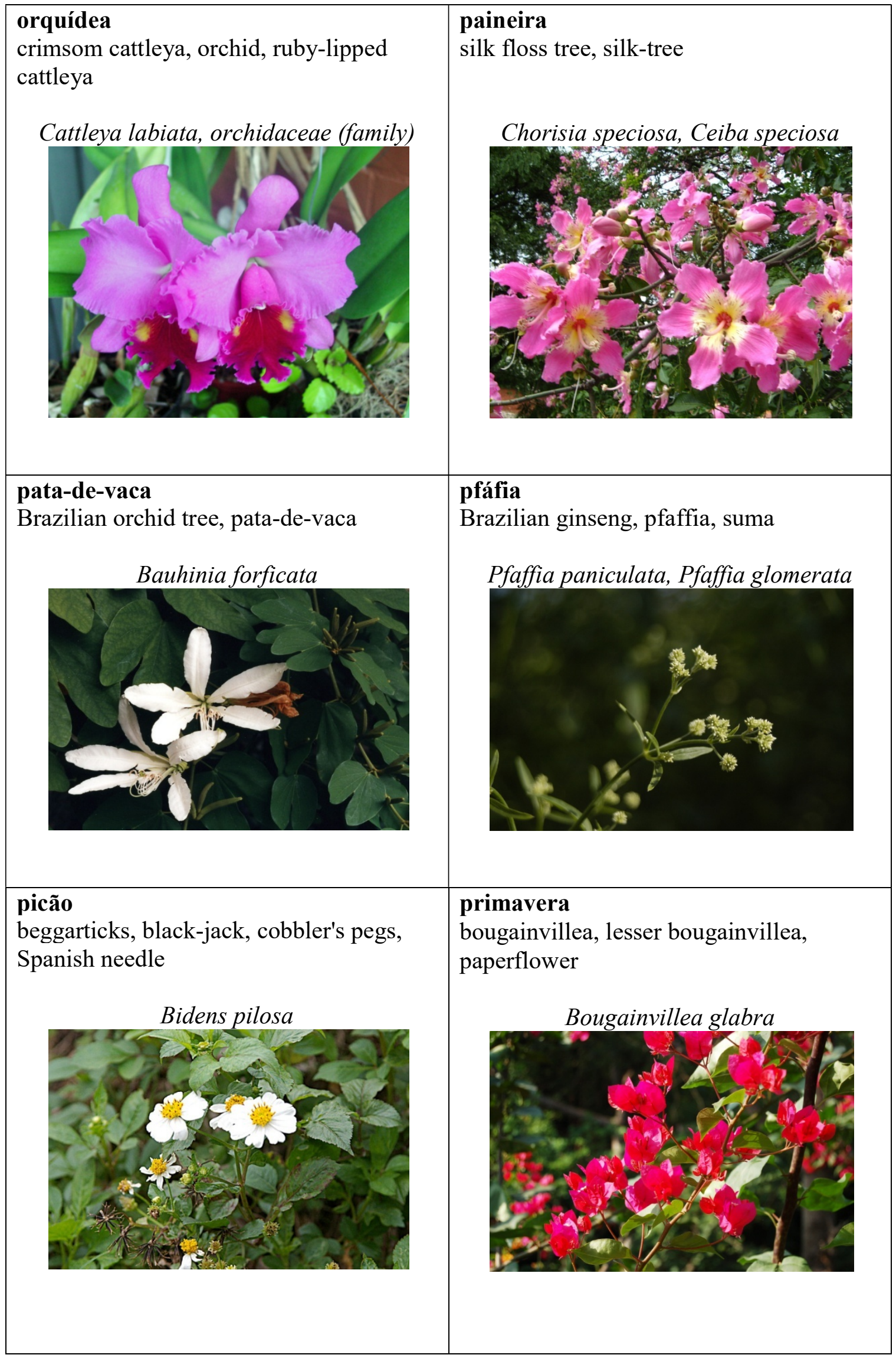




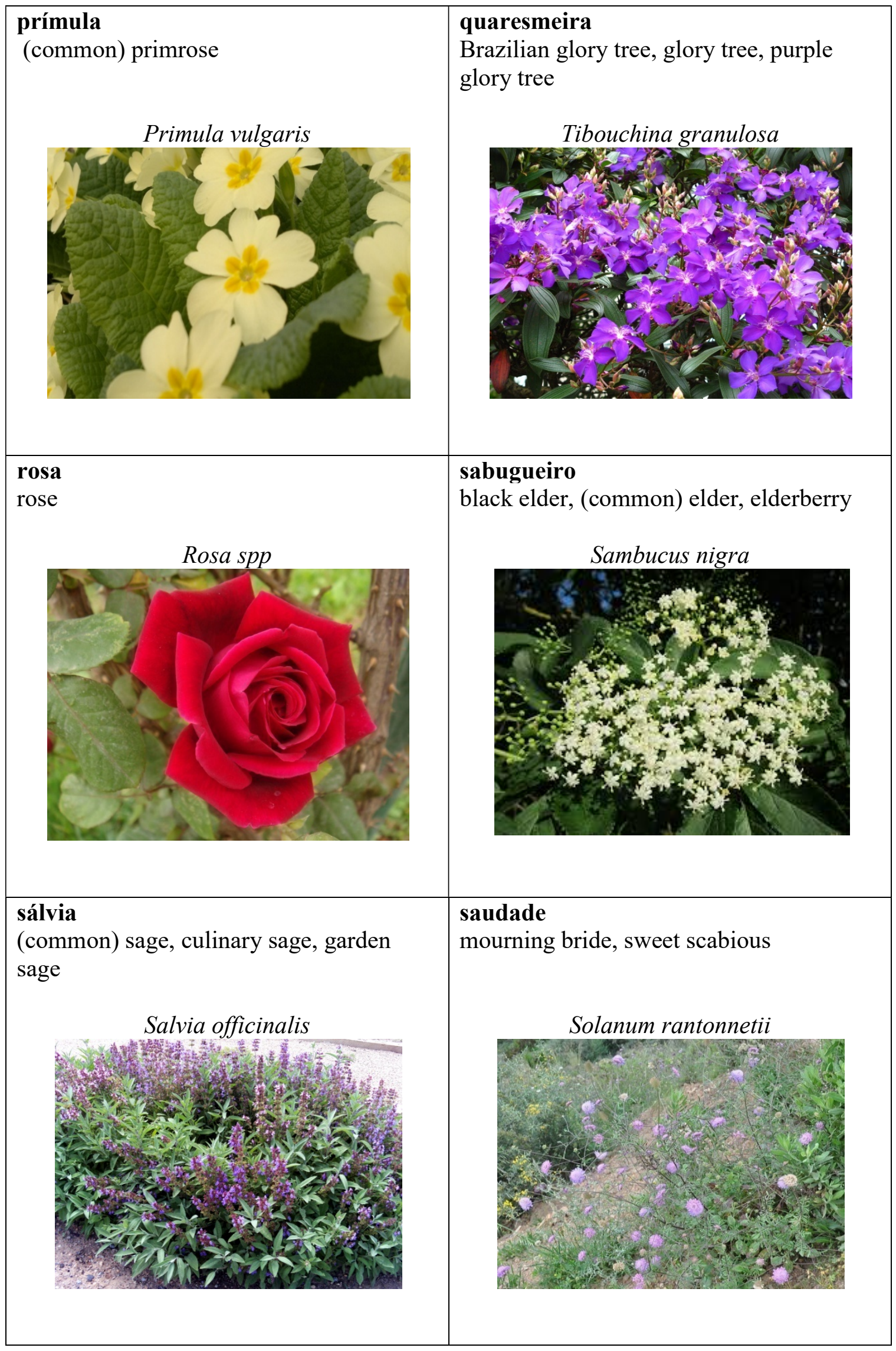




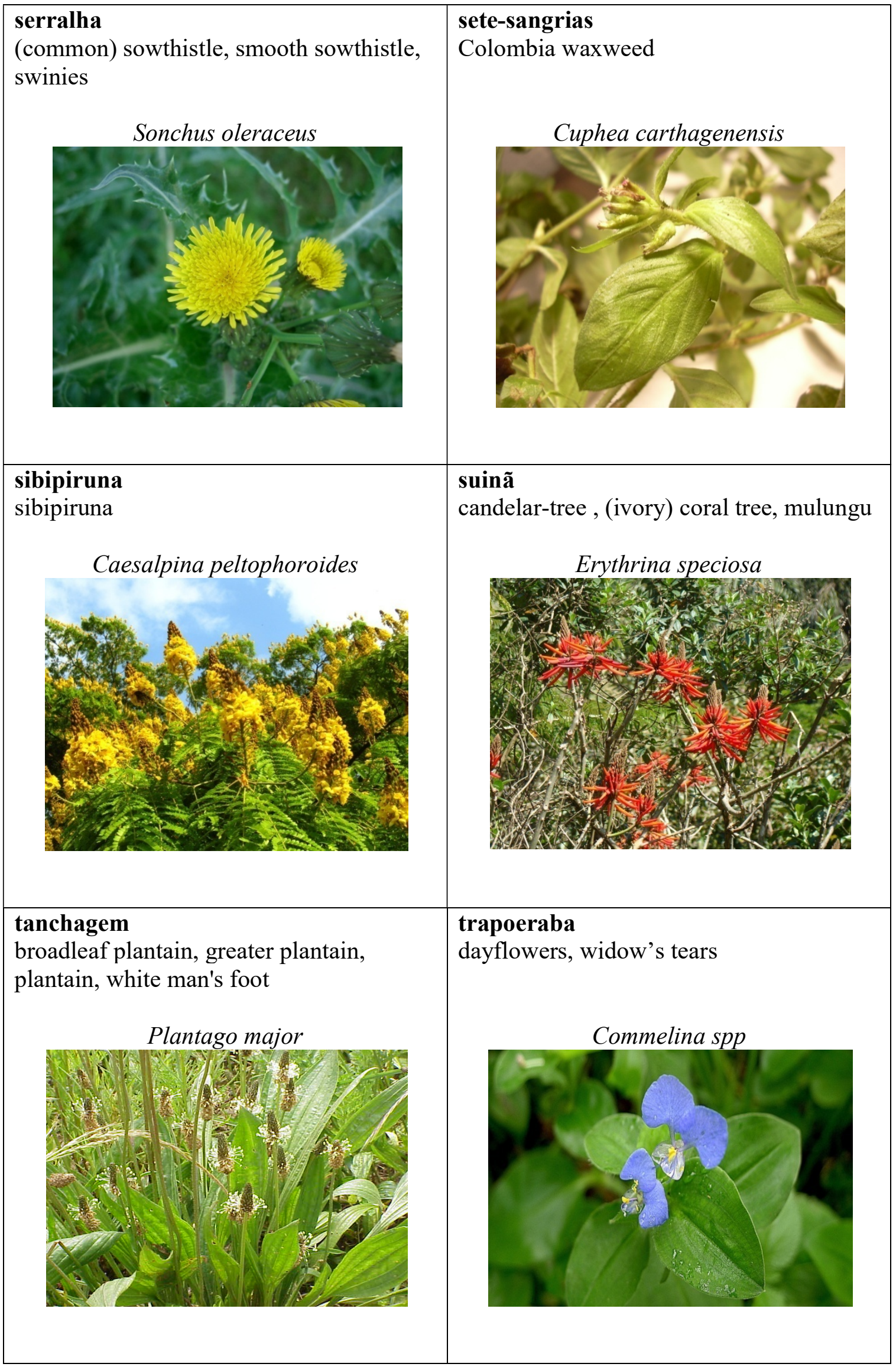




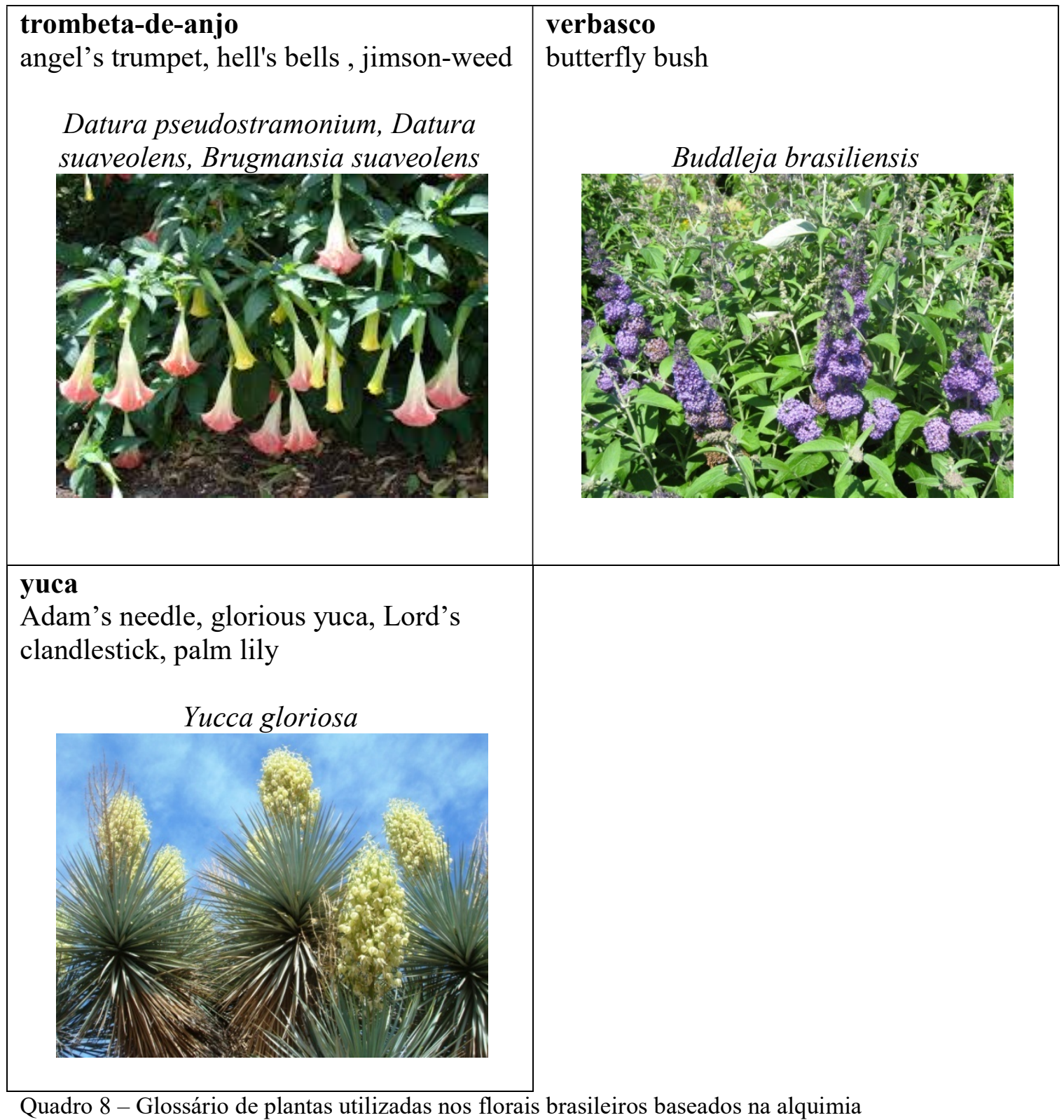




\subsubsection{Glossário inglês-português de plantas usadas nos florais brasileiros baseados na} alquimia

\begin{tabular}{|c|c|}
\hline abutilon, trailing abutilon & abutilom \\
\hline Adam's needle, glorious yuca, Lord's clandlestick, palm lily & yuca \\
\hline African lily & agapanto \\
\hline ageratum, bastard agrimony, billygoat weed & mentrasto \\
\hline aloe, kranz aloe & babosa \\
\hline angel's trumpet, hell's bells, jimson-weed & trombeta-de-anjo \\
\hline aniseed & anis \\
\hline anthurium, flamingo flower, tail flower & antúrio \\
\hline azalea & azaleia \\
\hline basil, great basil, Saint Joseph's wort & manjericão \\
\hline beggarticks, black-jack, cobbler's pegs, Spanish needle & picão \\
\hline begonia & begônia \\
\hline Bermuda lily, Easter lily & açucena \\
\hline bitter buttons, golden buttons, tansy & catinga-de-mulata \\
\hline black poui, blue jacaranda, green ebony tree, jacaranda & jacaranda \\
\hline black elder, (common) elder, elderberry & sabugueiro \\
\hline blue plumbago, Cape leadwort & bela-emília \\
\hline borage, starflower & borragem \\
\hline bougainvillea, lesser bougainvillea, paperflower & primavera \\
\hline Brazilian arnica, goldenrod & arnica \\
\hline Brazilian ginseng, pfaffia, suma & pfáfia \\
\hline Brazilian glory tree, glory tree, purple glory tree & quaresmeira \\
\hline Brazilian gloxinia, florist's gloxinia, gloxinia & gloxínia \\
\hline Brazilian orchid tree, pata-de-vaca & pata-de-vaca \\
\hline Brazilian pine tree & araucária \\
\hline Brazilian tea, blue snakeweed, snakeweed & gervão \\
\hline bridal wreath, Reeve's spiraea & buquê-de-noiva \\
\hline broadleaf plantain, greater plantain, plantain, white man's foot & tanchagem \\
\hline bromelia, flaming sword & bromélia \\
\hline bull bay, evergreen magnolia, magnolia, southern magnolia & magnólia \\
\hline
\end{tabular}




\begin{tabular}{|c|c|}
\hline burhead & chapéu-de-couro \\
\hline butterfly bush & verbasco \\
\hline cactus & cactos \\
\hline camellia, rose-of-winter & camélia \\
\hline camphor southerwood, camphor wormwood & cânfora \\
\hline canafistula, golden rain tree, golden shower & cássia \\
\hline candelar-tree, (ivory) coral tree, mulungu & suinã \\
\hline carnation, clove pink & cravo \\
\hline carqueja & carqueja \\
\hline chamomile, horse gowan & camomila \\
\hline China rose, hibiscus, shoeblack plant & hibisco \\
\hline chrysanth, chrysanthemum, mum & crisântemo \\
\hline cilantro, Chinese parsley, coriander & coentro \\
\hline Colombia waxweed & sete-sangrias \\
\hline comfrey, true comfrey & confrei \\
\hline common trumpetvine, golden trumpet, yellow allamanda & alamanda \\
\hline cosmea, garden cosmos, Mexican aster & cosmos \\
\hline crimsom cattleya, orchid, ruby-lipped cattleya & orquídea \\
\hline curtain ivy, millionaire vine, princess vine & insulina \\
\hline dahlia, garden dahlia & dália \\
\hline daisy, oxeye daisy, ox-eye daisy & margarida \\
\hline dandelion & dente-de-leão \\
\hline dayflowers, widow's tears & trapoeraba \\
\hline espinheira-santa, maytenus & espinheira-santa \\
\hline flamboyant, flame tree, royal poinciana & flamboyant \\
\hline flor-das-almas (flower-of-souls) & bracatinga \\
\hline forskohlii, Indian coleus & boldo \\
\hline fuchsia & brinco-de-princesa \\
\hline garden nasturtium, Indian cress, monks cress & capuchinha \\
\hline geranium & gerânio \\
\hline giant club cactus, hedge cactus, mandacaru & mandacaru \\
\hline golden shrimp plant, lollipop plant & camarão \\
\hline
\end{tabular}




\begin{tabular}{|c|c|}
\hline guinea hen weed, gully root & guiné \\
\hline herb-of-grace, rue & arruda \\
\hline hydrangea, penny mac, hortensia & hortênsia \\
\hline iris & flor-de-lis \\
\hline ironweed, vernonia & assa-peixe \\
\hline jaborandi & jaborandi \\
\hline jalap, morning glory & ipomeia \\
\hline jasmine & jasmim \\
\hline Johnny jump up, wild pansy & amor-perfeito \\
\hline jurubeba & jurubeba \\
\hline lantana, shrub verbena, yellow sage & lantana \\
\hline lavender & alfazema \\
\hline lemon balm & melissa \\
\hline macela, marcela & macela \\
\hline manaca & manacá \\
\hline marigold, garden marigold, pot marigold & calêndula \\
\hline mourning bride, sweet scabious & saudade \\
\hline mugwort, wormwood & artemísia \\
\hline night-blooming cestrum, night-blooming jasmine, lady of the night & dama-da-noite \\
\hline orange tree, sweet orange & laranjeira \\
\hline passion flower, passion vines & maracujá \\
\hline peppermint & hortelã \\
\hline poui, roble, trumpet tree & ipê \\
\hline primrose & prímula \\
\hline purslane & beldroega \\
\hline rose & rosa \\
\hline rosemary & alecrim \\
\hline sage, culinary sage, garden sage & sálvia \\
\hline sibipiruna & sibipiruna \\
\hline silk floss tree, silk-tree & paineira \\
\hline snapdragon & boca-de-leão \\
\hline sowthistle, smooth sowthistle, swinies & serralha \\
\hline
\end{tabular}




\begin{tabular}{|l|l|}
\hline stonecrop & bálsamo \\
\hline sunflower, helianthus & girassol \\
\hline water hyacinth & aguapé \\
\hline water lily & lótus \\
\hline yarrow & mil-folhas \\
\hline
\end{tabular}

Quadro 9 - Glossário inglês-português de pantas usadas nos florais brasileiros 


\section{CONSIDERAÇÕES FINAIS}

Este estudo teve como objetivos analisar a terminologia utilizada na área de Práticas Integrativas e Complementares e elaborar uma proposta de glossário bilíngue português/inglês, pois até o momento não encontramos disponíveis materiais de apoio ao tradutor - como glossários, dicionários bilíngues - dessa linguagem de especialidade.

Contextualizamos o uso dessas técnicas terapêuticas no Brasil e no âmbito da Medicina Complementar e Alternativa, de acordo com documentos da Organização Mundial da Saúde, para elucidar a abrangência de nosso objeto de estudo e sua importância para a população.

Em seguida abordamos os pressupostos teóricos no que tange à Linguística de Corpus e à Terminologia, esclarecendo nossas escolhas metodológicas na construção dos corpora de estudo e na elaboração da proposta de glossário, explicitando seus elementos essenciais.

Por meio de critérios qualitativos e quantitativos, selecionamos um rol de técnicas terapêuticas e de diagnose relacionadas às PIC, além de outros termos referentes a essa área de especialidade. Com apoio do software WordSmith Tools, utilizamos a ferramenta Concord para selecionar contextos explicativos e definitórios, sempre que possível, para esses termos, em ambas as línguas, para a composição do glossário.

Para apresentar um tipo de terapia desenvolvido no Brasil e que ainda não tinha sido vertido para o inglês, selecionamos os florais brasileiros baseados na alquimia (Joel Aleixo) e procedemos à pesquisa pontual para encontrar os equivalentes para as 99 plantas utilizadas em sua elaboração.

Ao analisarmos a linguagem das PIC, deparamos com hiperônimos, como o termo terapia, e grande quantidade de hipônimos formados com base nesse termo. Observamos a prevalência de termos simples em português em comparação com os termos complexos em inglês. Constatamos ainda a existência de epônimos. Exemplificamos os tipos de contextos extraídos dos corpora e traços conceptuais encontrados na busca por equivalentes em língua inglesa.

Nossos maiores desafios durante o desenvolvimento dessa pesquisa se deram durante a etapa de elaboração dos corpora, tanto na fase de testes, buscando encontrar materiais que nos 
dessem as respostas procuradas, contextos com informações suficientes para encontrar os equivalentes necessários na língua de chegada, quanto na etapa de compilação dos corpora propriamente ditos, com a necessidade de preparar um grande volume de dados para serem analisados computacionalmente. Foi preciso escanear muitas páginas e corrigir erros de OCR, o que demandou muito tempo, dedicação e persistência para a realização de nossos objetivos.

Ainda que seja um trabalho inicial, com a proposta de glossário bilíngue, esperamos ter desenvolvido um material de apoio aos tradutores, redatores e profissionais dessa área, além de incentivar o desenvolvimento de novas pesquisas com relação à linguagem utilizada. Temos a intenção de disponibilizar os corpora construídos para outros pesquisadores que desejem enveredar por esse caminho.

Como perspectivas futuras, pretendemos ampliar a nomenclatura do glossário, abrangendo outras modalidades de PIC que não tenham sido contempladas e a ampliação dos corpora.

Podem ser realizadas também pesquisas que vão além da observação dos termos, como o exame de possíveis colocações e fraseologias da área, a análise do discurso de profissionais, pesquisadores e pacientes, a elaboração de definições para o desenvolvimento de um dicionário bilíngue, ou mesmo multilíngue, com a compilação de corpora de PIC em outros idiomas.

Enfim, este trabalho não exauriu a terminologia existente em PIC, mas fornece um instrumento de auxílio para tradutores, pesquisadores e usuários das Práticas Integrativas e Complementares. 


\section{REFERÊNCIAS}

AlmeIDA, G. M. B. A Teoria Comunicativa da Terminologia e a sua prática. 2006. Disponível em <seer.fclar.unesp.br/alfa/article/download/1413/1114>. Acesso em: 12 jul. 2015.

AlpíZAR CAStillho, R. Como Hacer um Diccionario Científico Técnico? Buenos Aires, Memphis, 1997.

AUBERT, F. H. Introdução à metodologia da pesquisa terminológica bilíngüe. Cadernos de Terminologia, 2 ed, São Paulo: Humanitas Publicações - FFLCH/USP, 2001.

AUGER, P. \& ROUSSEAU, L. J. Méthodologie de la recherche terminológique. Québec, Office de la Langue Française, 1978.

AZENHA Jr., J. Aspectos culturais na produção de textos técnicos de instrução alemãoportuguês: teoria e prática. Tese de doutorado. São Paulo, FFLCH/USP, 1994

BAKER, M. Corpus linguistics and translation studies: implications and applications. In BAKER, M.; FRANCIS, G.; TOGNINI-BONELLI, E. (Org.). Text and technology: in honour of John Sinclair. Amsterdam: John Benjamins, 1993. p.233-250.

BAKER, M. Corpora in translation studies: an overview and some suggestions for future research. Target, Amsterdam, v. 7, n. 2, p. 223-243, 1995.

BAKER, M. Corpus-based translation studies: the challenges that lie ahead. In: SOMERS, H. (Ed). Terminology, LSP and translation studies in language engineering in honour of Juan C. Sager. Amsterdam: John Benjamins, 1996. p. 177-186.

BARROS, L. A. Curso Básico de Terminologia. São Paulo: Editora da Universidade de São Paulo, 2004.

BERBER SARDINHA, T. Lingüística de Corpus. Barueri: Manole, 2004. 410 p.

BERBER SARDINHA, T. Pesquisa em Linguística de Corpus com WordSmith Tools. Campinas: Mercado das Letras, 2009.

BETTEGA, P. V. C.; et al. Fitoterapia: dos canteiros ao balcão da farmácia. Archives of Oral Research. (Impr.), v. 7, n. 1, p. 89-97, abr. 2011. Disponível em: 
$<\mathrm{http}: / /$ www2.pucpr.br/reol/pb/index.php/aor?dd1=4745\&dd99=view\&dd98=pb $>$. Acesso em: 12 jun. 2017.

BEVILACQUA, Cleci R. Lexicografia bilíngue: aspectos teóricos e reflexões sobre os dicionários bilíngues português-espanhol e espanhol português. In: ROTTAVA, Lucia e dos SANTOS, S. S. (Org.). Ensino e Aprendizagem de Línguas - Língua Estrangeira. Ijuí: Ed. Ijuí, 2006. p. 107-138.

BEVILACQUA, C. Por que e para a lingüística de corpus na terminologia. In: TAGNIN, S. E. O.; BEVILACQUA, C. (Org.) Corpora na terminologia. São Paulo: Hub Editorial, 2013. p. 11 a 45 .

BIBLIOTECA VIRTUAL EM SAÚDE. Disponível em: $<$ http://www.bireme.br/php/index.php>. Acesso em 02 jul. 2015.

BIDERMAN, M. T. C.; ALMEIDA, G. M. B. (Org.). O estado da arte nas ciências do léxico: lexicologia, lexicografia e terminologia. São Paulo: EDUNESP, 1998. 268 p.

BIDERMAN, M. T. C. A língua e o computador. In: Teoria linguística. São Paulo: Martins Fontes, 2001, p. 75-93.

BOUTIN-QUESNEL, R. et al. Vocabulaire systématique de la terminologie. Québec: Publications du Québec, 1985. (Cahiers de l'Office de la langue française).

BRAZ, A. S. et al. Uso da terapia não farmacológica, medicina alternativa e complementar na fibromialgia. Revista Brasileira de Reumatologia. V. 51, n. 3, p. 275-282, 2011. Disponível em: <http://www.scielo.br/pdf/rbr/v51n3/v51n3a08.pdf>. Acesso em: 12 jun. 2017.

BRITISH NATIONAL CORPUS. Disponível em: <http://corpus.byu.edu/bnc/>. Acesso em: 20 jun. 2015.

CABRÉ, M. T. La terminología: la teoría, les metodes, les aplicacions. Barcelona: Editorial Empúries, 1992. 
CABRÉ, M. T. La terminologia: representación y comunicación. Elementos para una teoria de base comunicativa y otros artículos. Barcelona: IULA, 1999.

CABRERA-DIEGO, L. A. et al. Using Wikipedia do Validate the Terminology Found in a Corpus of Basic Textbooks. Apresentado em In Proceedings of LaRC 2011: First Int. Conference on Terminology, Languages, and Content Resources. Seoul. Disponível em: $<$ http://www.lrec-conf.org/proceedings/lrec2012/pdf/515_Paper.pdfv>. Acesso em 23 out. de 2017.

CHANUT, M. E. P. A noção de equivalência e a sua especificidade na tradução especializada. TradTerm, São Paulo, v. 19, novembro/2012, p. 43-70. Disponível em: $<$ https://www.revistas.usp.br/tradterm/article/view/47345/51082>. Acesso em: 20 jun. 2015.

COSTEIRA, O. Terapias naturais e holísticas: quais são, como foram criadas, para que servem, como são usadas. Curitiba/PR: Appris, 2015. $1^{\text {a }}$ edição. 423 p.

DELISLE, J. \& WORDSWORTH, J. (org.). Os Tradutores na História. São Paulo: Ática, 1998.

DUBUC, R. Manuel pratique de terminologie. 2. ed. Québec: Linguatech, 1985.

FRENKEL. M. Apresentação. In: LIMA, P. T. Medicina integrativa: a cura pelo equilíbrio. São Paulo/SP: MG Editores, 2009. $2^{\text {a }}$ edição.

GRIES, S. Phraseology and linguistic theory: a brief survey. In: GRANGER, S. e MEUNIER F. (Eds.) Phraseology: an interdisciplinary perspective. Amsterdam \& Philadelphia: John Benjamins, 2008, p. 3 - 25.

HARRISON, L. Latim para jardinistas. São Paulo: Editora Europa Ltda, 2012. 224 p.

HURTADO ALBIR, A. (2001). La tradución de textos especializados. In: HURTADO ALBIR, A. Traducción y traductologia: introducción a La traductología. Madrid: Cátedra, 2001, p. 59-61.

KRAMLICH D. Introduction to complementary, alternative, and traditional therapies. Critical Care Nurse; v. 34, n. 6, p. 50-56; 1 dez. 2014. Disponível em: $<$ https://www.aacn.org/docs/cemedia/C1463.pdf>. Acesso em: 22 abr. 2017. 
KRIEGER, M. G.; FINATTO, M. J. B. Introdução à Terminologia: teoria de prática. São Paulo: Contexto, 2004.

LERAT, P. Les langues spécialisées. Paris: PUF, 1995. (Linguistique nouvelle).

LIMA, K. M. S. V.; SILVA, K. L.; TESSER, C. D. Práticas integrativas e complementares e relação com promoção da saúde: experiência de um serviço municipal de saúde. Interface - Comunicação, Saúde, Educação. V. 18, n. 49, p. 261-272, jun. 2014. Disponível em: $<$ http://www.scielo.br/scielo.php?pid=S141432832014000200261\&script=sci_abstract\&tlng=pt>. Acesso em: 12 jun. 2017.

LIMA, P. T. Medicina integrativa: a cura pelo equilíbrio. São Paulo/SP: MG Editores, 2009. $2^{\mathrm{a}}$ edição.

MAGAlHÃES, C. Estra: um corpus para o estudo do estilo da tradução. 2014. Disponível em: $\quad<$ https://periodicos.ufsc.br/index.php/traducao/article/view/21757968.2014v2n34p248>. Acesso em: 13 jul. 2015.

NAIFF, N. Curso completo de terapia holística \& complementar. Rio de Janeiro/RJ: Bestseller, 2016. $4^{\mathrm{a}}$ edição.

PAVEL, S.; NOLET, D. Manual de terminologia. Trad. Enilde Faulstich. Quebec: Departamento de Tradução do Governo Canadense, 2002. Disponível em: $<$ https://linguisticadocumentaria.files.wordpress.com/2011/03/pavel-terminologia.pdf $>$. Acesso em 10/08/2017. Acesso em: 12 jun. 2017.

PIGEON, L. P. La traduction juridique. L'équivalence fonctionnelle. In : Langage du droit et traduction. Québec, Éd. J.-C. Gémar, 1982 p. 271-281.

PHILIP, G. Arriving at equivalence. Making a case for comparable corpora in Translation Studies. In: BEEBY, Allison, Patricia Rodríguez Inés and Pilar Sánchez-Gijón (Eds.), Corpus Use and Translating: Corpus use for learning to translate and learning corpus use to translate. 2009. x, 151 pp. (pp. 59-73) Disponível em: <http://amsacta.unibo.it/2124/1/ComparableCorpora.pdf. >. Acesso em: 12 jun. 2017.

OMS. WHO Traditional Medicine Strategy: 2002-2005. Geneva: World Health Organization, 2002. Disponível em: 
$<\mathrm{http}: / / w w w . w p r o . w h o . i n t / h e a l t h \_t e c h n o l o g y /$ book_who_traditional_medicine_strategy_200 2_2005.pdf $>$. Acesso em 10 mai. 2015.

OMS. WHO Traditional Medicine Strategy: 2014-2023. Geneva: World Health Organization, 2013. Disponível em: $<$ http://apps.who.int/iris/bitstream/10665/92455/1/9789241506090_eng.pdf?ua=1>. Acesso em 10 mai. 2015.

REBECHI, R. R. A Linguística de Corpus como metodologia para a compilação de um glossário de termos da culinária típica brasileira. In: TAGNIN, S. E. O.; BEVILACQUA, C. (Org.). Corpora na Terminologia. São Paulo: Hub Editorial, 2013.

SALAMA-CARR, M. et al. Os tradutores e a disseminação do conhecimento. In: DELISLE, J. \& WORDSWORTH, J. Os Tradutores na História. São Paulo: Ática, 1998, p. 113-139.

SINCLAIR, J. Corpus, Concordance, Collocation. Oxford: Oxford University Press, 1991.

SINCLAIR, J. Corpus and text: basic principles. In: WAYNE, M. (Ed.) Developing linguistic corpora: a guide to a good practice. Oxford: Oxford Books, 2005. p. 1-16. Disponível em: <https://ota.ox.ac.uk/documents/creating/dlc/chapter1.htm>. Acesso em: 16 ago. 2017.

TAGNIN, S. E. O. A identificação de equivalentes tradutórios em corpora comparáveis. Anais do I Congresso Internacional da ABRAPUI: Belo Horizonte, 3 a 6 de junho de 2007. Disponível em: $\quad<$ http://comet.fflch.usp.br/sites/comet.fflch.usp.br /files/u30/Stella_Abrapui\%202007_artigo.pdf>. Acesso em: 12 jun. 2017.

TAGNIN, S. E. O. Glossário de Linguística de Corpus. In: VIANA. V.; TAGNIN, S. E. O. (Org.). Corpora na Tradução. São Paulo: HUB Editorial. 2015.

TAGNIN, S. E. O. \&; TEIXEIRA, E. 2004. Linguística de Corpus e Tradução Técnica Relato da montagem de um corpus multivarietal de culinária. In TradTerm 10 - Revista do Centro interdepartamental de Tradução e Terminologia FFLCH-USP, São Paulo: Humanitas - $\quad$ FFLCH/USP, 313-358. Disponível em: $<$ http://www.revistas.usp.br/tradterm/article/view/47184>. Acesso em: 12 jun. 2017. 
TOGNINI-BONELLI. E.; MANCA, E. Welcoming children, pets and guests: towards functional equivalence in the languages of 'agriturismo' and 'farmhouse holidays. São Paulo: TradTerm, 2004, p. 295-312. Disponível em: $<$ https://www.revistas.usp.br/tradterm/article/view/47181>. Acesso em: 12 jun. 2017.

TOURY, G. The nature and role of norms in literary translation. In: HOLMES, J.; LAMBERT, J; VAN DEN BROECK, R. (Ed.). Literature and translation. Leuven: ACCO, 1978 p. 83-100 [Versão revisada em VENUTI, L. (Ed.). The translation studies reader. London/New York: Routledge, 2000, p. 198-211].

VAN HOOF, H. Os Tradutores e os Dicionários. In: DELISLE, J. \& WORDSWORTH, J. (org.). Os Tradutores na História. São Paulo: Ática, 1998, p. 241-253.

VEGA, M. A. Terminología y Traducción. Jornada Panllatina de Terminologia, 1995. Barcelona: Universitat Pompeu Fabra. Iula, 1996, p. 65-71.

WEIL, A. Prefácio. In: LIMA, P. T. Medicina integrativa: a cura pelo equilíbrio. São Paulo/SP: MG Editores, 2009. $2^{\mathrm{a}}$ edição.

ZANETTIN, F. Translation-Driven corpora - Corpus Resources for Descriptive and Applied Translation Studies. Translation Practices Explained Volume 14. St. Jerome. 2012. 244 pp. Disponível em: <http://www.stjerome.co.uk/books/b/156/>. Acesso em: 20 out. 2014.

ZUCCHI, A. M. T. O dicionário nos estudos de línguas estrangeiras: os efeitos de seu uso na compreensão escrita em italiano. Tese (Doutorado em Semiótica e Linguística Geral) Faculdade de Filosofia, Letras e Ciências Humanas. Universidade de São Paulo, São Paulo, 2010 . 


\section{BIBLIOGRAFIA DO CORPUS EM PORTUGUÊS}

\section{Artigos acadêmicos}

ADLER, M. S.; GALLIAN, D. M. C. Experiências e impactos do aprendizado em Homeopatia: relatos de médicos egressos do Curso de Especialização em Homeopatia da FMJ. Revista Brasileira de Educação Médica, v. 33, n. 3, p. 356 - 363, 2009. Disponível em: $<$ http://www.scielo.br/pdf/rbem/v33n3/06.pdf>. Acesso em: 12 jun. 2017.

AGUIAR JÚNIOR, N. R.; COSTA, I. M. C. O uso da medicina alternativa ou complementar em crianças com dermatite atópica. Anais Brasileiros de Dermatologia, v. 86, n. 1, p. 167-168, 2011. Disponível em: $<$ http://www.scielo.br/pdf/abd/v86n1/v86n1a33.pdf >. Acesso em: 12 jun. 2017.

ALMEIDA, A. P.; SILVA, M. J. P. Canto Gregoriano: redutor de ansiedade de mães com filhos hospitalizados. Acta Paulista de Enfermagem, v. 25, n. 1, p. 36-42, 2012. Disponível em: <http://www.scielo.br/pdf/ape/v25n1/v25n1a07.pdf >. Acesso em: 12 jun. 2017.

ALVES, A. R.; SILVA, M. J. P. O uso da fitoterapia no cuidado de crianças com até cinco anos em área central e periférica da cidade de São Paulo. Revista da Escola de Enfermagem da USP, v. 37, n. 4, p. 85-91, 2003. Disponível em: $<$ http://www.ee.usp.br/reeusp/upload/pdf/157.pdf>. Acesso em: 12 jun. 2017.

ANDRADE, J. T. ; COSTA, L. F. A. Medicina complementar no SUS: práticas integrativas sob a luz da Antropologia médica. Revista Saúde e Sociedade. São Paulo, v. 19, n. 3, p. 497-508, 2010. Disponível em: $<$ https://www.revistas.usp.br/sausoc/article/viewFile/29665/31537>. Acesso em: 12 jun. 2017.

ANDRADE, R. L. P.; PEDRÃO, L. J. Algumas considerações sobre a utilização de modalidades terapêuticas não tradicionais pelo enfermeiro na assistência de enfermagem psiquiátrica. Revista Latino-america de Enfermagem. outubro, v. 13, n. 5, p. 737-42, 2005. Disponível em: <http://www.scielo.br/pdf/rlae/v13n5/v13n5a19.pdf >. Acesso em: 12 jun. 2017.

ARAÚJO, M. A. M. Bactrins e quebra-pedras. Interface - Comunicação, Saúde, Educação, v. 4, n. 7, p. 103-110, 2000. Disponível em: <http://www.scielo.br/pdf/icse/v4n7/08.pdf>. Acesso em: 12 jun. 2017.

ARAÚJO, R. F. et al. Terapia floral em gatos domésticos (Felis catus, Linnaeus, 1758) portadores do complexo da doença respiratória felina: estudo clínico e hematológico. Revista Brasileira de Plantas Medicinais, v. 12, n. 4, p. 472-481, dez. 2010. Disponível em: $<$ http://www.scielo.br/pdf/rbpm/v12n4/a11v12n4.pdf $>$. Acesso em: 12 jun. 2017.

AURELIANO, W. A. Terapias espirituais e complementares no tratamento do câncer: a experiência de pacientes oncológicos em Florianópolis (SC). Cadernos Saúde Coletiva, v. 21, n. 1, p. 18-24, mar. 2013. Disponível em: $<$ http://www.scielo.br/pdf/cadsc/v21n1/a04.pdf>. Acesso em: 12 jun. 2017. 
AVILA-PIRES, F. D. Teoria e prática das práticas alternativas. Revista de Saúde Pública, v. 29, n. 2, p. 147-151, 1995. Disponível em: <http://www.scielo.br/pdf/rsp/v29n2/12.pdf>. Acesso em: 12 jun. 2017.

BACKES, D. S. et al. Oficinas de espiritualidade: alternativa de cuidado para o tratamento integral de dependentes químicos. Revista da Escola de Enfermagem da USP, v. 46, n. 5, p. 1254-1259, 2012. Disponível em: $<$ http://www.scielo.br/pdf/reeusp/v46n5/30.pdf>. Acesso em: 12 jun. 2017.

BARROS, N. F.; ADAMS, J. A pesquisa sobre as terapias alternativas e complementares e enfermagem no Brasil. Revista Latino-americana de Enfermagem, v. 13, n. 3, p. 453-4, 2005. Disponível em: <http://www.scielo.br/pdf/rlae/v13n3/v13n3a22.pdf $>$. Acesso em: 12 jun. 2017.

BARROS, N. F.; TOVEY, P. O ensino das terapias alternativas e complementares em escolas de enfermagem. Revista Gaúcha de Enfermagem, v. 28, n. 2, p. 207, 2007. Disponível em: $\quad<$ http://seer.ufrgs.br/RevistaGauchadeEnfermagem/article/view/3165>. Acesso em: 12 jun. 2017.

BETTEGA, P. V. C.; et al. Fitoterapia: dos canteiros ao balcão da farmácia. Archives of Oral Research. (Impr.), v. 7, n. 1, p. 89-97, abr. 2011. Disponível em: $<$ http://www2.pucpr.br/reol/pb/index.php/aor?dd1=4745\&dd99=view\&dd98=pb $>$. Acesso em: 12 jun. 2017.

BEUTER, M.; ALVIM, A. T. Expressões lúdicas no cuidado hospitalar sob a ótica de enfermeiras. Escola Anna Nery, v. 14, n. 3, p. 567-574, 2010. Disponível em: $<$ http://www.scielo.br/pdf/ean/v14n3/v14n3a19.pdf>. Acesso em: 12 jun. 2017.

BONA, T. D. M. M. et al. Óleo essencial de orégano, alecrim, canela e extrato de pimenta no controle de Salmonella, Eimeria e Clostridium em frangos de corte. Pesquisa Veterinária Brasileira, v. 32, n. 5, p. 411-418, 2012. Disponível em: $<$ http://www.scielo.br/pdf/pvb/v32n5/a09v32n5.pdf>. Acesso em: 12 jun. 2017.

BRAZ, A. de S. et al. Uso da terapia não farmacológica, medicina alternativa e complementar na fibromialgia. Revista Brasileira de Reumatologia, v. 51, n. 3, p. 275-282, 2011. Disponível em: <http://www.scielo.br/pdf/rbr/v51n3/v51n3a08.pdf >. Acesso em: 12 jun. 2017.

BRITO, A. M. G. et al. Aromaterapia: da gênese a atualidade. Revista Brasileira de Plantas Medicinais, v. 15, n. 4, p. 789-793, 2013. Disponível em: $<$ http://www.scielo.br/pdf/rbpm/v15n4s1/21.pdf $>$. Acesso em: 12 jun. 2017.

BUDÓ, M. L. D. et al. Práticas de cuidado em relação à dor: a cultura e as alternativas populares. Escola Anna Nery, v. 12, n. 1, p. 90-96, mar. 2008. Disponível em: $<$ http://www.scielo.br/pdf/rbpm/v15n4s1/21.pdf>. Acesso em: 12 jun. 2017.

BUSSOTTI, E. A. et al. Assistência individualizada: posso trazer meu cachorro? Revista da Escola de Enfermagem da USP, v. 39, n. 2, p. 195-201, jun. 2005. Disponível em: $<$ http://www.scielo.br/pdf/reeusp/v39n2/10.pdf $>$. Acesso em: 12 jun. 2017.

CAMPOS, B. C. P. et al. Ensino de massoterapia: habilidades envolvidas na relação fisioterapeuta-paciente. Fisioterapia e Pesquisa, v. 16, n. 1, p. 16-21, 2009. Disponível em: $<$ http://www.scielo.br/pdf/fp/v16n1/04.pdf $>$. Acesso em: 12 jun. 2017. 
CHRISTENSEN, M. C.; BARROS, N. F. Medicinas alternativas e complementares no ensino médico: revisão sistemática. Revista Brasileira de Educação Médica, v. 34, n. 1, p. 97-105, 2010. Disponível em: <http://www.scielo.br/pdf/rbem/v34n1/a12v34n1.pdf >. Acesso em: 12 jun. 2017.

COSTA, A. I. S.; REIS, P. E. D. Técnicas complementares para controle de sintomas oncológicos. Revista Dor, v. 15, n. 1, 2014. Disponível em: $<$ http://www.scielo.br/scielo.php?script=sci_arttext\&pid=S1806-

$00132014000100061 \& \operatorname{lng}=$ pt\&nrm=iso\&tlng=en>. Acesso em: 12 jun. 2017.

CRUZ, C. T.; BARROS, N. F.; HOEHNE, E. L. Evidências sobre o uso de práticas altrnativas e complementares no tratamento convencional de neoplasias mamárias. Revista Brasileira de Cancerologia, v. 55, n. 3, p. 237-246, set. 2009. Disponível em: $<$ http://www.inca.gov.br/rbc/n_55/v03/pdf/41_artigo5.pdf $>$. Acesso em: 12 jun. 2017.

DALLAQUA, B.; DAMASCENO, D. C. Comprovação do efeito antioxidante de plantas medicinais utilizadas no tratamento do Diabetes mellitus em animais: artigo de atualização. Revista Brasileira de Plantas Medicinais, v. 13, p. 367-373, 2011. Disponível em: <http://www.scielo.br/pdf/rbpm/v13n3/a17v13n3.pdf>. Acesso em: 12 jun. 2017.

DONINI FILHO, L. A. et al. Impacto de um modelo de tratamento não farmacológico para diabetes e hipertensão no município de Rincão: projeto saúde e vida. Revista da Sociedade Brasileira de Clínica Médica, v. 8, n. 6, dez. 2010. Disponível em: <http://files.bvs.br/upload/S/1679-1010/2010/v8n6/a1601>. Acesso em: 12 jun. 2017.

ELIAS, M. C.; ALVES, E.; TUBINO, P. Uso de medicina não-convencional em crianças com câncer. Revista Brasileira de Cancerologia, v. 52, n. 3, p. 237-243, set. 2006. Disponível em: <http://www.inca.gov.br/rbc/n_52/v03/pdf/artigos_uso_de_medicina.pdf $>$. Acesso em: 12 jun. 2017.

ELIAS, M. C.; ALVES, E. Medicina não-convencional: prevalência em pacientes oncológicos. Revista Brasileira de Cancerologia, v. 48, n. 4, p. 523-532, dez. 2002. Disponível em: <http://wwwl.inca.gov.br/rbc/n_48/v04/pdf/artigo6.pdf > . Acesso em: 12 jun. 2017.

FELIPE, M. R. et al. Implicações da alimentação e nutrição e do uso de fitoterápicos na profilaxia e tratamento sintomático da enxaqueca: uma revisão. Revista Nutrire Sociedade Brasileira de Alimentação e Nutrição, v. 35, n. 2, ago. 2010. Disponível em: $<$ http://files.bvs.br/upload/S/1519-8928/2010/v35n2/a0012.pdf >. Acesso em: 12 jun. 2017.

FÉLIX, L. M. C.; CAMPANER, A. B.; LIMA, S. M. R. R. Terapêutica não hormonal no tratamento de distúrbios do climatério. Femina, v. 37, n. 10, out. 2009. Disponível em: $<$ http://files.bvs.br/upload/S/0100-7254/2009/v37n10/a005.pdf >. Acesso em: 12 jun. 2017.

FEUERWERKER, L. C. M.; MERHY, E. E. A contribuição da atenção domiciliar para a configuração de redes substitutivas de saúde: desinstitucionalização e transformação de práticas. Revista Panamericana de Salud Pública, v. 24, n. 3, p. 180-188, 2008. Disponível em: <https://scielosp.org/pdf/rpsp/v24n3/a04v24n3.pdf>. Acesso em: 12 jun. 2017.

FOLLADOR, E. C. R. Medicina antroposófica: um novo paradigma para as questões da medicina moderna. Revista de Medicina, v. 92, n. 3, p. 166, 30 set. 2013. Disponível em: $<$ http://www.revistas.usp.br/revistadc/article/view/79997>. Acesso em: 12 jun. 2017. 
FONTANELLA, Fabrício et al. Conhecimento, acesso e aceitação das práticas integrativas e complementares em saúde por uma comunidade usuária do Sistema Único de Saúde na cidade de Tubarão/SC. ACM: arquivos catarinenses de medicina, v. 36, n. 2, jun. 2007. Disponível em: <http://www.acm.org.br/revista/pdf/artigos/484.pdf > . Acesso em: 12 jun. 2017.

GALHARDI, W. M. P.; BARROS, N. F.; LEITE-MOR, A. C.M. B. O conhecimento de gestores municipais de saúde sobre a Política Nacional de Prática Integrativa e Complementar e sua influência para a oferta de homeopatia no Sistema Único de Saúde local. Ciência \& Saúde Coletiva, v. 18, p. 213-20, 2013. Disponível em: $<$ http://www.scielo.br/pdf/csc/v18n1/22.pdf>. Acesso em: 12 jun. 2017.

GENTIL, L. B.; ROBLES, A. C. C.; GROSSEMAN, S. Uso de terapias complementares por mães em seus filhos: estudo em um hospital universitário. Ciência \& Saúde Coletiva, v. 15, n. 1, p. 1293-1299, 2010. Disponível em: $<$ http://www.scielo.br/pdf/csc/v15s1/038.pdf >. Acesso em: 12 jun. 2017.

GOMES, V. M.; SILVA, M. J. P.; ARAÚJO, E. A. C. Efeitos gradativos do toque terapêutico na redução da ansiedade de estudantes universitários. Revista Brasileira de Enfermagem, v. 61, n. 6, p. 841-846, 2008. Disponível em: $<$ http://www.producao.usp.br/handle/BDPI/3982>. Acesso em: 12 jun. 2017.

HELLMANN, F; VERDI, M. I. M. Temas e referenciais de análise em Bioética no ensino da graduação em naturologia no Brasil à luz da bioética social. Interface - Comunicação, Saúde, Educação, v. 16, p. 733-47, 2012. Disponível em: $<$ http://www.scielo.br/pdf/icse/v16n42/v16n42a12.pdf $>$. Acesso em: 12 jun. 2017.

IORIO, R. C.; SIQUEIRA, A. A. F.; YAMAMURA, Y. Acupuntura: motivações de médicos para a procura de especialização. Revista Brasileira de Educação Médica, v. 34, n. 2,2010 p. 247-254, Disponível em: $<$ http://www.scielo.br/pdf/rbem/v34n2/a08v34n2.pdf $>$. Acesso em: 12 jun. 2017.

JACONODINO, C. B.; AMESTOY, S. C.; THOFEHRN, M. B. A utilização de terapias alternativas por paciente em tratamento quimioterápico. Cogitare Enfermagem, v. 13, n. 1, 5 ago. 2008. Disponível em: <http://revistas.ufpr.br/cogitare/article/view/11953>. Acesso em: 12 jun. 2017.

KÜLKAMP, I. C. et al. Aceitação de práticas não-convencionais em saúde por estudantes de medicina da Universidade do Sul de Santa Catarina. Revista Brasileira de Educação Médica, v. 31, n. 3, p. 229-235, 2007. Disponível em: $<$ http://www.scielo.br/pdf/rbem/v31n3/05.pdf Acesso em: 12 jun. 2017.

LEAL, F; SCHWARTSMANN, G.; LUCAS, H. S. Medicina complementar e alternativa: uma prática comum entre os pacientes com câncer. Revista da Associação Médica Brasileira, v. 54, n. 6, p. 481-482, 2008. Disponível em: $<$ http://www.scielo.br/pdf/ramb/v54n6/v54n6a07.pdf>. Acesso em: 12 jun. 2017.

LEÃO, E. R.; SILVA, M. J. P. Música e dor crônica músculoesquelética: o potencial evocativo de imagens mentais. Revista Latino-americana de Enfermagem, v. 12, n. 2, p. 235-241, 2004. Disponível em: <http://www.scielo.br/pdf/rlae/v12n2/v12n2a13.pdf $>$. Acesso em: 12 jun. 2017. 
LIMA, D. M.; ABREU, N.; NETO, S. Danças Brasileiras e Psicoterapia: Um Estudo Sobre Efeitos Terapêuticos. Psicologia: Teoria e Pesquisa, v. 27, n. 1, p. 41-48, 2011. Disponível em: <http://www.scielo.br/pdf/ptp/v27n1/a06v27n1.pdf $>$. Acesso em: 12 jun. 2017.

LIMA, D. F. et al. Conhecimento e uso de plantas medicinais por usuários de duas unidades básicas de saúde. Revista da Rede de Enfermagem do Nordeste. Disponível em: $<$ http://www.periodicos.ufc.br/rene/article/view/3181>. Acesso em: 12 jun. 2017.

LIMA, K. M. S. V.; SILVA, K. L.; TESSER, C. D. Práticas integrativas e complementares e relação com promoção da saúde: experiência de um serviço municipal de saúde. Interface - Comunicação, Saúde, Educação, v. 18, n. 49, p. 261-272, jun. 2014. Disponível em: $\quad<$ http://www.scielo.br/pdf/icse/v18n49/1807-5762-icse-1807-576220130133.pdf>. Acesso em: 12 jun. 2017.

LORENZETTI, B. T. A. et al. Eficácia da acupuntura no tratamento da lombalgia. Arquivos de Ciências da Saúde da UNIPAR, v. 10, n. 3, 22 abr. 2008. Disponível em: $<$ http://revistas.unipar.br/index.php/saude/article/view/625>. Acesso em: 12 jun. 2017.

LOURES, Marta Carvalho et al. Contribuições da fitoterapia para a qualidade de vida: percepções de seus usuários. Revista de Enfermagem da UERJ, v. 18, n. 2, p. 278-283, jun. 2010. Disponível em: <http://www.facenf.uerj.br/v18n2/v18n2a19.pdf $>$. Acesso em: 12 jun. 2017.

NEVES, L. C. P.; SELLI, L; JUNGES, R. A integralidade na Terapia Floral e a viabilidade de sua inserção no Sistema Único de Saúde. Disponível em: $<$ https://www.saocamilo-sp.br/pdf/mundo_saude/74/07_original_integridade.pdf >. Acesso em: 12 jun. 2017.

LUZ, M. T. Cultura contemporânea e medicinas alternativas: novos paradigmas em saúde no fim do século XX. Physis: Revista de Saúde Coletiva, v. 7, n. 1, p. 13-43, 1997. Disponível em: <http://www.scielo.br/pdf/physis/v7n1/02.pdf >.Acesso em: 12 jun. 2017.

LYRA, C. S.; NAKAI, L. S.; MARQUES, A. P. Eficácia da aromaterapia na redução de níveis de estresse e ansiedade em alunos de graduação da área da saúde: estudo preliminar. Fisioterapia e Pesquisa, v. 17, n. 1, p. 13-17, mar. 2010. Disponível em: $<$ http://www.scielo.br/pdf/fp/v17n1/03.pdf>. Acesso em: 12 jun. 2017.

MAFETONI, R. R.; SHIMO, A. K. K. Métodos não farmacológicos para alívio da dor no trabalho de parto: revisão integrativa. REME: Revista Mineira de Enfermagem, v. 18, n. 2, 2014. Disponível em: <http://www.gnresearch.org/doi/10.5935/1415-2762.20140037>. Acesso em: 12 jun. 2017.

MANZINI, T.; MARTINEZ, E. Z.; CARVALHO, A. C. D. Conhecimento, crença e uso de medicina alternativa e complementar por fonoaudiólogas. Revista Brasileira de Epidemiologia, v. 11, n. 2, p. 304-314, jun. 2008. Disponível em: $<$ http://www.scielo.br/pdf/rbepid/v11n2/12.pdf >. Acesso em: 12 jun. 2017.

MARCELINO, J. F. Q.; MELO, Z. M. Equoterapia: suas repercussões nas relações familiares da criança com atraso de desenvolvimento por prematuridade. Estudos de Psicologia (Campinas), v. 23, n. 3, p. 279-287, 2006. Disponível em: $<$ http://www.scielo.br/pdf/estpsi/v23n3/v23n3a07.pdf>. Acesso em: 12 jun. 2017. 
MARQUES, L. A. M. et al. Atenção farmacêutica e práticas integrativas e complementares no SUS: conhecimento e aceitação por parte da população sãojoanense. Physis: Revista de Saúde Coletiva, v. 21, n. 2, p. 663-674, 2011. Disponível em: $<$ http://www.scielo.br/pdf/physis/v21n2/a17v21n2.pdf $>$. Acesso em: 12 jun. 2017.

MOREIRA, R. C. R. et al. Nível de conhecimentos sobre Leishmaniose Tegumentar Americana (LTA) e uso de terapias alternativas por populações de uma área endêmica da Amazônia do Maranhão, Brasil. Cadernos de Saúde Pública, v. 18, n. 1, p. 187-195, 2002. Disponível em: <http://www.scielo.br/pdf/csp/v18n1/8155.pdf>. Acesso em: 12 jun. 2017.

MOTA, C. S.; TRAD, L. A. B. A gente vive pra cuidar da população: estratégias de cuidado e sentidos para a saúde, doença e cura em terreiros de candomblé. Saúde e Sociedade, v. 20, n. 2, p. 325-337, 2011. Disponível em: $<$ http://www.scielo.br/pdf/sausoc/v20n2/06.pdf $>$. Acesso em: 12 jun. 2017.

NAGAI, S. C.; QUEIROZ, M. S. Medicina complementar e alternativa na rede básica de serviços de saúde: uma aproximação qualitativa. Ciência \& Saúde Coletiva, 2011. Disponível em: <http://www.scielo.br/pdf/csc/v16n3/15.pdf >. Acesso em: 12 jun. 2017.

NAVOLAR, T. S.; TESSER, C. D.; AZEVEDO, E. Contribuições para a construção da Nutrição Complementar Integrada. Interface, 2012. Disponível em: $<$ https://scielosp.org/pdf/icse/v16n41/aop2412.pdf>. Acesso em: 12 jun. 2017.

NEUBERN, M. S. Reflexões sobre o magnetismo animal: contribuições para revisão da história da psicologia. Estudos de Psicologia (Campinas), v. 25, n. 3, p. 439-448, 2008. Disponível em: <http://www.scielo.br/pdf/estpsi/v25n3/a12v25n3.pdf>. Acesso em: 12 jun. 2017.

NEUBERN, M. S. Sobre a condenação do magnetismo animal: revisitando a história da psicologia. Psicologia: Teoria e Pesquisa, v. 23, n. 3, p. 347-356, 2007. Disponível em: $<$ http://www.scielo.br/pdf/ptp/v23n3/a15v23n3.pdf $>$. Acesso em: 12 jun. 2017.

NEUBERN, M. S. Milton H. Erickson e o cavalo de tróia: a terapia não convencional no cenário da crise dos paradigmas em psicologia clínica. Psicologia: Reflexão e Crítica, v. 15, n. 2, p. 363-372, 2002. Disponível em: <http://www.scielo.br/pdf/prc/v15n2/14359.pdf >. Acesso em: 12 jun. 2017.

NOGUEIRA, J. L. et al. O comportamento animal e a utilização de terapias alternativas. Arquivo de Ciências Veterinárias e Zoologia da UNIPAR, p. 121-124, 2010. Disponível em: $<$ http://revistas.unipar.br/index.php/veterinaria/article/view/3776>. Acesso em: 12 jun. 2017.

NOSOW, V.; PENICHE, A. C. G. Paciente cirúrgico ambulatorial: calatonia e ansiedade. Acta Paulista de Enfermagem, v. 20, n. 2, p. 161-167, 2007. Disponível em: $<$ http://www.scielo.br/scielo.php?script=sci_arttext\&pid=S0103-21002007000200008>. Acesso em: 12 jun. 2017.

NUÑEZ, H. M. F.; CIOSAK, S. I. Terapias alternativas/complementares: o saber e o fazer das enfermeiras do distrito administrativo 71-Santo Amaro-São Paulo. Revista da Escola de Enfermagem da USP, v. 37, n. 3, p. 11-8, 2003. Disponível em: $<$ http://www.scielo.br/pdf/reeusp/v37n3/02.pdf $>$. Acesso em: 12 jun. 2017. 
OLIVEIRA, A. A.; SALVI, J. O. Percepções de acadêmicos de farmácia sobre a homeopatia. Revista de Homeopatia (São Paulo), v. 77, n. 1/2, p. 16-20, 2014. Disponível em: <http://aph.org.br/revista/index.php/aph/article/view/276/339>. Acesso em: 12 jun. 2017.

OLIVEIRA, F. A. Antropologia nos serviços de saúde: integralidade, cultura e comunicação. Interface - Comunicação, Saúde, Educação, v. 6, n. 10, p. 63-74, 2002. Disponível em: <http://www.scielo.br/pdf/icse/v6n10/06.pdf>. Acesso em: 12 jun. 2017.

OTANI, M. A. P.; BARROS, N. F. A Medicina Integrativa e a construção de um novo modelo na saúde. Ciência \& Saúde Coletiva, v. 16, n. 3, p. 1801-1811, 2011. Disponível em: $<$ http://www.scielo.br/pdf/csc/v16n3/16.pdf>. Acesso em: 12 jun. 2017.

PÉRICO, B. C. et al. Estabilidade locomotora durante a condução de um cão. Motriz: Revista de Educação Física, v. 19, n. 3 - Suplemento, p. S57-S67, 2013. Disponível em: $<$ http://www.scielo.br/pdf/motriz/v19n3s0/a09v19n3s0.pdf >. Acesso em: 12 jun. 2017.

PIMENTA, T. S. Transformações no exercício das artes de curar no Rio de Janeiro durante a primeira metade do Oitocentos. História, Ciências, Saúde-Manguinhos, v. 11, n. 1, p. 67-92, 2004. Disponível em: <http://www.scielo.br/pdf/hcsm/v11s1/03.pdf >. Acesso em: 12 jun. 2017.

QUEIROZ, M. S. O itinerário rumo às medicinas alternativas: uma análise em representações sociais de profissionais da saúde. Cadernos de Saúde Pública, v. 16, n. 2, p. 363-375, 2000. Disponível em: <http://www.scielo.br/pdf/csp/v16n2/2086.pdf>. Acesso em: 12 jun. 2017.

REBERTE, L. M.; HOGA, L. A. K. O desenvolvimento de um grupo de gestantes com a utilização da aobordagem corporal. Texto \& Contexto - Enfermagem, v. 14, n. 2, p. 186192, 2005. Disponível em: <http://www.scielo.br/pdf/tce/v14n2/a05v14n2.pdf $>$. Acesso em: 12 jun. 2017.

RODRIGUES NETO, J. F. et al. Transtornos mentais comuns e o uso de práticas de medicina complementar e alternativa - estudo de base populacional. Jornal Brasileiro de Psiquiatria, v. 57, n. 4, p. 233-9, 2008. Disponível em: $<$ http://www.scielo.br/pdf/jbpsiq/v57n4/a02v57n4.pdf>. Acesso em: 12 jun. 2017.

RODRIGUES NETO, J. F.; FARIA, A. A.; FIGUEIREDO, M. F. S. Medicina complementar e alternativa: utilização pela comunidade de Montes Claros, Minas Gerais. Revista da Associação Médica Brasileira, v. 55, n. 3, p. 296-301, 2009. Disponível em: <http://www.scielo.br/pdf/ramb/v55n3/v55n3a22.pdf>. Acesso em: 12 jun. 2017.

SALLES, L. F.; SILVA, M. J. P. Efeito das essências florais em indivíduos ansiosos. Acta Paulista de Enfermagem, v. 25, n. 2, p. 238-242, 2012. Disponível em: $<$ http://www.scielo.br/pdf/ape/v25n2/a13v25n2.pdf $>$. Acesso em: 12 jun. 2017.

SALLES, L. F.; SILVA, M. J. P. Iridologia: revisão sistemática. Revista da Escola de Enfermagem da USP, v. 42, n. 3, p. 596-600, 2008. Disponível em: $<$ http://www.scielo.br/pdf/reeusp/v42n3/v42n3a25.pdf $>$. Acesso em: 12 jun. 2017.

SANTOS, M. C.; TESSER, C. D. Um método para a implantação e promoção de acesso às Práticas Integrativas e Complementares na Atenção Primária à Saúde. Ciência \& Saúde 
Coletiva, v. 17, n. 11, p. 3011-3024, 2012. Disponível em: $<$ http://www.scielo.br/pdf/csc/v17n11/v17n11a17.pdf $>$. Acesso em: 12 jun. 2017.

SANTOS, R. L. et al. Análise sobre a fitoterapia como prática integrativa no Sistema Único de Saúde. Revista Brasileira de Plantas Medicinais, v. 13, n. 4, p. 486-91, 2011. Disponível em: <http://www.scielo.br/pdf/rbpm/v13n4/a14v13n4.pdf $>$. Acesso em: 12 jun. 2017.

SILVA, A. R.; SOUSA, A. I.; SANT'ANNA, C. C. Práticas de cuidado empregadas no tratamento de crianças $e$ adolescentes com infecção latente por tuberculose. Epidemiologia e Serviços de Saúde, v. 23, n. 3, p. 547-552, set. 2014. Disponível em: $<$ http://www.scielo.br/pdf/ress/v23n3/1679-4974-ress-23-03-00547.pdf >. Acesso em: 12 jun. 2017.

SILVA, G. D.; LAGE, L. V. Ioga e Fibromialgia. Revista Brasileira de Reumatologia, v. 46, n. 1, p. 37-39, 2006. Disponível em: <http://www.scielo.br/pdf/rbr/v46n1/29385.pdf>. Acesso em: 12 jun. 2017.

SOUSA, I. M. C. et al. Práticas integrativas e complementares: oferta e produção de atendimentos no SUS e em municípios selecionados. Cadernos de Saúde Pública, v. 28, n. 11, p. 2143-2154, 2012. Disponível em: <http://www.scielo.br/pdf/csp/v28n11/14.pdf>. Acesso em: 12 jun. 2017.

SOUZA, A. C.; LOPES, M. J. M. Práticas terapêuticas entre idosos de Porto Alegre: uma abordagem qualitativa. Revista da Escola de Enfermagem da USP, p. 52-56, 2007. Disponível em: $<$ https://www.lume.ufrgs.br/bitstream/handle/10183/69662/000194654.pdf?sequence=1 $>$. Acesso em: 12 jun. 2017.

SOUZA, E. F. A. A.; LUZ, M. T. Bases socioculturais das práticas terapêuticas alternativas. História, Ciências, Saúde-Manguinhos, v. 16, n. 2, p. 393-405, 2009. Disponível em: <http://www.scielo.br/pdf/hcsm/v16n2/08.pdf>. Acesso em: 12 jun. 2017.

SPADACIO, C. et al. Medicinas Alternativas e Complementares: uma metassíntese. Cad. Saude Publica, v. 26, n. 1, p. 7-13, 2010. Disponível em: $<$ http://www.scielo.br/pdf/csp/v26n1/02.pdf $>$. Acesso em: 12 jun. 2017.

SPADACIO, C.; BARROS, N. F. Terapêuticas convencionais e não convencionais no tratamento do câncer: os sentidos das práticas religiosas. Interface - Comunicação, Saúde, Educação, v. 13, n. 30, p. 45-52, 2009. Disponível em: $<$ http://www.scielo.br/pdf/icse/v13n30/v13n30a05.pdf>. Acesso em: 12 jun. 2017.

SPADACIO, C.; BARROS, N. F. Uso de medicinas alternativas e complementares por pacientes com câncer: revisão sistemática. Revista de Saúde Pública, v. 42, n. 1, p. 158-64, 2008. Disponível em: <http://www.scielo.org.co/pdf/aven/v33n3/v33n3a05.pdf $>$. Acesso em: 12 jun. 2017.

TASHIRO, M. T. O. et al. Novas tendências terapêuticas de enfermagem: terapias naturais - programa de atendimento. Revista Brasileira de Enfermagem, v. 54, n. 4, p. 658667, dez. 2001. Disponível em: <http://www.scielo.br/pdf/reben/v54n4/v54n4a15.pdf>. Acesso em: 12 jun. 2017. 
TAVARES, F. R. G. Legitimidade terapêutica no Brasil contemporâneo: as terapias alternativas no âmbito do saber psicológico. Physis: Revista de Saúde Coletiva, v. 13, n. 2, p. 83-104, 2003. Disponível em: <http://www.scielo.br/pdf/physis/v13n2/a06v13n2.pdf>. Acesso em: 12 jun. 2017.

TAVARES, F. R. G. A diversidade da rede terapêutica alternativa no Rio de Janeiro. Physis: Revista de Saúde Coletiva, v. 12, n. 2, p. 325-44, 2002. Disponível em: $<$ http://www.scielo.br/pdf/physis/v13n2/a06v13n2>. Acesso em: 12 jun. 2017.

TEIXEIRA, M. Z. Homeopatia: desinformação e preconceito no ensino médico. Revista Brasileira de Educação Médica, v. 31, n. 1, p. 15-20, abr. 2007. Disponível em: $<$ http://www.scielo.br/pdf/rbem/v31n1/03.pdf>. Acesso em: 12 jun. 2017.

TEIXEIRA, M. Z.; LIN, C. A. Educação médica em terapêuticas não convencionais. Revista de Medicina, v. 92, n. 4, p. 224-235, 21 dez. 2013. Disponível em: $<$ http://www.revistas.usp.br/revistadc/article/view/80004>. Acesso em: 12 jun. 2017.

TESSER, C. D.; SOUSA, I. M. C. Atenção Primária, Atenção Psicossocial, Práticas Integrativas e Complementares e suas afinidades eletivas. Saúde e Sociedade, v. 21, n. 2, p. 336-350, 2012. Disponível em: <http://www.scielo.br/pdf/sausoc/v21n2/a08v21n2.pdf>. Acesso em: 12 jun. 2017.

TESSER, C. D. Práticas complementares, racionalidades médicas e promoção da saúde: contribuições poucos exploradas. Cadernos de Saúde Pública, v. 25, n. 8, p. 1732-1742, 2009. Disponível em: <http://www.scielo.br/pdf/csp/v25n8/09.pdf $>$. Acesso em: 12 jun. 2017.

TESSER, C. D.; BARROS, N. F. Medicalização social e medicina alternativa e complementar: pluralização terapêutica do Sistema Único de Saúde. Revista de Saúde Pública, v. 42, n. 5, p. 914-20, 2008. Disponível em: $<$ http://www.scielo.br/pdf/rsp/v42n5/7115.pdf $>$. Acesso em: 12 jun. 2017.

THIAGO, S. C. S.; TESSER, C. D. Percepção de médicos e enfermeiros da Estratégia de Saúde da Família sobre terapias complementares. Revista de Saúde Pública, v. 45, n. 2, p. 249-57, 2011. Disponível em: <http://www.scielo.br/pdf/rsp/v45n2/2243.pdf>. Acesso em: 12 jun. 2017.

TROVO, M. M.; SILVA, J. P.; LEÃO, E. R. Terapias alternativas/complementares no ensino público e privado: análise do conhecimento dos acadêmicos de enfermagem. Revista Latino-americana de Enfermagem, v. 11, n. 4, p. 483-9, 2003. Disponível em: $<$ http://www.scielo.br/pdf/rlae/v11n4/v11n4a11.pdf>. Acesso em: 12 jun. 2017.

TROVÓ, M. M.; SILVA, M. E. P. Terapias alternativas/complementares a visão do graduando de enfermagem. Revista da Escola de Enfermagem da USP, v. 36, n. 1, p. 75-79, 2002. Disponível em: <http://www.scielo.br/pdf/reeusp/v36n1/v36n1a11.pdf $>$. Acesso em: 12 jun. 2017.

VANINI, M. et al. A relação do tubérculo andino yacon com a saúde humana. Ciência, Cuidado e Saúde, v. 8, n. 0, 31 dez. 2009. Disponível em: $<$ http://periodicos.uem.br/ojs/index.php/CiencCuidSaude/article/view/9723/5536>. Acesso em: 12 jun. 2017. 
VIEIRA, J. L. L.; PORCU, M.; BUZZO, V. A. S. A prática da hidroginástica como tratamento complementar para pacientes com transtorno de ansiedade. Jornal Brasileiro de Psiquiatria, v. 58, n. 1, p. 8-16, 2009. Disponível em: $<$ http://www.scielo.br/pdf/jbpsiq/v58n1/a02v58n1.pdf>. Acesso em: 12 jun. 2017.

VEIGA JUNIOR, V. F. Estudo do consumo de plantas medicinais na Região CentroNorte do Estado do Rio de Janeiro: aceitação pelos profissionais de saúde e modo de uso pela população. Revista Brasileira de Farmacognosia, v. 18, n. 2, p. 308-313, 2008. Disponível em: <http://www.scielo.br/pdf/rbfar/v18n2/27.pdf>. Acesso em: 12 jun. 2017.

WILLIAMS, A. V.; MEYER, E.; PECHANSKY, F. Desenvolvimento de um jogo terapêutico para prevenção da recaída e motivação para mudança em jovens usuários de drogas. Psicologia: Teoria e Pesquisa, v. 23, n. 4, p. 407-414, 2007. Disponível em: $<$ http://www.scielo.br/pdf/ptp/v23n4/06.pdf $>$. Acesso em: 12 jun. 2017.

\section{Legislação}

BRASIL. Ministério da Saúde. Portaria n⿳0 971, de 03 de maio de 2006. Aprova a Política Nacional de Práticas Integrativas e Complementares (PNPIC) no Sistema Único de Saúde. 2006. Disponível

em: $<$ http://bvsms.saude.gov.br/bvs/saudelegis/gm/2006/prt0971_03_05_2006.html >. Acesso em: 12 abr. 2017.

BRASIL. Ministério da Saúde. Política Nacional de Práticas Integrativas e Complementares no SUS. 2006. Disponível em: $<$ http://bvsms.saude.gov.br/bvs/publicacoes/pnpic.pdf>. Acesso em: 12 abr. 2017.

\section{Livros}

ALMEIDA, N. M. et al. (Org.). Manual de medicina integrativa: memento fitoterápico. Porto Alegre/RS: Simplíssimo Livros Ltda. 2015. 1ª edição revista e ampliada.

COSTEIRA, O. Terapias naturais e holísticas: quais são, como foram criadas, para que servem, como são usadas. Curitiba/PR: Appris, 2015. 1ª edição. 423 p.

KLEIN, M.; RODRIGUES, R. B. Guia completo das terapias alternativas: métodos terapêuticos naturais que proporcionam saúde integral. Joinville/SC: Clube de Autores Publicações S/A. 2016. $1^{\text {a }}$ edição.

LIMA, P. T. Medicina integrativa: a cura pelo equilíbrio. São Paulo/SP: MG Editores, 2009. $2^{\mathrm{a}}$ edição.

NAIFF, N. Curso completo de terapia holistica \& complementar. Rio de Janeiro/RJ: Bestseller, 2016. $4^{\text {a }}$ edição.

\section{Sites especializados}

Hospital Divina Providência. Ambulatório de Terapias Naturais e Complementares $\mathbf{1}^{\mathbf{0}}$ de maio. Porto Alegre/RS. Disponível em: $<$ http://divinaprovidencia.org.br/rede-de-saudedivina-providencia/acoes-sociais/ > . Acesso em: 12 abr. 2017. 
Sociedade Beneficente Israelita Brasileira Albert Einstein. Bases da Medicina Integrativa. São Paulo/SP. Disponível em: $<$ https://www.einstein.br/ensino/pos_graduacao/bases_da_medicina_integrativa_sp $>$. Acesso em: 17 abr. 2017.

Hospital Sírio-Libanês. Núcleo de Cuidados Integrativos. São Paulo/SP. Disponível em: $<$ https://www.hospitalsiriolibanes.org.br/hospital/especialidades/nucleo-cuidadosintegrativos/Paginas/default.aspx>. Acesso em: 12 abr. 2017.

SINTE - Sociedade Internacional de Terapia. Dicionário de Técnicas. Disponível em: $<$ http://www.sinte.com.br/publico-geral/dicionario-tecnicas $>$. Acesso em: 12 abr. 2017.

Hospital São Paulo. Grupo de Trabalho de Humanização. São Paulo/SP. Disponível em: $<$ http://www.hospitalsaopaulo.org.br/sites/humaniza/projeto_equilibrio_saude.php $>$. Acesso em: 12 abr. 2017.

Governo de Goiás. Secretaria de Estado da Saúde. CREMIC - Centro Estadual de Referência em Medicina Integrativa e Complementar. Goiânia/GO. Disponível em: $<$ http://www.saude.go.gov.br/?unidades=centro-de-especialidades-em-praticas-integrativas-ecomplementares-cremic >. Acesso em: 12 abr. 2017.

Hospital Sofia Feldman. Núcleo de Terapias Integrativas e Complementares. Belo Horizonte/MG. Disponível em: <http://www.sofiafeldman.org.br/atencao-a-mulher/ntintegrativas/>. Acesso em: 12 abr. 2017.

Universidade Federal de São Paulo. Núcleo Anthropos. Núcleo de Integração Mente, Corpo e Espiritualidade. Introdução à Medicina Integrativa. São Paulo/SP. Disponível em: $<$ http://www.nucleoanthropos.com/site/fundamentacao-teorica/medicina-integrativa.html $>$.

Acesso em: 12 abr. 2017.

Complexo Educacional FMU. Musicoterapia. São Paulo/SP. Disponível em: $<$ http://portal.fmu.br/curso/35/0/musicoterapia.aspx>. Acesso em: 17 abr. 2017.

Unisul - Universidade do Sul de Santa Catarina. Naturologia. Tubarão/SC. Disponível em: $<$ http://www.unisul.br/wps/portal/home/ensino/graduacao/naturologia/\#?unidade=11 $>$.

Acesso em: 17 abr. 2017.

Universidade Federal de São Paulo. NUMEPI - Núcleo de Medicina e Práticas Integrativas. São Paulo/SP. $<$ https://www.unifesp.br/reitoria/proex/acoes/nucleos-associados/numepi>. Acesso em: 12 abr. 2017.

Universidade Anhembi Morumbi. Naturologia. Disponível em: $<$ http://portal.anhembi.br/cursos/naturologia/>. São Paulo/SP. Acesso em: 17 abr. 2017.

\section{Corpus de florais brasileiros baseados na alquimia}

ALEIXO, J. Essências florais brasileiras. São Paulo: Editora Ground, 1995. $2^{\text {a }}$ edição. 190p.

ALEIXO, J. Introdução ao Sistema Floral Joel Aleixo. 4 ed. São Paulo: Joel Aleixo Florais e Alquimia. 2014. 122 p. 


\section{BIBLIOGRAFIA DO CORPUS EM INGLESS}

\section{Artigos acadêmicos}

ADAMS, M.; JEWELL, A. The use of complementary and alternative medicine by cancer patients. International Seminars in Surgical Oncology, v. 4, n. 1, p. 10, 2007. Disponível em: <https://www.ncbi.nlm.nih.gov/pmc/articles/PMC1872026/>. Acesso em: 22 abr. 2017.

ARTUS, M.; CROFT, P.; LEWIS, M. The use of CAM and conventional treatments among primary care consulters with chronic musculoskeletal pain. BMC Family Practice, v. $8, \quad$ n. $1, \quad$ p. 26, 2007. Disponível em: $<$ https://www.ncbi.nlm.nih.gov/pmc/articles/PMC1878478/>. Acesso em: 22 abr. 2017.

ASTBURY, N. Alternative eye care. The British Journal of Ophthalmology, v. 85, n. 7, p. 767-768, jul. 2001. Disponível em: <http://bjo.bmj.com/content/85/7/767>. Acesso em: 22 abr. 2017.

BARNES, J. Quality, efficacy and safety of complementary medicines: fashions, facts and the future. Part I: Regulation and quality. British journal of clinical pharmacology, v. 55, n. 3, p. 226-233, 2003a. Disponível em: $<$ https://www.ncbi.nlm.nih.gov/pmc/articles/PMC1884210/pdf/bcp0055-0226.pdf $>$. Acesso em: 22 abr. 2017.

BARNES, J. Quality, efficacy and safety of complementary medicines: fashions, facts and the future. Part II: Efficacy and safety. British journal of clinical pharmacology, v. 55, n. $4, \quad$ p. 331-340, 2003b. Disponível em: $<$ https://www.ncbi.nlm.nih.gov/pmc/articles/PMC1884225/>. Acesso em: 22 abr. 2017.

BARNES, J. et al. Different standards for reporting ADRs to herbal remedies and conventional OTC medicines: face-to-face interviews with 515 users of herbal remedies. $\mathrm{Br} J$ Clin Pharmacol, v. 45, p. 496-500, 1998. Disponível em: $<$ https://www.ncbi.nlm.nih.gov/pmc/articles/PMC1873549/pdf/bcp0045-0496.pdf $>$. Acesso em: 22 abr. 2017.

BARRETT, B. et al. What Complementary and Alternative Medicine Practitioners Say About Health and Health Care. The Annals of Family Medicine, v. 2, n. 3, p. 253-259, 1 maio 2004. Disponível em: $<$ https://www.ncbi.nlm.nih.gov/pmc/articles/PMC1466673/pdf/0020253.pdf $>$. Acesso em: 22 abr. 2017.

BAUM, M. Quack cancer cures or scientific remedies. Journal of the Royal Society of Medicine, v. 89, n. 10, p. 543, out. 1996. Disponível em: $<$ https://www.ncbi.nlm.nih.gov/pmc/articles/PMC1295952/pdf/jrsocmed00050-0009.pdf>. Acesso em: 22 abr. 2017.

BISHOP, F. L.; YARDLEY, L.; LEWITH, G. T. Treat or treatment: a qualitative study analyzing patients' use of complementary and alternative medicine. American Journal of Public Health, v. 98, n. 9, p. 1700, 2008. Disponível em: $<$ https://www.ncbi.nlm.nih.gov/pmc/articles/PMC2509600/pdf/0981700.pdf > Acesso em: 22 abr. 2017. 
BISHOP, J. L. et al. The use of Complementary and Alternative Medicine in pregnancy: Data from the Avon Longitudinal Study of Parents and Children (ALSPAC). Complementary Therapies in Medicine, v. 19, n. 6, p. 303-310, dez. 2011. Disponível em: $<$ https://www.sciencedirect.com/science/article/pii/S0965229911001117?via\%3Dihub>.

Acesso em: 22 abr. 2017.

BODEKER, G.; KRONENBERG, F. A public health agenda for traditional, complementary, and alternative medicine. American Journal of Public Health, v. 92, n. 10, p. 1582-1591, out. 2002. Disponível em: <https://www.ncbi.nlm.nih.gov/pmc/articles/PMC3221447/pdf/0921582.pdf>. Acesso em: 22 abr. 2017.

BOIVIN, J.; SCHMIDT, L. Use of complementary and alternative medicines associated with a 30\% lower ongoing pregnancy/live birth rate during 12 months of fertility treatment. Human Reproduction, v. 24, n. 7, p. 1626-1631, 1 jul. 2009. Disponível em: $<$ https://academic.oup.com/humrep/article/24/7/1626/2357508>. Acesso em: 22 abr. 2017.

BOUDIONI, M. et al. Do men with prostate or colorectal cancer seek different information and support from women with cancer? British Journal of Cancer, v. 85, n. 5, p. 641-648, 5 set. 2001. Disponível em: $<$ https://www.ncbi.nlm.nih.gov/pmc/articles/PMC2364117/>. Acesso em: 22 abr. 2017.

BRECKONS, M. et al. What Do Evaluation Instruments Tell Us About the Quality of Complementary Medicine Information on the Internet? Journal of Medical Internet Research, $\quad$ v. $10, \quad$ n. $1, \quad 2008 . \quad$ Disponível em: $<$ http://www.ncbi.nlm.nih.gov/pmc/articles/PMC2483844/>. Acesso em: 23 jul. 2015. Acesso em: 22 abr. 2017.

BRIEN, S. B. et al. Integrated medicine in the management of chronic illness: a qualitative study. British Journal of General Practice, v. 61, n. 583, p. 89-96, 1 fev. 2011. Disponível em: <https://www.ncbi.nlm.nih.gov/pmc/articles/PMC3026175/pdf/bjgp61e89.pdf>. Acesso em: 22 abr. 2017.

CASSIDY, A. Are herbal remedies and dietary supplements safe and effective for breast cancer patients? Breast Cancer Research, v. 5, n. 6, p. 300-302, 2003. Disponível em: $<$ https://www.ncbi.nlm.nih.gov/pmc/articles/PMC314418/pdf/bcr724.pdf>. Acesso em: 22 abr. 2017.

CHANDOLA, A. et al. Use of complementary therapies by patients attending musculoskeletal clinics. Journal of the Royal Society of Medicine. Disponível em: <https://www.ncbi.nlm.nih.gov/pmc/articles/PMC1297030/>. Acesso em: 22 abr. 2017.

CINCOTTA, D R. et al. Comparison of complementary and alternative medicine use: reasons and motivations between two tertiary children's hospitals. Archives of Disease in Childhood, v. 91, n. 2, p. 153-158, 24 maio 2005. Disponível em: $<$ http://adc.bmj.com/content/91/2/153.long>. Acesso em: 22 abr. 2017.

COLLINS, D.; OAKEY, S.; RAMAKRISHNAN, V. Perioperative use of herbal, complementary, and over the counter medicines in plastic surgery patients. Eplasty, $v$. 11, 2011. Disponível em: $<$ https://www.ncbi.nlm.nih.gov/pmc/articles/PMC3098682/pdf/eplasty11e27.pdf $>$. Acesso em: 22 abr. 2017. 
CRAWFORD, N. W. et al. A cross-sectional survey of complementary and alternative medicine use by children and adolescents attending the University Hospital of Wales. BMC Complementary and Alternative Medicine, v. 6, 2006. Disponível em: $<$ https://www.ncbi.nlm.nih.gov/pmc/articles/PMC1475886/pdf/1472-6882-6-16.pdf >. Acesso em: 22 abr. 2017.

DONALD, G. K; MACKERETH, P.; TOBIN, I. Medical students and acupuncture: a short sharp placement experience! Acupuncture in Medicine, v. 28, n. 1, p. 12-15, 1 mar. 2010. Disponível em: <http://aim.bmj.com/content/28/1/12.long>. Acesso em: 22 abr. 2017.

ERNST, E. Prevalence of use of complementary/alternative medicine: a systematic review. Bulletin of the World Health Organization. Disponível em: $<$ https://www.ncbi.nlm.nih.gov/pmc/articles/PMC2560678/>. Acesso em: 22 abr. 2017.

ERNST, E. Complementary and alternative medicine (CAM) and cancer: The kind face of complementary medicine. International Journal of Surgery, v. 7, n. 6, p. 499-500, 2009. Disponível em: <http://www.journal-surgery.net/article/S1743-9191(09)00115-0/fulltext>. Acesso em: 22 abr. 2017.

ERNST, E. Complementary and alternative medicine for children: a good or a bad thing? Archives of Disease in Childhood, v. 91, n. 2, p. 96-97, 2006. Disponível em: $<$ https://www.ncbi.nlm.nih.gov/pmc/articles/PMC2082708/pdf/96.pdf > Acesso em: 22 abr. 2017.

ERNST, E. Ethical problems arising in evidence based complementary and alternative medicine. Journal of Medical Ethics, v. 30, n. 2, p. 156-159, 1 abr. 2004. Disponível em: $<$ http://jme.bmj.com/content/30/2/156>. Acesso em: 22 abr. 2017.

ERNST, E. How the public is being misled about complementary/alternative medicine. Journal of the Royal Society of Medicine, v. 101, n. 11, p. 528-530, 1 nov. 2008. Disponível em: <https://www.ncbi.nlm.nih.gov/pmc/articles/PMC2586853/>. Acesso em: 22 abr. 2017.

ERNST, E. Patient choice and complementary medicine. Journal of the Royal Society of Medicine, v. 97, n. 1, p. 41-41, 2004. Disponível em: $<$ https://www.ncbi.nlm.nih.gov/pmc/articles/PMC1079272/>. Acesso em: 22 abr. 2017.

ERNST, E. The "Hoddle Muddle": using faith healers and other complementary therapists in sports medicine. British Journal of Sports Medicine, v. 32, n. 3, p. 195, set. 1998.

Disponível

em:

$<$ https://www.ncbi.nlm.nih.gov/pmc/articles/PMC1756105/pdf/v032p00195.pdf > . Acesso em: 22 abr. 2017.

ERNST, E. What's the point of rigorous research on complementary/alternative medicine? Journal of the Royal Society of Medicine, v. 95, n. 4, p. 211-213, 2002. Disponível em: <https://www.ncbi.nlm.nih.gov/pmc/articles/PMC1279522/>. Acesso em: 22 abr. 2017.

ERNST, E. Fatalities after CAM: an overview. British Journal of General Practice, v. 61, p. 404-405, 2011. Disponível em: <https:/www.ncbi.nlm.nih.gov/pmc/articles/PMC3103684/> Acesso em: 22 abr. 2017. 
ERNST, E.; FUGH-BERMAN, A. Complementary and alternative medicine needs an evidence base before regulation. The Western Journal of Medicine. 1999. Disponível em: $<$ https://www.ncbi.nlm.nih.gov/pmc/articles/PMC1305792/>. Acesso em: 22 abr. 2017.

ERNST, E.; FUGH-BERMAN, A. Complementary and alternative medicine: what is it all about? Occupational and Environmental Medicine. 2002. Disponível em: $<$ http://oem.bmj.com/content/59/2/140.long>. Acesso em: 22 abr. 2017.

ERNST, E.; POSADZKI, P.; LEE, M. S. Complementary and alternative medicine (CAM) for sexual dysfunction and erectile dysfunction in older men and women: An overview of systematic reviews. Maturitas, v. 70, n. 1, p. 37-41, set. 2011. Disponível em: $<$ http://www.maturitas.org/article/S0378-5122(11)00210-6/pdf>. Acesso em: 22 abr. 2017.

EVANS, M. et al. Decisions to use complementary and alternative medicine (CAM) by male cancer patients: information-seeking roles and types of evidence used. BMC Complementary and Alternative Medicine, v. 7, n. 1, p. 25, 2007. Disponível em: <https://www.ncbi.nlm.nih.gov/pmc/articles/PMC2000907/>. Acesso em: 22 abr. 2017.

FEATHERSTONE, C. et al. Prevalence Study of Concurrent Use of Complementary and Alternative Medicine in Patients Attending Primary Care Services in Scotland. American Journal of Public Health, v. 93, n. 7, p. 1080-1082, 2003. Disponível em: $<$ https://www.ncbi.nlm.nih.gov/pmc/articles/PMC1447911/>. Acesso em: 22 abr. 2017.

FERRY, P.; JOHNSON, M. WALLIS, P. Use of complementary therapies and nonprescribed medication in patients with Parkinson's disease. Postgraduate Medical Journal, v. $78, \quad$ n. $924, \quad$ p. 612-614, 1 out. 2002. Disponível em: $<$ https://www.ncbi.nlm.nih.gov/pmc/articles/PMC1742510/>. Acesso em: 22 abr. 2017.

FOUNTAIN-POLLEY, S. et al. Knowledge and exposure to complementary and alternative medicine in paediatric doctors: a questionnaire survey. BMC Complementary and Alternative Medicine, v. 7, n. 1, p. 38, 2007. Disponível em: $<$ https://www.ncbi.nlm.nih.gov/pmc/articles/PMC2219994/>. Acesso em: 22 abr. 2017.

GRATUS, C. et al. The use of herbal medicines by people with cancer in the UK: a systematic review of the literature. QJM, v. 102, n. 12, p. 831-842, 1 dez. 2009. Disponível em: <https://academic.oup.com/qjmed/article/102/12/831/1563244>. Acesso em: 22 abr. 2017.

GREENFIELD, S.; PATTISON, H.; JOLLY, K. Use of complementary and alternative medicine and self-tests by coronary heart disease patients. BMC Complementary and Alternative Medicine, v. 8, n. 1, p. 47, 2008. Disponível em: $<$ https://bmccomplementalternmed.biomedcentral.com/articles/10.1186/1472-6882-8-47>.

Acesso em: 22 abr. 2017.

HADLEY, J.; HASSAN, I.; KHAN, K. S. Knowledge and beliefs concerning evidencebased practice amongst complementary and alternative medicine health care practitioners and allied health care professionals: A questionnaire survey. BMC Complementary and Alternative Medicine, v. 8, n. 1, p. 45, 2008. Disponível em: $<$ https://bmccomplementalternmed.biomedcentral.com/articles/10.1186/1472-6882-8-45>. Acesso em: 22 abr. 2017. 
HASLOCK, I. Evaluating new physical treatments. Annals of the Rheumatic Diseases, v. 52, n. 10, p. 697, out. 1993. Disponível em: $<$ https://www.ncbi.nlm.nih.gov/pmc/articles/PMC1005157/>. Acesso em: 22 abr. 2017.

HORI, S. et al. Patterns of complementary and alternative medicine use amongst outpatients in Tokyo, Japan. BMC Complementary and Alternative Medicine, v. 8, n. 1, p. 14, 2008.2 Disponível em: $<$ https://www.ncbi.nlm.nih.gov/pmc/articles/PMC2375857/pdf/1472-6882-8-14.pdf $>$. Acesso em: 22 abr. 2017.

HUNT, K. J. et al. Complementary and alternative medicine use in England: results from a national survey: CAM use in England: A national survey. International Journal of Clinical Practice, v. 64, n. 11, p. 1496-1502, out. 2010. Disponível em: $<$ http://onlinelibrary.wiley.com/doi/10.1111/j.1742-

1241.2010.02484.x/abstract;jsessionid=33D4FBC6A22BEBF3CAED148B05492D51.f04t02> Acesso em: 22 abr. 2017.

HUNTLEY, A.; WHITE, A. R.; ERNST, E. Relaxation therapies for asthma: a systematic review. Thorax, v. 57, n. 2, p. 127-131, 1 fev. 2002. Disponível em: $<$ https://www.ncbi.nlm.nih.gov/pmc/articles/PMC1746244/pdf/v057p00127.pdf $>$. Acesso em: 22 abr. 2017.

JANSEN, R. L. M. et al. Effects of Five Ayurvedic Herbs on Locomotor Behaviour in a Drosophila melanogaster Parkinson's Disease Model. Phytotherapy Research, v. 28, n. 12, p. 1789-1795, dez. 2014. Disponível em: <https://www.ncbi.nlm.nih.gov/pmc/articles/PMC4310928/>. Acesso em: 22 abr. 2017.

JENNINGS, H. M. et al. Food or medicine? The food-medicine interface in households in Sylhet. Journal of Ethnopharmacology, v. 167, p. 97-104, jun. 2015. Disponível em: $<$ https://www.ncbi.nlm.nih.gov/pubmed/25240587>. Acesso em: 22 abr. 2017.

KRAMLICH D. Introduction to complementary, alternative, and traditional therapies. Critical Care Nurse; v. 34, n. 6, p. 50-56; 1 dez. 2014. Disponível em: $<$ https://www.aacn.org/docs/cemedia/C1463.pdf>. Acesso em: 22 abr. 2017.

LADENHEIM, D. et al. Potential health risks of complementary alternative medicines in HIV patients. HIV Medicine, v. 9, n. 8, p. 653-659, set. 2008. Disponível em: $<$ http://onlinelibrary.wiley.com/doi/10.1111/j.1468-1293.2008.00610.x/abstract $>$. Acesso em: 22 abr. 2017.

LEWITH, G. T. Respiratory illness: a complementary perspective. Thorax, v. 53, n. 10, p. 898, out. 1998. Disponível em: $<$ https://www.ncbi.nlm.nih.gov/pmc/articles/PMC1745097/pdf/v053p00898.pdf > . Acesso em: 22 abr. 2017.

LEWITH, G. T.; ROBINSON, N. Complementary and alternative medicine: what the public want and how it may be delivered safely and effectively. JRSM, v. 102, n. 10, p. 411-414, 12 out. 2009.2009 Disponível $<$ http://journals.sagepub.com/doi/abs/10.1258/jrsm.2009.090123?url_ver=Z39.88$2003 \&$ rfr_id $=$ ori\%3Arid\%3Acrossref.org\&rfr_dat $=$ cr_pub\%3Dpubmed\&>. Acesso em: 22 abr. 2017. 
LEWITH, G. T..; HYLAND, M. E.; SHAW, S. Do Attitudes Toward and Beliefs About Complementary Medicine Affect Treatment Outcomes? American Journal of Public Health, v. 92, n. 10, p. 1604-1606, 2002. Disponível em: $<$ https://www.ncbi.nlm.nih.gov/pmc/articles/PMC1447291/>. Acesso em: 22 abr. 2017.

LONG, A. F. The potential of complementary and alternative medicine in promoting well-being and critical health literacy: a prospective, observational study of shiatsu. BMC Complementary and Alternative Medicine, v. 9, n. 1, p. 19, 2009. Disponível em: $<$ https://www.ncbi.nlm.nih.gov/pmc/articles/PMC2706798/>. Acesso em: 22 abr. 2017.

LORENC, A. et al. How parents choose to use CAM: a systematic review of theoretical models. BMC Complementary and Alternative Medicine, v. 9, n. 1, p. 9, 2009. Disponível em: <https://www.ncbi.nlm.nih.gov/pmc/articles/PMC2680396/>. Acesso em: 22 abr. 2017.

LORENC, A.; ROBINSON, N. A Review of the Use of Complementary and Alternative Medicine and HIV: Issues for Patient Care. AIDS Patient Care and STDs, v. 27, n. 9, p. 503-510, set. 2013. Disponível em: <https://www.ncbi.nlm.nih.gov/pmc/articles/PMC3760022/>. Acesso em: 22 abr. 2017.

MACFARLANE, G. J. et al. Evidence for the efficacy of complementary and alternative medicines in the management of rheumatoid arthritis: a systematic review. Rheumatology, v. 50, n. 9, p. 1672-1683, 1 set. 2011. Disponível em: $<$ https://academic.oup.com/rheumatology/article/50/9/1672/1785865 $>$. Acesso em: 22 abr. 2017.

MARLAND, H.; ADAMS, J. Hydropathy at Home:: The Water Cure and Domestic Healing in Mid-Nineteenth-Century Britain. Bulletin of the History of Medicine, p. 499, 2009. Disponível em: <https://www.ncbi.nlm.nih.gov/pmc/articles/PMC2774269/>. Acesso em: 22 abr. 2017.

McCANN, L J.; NEWELL, S. J. Survey of paediatric complementary and alternative medicine use in health and chronic illness. Archives of Disease in Childhood, v. 91, n. 2, p. 173-174, 24 maio 2005.2 Disponível em: $<$ https://www.ncbi.nlm.nih.gov/pmc/articles/PMC2082683/pdf/173.pdf $>$. Acesso em: 22 abr. 2017.

McLAY, J. S. et al. Complementary and alternative medicines use by Scottish women with breast cancer. What, why and the potential for drug interactions? European Journal of Clinical Pharmacology, v. 68, n. 5, p. 811-819, maio 2012. Disponível em: $<$ https://link.springer.com/article/10.1007\%2Fs00228-011-1181-6>. Acesso em: 22 abr. 2017.

MILLS, S. Y. Regulation in complementary and alternative medicine. BMJ: British Medical Journal, v. 322, n. 7279, p. 158, 2001. Disponível em: $<$ http://www.bmj.com/content/322/7279/158>. Acesso em: 22 abr. 2017.

MOLASSIOTIS, A. et al. The effectiveness and cost-effectiveness of acupressure for the control and management of chemotherapy-related acute and delayed nausea: Assessment of Nausea in Chemotherapy Research (ANCHoR), a randomised controlled trial. Health Technol Assess, v. 17, n. 26, jun. 2013. Disponível em: $<$ https://www.journalslibrary.nihr.ac.uk/hta/hta17260/\#/abstract/>. Acesso em: 22 abr. 2017.

MUÑOZ-SELLÉS, E.; VALLÈS-SEGALÉS, A.; GOBERNA-TRICAS, J. Use of alternative and complementary therapies in labor and delivery care: a cross-sectional study of 
midwives' training in Catalan hospitals accredited as centers for normal birth. BMC Complementary and Alternative Medicine, v. 13, n. 1, dez. 2013. Disponível em: $<$ http://bmccomplementalternmed.biomedcentral.com/articles/10.1186/1472-6882-13-318>.

Acesso em: 22 abr. 2017.

NEWSOM-DAVIS, T. et al. Voodoo dolls and the cancer patient: patients do trust their doctors. QJM, v. 102, n. 5, p. 311-319, 1 maio 2009. Disponível em: $<$ https://academic.oup.com/qjmed/article/102/5/311/1603513>. Acesso em: 22 abr. 2017.

ONAKPOYA, I. J. et al. Food Supplements for Body Weight Reduction: A Systematic Review of Systematic Reviews. Obesity, v. 19, n. 2, p. 239-244, fev. 2011. Disponível em: $<$ http://onlinelibrary.wiley.com/doi/10.1038/oby.2010.185/abstract $>$. Acesso em: 22 abr. 2017.

ONG, C. K. et al. Health status of people using complementary and alternative medical practitioner services in 4 English counties. American Journal of Public Health, v. 92, n. 10, p. 1653-1656, 2002. Disponível em: <https://www.ncbi.nlm.nih.gov/pmc/articles/PMC1447302/>. Acesso em: 22 abr. 2017.

OWEN, D. K; LEWITH, G.; STEPHENS, C. R. Can doctors respond to patients' increasing interest in complementary and alternative medicine? British Medical Journal, $\begin{array}{llll}\mathrm{v} . & 322, & \text { p. } & 154-158,\end{array}$ $<$ https://www.ncbi.nlm.nih.gov/pmc/articles/PMC1119418/pdf/154.pdf>. Acesso em: 22 abr. 2017.

PETERS, D. Complementary therapies in the NHS: some thoughts and three cases. London Journal of Primary Care, v. 1, n. 2, p. 108, 2008. Disponível em: $<$ https://www.ncbi.nlm.nih.gov/pmc/articles/PMC4212729/pdf/LJPC-01-108.pdf $>$. Acesso em: 22 abr. 2017.

PIETRONI, P. C. The interface between complementary medicine and general practice. Journal of the Royal Society of Medicine, v. 87, n. Suppl 22, p. 28, 1994. Disponível em: $<$ https://www.ncbi.nlm.nih.gov/pmc/articles/PMC1294197/pdf/jrsocmed00076-0031.pdf $>$. Acesso em: 22 abr. 2017.

PLAUT, G. S. A comparison of the attitudes shown by general practitioners, hospital doctors and medical students towards alternative medicine. Med Journal of the Royal Society of Medicine. Disponível em: $<$ https://www.ncbi.nlm.nih.gov/pmc/articles/PMC1295180/>. Acesso em: 22 abr. 2017.

POSADZKI, P. et al. Prevalence of use of complementary and alternative medicine (CAM) by patients/consumers in the UK: systematic review of surveys. Clinical Medicine, v. 13, n. 2, p. 126-131, 2013. Disponível em: $<$ http://www.clinmed.rcpjournal.org/content/13/2/126.long>. Acesso em: 22 abr. 2017.

POWER, M.; HOPAYIAN, K. Exposing the evidence gap for complementary and alternative medicine to be integrated into science-based medicine. Journal of the Royal Society of Medicine, v. 104, n. 4, p. 155-161, 1 abr. 2011. Disponível em: $<$ https://www.ncbi.nlm.nih.gov/pmc/articles/PMC3078611/>. Acesso em: 22 abr. 2017.

RAFFERTY, J.; TSIKOUDAS, A.; DAVIS, B. C. Ear candling: should general practitioners recommend it? Canadian Family Physician, v. 53, n. 12, p. 2121-2122, 2007. 
Disponível em: <https://www.ncbi.nlm.nih.gov/pmc/articles/PMC2231549/>. Acesso em: 22 abr. 2017.

RAMPES, H. et al. Introducing complementary medicine into the medical curriculum. Journal of the Royal Society of Medicine. Disponível em: $<$ https://www.ncbi.nlm.nih.gov/pmc/articles/PMC1296110/>. Acesso em: 22 abr. 2017.

REES, M. Alternative treatments for the menopause. Best Practice \& Research Clinical Obstetrics \& Gynaecology, v. 23, n. 1, p. 151-161, fev. 2009. Disponível em: $<$ https://www.sciencedirect.com/science/article/pii/S1521693408001466?via\%3Dihub>. Acesso em: 22 abr. 2017.

RHODES, P. J. et al. The use of biomedicine, complementary and alternative medicine, and ethnomedicine for the treatment of epilepsy among people of South Asian origin in the UK. BMC Complementary and Alternative Medicine, v. 8, n. 1, p. 7, 2008. Disponível em: <https://www.ncbi.nlm.nih.gov/pmc/articles/PMC2329602/>. Acesso em: 22 abr. 2017.

RICHARDSON, J. What Patients Expect From Complementary Therapy: A Qualitative Study. American Journal of Public Health, v. 94, n. 6, p. 1049-1053, 2004. Disponível em: $<$ https://www.ncbi.nlm.nih.gov/pmc/articles/PMC1448388/pdf/0941049.pdf >. Acesso em: 22 abr. 2017.

RÜDELL, K.; BHUI, K.; PRIEBE, S. Do "alternative" help-seeking strategies affect primary care service use? A survey of help-seeking for mental distress. BMC Public Health, v. 8, n. 1, p. 207, 2008. Disponível em: $<$ https://www.ncbi.nlm.nih.gov/pmc/articles/PMC2443800/pdf/1471-2458-8-207.pdf>. Acesso em: 22 abr. 2017.

RYAN, A. et al. Factors associated with self-care activities among adults in the United Kingdom: a systematic review. BMC Public Health, v. 9, n. 1, p. 96, 2009. Disponível em: $<$ https://www.ncbi.nlm.nih.gov/pmc/articles/PMC2674604/>. Acesso em: 22 abr. 2017.

SERFATY, M. et al. The ToT Study: Helping with Touch or Talk (ToT): a pilot randomised controlled trial to examine the clinical effectiveness of aromatherapy massage versus cognitive behaviour therapy for emotional distress in patients in cancer/palliative care. Psycho-Oncology, v. 21, n. 5, p. 563-569, maio 2012. Disponível em: $<$ http://onlinelibrary.wiley.com/doi/10.1002/pon.1921/full>. Acesso em: 22 abr. 2017.

SHAKEEL, M. et al. Use of complementary and alternative medicine by patients admitted to a surgical unit in Scotland. Annals of The Royal College of Surgeons of England, v. $90, \quad$ n. 7, p. 571-576, 1 out. 2008. Disponível em: $<$ https://www.ncbi.nlm.nih.gov/pmc/articles/PMC2728305/pdf/rcse9007-571.pdf $>$. Acesso em: 22 abr. 2017.

SHAKEEL, M.; TRINIDADE, A.; AH-SEE, K. W. Complementary and alternative medicine use by otolaryngology patients: a paradigm for practitioners in all surgical specialties. European Archives of Otorhinolaryngology, v. 267, n. 6, p. 961-971, jun. 2010. Disponível em: <https://link.springer.com/article/10.1007\%2Fs00405-009-1098-1>. Acesso em: 22 abr. 2017.

SHAKIR, T.; COULIBALY, A. Y; KEHOE, P. G. An exploration of the potential mechanisms and translational potential of five medicinal plants for applications in Alzheimer's disease. American Journal of Neurodegenerative Disease, v. 2, p. 70-88, 2012. 
Disponível em: <https://www.ncbi.nlm.nih.gov/pmc/articles/PMC3703121/pdf/ajnd00020070.pdf>. Acesso em: 22 abr. 2017.

SHAW, A.; THOMPSON, E. A.; SHARP, D. Complementary therapy use by patients and parents of children with asthma and the implications for NHS care: a qualitative study. BMC Health Services Research, v. 6, n. 1, p. 76, 2006. Disponível em: $<$ https://www.ncbi.nlm.nih.gov/pmc/articles/PMC1538997/pdf/1472-6963-6-76.pdf $>$. Acesso em: 22 abr. 2017.

SHUMER, G. et al. Complementary and alternative medicine use by visitors to rural Japanese family medicine clinics: results from the international complementary and alternative medicine survey. BMC complementary and alternative medicine, v. 14, n. 1, p. 360, 2014. Disponível em: $<$ https://bmccomplementalternmed.biomedcentral.com/articles/10.1186/1472-6882-14-360>. Acesso em: 22 abr. 2017.

SMITH, K. R.; SAMPSON, W. Word Use and Semantics in Alternative Medicine: A Survey of Editors of Medical and Related Journals. The Medscape Journal of Medicine, v. 10, n. 5, p. 125, 2008. Disponível em: <https://www.medscape.com/viewarticle/572553>. Acesso em: 22 abr. 2017.

SOUNDY, A. et al. Experiences of healing therapy in patients with irritable bowel syndrome and inflammatory bowel disease. BMC Complementary and Alternative Medicine, v. 15, n. 1, dez. 2015. Disponível em: <http://www.biomedcentral.com/14726882/15/106>. Acesso em: 23 jul. 2015. Acesso em: 22 abr. 2017.

STEWART, D. et al. Healthcare professional views and experiences of complementary and alternative therapies in obstetric practice in North East Scotland: a prospective questionnaire survey. BJOG: An International Journal of Obstetrics \& Gynaecology, v. 121, n. $8, \quad$ p. 1015-1019, jul. 2014. Disponível em: $<$ http://onlinelibrary.wiley.com/doi/10.1111/1471-0528.12618/abstract>. Acesso em: 22 abr. 2017.

STICKLEY, A. et al. Prevalence and factors associated with the use of alternative (folk) medicine practitioners in 8 countries of the former Soviet Union. BMC Complementary and Alternative Medicine, v. 13, n. 1, p. 83, 2013. Disponível em: $<$ https://www.ncbi.nlm.nih.gov/pmc/articles/PMC3636035/>. Acesso em: 22 abr. 2017.

STONEMAN, P. et al. Incommensurable Worldviews? Is Public Use of Complementary and Alternative Medicines Incompatible with Support for Science and Conventional Medicine? Plos One, v. 8, n. 1, p. e53174, 30 jan. 2013. Disponível em: $<$ http://journals.plos.org/plosone/article?id=10.1371/journal.pone.0053174>. Acesso em: 22 abr. 2017.

STRINGER, J.; DONALD, G. Aromasticks in cancer care: An innovation not to be Sniffed at. Complementary Therapies in Clinical Practice, v. 17, n. 2, p. 116-121, maio 2011. Disponível em: $<$ https://www.sciencedirect.com/science/article/pii/S1744388110000496?via\%3Dihub>. Acesso em: 22 abr. 2017. 
THOMPSON, E. A. Alternative and complementary therapies for the menopause: A homeopathic approach. Maturitas, v. 66, n. 4, p. 350-354, ago. 2010. Disponível em: $<$ http://www.maturitas.org/article/S0378-5122(10)00053-8/pdf>. Acesso em: 22 abr. 2017.

VINCENT, C.; FURNHAM, A. Complementary medicine: state of the evidence. Journal of the Royal Society of Medicine, v. 92, n. 4, p. 170, abr. 1999. Disponível em: $<$ https://www.ncbi.nlm.nih.gov/pmc/articles/PMC1297137/>. Acesso em: 22 abr. 2017.

WELSH, S. et al. Moving forward? Complementary and alternative practitioners seeking self-regulation. Sociology of Health and Illness, v. 26, n. 2, p. 216-241, mar. 2004. Disponível em: $\quad<$ http://onlinelibrary.wiley.com/doi/10.1111/j.14679566.2004.00387.x/abstract>. Acesso em: 22 abr. 2017.

WERNEKE, U. et al. Potential health risks of complementary alternative medicines in cancer patients. British Journal of Cancer, v. 90, n. 2, p. 408-413, 26 jan. 2004. Disponível em: $\quad<$ https://www.ncbi.nlm.nih.gov/pmc/articles/PMC2410154/pdf/90-6601560a.pdf>. Acesso em: 22 abr. 2017.

WHITE, A.; EDITORIAL Board of Acupuncture in Medicine. Western medical acupuncture: a definition. Acupuncture in Medicine, v. 27, n. 1, p. 33-35, 1 mar. 2009. Disponível em: <http://aim.bmj.com/content/27/1/33>. Acesso em: 22 abr. 2017.

WILKIE, A.; CORDESS, C. Ginseng--a root just like a carrot? Journal of the Royal Society of Medicine. Disponível em: $<$ https://www.ncbi.nlm.nih.gov/pmc/articles/PMC1294848/pdf/jrsocmed00080-0024.pdf>. Acesso em: 22 abr. 2017. Acesso em: 22 abr. 2017.

WILliAMS, T. I. Evaluating Effects of Aromatherapy Massage on Sleep in Children with Autism: A Pilot Study. Evidence-Based Complementary and Alternative Medicine, v. 3, n. 3, p. 373-377, 2006. Disponível em: $<$ https://www.ncbi.nlm.nih.gov/pmc/articles/PMC1513142/pdf/nel017.pdf $>$. Acesso em: 22 abr. 2017.

WYE, L. et al. Complementary or alternative? The use of homeopathic products and antibiotics amongst pre-school children. BMC Family Practice, v. 9, n. 1, p. 8, 2008. Disponível em: < https://www.ncbi.nlm.nih.gov/pmc/articles/PMC2270831/>. Acesso em: 22 abr. 2017.

WYE, L.; SHARP, D.; SHAW, A. The impact of NHS based primary care complementary therapy services on health outcomes and NHS costs: a review of service audits and evaluations. BMC Complementary and Alternative Medicine, v. 9, n. 1, p. 5, 2009. Disponível em: <https://www.ncbi.nlm.nih.gov/pmc/articles/PMC2667472/pdf/14726882-9-5.pdf>. Acesso em: 22 abr. 2017.

WYE, L.; SHAW, A.; SHARP, D. Designing a "NHS friendly" complementary therapy service: A qualitative case study. BMC Health Services Research, v. 8, n. 1, p. 173, 2008. Disponível em: <https:/www.ncbi.nlm.nih.gov/pmc/articles/PMC2529289/pdf/1472-6963-8173.pdf $>$. Acesso em: 22 abr. 2017.

YOUNGER, P.; BODDY, K. When is a search not a search? A comparison of searching the amed complementary health database via EBSCOhost, OVID and DIALOG. Health Information \& Libraries Journal, v. 26, n. 2, p. 126-135, jun. 2009. Disponível em: $<$ http://onlinelibrary.wiley.com/doi/10.1111/j.1471-1842.2008.00785.x/abstract $>$. 


\section{Legislação}

GRCCT - The General Regulatory Council for Complementary Therapies. Regulation. Disponível em: <http://www.grcct.org/>. Acesso em: 24 abr. 2017. , [S.d.]

House of Lords - Science and Technology. Sixth Report. Disponível em: $<$ https://www.publications.parliament.uk/pa/ld199900/ldselect/ldsctech/123/12301.htm>.

Acesso em: 24 abr. 2017.

\section{Livro}

BODDY, K. et al. Oxford Handbook of Complementary Medicine. Oxford University Press, 2008.

\section{Sites especializados}

BCIM - British College of Integrative Medicine. Disponível em: $<$ http://www.integrativemedicine.uk.com/index.php>. Acesso em: 24 abr. 2017.

BSIM - British Society of Integrated Medicine. Disponível em: <http://www.bsim.org.uk/>. Acesso em: 24 abr. 2017.

CARDIFF METROPOLITAN UNIVERSITY. Complementary Healthcare Degree Course. Disponível em: <http://www.cardiffmet.ac.uk/health/courses/Pages/ComplementaryHealthcare-BSc-(Hons).aspx>. Acesso em: 24 abr. 2017.

FEDERATION OF HOLISTIC THERAPISTS. Directory. Disponível em: < https://www.fht.org.uk/>. Acesso em: 24 abr. 2017.

RLHIM - ROYAL LONDON HOSPITAL FOR INTEGRATED MEDICINE. Disponível em: $<$ https://www.uclh.nhs.uk/OurServices/ServiceA-Z/INTMED/Pages/Home.aspx $>$. Acesso em: 24 abr. 2017.

SCHOOL OF NATURAL MEDICINE UK. Disponível em: $<$ https://www.herenowhealing.com/>. Acesso em: 24 abr. 2017.

PURE HEALTH SCHOOL OF NATURAL MEDICINE. Naturopathy Diploma. Disponível em: $\quad<$ https://purehealth.com/naturopathy-training-cambridge-england/naturopath-naturalphysician-diploma/>. Acesso em: 24 abr. 2017.

UNIVERSITY OF GREENWICH. Equine Sports Therapy and Rehabilitation, BSc (Hons) (Hadlow College). Disponível em: $<$ http://www.gre.ac.uk/ug/pc/bsc-hons-equinesports-therapy-and-rehabilitation>. Acesso em: 24 abr. 2017. 


\section{APÊNDICE I - LISTA DE PALAVRAS-CHAVE DO CORPUS EM PORTUGUÊS}

\begin{tabular}{|c|c|c|c|c|c|}
\hline $\mathbf{N}$ & Keyword & Freq. & $\%$ & Texts & Keyness \\
\hline 1 & PRÁTICAS & 1836 & 0,23 & 92 & 1020,92 \\
\hline 2 & ACUPUNTURA & 816 & 0,10 & 59 & 801,29 \\
\hline 3 & COMPLEMENTARES & 937 & 0,12 & 81 & 781,71 \\
\hline 4 & TERAPIAS & 855 & 0,11 & 95 & 756,57 \\
\hline 5 & FLORAIS & 674 & 0,08 & 34 & 661,80 \\
\hline 6 & HOMEOPATIA & 761 & 0,09 & 62 & 659,42 \\
\hline 7 & MEDICINA & 2040 & 0,25 & 100 & 652,58 \\
\hline 8 & $\mathrm{E}$ & 28417 & 3,50 & 118 & 602,62 \\
\hline 9 & ALTERNATIVAS & 747 & 0,09 & 83 & 555,22 \\
\hline 10 & PLANTAS & 799 & 0,10 & 48 & 477,07 \\
\hline 11 & FITOTERAPIA & 510 & 0,06 & 56 & 453,90 \\
\hline 12 & INTEGRATIVAS & 435 & 0,05 & 41 & 427,08 \\
\hline 13 & CORPO & 1087 & 0,13 & 71 & 421,48 \\
\hline 14 & CURA & 623 & 0,08 & 67 & 420,85 \\
\hline 15 & MEDICINAIS & 563 & 0,07 & 43 & 406,93 \\
\hline 16 & ESSÊNCIAS & 397 & 0,05 & 14 & 389,76 \\
\hline 17 & TERAPIA & 811 & 0,10 & 78 & 386,86 \\
\hline 18 & TERAPÊUTICAS & 488 & 0,06 & 70 & 383,14 \\
\hline 19 & ESPIRITUAL & 387 & 0,05 & 36 & 379,94 \\
\hline 20 & MAC & 388 & 0,05 & 17 & 359,63 \\
\hline 21 & PIC & 355 & 0,04 & 13 & 348,52 \\
\hline 22 & CUIDADO & 801 & 0,10 & 68 & 345,24 \\
\hline 23 & ENERGIA & 641 & 0,08 & 34 & 339,40 \\
\hline 24 & PROFISSIONAIS & 1036 & 0,13 & 100 & 319,67 \\
\hline 25 & TRATAMENTO & 1436 & 0,18 & 99 & 311,11 \\
\hline 26 & ANSIEDADE & 546 & 0,07 & 39 & 306,32 \\
\hline 27 & DIETA & 449 & 0,06 & 17 & 292,39 \\
\hline 28 & MEDICINAS & 287 & 0,04 & 44 & 270,32 \\
\hline 29 & USO & 1508 & 0,19 & 101 & 265,51 \\
\hline 30 & CONVENCIONAL & 386 & 0,05 & 50 & 257,41 \\
\hline 31 & PSICOLOGIA & 369 & 0,05 & 25 & 255,05 \\
\hline 32 & FLORAL & 255 & 0,03 & 17 & 250,33 \\
\hline 33 & CHÁ & 265 & 0,03 & 25 & 248,88 \\
\hline 34 & CHINESA & 271 & 0,03 & 45 & 246,18 \\
\hline 35 & MEDITAÇÃO & 261 & 0,03 & 40 & 244,99 \\
\hline 36 & TERAPÊUTICO & 378 & 0,05 & 76 & 242,38 \\
\hline 37 & TERAPÊUTICA & 568 & 0,07 & 83 & 236,51 \\
\hline 38 & RELAXAMENTO & 306 & 0,04 & 41 & 235,72 \\
\hline 39 & CHACRA & 239 & 0,03 & 2 & 234,62 \\
\hline 40 & PRÁTICA & 791 & 0,10 & 101 & 229,82 \\
\hline 41 & MENTE & 301 & 0,04 & 41 & 221,13 \\
\hline 42 & ENTREVISTADOS & 361 & 0,04 & 40 & 216,56 \\
\hline 43 & MASSAGEM & 238 & 0,03 & 31 & 214,30 \\
\hline 44 & TRADICIONAL & 345 & 0,04 & 69 & 213,88 \\
\hline
\end{tabular}




\begin{tabular}{|c|c|c|c|c|c|}
\hline 45 & COMPLEMENTARY & 227 & 0,03 & 34 & 211,88 \\
\hline 46 & EQUILÍBRIO & 336 & 0,04 & 49 & 206,17 \\
\hline 47 & INTEGRATIVA & 205 & 0,03 & 31 & 201,24 \\
\hline 48 & SAÚDE & 4250 & 0,52 & 109 & 196,25 \\
\hline 49 & ERVAS & 233 & 0,03 & 40 & 195,72 \\
\hline 50 & HOLÍSTICA & 207 & 0,03 & 37 & 192,43 \\
\hline 51 & DOR & 578 & 0,07 & 51 & 189,60 \\
\hline 52 & MEDICINE & 292 & 0,04 & 37 & 187,20 \\
\hline 53 & CHACRAS & 186 & 0,02 & 4 & 182,59 \\
\hline 54 & PROMOÇÃO & 361 & 0,04 & 50 & 181,12 \\
\hline 55 & BIOMEDICINA & 182 & 0,02 & 22 & 178,66 \\
\hline 56 & COMPLEMENTAR & 328 & 0,04 & 71 & 175,75 \\
\hline 57 & PROFISSIONAL & 481 & 0,06 & 78 & 172,28 \\
\hline 58 & PNPIC & 169 & 0,02 & 21 & 165,90 \\
\hline 59 & TERAPEUTAS & 187 & 0,02 & 30 & 165,19 \\
\hline 60 & TERAPÊUTICOS & 253 & 0,03 & 55 & 165,08 \\
\hline 61 & MENTAL & 297 & 0,04 & 40 & 163,13 \\
\hline 62 & MAGNETISMO & 173 & 0,02 & 7 & 159,41 \\
\hline 63 & RACIONALIDADES & 159 & 0,02 & 28 & 156,08 \\
\hline 64 & ALTERNATIVE & 213 & 0,03 & 32 & 155,44 \\
\hline 65 & CIENTÍFICO & 370 & 0,05 & 50 & 153,70 \\
\hline 66 & FLORES & 174 & 0,02 & 11 & 152,71 \\
\hline 67 & EMOCIONAL & 263 & 0,03 & 46 & 148,16 \\
\hline 68 & COR & 261 & 0,03 & 14 & 146,51 \\
\hline 69 & CONVENCIONAIS & 216 & 0,03 & 50 & 144,82 \\
\hline 70 & TERAPEUTA & 225 & 0,03 & 33 & 144,63 \\
\hline 71 & MERIDIANOS & 147 & 0,02 & 10 & 144,30 \\
\hline 72 & ENERGIAS & 147 & 0,02 & 18 & 144,30 \\
\hline 73 & ÁGUA & 521 & 0,06 & 26 & 144,11 \\
\hline 74 & ENERGÉTICO & 171 & 0,02 & 16 & 143,24 \\
\hline 75 & CAMPO & 524 & 0,06 & 73 & 140,97 \\
\hline 76 & FOLHAS & 178 & 0,02 & 15 & 138,34 \\
\hline 77 & ROSA & 254 & 0,03 & 12 & 137,53 \\
\hline 78 & TRATAMENTOS & 282 & 0,03 & 66 & 136,13 \\
\hline 79 & YOGA & 138 & 0,02 & 22 & 135,47 \\
\hline 80 & TOQUE & 147 & 0,02 & 29 & 134,21 \\
\hline 81 & TAC & 134 & 0,02 & 3 & 131,54 \\
\hline 82 & AROMATERAPIA & 134 & 0,02 & 15 & 131,54 \\
\hline 83 & NATUROLOGIA & 134 & 0,02 & 5 & 131,54 \\
\hline 84 & ALECRIM & 132 & 0,02 & 11 & 129,58 \\
\hline 85 & SUS & 645 & 0,08 & 51 & 126,84 \\
\hline 86 & APS & 128 & 0,02 & 6 & 125,65 \\
\hline 87 & REIKI & 128 & 0,02 & 23 & 125,65 \\
\hline 88 & ERVA & 138 & 0,02 & 20 & 125,50 \\
\hline 89 & FÍSICO & 375 & 0,05 & 63 & 124,70 \\
\hline 90 & HARMONIA & 137 & 0,02 & 27 & 124,53 \\
\hline 91 & NATURAIS & 229 & 0,03 & 50 & 123,47 \\
\hline 92 & POSOLOGIA & 125 & 0,02 & 4 & 122,70 \\
\hline 93 & ATENÇÃO & 842 & 0,10 & 83 & 122,04 \\
\hline 94 & PARADIGMA & 170 & 0,02 & 36 & 121,20 \\
\hline 95 & ESTRESSE & 247 & 0,03 & 30 & 120,01 \\
\hline 96 & CORRETAS & 158 & 0,02 & 8 & 119,88 \\
\hline
\end{tabular}




\begin{tabular}{|c|c|c|c|c|c|}
\hline 97 & ÓLEOS & 238 & 0,03 & 14 & 118,63 \\
\hline 98 & INDICACCÕES & 218 & 0,03 & 25 & 117,66 \\
\hline 99 & TÉCNICAS & 507 & 0,06 & 69 & 117,08 \\
\hline 100 & LAVANDA & 119 & 0,01 & 7 & 116,81 \\
\hline 101 & CIÊNCIA & 411 & 0,05 & 49 & 115,08 \\
\hline 102 & ESSENCIAIS & 202 & 0,02 & 21 & 114,22 \\
\hline 103 & LIÇÃO & 140 & 0,02 & 2 & 113,99 \\
\hline 104 & NOME & 346 & 0,04 & 30 & 113,21 \\
\hline 105 & VEGETAL & 166 & 0,02 & 16 & 113,21 \\
\hline 106 & CROMOTERAPIA & 113 & 0,01 & 18 & 110,92 \\
\hline 107 & YIN & 112 & 0,01 & 12 & 109,94 \\
\hline 108 & CRISTAL & 129 & 0,02 & 5 & 109,72 \\
\hline 109 & LUZ & 319 & 0,04 & 36 & 108,93 \\
\hline 110 & ESPIRITUAIS & 126 & 0,02 & 32 & 106,87 \\
\hline 111 & ESPIRITUALIDADE & 108 & 0,01 & 13 & 106,02 \\
\hline 112 & POPULAR & 207 & 0,03 & 45 & 105,73 \\
\hline 113 & HOMEOPÁTICA & 117 & 0,01 & 19 & 105,21 \\
\hline 114 & PACIENTE & 760 & 0,09 & 84 & 104,40 \\
\hline 115 & IMAGINAÇÃO & 106 & 0,01 & 13 & 104,05 \\
\hline 116 & EFICÁCIA & 288 & 0,04 & 71 & 102,11 \\
\hline 117 & BIOÉTICA & 131 & 0,02 & 8 & 100,14 \\
\hline 118 & RADIESTESIA & 102 & 0,01 & 7 & 100,13 \\
\hline 119 & FITOTERÁPICOS & 231 & 0,03 & 24 & 99,84 \\
\hline 120 & $\mathrm{CHI}$ & 118 & 0,01 & 20 & 99,28 \\
\hline 121 & AMETISTA & 101 & 0,01 & 2 & 99,14 \\
\hline 122 & MTC & 99 & 0,01 & 6 & 97,18 \\
\hline 123 & ENERGÉTICA & 108 & 0,01 & 11 & 96,54 \\
\hline 124 & YANG & 115 & 0,01 & 13 & 96,43 \\
\hline 125 & CAM & 98 & 0,01 & 11 & 96,20 \\
\hline 126 & CORPORAL & 183 & 0,02 & 32 & 95,52 \\
\hline 127 & $\mathrm{BACH}$ & 120 & 0,01 & 23 & 95,27 \\
\hline 128 & THERAPIES & 105 & 0,01 & 26 & 93,65 \\
\hline 129 & SABERES & 139 & 0,02 & 28 & 93,52 \\
\hline 130 & VIOLETA & 118 & 0,01 & 3 & 93,41 \\
\hline 131 & MÉDICAS & 277 & 0,03 & 61 & 92,64 \\
\hline 132 & AMARELO & 103 & 0,01 & 6 & 91,72 \\
\hline 133 & ALTERNATIVA & 325 & 0,04 & 73 & 90,72 \\
\hline 134 & ANIMAL & 319 & 0,04 & 21 & 90,41 \\
\hline 135 & STENGERS & 92 & 0,01 & 4 & 90,31 \\
\hline 136 & VIDA & 1067 & 0,13 & 96 & 89,70 \\
\hline 137 & ESTIMULA & 160 & 0,02 & 16 & 89,39 \\
\hline 138 & VISÃO & 320 & 0,04 & 57 & 89,33 \\
\hline 139 & ESF & 89 & 0,01 & 12 & 87,36 \\
\hline 140 & PENSAMENTO & 179 & 0,02 & 30 & 86,52 \\
\hline 141 & MINERAIS & 104 & 0,01 & 20 & 86,03 \\
\hline 142 & ANTROPOSÓFICA & 87 & 0,01 & 14 & 85,40 \\
\hline 143 & PÉS & 103 & 0,01 & 13 & 85,09 \\
\hline 144 & PLANO & 268 & 0,03 & 27 & 84,78 \\
\hline 145 & MCA & 86 & 0,01 & 8 & 84,42 \\
\hline 146 & SHIATSU & 86 & 0,01 & 14 & 84,42 \\
\hline 147 & SINERGIA & 102 & 0,01 & 3 & 84,15 \\
\hline 148 & SUJEITOS & 175 & 0,02 & 41 & 83,41 \\
\hline
\end{tabular}




\begin{tabular}{|c|c|c|c|c|c|}
\hline 149 & EFEITOS & 483 & 0,06 & 83 & 83,36 \\
\hline 150 & AZUL & 140 & 0,02 & 9 & 82,89 \\
\hline 151 & AURA & 93 & 0,01 & 4 & 82,11 \\
\hline 152 & CRÔNICAS & 126 & 0,02 & 42 & 82,10 \\
\hline 153 & CLIENTE & 92 & 0,01 & 20 & 81,15 \\
\hline 154 & ENFERMEIRO & 146 & 0,02 & 27 & 81,12 \\
\hline 155 & PONTOS & 293 & 0,04 & 36 & 81,12 \\
\hline 156 & COAR & 82 & 0,01 & 1 & 80,49 \\
\hline 157 & HOMEOPÁTICOS & 82 & 0,01 & 23 & 80,49 \\
\hline 158 & GOTAS & 104 & 0,01 & 11 & 80,41 \\
\hline 159 & LARANJA & 108 & 0,01 & 9 & 79,08 \\
\hline 160 & MUSCULAR & 147 & 0,02 & 19 & 78,74 \\
\hline 161 & HTTP & 158 & 0,02 & 26 & 78,56 \\
\hline 162 & ESMERALDA & 80 & & 2 & 78,53 \\
\hline 163 & MUSICOTERAPIA & 96 & 0,01 & 18 & 78,50 \\
\hline 164 & CONHECIMENTO & 606 & 0,07 & 92 & 77,95 \\
\hline 165 & TÉCNICA & 583 & 0,07 & 53 & 77,61 \\
\hline 166 & QUIROPRAXIA & 79 & & 18 & 77,55 \\
\hline 167 & VERDE & 197 & 0,02 & 11 & 77,36 \\
\hline 168 & ENFERMAGEM & 528 & 0,07 & 46 & 77,18 \\
\hline 169 & BR & 196 & 0,02 & 59 & 76,65 \\
\hline 170 & AUTOCURA & 78 & & 10 & 76,57 \\
\hline 171 & ENERGÉTICOS & 87 & 0,01 & 14 & 76,35 \\
\hline 172 & OFERTA & 171 & 0,02 & 34 & 75,08 \\
\hline 173 & CAMOMILA & 76 & & 13 & 74,60 \\
\hline 174 & HOLÍSTICO & 90 & 0,01 & 27 & 72,86 \\
\hline 175 & CORES & 127 & 0,02 & 10 & 72,01 \\
\hline 176 & INTEGRALIDADE & 100 & 0,01 & 25 & 71,83 \\
\hline 177 & ÓLEO & 228 & 0,03 & 11 & 71,82 \\
\hline 178 & INCENSO & 73 & & 3 & 71,66 \\
\hline 179 & ESCORES & 73 & & 13 & 71,66 \\
\hline 180 & RACIONALIDADE & 118 & 0,01 & 31 & 71,39 \\
\hline 181 & OCIDENTAL & 109 & 0,01 & 33 & 71,24 \\
\hline 182 & ESPÍRITO & 130 & 0,02 & 27 & 71,21 \\
\hline 183 & DORES & 159 & 0,02 & 31 & 71,15 \\
\hline 184 & CRISTAIS & 169 & 0,02 & 10 & 71,11 \\
\hline 185 & TRADICIONAIS & 165 & 0,02 & 51 & 70,60 \\
\hline 186 & RELIGIÃO & 133 & 0,02 & 29 & 70,50 \\
\hline 187 & FLOR & 87 & 0,01 & 9 & 70,05 \\
\hline 188 & GRUPO & 879 & 0,11 & 72 & 69,90 \\
\hline 189 & DOI & 71 & & 2 & 69,69 \\
\hline 190 & SOLAR & 71 & & 6 & 69,69 \\
\hline 191 & DAS & 4033 & 0,50 & 116 & 68,91 \\
\hline 192 & FLORIANÓPOLIS & 96 & 0,01 & 15 & 68,22 \\
\hline 193 & IRIDOLOGIA & 69 & & 13 & 67,73 \\
\hline 194 & CANDOMBLÉ & 69 & & 4 & 67,73 \\
\hline 195 & DENTRE & 174 & 0,02 & 56 & 67,72 \\
\hline 196 & AUTOCONHECIMENTO & 68 & & 11 & 66,75 \\
\hline 197 & HIPNOSE & 68 & & 15 & 66,75 \\
\hline 198 & MESMER & 68 & & 3 & 66,75 \\
\hline 199 & QUARTZO & 83 & 0,01 & 3 & 66,31 \\
\hline 200 & EXERCÍCIOS & 178 & 0,02 & 32 & 66,13 \\
\hline
\end{tabular}




\begin{tabular}{|c|c|c|c|c|c|}
\hline 201 & PLANTA & 181 & 0,02 & 22 & 66,08 \\
\hline 202 & PROPRIEDADES & 238 & 0,03 & 28 & 65,76 \\
\hline 203 & MEDICINAL & 88 & 0,01 & 19 & 65,69 \\
\hline 204 & SESSÕES & 98 & 0,01 & 22 & 65,66 \\
\hline 205 & LIMÃO & 75 & & 11 & 64,87 \\
\hline 206 & CORPORAIS & 110 & 0,01 & 24 & 64,63 \\
\hline 207 & XÍCARAS & 81 & & 4 & 64,44 \\
\hline 208 & ADOECIMENTO & 81 & & 26 & 64,44 \\
\hline 209 & DOCE & 91 & 0,01 & 14 & 63,73 \\
\hline 210 & CHÁS & 91 & 0,01 & 32 & 63,73 \\
\hline 211 & CIENTÍFICA & 287 & 0,04 & 71 & 63,73 \\
\hline 212 & AVILAMICINA & 64 & & 2 & 62,82 \\
\hline 213 & SOBRE & 1756 & 0,22 & 112 & 62,63 \\
\hline 214 & HORTELÃ & 63 & & 12 & 61,84 \\
\hline 215 & MENTAIS & 122 & 0,02 & 32 & 61,69 \\
\hline 216 & PACIENTES & 1121 & 0,14 & 85 & 61,67 \\
\hline 217 & ACADÊMICOS & 93 & 0,01 & 21 & 61,27 \\
\hline 218 & RELAÇÃO & 996 & 0,12 & 106 & 61,15 \\
\hline 219 & PNCS & 62 & & 3 & 60,86 \\
\hline 220 & MASSOTERAPIA & 61 & & 14 & 59,88 \\
\hline 221 & AYURVÉDICA & 61 & & 16 & 59,88 \\
\hline 222 & FORMA & 1234 & 0,15 & 107 & 59,83 \\
\hline 223 & FAMÍLIA & 497 & 0,06 & 55 & 59,68 \\
\hline 224 & SESSÃO & 126 & 0,02 & 21 & 59,18 \\
\hline 225 & INSÔNIA & 69 & & 11 & 59,14 \\
\hline 226 & ÍRIS & 69 & & 5 & 59,14 \\
\hline 227 & DANÇAS & 69 & & 6 & 59,14 \\
\hline 228 & AYURVEDA & 60 & & 15 & 58,90 \\
\hline 229 & REFLEXOLOGIA & 60 & & 15 & 58,90 \\
\hline 230 & PSICOEMOCIONAL & 60 & & 3 & 58,90 \\
\hline 231 & FREUD & 60 & & 8 & 58,90 \\
\hline 232 & VEGETAIS & 111 & 0,01 & 21 & 58,89 \\
\hline 233 & BIOMÉDICO & 75 & & 22 & 58,86 \\
\hline 234 & CURAR & 122 & 0,02 & 29 & 58,83 \\
\hline 235 & CRENÇAS & 103 & 0,01 & 37 & 58,77 \\
\hline 236 & SUA & 2158 & 0,27 & 112 & 58,57 \\
\hline 237 & RESPONDERAM & 85 & 0,01 & 23 & 58,38 \\
\hline 238 & ERICKSON & 59 & & 4 & 57,91 \\
\hline 239 & TERMALISMO & 59 & & 17 & 57,91 \\
\hline 240 & ESSENCIAL & 166 & 0,02 & 20 & 57,85 \\
\hline 241 & NATURAL & 216 & 0,03 & 54 & 57,31 \\
\hline 242 & MUSICAL & 109 & 0,01 & 8 & 57,27 \\
\hline 243 & FRUTAS & 101 & 0,01 & 11 & 57,11 \\
\hline 244 & HOMEOPÁTICO & 58 & & 15 & 56,93 \\
\hline 245 & CHESTNUT & 58 & & 5 & 56,93 \\
\hline 246 & CNES & 58 & & 3 & 56,93 \\
\hline 247 & MODALIDADES & 88 & 0,01 & 28 & 56,90 \\
\hline 248 & ENXAQUECA & 108 & 0,01 & 9 & 56,47 \\
\hline 249 & FERVER & 66 & & 2 & 56,29 \\
\hline 250 & HOMEOPATA & 66 & & 17 & 56,29 \\
\hline 251 & MILENAR & 57 & & 15 & 55,95 \\
\hline 252 & MERIDIANO & 57 & & 5 & 55,95 \\
\hline
\end{tabular}




\begin{tabular}{|c|c|c|c|c|c|}
\hline 253 & CORPOS & 82 & 0,01 & 15 & 55,71 \\
\hline 254 & LÚDICO & 77 & & 3 & 55,68 \\
\hline 255 & FREQUÊNCIA & 77 & & 20 & 55,68 \\
\hline 256 & MELHORA & 221 & 0,03 & 51 & 55,53 \\
\hline 257 & QUESTIONÁRIO & 103 & 0,01 & 33 & 55,51 \\
\hline 258 & INDICADO & 128 & 0,02 & 20 & 55,49 \\
\hline 259 & DIMENSÃO & 144 & 0,02 & 35 & 55,35 \\
\hline 260 & MÉDICO & 722 & 0,09 & 82 & 55,25 \\
\hline 261 & RESPIRAÇÃO & 134 & 0,02 & 14 & 55,05 \\
\hline 262 & EQUILIBRADOR & 56 & & 2 & 54,97 \\
\hline 263 & YACON & 56 & & 1 & 54,97 \\
\hline 264 & GONG & 56 & & 13 & 54,97 \\
\hline 265 & MÉHEUST & 56 & & 3 & 54,97 \\
\hline 266 & GERÂNIO & 56 & & 3 & 54,97 \\
\hline 267 & IOGA & 76 & & 15 & 54,78 \\
\hline 268 & UTILIZAM & 102 & 0,01 & 38 & 54,70 \\
\hline 269 & $\mathrm{OU}$ & 4164 & 0,51 & 110 & 54,55 \\
\hline 270 & ALIMENTOS & 265 & 0,03 & 24 & 54,44 \\
\hline 271 & MÉDICOS & 594 & 0,07 & 75 & 54,29 \\
\hline 272 & ESCORE & 55 & & 10 & 53,99 \\
\hline 273 & ORAÇÃO & 55 & & 12 & 53,99 \\
\hline 274 & CANCER & 89 & 0,01 & 14 & 53,97 \\
\hline 275 & EMOCIONAIS & 112 & 0,01 & 33 & 53,82 \\
\hline 276 & ALOPÁTICA & 63 & & 23 & 53,43 \\
\hline 277 & SENTIMENTOS & 115 & 0,01 & 28 & 53,41 \\
\hline 278 & ALEGRIA & 88 & 0,01 & 14 & 53,12 \\
\hline 279 & CALATONIA & 54 & & 7 & 53,01 \\
\hline 280 & TEA & 54 & & 4 & 53,01 \\
\hline 281 & BANHOS & 54 & & 12 & 53,01 \\
\hline 282 & BERGAMOTA & 54 & & 3 & 53,01 \\
\hline 283 & DESEQUILÍBRIO & 92 & 0,01 & 18 & 52,99 \\
\hline 284 & ARTE & 137 & 0,02 & 36 & 52,61 \\
\hline 285 & MÃOS & 143 & 0,02 & 19 & 52,46 \\
\hline 286 & APLICAÇÃO & 271 & 0,03 & 54 & 52,41 \\
\hline 287 & RESUMO & 127 & 0,02 & 99 & 52,31 \\
\hline 288 & ALTERNATIVOS & 73 & & 29 & 52,07 \\
\hline 289 & CANELA & 53 & & 8 & 52,02 \\
\hline 290 & TMC & 53 & & 1 & 52,02 \\
\hline 291 & INTEGRAL & 154 & 0,02 & 36 & 51,76 \\
\hline 292 & AROMA & 61 & & 8 & 51,53 \\
\hline 293 & TRADIÇÃO & 90 & 0,01 & 31 & 51,32 \\
\hline 294 & PENSAMENTOS & 77 & & 13 & 51,30 \\
\hline 295 & BANHO & 119 & 0,01 & 8 & 51,28 \\
\hline 296 & ACUPUNTURISTA & 52 & & 11 & 51,04 \\
\hline 297 & DESINTOXICAÇÃO & 52 & & 7 & 51,04 \\
\hline 298 & DX & 52 & & 2 & 51,04 \\
\hline 299 & FOGO & 81 & & 11 & 50,83 \\
\hline 300 & ALMA & 89 & 0,01 & 21 & 50,49 \\
\hline 301 & ESSÊNCIA & 80 & & 12 & 49,97 \\
\hline 302 & UTILIZA & 136 & 0,02 & 33 & 49,73 \\
\hline 303 & USE & 136 & 0,02 & 26 & 49,73 \\
\hline 304 & TAI & 65 & & 18 & 49,61 \\
\hline
\end{tabular}




\begin{tabular}{|c|c|c|c|c|c|}
\hline 305 & CHINA & 79 & & 20 & 49,11 \\
\hline 306 & PAIN & 50 & & 5 & 49,08 \\
\hline 307 & ESCLAREIA & 50 & & 1 & 49,08 \\
\hline 308 & LINKS & 50 & & 2 & 49,08 \\
\hline 309 & VILO & 50 & & 2 & 49,08 \\
\hline 310 & CAPC & 50 & & 1 & 49,08 \\
\hline 311 & CIENTÍFICAS & 116 & 0,01 & 43 & 49,05 \\
\hline 312 & COLOCAR & 144 & 0,02 & 17 & 49,02 \\
\hline 313 & MASSAGENS & 58 & & 20 & 48,69 \\
\hline 314 & MÚSICA & 196 & 0,02 & 21 & 48,58 \\
\hline 315 & PERSPECTIVA & 214 & 0,03 & 48 & 48,52 \\
\hline 316 & SÉCULO & 273 & 0,03 & 36 & 48,50 \\
\hline 317 & ESTATISTICAMENTE & 69 & & 18 & 48,47 \\
\hline 318 & EXPERIÊNCIAS & 226 & 0,03 & 54 & 48,16 \\
\hline 319 & FILOSOFIA & 118 & 0,01 & 30 & 48,12 \\
\hline 320 & MA & 101 & 0,01 & 24 & 48,04 \\
\hline 321 & CULTURAL & 157 & 0,02 & 47 & 48,03 \\
\hline 322 & CONTUDO & 154 & 0,02 & 37 & 47,93 \\
\hline 323 & USADA & 218 & 0,03 & 28 & 47,91 \\
\hline 324 & RELIGIOSAS & 63 & & 25 & 47,77 \\
\hline 325 & INSERÇÃO & 142 & 0,02 & 32 & 47,67 \\
\hline 326 & UTILIZADAS & 194 & 0,02 & 63 & 47,42 \\
\hline 327 & PESSOA & 417 & 0,05 & 47 & 47,32 \\
\hline 328 & POLARIZAÇÃO & 48 & & 1 & 47,12 \\
\hline 329 & REICH & 48 & & 6 & 47,12 \\
\hline 330 & VIBRACIONAL & 48 & & 4 & 47,12 \\
\hline 331 & MANIPULAÇÃO & 110 & 0,01 & 27 & 47,07 \\
\hline 332 & CULTURAIS & 129 & 0,02 & 46 & 47,00 \\
\hline 333 & $\mathrm{XX}$ & 67 & & 22 & 46,68 \\
\hline 334 & ÍNDIGO & 47 & & 3 & 46,14 \\
\hline 335 & CIDREIRA & 47 & & 10 & 46,14 \\
\hline 336 & AGULHAS & 61 & & 14 & 45,93 \\
\hline 337 & AUTOCUIDADO & 61 & & 19 & 45,93 \\
\hline 338 & QUESTIONADOS & 55 & & 18 & 45,85 \\
\hline 339 & AS & 6130 & 0,75 & 116 & 45,79 \\
\hline 340 & MODO & 507 & 0,06 & 73 & 45,32 \\
\hline 341 & CITRINO & 46 & & 2 & 45,15 \\
\hline 342 & AUTOESTIMA & 46 & & 7 & 45,15 \\
\hline 343 & ORIENTAL & 46 & & 17 & 45,15 \\
\hline 344 & OCIDENTE & 60 & & 18 & 45,01 \\
\hline 345 & RESOLUÇÃO & 126 & 0,02 & 46 & 44,93 \\
\hline 346 & INDIVÍDUO & 305 & 0,04 & 63 & 44,86 \\
\hline 347 & ENFERMEIRAS & 140 & 0,02 & 13 & 44,42 \\
\hline 348 & CONSEQUENTEMENTE & 45 & & 15 & 44,17 \\
\hline 349 & MIGRAINE & 45 & & 1 & 44,17 \\
\hline 350 & PODEMOS & 175 & 0,02 & 30 & 43,98 \\
\hline 351 & MESTRE & 73 & & 19 & 43,98 \\
\hline 352 & ENFERMEIROS & 99 & 0,01 & 31 & 43,87 \\
\hline 353 & $\mathrm{COMO}$ & 5163 & 0,64 & 117 & 43,86 \\
\hline 354 & SEU & 1358 & 0,17 & 109 & 43,76 \\
\hline 355 & POPULARES & 124 & 0,02 & 30 & 43,56 \\
\hline 356 & RELIGIOSA & 68 & & 26 & 43,43 \\
\hline
\end{tabular}




\begin{tabular}{|c|c|c|c|c|c|}
\hline 357 & FADIGA & 84 & 0,01 & 12 & 43,25 \\
\hline 358 & TENSÕES & 44 & & 14 & 43,19 \\
\hline 359 & APPLE & 44 & & 3 & 43,19 \\
\hline 360 & CRAB & 44 & & 3 & 43,19 \\
\hline 361 & PLEXO & 44 & & 3 & 43,19 \\
\hline 362 & VITALIDADE & 58 & & 12 & 43,18 \\
\hline 363 & HOMEOPATAS & 58 & & 18 & 43,18 \\
\hline 364 & SIGNIFICADOS & 72 & & 23 & 43,14 \\
\hline 365 & VITAMINAS & 63 & & 12 & 43,12 \\
\hline 366 & MÉDICA & 511 & 0,06 & 72 & 43,06 \\
\hline 367 & SEUS & 1011 & 0,12 & 103 & 42,84 \\
\hline 368 & INTERESSE & 280 & 0,03 & 67 & 42,81 \\
\hline 369 & PERCEPÇÃO & 178 & 0,02 & 50 & 42,68 \\
\hline 370 & PALAVRAS & 180 & 0,02 & 82 & 42,34 \\
\hline 371 & ELETIVA & 57 & & 5 & 42,27 \\
\hline 372 & DIRETRIZ & 62 & & 10 & 42,23 \\
\hline 373 & INTEGRAIS & 43 & & 10 & 42,21 \\
\hline 374 & CONTRAINDICAÇÕES & 43 & & 7 & 42,21 \\
\hline 375 & EQUOTERAPIA & 43 & & 2 & 42,21 \\
\hline 376 & VITAL & 119 & 0,01 & 21 & 42,20 \\
\hline 377 & TA & 106 & 0,01 & 9 & 41,77 \\
\hline 378 & INFUSÃO & 66 & & 7 & 41,70 \\
\hline 379 & MOVIMENTO & 261 & 0,03 & 43 & 41,47 \\
\hline 380 & FÓRMULA & 78 & & 10 & 41,46 \\
\hline 381 & EQUILIBRAR & 56 & & 14 & 41,36 \\
\hline 382 & BAIADÔ & 42 & & 1 & 41,23 \\
\hline 383 & CECO & 42 & & 2 & 41,23 \\
\hline 384 & LIAN & 42 & & 12 & 41,23 \\
\hline 385 & ESSENCES & 42 & & 2 & 41,23 \\
\hline 386 & ONCOLÓGICOS & 50 & & 14 & 41,13 \\
\hline 387 & INSATISFAÇÃO & 50 & & 25 & 41,13 \\
\hline 388 & FISIOTERAPEUTA & 50 & & 8 & 41,13 \\
\hline 389 & FUNDAMENTOS & 65 & & 28 & 40,84 \\
\hline 390 & RPM & 65 & & 4 & 40,84 \\
\hline 391 & RACIONAL & 65 & & 28 & 40,84 \\
\hline 392 & DIVERSAS & 243 & 0,03 & 69 & 40,67 \\
\hline 393 & REFERIRAM & 60 & & 16 & 40,46 \\
\hline 394 & TAIS & 374 & 0,05 & 75 & 40,42 \\
\hline 395 & LIMPEZA & 91 & 0,01 & 12 & 40,40 \\
\hline 396 & INSPIRE & 41 & & 2 & 40,25 \\
\hline 397 & CAPIM & 41 & & 8 & 40,25 \\
\hline 398 & HIDROTERAPIA & 41 & & 13 & 40,25 \\
\hline 399 & PÊNDULO & 49 & & 4 & 40,19 \\
\hline 400 & ASTRAL & 49 & & 7 & 40,19 \\
\hline 401 & LIVROS & 116 & 0,01 & 21 & 40,15 \\
\hline 402 & ASSIM & 765 & 0,09 & 98 & 39,89 \\
\hline 403 & PELE & 188 & 0,02 & 21 & 39,72 \\
\hline 404 & AUTOAVALIAÇÃO & 40 & & 1 & 39,26 \\
\hline 405 & CHERTOK & 40 & & 4 & 39,26 \\
\hline 406 & PERRY & 40 & & 5 & 39,26 \\
\hline 407 & CHINESES & 40 & & 10 & 39,26 \\
\hline 408 & SALMONELLA & 40 & & 2 & 39,26 \\
\hline
\end{tabular}




\begin{tabular}{|c|c|c|c|c|c|}
\hline 409 & COLOQUE & 48 & & 7 & 39,25 \\
\hline 410 & QUANTO & 544 & 0,07 & 97 & 39,08 \\
\hline 411 & CÃO & 75 & & 6 & 39,04 \\
\hline 412 & DEPRESSÃO & 148 & 0,02 & 32 & 39,00 \\
\hline 413 & MODERNA & 102 & 0,01 & 29 & 38,92 \\
\hline 414 & QUIMIOTERAPIA & 82 & 0,01 & 19 & 38,82 \\
\hline 415 & SABEDORIA & 53 & & 11 & 38,63 \\
\hline 416 & ROSAS & 53 & & 3 & 38,63 \\
\hline 417 & DANÇA & 85 & 0,01 & 12 & 38,44 \\
\hline 418 & INTENSIDADE & 85 & 0,01 & 27 & 38,44 \\
\hline 419 & $\mathrm{TP}$ & 47 & & 1 & 38,31 \\
\hline 420 & STUDENTS & 39 & & 11 & 38,28 \\
\hline 421 & DECOCÇÃO & 39 & & 4 & 38,28 \\
\hline 422 & RELIGIÕES & 39 & & 16 & 38,28 \\
\hline 423 & WHITE & 39 & & 9 & 38,28 \\
\hline 424 & UTILIZAÇÃO & 447 & 0,06 & 79 & 37,90 \\
\hline 425 & PASSADAS & 57 & & 10 & 37,81 \\
\hline 426 & RAIZ & 57 & & 11 & 37,81 \\
\hline 427 & ORGÂNICO & 57 & & 12 & 37,81 \\
\hline 428 & PROMOVE & 84 & 0,01 & 21 & 37,69 \\
\hline 429 & TREE & 61 & & 3 & 37,40 \\
\hline 430 & INTUIÇÃO & 46 & & 7 & 37,37 \\
\hline 431 & SUAS & 870 & 0,11 & 92 & 37,31 \\
\hline 432 & FENG & 38 & & 3 & 37,30 \\
\hline 433 & DIURÉTICO & 38 & & 4 & 37,30 \\
\hline 434 & XÍCARA & 38 & & 6 & 37,30 \\
\hline 435 & LAURENCE & 38 & & 4 & 37,30 \\
\hline 436 & MEDICAMENTOS & 336 & 0,04 & 66 & 37,25 \\
\hline 437 & EMOÇÕES & 90 & 0,01 & 28 & 37,18 \\
\hline 438 & PREPARO & 173 & 0,02 & 14 & 37,01 \\
\hline 439 & SIGNIFICATIVA & 142 & 0,02 & 43 & 37,00 \\
\hline 440 & POLÍTICA & 348 & 0,04 & 48 & 36,91 \\
\hline 441 & TODAS & 553 & 0,07 & 80 & 36,84 \\
\hline 442 & ESTIMULAR & 105 & 0,01 & 28 & 36,75 \\
\hline 443 & COMISSÕES & 72 & & 5 & 36,64 \\
\hline 444 & MAIL & 60 & & 32 & 36,55 \\
\hline 445 & INTERMÉDIO & 60 & & 16 & 36,55 \\
\hline 446 & HUMOR & 79 & & 14 & 36,51 \\
\hline 447 & INCONSCIENTE & 45 & & 9 & 36,43 \\
\hline 448 & EPISTEMOLÓGICAS & 45 & & 11 & 36,43 \\
\hline 449 & RADIÔNICA & 37 & & 7 & 36,32 \\
\hline 450 & ORIXÁS & 37 & & 4 & 36,32 \\
\hline 451 & CALMANTE & 37 & & 7 & 36,32 \\
\hline 452 & UNIVERSO & 138 & 0,02 & 38 & 36,21 \\
\hline 453 & ALIMENTARES & 75 & & 20 & 36,14 \\
\hline 454 & USUÁRIOS & 348 & 0,04 & 48 & 36,07 \\
\hline 455 & ESCLARECIDO & 55 & & 35 & 36,06 \\
\hline 456 & NATUREZA & 258 & 0,03 & 54 & 35,86 \\
\hline 457 & OFICIAL & 121 & 0,01 & 35 & 35,85 \\
\hline 458 & POSTURA & 118 & 0,01 & 33 & 35,73 \\
\hline 459 & REFERENCIAIS & 59 & & 13 & 35,70 \\
\hline 460 & DIRETRIZES & 91 & 0,01 & 31 & 35,58 \\
\hline
\end{tabular}




\begin{tabular}{|c|c|c|c|c|c|}
\hline 461 & SOFRIMENTO & 91 & 0,01 & 36 & 35,58 \\
\hline 462 & $\mathrm{SC}$ & 44 & & 24 & 35,49 \\
\hline 463 & ALÍVIO & 103 & 0,01 & 32 & 35,39 \\
\hline 464 & SI & 225 & 0,03 & 56 & 35,37 \\
\hline 465 & SHUI & 36 & & 3 & 35,34 \\
\hline 466 & OSTEOPATIA & 36 & & 8 & 35,34 \\
\hline 467 & IMPATIENS & 36 & & 4 & 35,34 \\
\hline 468 & OBJETIVO & 365 & 0,04 & 94 & 35,30 \\
\hline 469 & CHUAN & 49 & & 18 & 35,01 \\
\hline 470 & ESCOLAS & 161 & 0,02 & 36 & 34,56 \\
\hline 471 & EFEITO & 312 & 0,04 & 61 & 34,53 \\
\hline 472 & MODERNO & 83 & 0,01 & 13 & 34,45 \\
\hline 473 & INTEGRATIVE & 35 & & 11 & 34,36 \\
\hline 474 & CEREAIS & 35 & & 6 & 34,36 \\
\hline 475 & VIVÊNCIAS & 35 & & 16 & 34,36 \\
\hline 476 & JUNG & 35 & & 5 & 34,36 \\
\hline 477 & HORTA & 35 & & 6 & 34,36 \\
\hline 478 & SEQUÊNCIA & 35 & & 12 & 34,36 \\
\hline 479 & CHOCOLATE & 35 & & 5 & 34,36 \\
\hline 480 & IDEIA & 35 & & 10 & 34,36 \\
\hline 481 & HOLÍSTICAS & 35 & & 10 & 34,36 \\
\hline 482 & PSICOLÓGICO & 86 & 0,01 & 27 & 34,28 \\
\hline 483 & ALTERNATIVO & 69 & & 18 & 34,27 \\
\hline 484 & RECIFE & 48 & & 8 & 34,11 \\
\hline 485 & AFECÇÕES & 48 & & 14 & 34,11 \\
\hline 486 & CRISE & 101 & 0,01 & 24 & 34,05 \\
\hline 487 & AMOR & 137 & 0,02 & 17 & 34,04 \\
\hline 488 & ARTES & 65 & & 14 & 34,04 \\
\hline 489 & EIXO & 57 & & 15 & 34,00 \\
\hline 490 & PAZ & 79 & & 10 & 33,94 \\
\hline 491 & $\mathrm{NO}$ & 6732 & 0,83 & 118 & 33,75 \\
\hline 492 & HOLISMO & 42 & & 10 & 33,62 \\
\hline 493 & DESCRITORES & 42 & & 29 & 33,62 \\
\hline 494 & ALEGRE & 68 & & 19 & 33,48 \\
\hline 495 & QUENTE & 52 & & 5 & 33,44 \\
\hline 496 & PERFRINGENS & 34 & & 2 & 33,37 \\
\hline 497 & ORIENTAIS & 34 & & 11 & 33,37 \\
\hline 498 & LTA & 34 & & 1 & 33,37 \\
\hline 499 & PIRÂMIDE & 34 & & 5 & 33,37 \\
\hline 500 & ATIVADOR & 34 & & 2 & 33,37 \\
\hline 501 & INOCULAÇÃO & 34 & & 2 & 33,37 \\
\hline 502 & TESSER & 34 & & 8 & 33,37 \\
\hline 503 & HOMEOPÁTICAS & 34 & & 10 & 33,37 \\
\hline 504 & CRENOTERAPIA & 34 & & 10 & 33,37 \\
\hline 505 & POSTURAL & 47 & & 10 & 33,21 \\
\hline 506 & AFIRMARAM & 60 & & 25 & 33,11 \\
\hline 507 & CRIADOR & 60 & & 9 & 33,11 \\
\hline 508 & ACEITAÇÃO & 122 & 0,02 & 41 & 33,05 \\
\hline 509 & DIMENSÕES & 102 & 0,01 & 38 & 32,77 \\
\hline 510 & MEDICALIZAÇÃO & 51 & & 11 & 32,57 \\
\hline 511 & DOMINANTES & 51 & & 7 & 32,57 \\
\hline 512 & MEDIANTE & 63 & & 25 & 32,44 \\
\hline
\end{tabular}




\begin{tabular}{|c|c|c|c|c|c|}
\hline 513 & ELIXIR & 33 & & 4 & 32,39 \\
\hline 514 & NEUBERN & 33 & & 4 & 32,39 \\
\hline 515 & INDÍGENA & 33 & & 14 & 32,39 \\
\hline 516 & PRATICANTE & 33 & & 7 & 32,39 \\
\hline 517 & BOLDO & 33 & & 8 & 32,39 \\
\hline 518 & HARMONIZAÇÃO & 33 & & 10 & 32,39 \\
\hline 519 & VIBRAÇÕES & 46 & & 7 & 32,31 \\
\hline 520 & FALECEU & 46 & & 2 & 32,31 \\
\hline 521 & PRATICANTES & 59 & & 20 & 32,29 \\
\hline 522 & INCLUSÃO & 139 & 0,02 & 49 & 32,20 \\
\hline 523 & FÍSICOS & 139 & 0,02 & 34 & 32,20 \\
\hline 524 & HUMANO & 401 & 0,05 & 63 & 31,87 \\
\hline 525 & BERTRAND & 40 & & 5 & 31,76 \\
\hline 526 & SUJEITO & 153 & 0,02 & 35 & 31,57 \\
\hline 527 & ESPECIALIZAÇÃO & 103 & 0,01 & 20 & 31,56 \\
\hline 528 & DIETAS & 58 & & 18 & 31,47 \\
\hline 529 & PULSO & 45 & & 8 & 31,42 \\
\hline 530 & ORTOMOLECULAR & 32 & & 8 & 31,41 \\
\hline 531 & ADSTRINGENTE & 32 & & 5 & 31,41 \\
\hline 532 & ALTERN & 32 & & 5 & 31,41 \\
\hline 533 & MINUTOS & 145 & 0,02 & 22 & 31,29 \\
\hline 534 & PEDRAS & 65 & & 8 & 31,14 \\
\hline 535 & ORGÂNICA & 65 & & 13 & 31,14 \\
\hline 536 & ACESSO & 269 & 0,03 & 63 & 31,11 \\
\hline 537 & CARTAS & 61 & & 5 & 30,84 \\
\hline 538 & CÓDIGOS & 39 & & 11 & 30,82 \\
\hline 539 & SER & 2520 & 0,31 & 115 & 30,61 \\
\hline 540 & EMPREGAR & 44 & & 10 & 30,52 \\
\hline 541 & CURSO & 308 & 0,04 & 60 & 30,46 \\
\hline 542 & INVEJA & 31 & & 4 & 30,43 \\
\hline 543 & CRISTALOTERAPIA & 31 & & 6 & 30,43 \\
\hline 544 & ALOPÁTICOS & 31 & & 15 & 30,43 \\
\hline 545 & ALOPÁTICO & 31 & & 14 & 30,43 \\
\hline 546 & PROPICIA & 31 & & 11 & 30,43 \\
\hline 547 & BALANCEAMENTO & 31 & & 3 & 30,43 \\
\hline 548 & MESMERISMO & 31 & & 4 & 30,43 \\
\hline 549 & ACUPUNTURISTAS & 31 & & 9 & 30,43 \\
\hline 550 & INDIANA & 31 & & 9 & 30,43 \\
\hline 551 & EPISTEMOLÓGICOS & 31 & & 6 & 30,43 \\
\hline 552 & FENÔMENOS & 101 & 0,01 & 22 & 30,28 \\
\hline 553 & SONO & 98 & 0,01 & 21 & 30,17 \\
\hline 554 & PROCURA & 130 & 0,02 & 53 & 30,01 \\
\hline 555 & CONTEMPORÂNEA & 48 & & 19 & 29,98 \\
\hline 556 & REUMATISMO & 48 & & 6 & 29,98 \\
\hline 557 & SENTIDOS & 86 & 0,01 & 26 & 29,94 \\
\hline 558 & ALOPATIA & 38 & & 16 & 29,89 \\
\hline 559 & CURAS & 38 & & 13 & 29,89 \\
\hline 560 & EXPERIMENTAL & 122 & 0,02 & 24 & 29,88 \\
\hline 561 & INTESTINO & 70 & & 12 & 29,73 \\
\hline 562 & MANEIRA & 308 & 0,04 & 66 & 29,67 \\
\hline 563 & DISCIPLINAS & 100 & 0,01 & 26 & 29,64 \\
\hline 564 & RITUAIS & 43 & & 13 & 29,63 \\
\hline
\end{tabular}




\begin{tabular}{|r|r|r|r|r|r|}
\hline 565 & CHAVE & 124 & 0,02 & 72 & 29,53 \\
\hline 566 & EEUSP & 30 & & 8 & 29,45 \\
\hline 567 & MACROBIÓTICA & 30 & & 6 & 29,45 \\
\hline 568 & TPI & 30 & & 2 & 29,45 \\
\hline 569 & SERENIDADE & 30 & & 3 & 29,45 \\
\hline 570 & FOGACHOS & 30 & & 1 & 29,45 \\
\hline 571 & VICINAL & 30 & & 1 & 29,45 \\
\hline 572 & SUTIS & 51 & & 12 & 28,97 \\
\hline 573 & VERTEBRAL & 37 & & 10 & 28,96 \\
\hline 574 & PSICOSSOCIAL & 62 & & 11 & 28,82 \\
\hline 575 & PLACEBO & 93 & 0,01 & 17 & 28,78 \\
\hline 576 & COLATERAIS & 120 & 0,01 & 39 & 28,72 \\
\hline 577 & FARMÁCIA & 84 & 0,01 & 27 & 28,59 \\
\hline 578 & FUNÇÕES & 135 & 0,02 & 30 & 28,57 \\
\hline 579 & CONVENTIONAL & 29 & & 10 & 28,47 \\
\hline 580 & HOMEOPATHY & 29 & & 7 & 28,47 \\
\hline 581 & CLEMATIS & 29 & & 4 & 28,47 \\
\hline 582 & VIBRACIONAIS & 29 & & 6 & 28,47 \\
\hline 583 & TRANSCENDÊNCIA & 29 & & 7 & 28,47 \\
\hline 584 & FAMILIARES & 147 & 0,02 & 34 & 28,39 \\
\hline
\end{tabular}




\section{APÊNDICE II - 500 PRIMEIRAS PALAVRAS-CHAVE DO CORPUS EM INGLÊS}

\begin{tabular}{|c|c|c|c|c|c|}
\hline $\mathbf{N}$ & Keyword & Freq. & $\%$ & Texts & Keyness \\
\hline 1 & \# & 47792 & 6,09 & 109 & 65827,84 \\
\hline 2 & CAM & 4890 & 0,62 & 74 & 44186,39 \\
\hline 3 & COMPLEMENTARY & 3692 & 0,47 & 108 & 31491,50 \\
\hline 4 & MEDICINE & 3996 & 0,51 & 110 & 29763,16 \\
\hline 5 & THERAPIES & 1891 & 0,24 & 100 & 17105,80 \\
\hline 6 & PUBMED & 1609 & 0,21 & 64 & 15584,43 \\
\hline 7 & PATIENTS & 3370 & 0,43 & 105 & 14523,86 \\
\hline 8 & MASSAGE & 1647 & 0,21 & 57 & 13243,62 \\
\hline 9 & HEALTH & 3322 & 0,42 & 106 & 12149,34 \\
\hline 10 & THERAPY & 1713 & 0,22 & 93 & 11644,68 \\
\hline 11 & HERBAL & 1271 & 0,16 & 74 & 11020,59 \\
\hline 12 & ALTERNATIVE & 2110 & 0,27 & 104 & 10004,22 \\
\hline 13 & TREATMENT & 2245 & 0,29 & 100 & 9467,01 \\
\hline 14 & ACUPUNCTURE & 984 & 0,13 & 72 & 8508,14 \\
\hline 15 & USE & 3703 & 0,47 & 105 & 8310,19 \\
\hline 16 & THERAPIST & 1092 & 0,14 & 28 & 8288,82 \\
\hline 17 & MEDICAL & 1759 & 0,22 & 101 & 7489,81 \\
\hline 18 & HEALTHCARE & 889 & 0,11 & 65 & 7408,96 \\
\hline 19 & TREATMENTS & 1018 & 0,13 & 82 & 7273,57 \\
\hline 20 & CANCER & 1316 & 0,17 & 68 & 6717,43 \\
\hline 21 & PRACTITIONERS & 1102 & 0,14 & 80 & 6666,39 \\
\hline 22 & CONVENTIONAL & 1261 & 0,16 & 88 & 6563,59 \\
\hline 23 & DATA & 1970 & 0,25 & 88 & 6444,43 \\
\hline 24 & MEDICINES & 845 & 0,11 & 70 & 6214,39 \\
\hline 25 & $\mathrm{~J}$ & 1538 & 0,20 & 98 & 5922,88 \\
\hline 26 & CLINICAL & 1034 & 0,13 & 89 & 5465,70 \\
\hline 27 & DOI & 575 & 0,07 & 40 & 5050,78 \\
\hline 28 & ACUPRESSURE & 513 & 0,07 & 22 & 4921,30 \\
\hline 29 & MED & 572 & 0,07 & 78 & 4875,57 \\
\hline 30 & $\mathrm{~S}$ & 1816 & 0,23 & 105 & 4722,86 \\
\hline 31 & NAUSEA & 586 & 0,07 & 10 & 4596,26 \\
\hline 32 & CARE & 1744 & 0,22 & 99 & 4447,00 \\
\hline 33 & HOMEOPATHY & 477 & 0,06 & 55 & 4421,11 \\
\hline 34 & STUDY & 1648 & 0,21 & 97 & 4367,95 \\
\hline 35 & RESEARCH & 1742 & 0,22 & 98 & 4198,74 \\
\hline 36 & HEALING & 680 & 0,09 & 51 & 4119,56 \\
\hline 37 & EFFECTS & 1210 & 0,15 & 85 & 3985,50 \\
\hline 38 & PAIN & 1035 & 0,13 & 60 & 3946,47 \\
\hline 39 & HOMEOPATHIC & 410 & 0,05 & 39 & 3797,03 \\
\hline 40 & ET & 916 & 0,12 & 78 & 3722,90 \\
\hline 41 & NHS & 721 & 0,09 & 51 & 3626,10 \\
\hline 42 & EVIDENCE & 1409 & 0,18 & 94 & 3451,10 \\
\hline 43 & $\mathrm{AL}$ & 940 & 0,12 & 78 & 3387,01 \\
\hline 44 & AROMATHERAPY & 426 & 0,05 & 43 & 3379,10 \\
\hline
\end{tabular}




\begin{tabular}{|c|c|c|c|c|c|}
\hline 45 & REFLEXOLOGY & 368 & 0,05 & 35 & 3284,52 \\
\hline 46 & CHEMOTHERAPY & 425 & 0,05 & 20 & 3195,24 \\
\hline 47 & PMC & 338 & 0,04 & 54 & 3175,72 \\
\hline 48 & TRIALS & 607 & 0,08 & 53 & 3044,21 \\
\hline 49 & PATIENT & 874 & 0,11 & 88 & 2978,90 \\
\hline 50 & PLACEBO & 421 & 0,05 & 38 & 2963,06 \\
\hline 51 & PRACTITIONER & 500 & 0,06 & 63 & 2924,93 \\
\hline 52 & WWW & 294 & 0,04 & 69 & 2823,19 \\
\hline 53 & STUDIES & 1027 & 0,13 & 91 & 2737,10 \\
\hline 54 & EFFECTIVENESS & 563 & 0,07 & 64 & 2716,95 \\
\hline 55 & USED & 2125 & 0,27 & 99 & 2700,70 \\
\hline 56 & VOMITING & 374 & 0,05 & 8 & 2675,24 \\
\hline 57 & EFFICACY & 403 & 0,05 & 64 & 2653,13 \\
\hline 58 & BENEFICIAL & 490 & 0,06 & 23 & 2616,65 \\
\hline 59 & PREVALENCE & 439 & 0,06 & 58 & 2523,02 \\
\hline 60 & SYMPTOMS & 584 & 0,07 & 57 & 2485,09 \\
\hline 61 & $\mathrm{~N}$ & 838 & 0,11 & 83 & 2473,63 \\
\hline 62 & CHRONIC & 490 & 0,06 & 60 & 2455,68 \\
\hline 63 & ADVERSE & 449 & 0,06 & 56 & 2453,76 \\
\hline 64 & ERNST & 354 & 0,05 & 76 & 2441,44 \\
\hline 65 & ASTHMA & 387 & 0,05 & 23 & 2395,33 \\
\hline 66 & SYSTEMATIC & 475 & 0,06 & 69 & 2359,23 \\
\hline 67 & PRACTICE & 1025 & 0,13 & 86 & 2348,98 \\
\hline 68 & HTTP & 237 & 0,03 & 67 & 2295,12 \\
\hline 69 & BODY & 1189 & 0,15 & 58 & 2290,25 \\
\hline 70 & MEDICINAL & 311 & 0,04 & 33 & 2227,32 \\
\hline 71 & RELAXATION & 415 & 0,05 & 46 & 2220,22 \\
\hline 72 & REGULATORY & 422 & 0,05 & 23 & 2204,47 \\
\hline 73 & AVAILABLE & 1218 & 0,16 & 83 & 2188,46 \\
\hline 74 & GINSENG & 245 & 0,03 & 21 & 2126,72 \\
\hline 75 & REMEDIES & 387 & 0,05 & 56 & 2100,59 \\
\hline 76 & CAMS & 246 & 0,03 & 19 & 2028,70 \\
\hline 77 & $\mathrm{E}$ & 1133 & 0,14 & 104 & 2009,58 \\
\hline 78 & REF & 538 & 0,07 & 24 & 1895,69 \\
\hline 79 & GP & 346 & 0,04 & 37 & 1883,99 \\
\hline 80 & WRISTBANDS & 196 & 0,02 & 1 & 1851,33 \\
\hline 81 & PARTICIPANTS & 427 & 0,05 & 47 & 1838,66 \\
\hline 82 & THERAPEUTIC & 315 & 0,04 & 68 & 1818,99 \\
\hline 83 & REVIEW & 695 & 0,09 & 77 & 1802,80 \\
\hline 84 & THERAPISTS & 249 & 0,03 & 37 & 1751,69 \\
\hline 85 & REGISTERED & 474 & 0,06 & 23 & 1749,13 \\
\hline 86 & SCHOLAR & 296 & 0,04 & 9 & 1699,64 \\
\hline 87 & BMJ & 195 & 0,02 & 54 & 1685,36 \\
\hline 88 & INTERACTIONS & 328 & 0,04 & 45 & 1684,27 \\
\hline 89 & PROFESSIONAL & 703 & 0,09 & 56 & 1671,63 \\
\hline 90 & DISEASE & 640 & 0,08 & 70 & 1653,72 \\
\hline 91 & SPECIFIC & 718 & 0,09 & 76 & 1618,60 \\
\hline 92 & SURVEY & 608 & 0,08 & 79 & 1614,27 \\
\hline 93 & TRIAL & 555 & 0,07 & 47 & 1583,82 \\
\hline 94 & CHIROPRACTIC & 184 & 0,02 & 44 & 1582,76 \\
\hline 95 & HYDROPATHY & 161 & 0,02 & 3 & 1559,12 \\
\hline 96 & REPORTED & 694 & 0,09 & 80 & 1531,18 \\
\hline
\end{tabular}




\begin{tabular}{|c|c|c|c|c|c|}
\hline 97 & NATUROPATHY & 165 & 0,02 & 21 & 1527,16 \\
\hline 98 & UK & 805 & 0,10 & 94 & 1524,31 \\
\hline 99 & TRAINING & 883 & 0,11 & 51 & 1517,73 \\
\hline 100 & OSTEOPATHY & 168 & 0,02 & 44 & 1513,62 \\
\hline 101 & RISKS & 386 & 0,05 & 41 & 1498,08 \\
\hline 102 & SHAM & 216 & 0,03 & 8 & 1493,56 \\
\hline 103 & SUPPLEMENTS & 268 & 0,03 & 48 & 1481,63 \\
\hline 104 & SELF & 831 & 0,11 & 67 & 1481,50 \\
\hline 105 & CLIN & 152 & 0,02 & 49 & 1471,96 \\
\hline 106 & GINKGO & 157 & 0,02 & 15 & 1469,07 \\
\hline 107 & REGULATION & 381 & 0,05 & 37 & 1429,89 \\
\hline 108 & PREGNANCY & 322 & 0,04 & 21 & 1421,98 \\
\hline 109 & HERBS & 275 & 0,04 & 35 & 1415,54 \\
\hline 110 & INFORMATION & 1171 & 0,15 & 98 & 1402,09 \\
\hline 111 & RESPONDENTS & 289 & 0,04 & 39 & 1395,07 \\
\hline 112 & PROFESSIONALS & 354 & 0,05 & 60 & 1381,45 \\
\hline 113 & KAVA & 146 & 0,02 & 12 & 1357,11 \\
\hline 114 & DOCTORS & 434 & 0,06 & 64 & 1352,65 \\
\hline 115 & LIKELY & 874 & 0,11 & 77 & 1334,39 \\
\hline 116 & OILS & 256 & 0,03 & 26 & 1329,66 \\
\hline 117 & OR & 5109 & 0,65 & 110 & 1323,52 \\
\hline 118 & ARTICLE & 493 & 0,06 & 82 & 1301,69 \\
\hline 119 & CROSS & 607 & 0,08 & 43 & 1297,81 \\
\hline 120 & FHT & 134 & 0,02 & 2 & 1297,65 \\
\hline 121 & $\mathrm{M}$ & 742 & 0,09 & 91 & 1293,84 \\
\hline 122 & POSITIVE & 539 & 0,07 & 60 & 1289,98 \\
\hline 123 & QUESTIONNAIRE & 275 & 0,04 & 51 & 1269,92 \\
\hline 124 & JOURNAL & 331 & 0,04 & 41 & 1247,54 \\
\hline 125 & RESULTS & 691 & 0,09 & 91 & 1243,80 \\
\hline 126 & USING & 864 & 0,11 & 92 & 1220,66 \\
\hline 127 & HYPNOTHERAPY & 149 & 0,02 & 22 & 1219,34 \\
\hline 128 & CROSSREF & 125 & 0,02 & 8 & 1210,49 \\
\hline 129 & QUALITATIVE & 222 & 0,03 & 33 & 1207,17 \\
\hline 130 & USERS & 470 & 0,06 & 59 & 1198,57 \\
\hline 131 & ONCOLOGY & 143 & 0,02 & 25 & 1190,24 \\
\hline 132 & RANDOMIZED & 145 & 0,02 & 33 & 1185,67 \\
\hline 133 & PHYSICIANS & 196 & 0,02 & 51 & 1178,69 \\
\hline 134 & MEDICATION & 207 & 0,03 & 46 & 1161,65 \\
\hline 135 & BENEFITS & 489 & 0,06 & 51 & 1156,13 \\
\hline 136 & ORG & 130 & 0,02 & 40 & 1149,63 \\
\hline 137 & REIKI & 123 & 0,02 & 20 & 1148,97 \\
\hline 138 & CONTRAINDICATIONS & 129 & 0,02 & 10 & 1148,78 \\
\hline 139 & SHIATSU & 129 & 0,02 & 12 & 1140,21 \\
\hline 140 & BILOBA & 122 & 0,02 & 16 & 1133,09 \\
\hline 141 & $\mathrm{P}$ & 992 & 0,13 & 87 & 1103,97 \\
\hline 142 & MAY & 2234 & 0,28 & 103 & 1088,31 \\
\hline 143 & QUALITY & 669 & 0,09 & 65 & 1087,34 \\
\hline 144 & $\mathrm{G}$ & 633 & 0,08 & 88 & 1053,75 \\
\hline 145 & IRIDOLOGY & 110 & 0,01 & 16 & 1030,63 \\
\hline 146 & COMMONLY & 300 & 0,04 & 55 & 1027,19 \\
\hline 147 & RANDOMISED & 167 & 0,02 & 37 & 1011,25 \\
\hline 148 & MUSCULOSKELETAL & 112 & 0,01 & 22 & 1010,67 \\
\hline
\end{tabular}




\begin{tabular}{|c|c|c|c|c|c|}
\hline 149 & TABLE & 707 & 0,09 & 70 & 1009,27 \\
\hline 150 & REVIEWS & 242 & 0,03 & 39 & 1008,60 \\
\hline 151 & QUALIFIED & 308 & 0,04 & 22 & 1008,56 \\
\hline 152 & HOLISTIC & 161 & 0,02 & 47 & 1007,88 \\
\hline 153 & THER & 124 & 0,02 & 45 & 995,37 \\
\hline 154 & BREAST & 259 & 0,03 & 30 & 985,72 \\
\hline 155 & $\mathrm{~K}$ & 392 & 0,05 & 92 & 979,64 \\
\hline 156 & SYMPTOM & 188 & 0,02 & 32 & 976,03 \\
\hline 157 & ONLINE & 189 & 0,02 & 36 & 974,75 \\
\hline 158 & PRIMARY & 482 & 0,06 & 72 & 970,94 \\
\hline 159 & COCHRANE & 140 & 0,02 & 34 & 964,38 \\
\hline 160 & SURVEYS & 260 & 0,03 & 46 & 953,92 \\
\hline 161 & COMPLEMENT & 204 & 0,03 & 57 & 945,90 \\
\hline 162 & RISK & 536 & 0,07 & 57 & 945,56 \\
\hline 163 & INTERNET & 129 & 0,02 & 30 & 938,68 \\
\hline 164 & ALTERN & 105 & 0,01 & 36 & 935,15 \\
\hline 165 & BASED & 803 & 0,10 & 98 & 931,12 \\
\hline 166 & SCIENCE & 495 & 0,06 & 68 & 930,42 \\
\hline 167 & $\mathrm{OM}$ & 121 & 0,02 & 3 & 927,92 \\
\hline 168 & CONCLUSIONS & 273 & 0,03 & 48 & 926,82 \\
\hline 169 & TECHNIQUES & 383 & 0,05 & 41 & 921,06 \\
\hline 170 & WEB & 180 & 0,02 & 20 & 912,46 \\
\hline 171 & META & 126 & 0,02 & 25 & 886,94 \\
\hline 172 & HERB & 159 & 0,02 & 33 & 877,23 \\
\hline 173 & ILLNESS & 291 & 0,04 & 61 & 870,13 \\
\hline 174 & EPILEPSY & 137 & 0,02 & 7 & 866,44 \\
\hline 175 & INEFFECTIVE & 176 & 0,02 & 11 & 858,94 \\
\hline 176 & ARTHRITIS & 161 & 0,02 & 23 & 854,47 \\
\hline 177 & EFFECTIVE & 468 & 0,06 & 74 & 853,78 \\
\hline 178 & INTERVENTIONS & 157 & 0,02 & 41 & 850,94 \\
\hline 179 & MODALITIES & 110 & 0,01 & 35 & 849,61 \\
\hline 180 & $\mathrm{TCM}$ & 87 & 0,01 & 6 & 842,50 \\
\hline 181 & $\mathrm{CI}$ & 159 & 0,02 & 25 & 841,68 \\
\hline 182 & CLIENT & 361 & 0,05 & 9 & 838,84 \\
\hline 183 & CONTROLLED & 344 & 0,04 & 52 & 834,22 \\
\hline 184 & MENOPAUSE & 134 & 0,02 & 11 & 830,55 \\
\hline 185 & HIV & 241 & 0,03 & 14 & 826,63 \\
\hline 186 & PRODUCTS & 467 & 0,06 & 53 & 818,30 \\
\hline 187 & COMMITTEE & 620 & 0,08 & 48 & 816,03 \\
\hline 188 & POTENTIAL & 474 & 0,06 & 74 & 810,08 \\
\hline 189 & ANXIETY & 257 & 0,03 & 38 & 806,76 \\
\hline 190 & CITED & 213 & 0,03 & 60 & 805,31 \\
\hline 191 & INTEGRATIVE & 111 & 0,01 & 28 & 804,72 \\
\hline 192 & RCTS & 84 & 0,01 & 12 & 802,59 \\
\hline 193 & METHODS & 423 & 0,05 & 87 & 801,24 \\
\hline 194 & SOY & 114 & 0,01 & 5 & 799,51 \\
\hline 195 & COMPETENCE & 211 & 0,03 & 14 & 798,03 \\
\hline 196 & WORT & 101 & 0,01 & 21 & 796,10 \\
\hline 197 & ASSOCIATED & 428 & 0,05 & 78 & 786,07 \\
\hline 198 & OUTCOMES & 181 & 0,02 & 39 & 779,91 \\
\hline 199 & NON & 658 & 0,08 & 72 & 779,08 \\
\hline 200 & $\mathrm{D}$ & 547 & 0,07 & 88 & 775,43 \\
\hline
\end{tabular}




\begin{tabular}{|c|c|c|c|c|c|}
\hline 201 & REGISTER & 268 & 0,03 & 11 & 770,56 \\
\hline 202 & NCCAM & 79 & 0,01 & 20 & 765,02 \\
\hline 203 & PHARMACOLOGIC & 81 & 0,01 & 2 & 758,55 \\
\hline 204 & CHOOSING & 219 & 0,03 & 19 & 758,17 \\
\hline 205 & BIOFEEDBACK & 93 & 0,01 & 11 & 756,21 \\
\hline 206 & TRADITIONAL & 428 & 0,05 & 62 & 755,58 \\
\hline 207 & CROSSREFMEDLINEGOOGLE & 78 & & 3 & 755,34 \\
\hline 208 & FIBROMYALGIA & 82 & 0,01 & 7 & 750,36 \\
\hline 209 & JAMA & 90 & 0,01 & 40 & 748,51 \\
\hline 210 & ANALYSIS & 495 & 0,06 & 77 & 745,77 \\
\hline 211 & CHINESE & 296 & 0,04 & 47 & 745,47 \\
\hline 212 & LACTATION & 96 & 0,01 & 5 & 744,93 \\
\hline 213 & DRUG & 327 & 0,04 & 52 & 744,50 \\
\hline 214 & PROFESSIONS & 170 & 0,02 & 18 & 739,90 \\
\hline 215 & CURE & 201 & 0,03 & 35 & 738,01 \\
\hline 216 & MOLASSIOTIS & 76 & & 8 & 735,97 \\
\hline 217 & HOMOEOPATHY & 120 & 0,02 & 27 & 735,46 \\
\hline 218 & DIAGNOSIS & 209 & 0,03 & 47 & 730,10 \\
\hline 219 & EISENBERG & 81 & 0,01 & 41 & 726,02 \\
\hline 220 & FARIDA & 76 & & 2 & 725,31 \\
\hline 221 & ANTIOXIDANT & 85 & 0,01 & 10 & 717,93 \\
\hline 222 & SAMPLE & 301 & 0,04 & 61 & 717,45 \\
\hline 223 & DISCIPLINARY & 186 & 0,02 & 6 & 712,61 \\
\hline 224 & OSTEOARTHRITIS & 84 & 0,01 & 10 & 711,93 \\
\hline 225 & GRCCT & 73 & & 1 & 706,92 \\
\hline 226 & IMPROVE & 334 & 0,04 & 46 & 700,82 \\
\hline 227 & INDUCED & 199 & 0,03 & 20 & 690,31 \\
\hline 228 & CONDITIONS & 514 & 0,07 & 58 & 689,14 \\
\hline 229 & DIETARY & 153 & 0,02 & 40 & 687,91 \\
\hline 230 & YOGA & 114 & 0,01 & 25 & 686,16 \\
\hline 231 & ENOUGH & 763 & 0,10 & 26 & 685,26 \\
\hline 232 & EXTRACT & 189 & 0,02 & 20 & 682,56 \\
\hline 233 & PROSTATE & 107 & 0,01 & 17 & 679,16 \\
\hline 234 & HYDROPATHIC & 72 & & 1 & 678,88 \\
\hline 235 & ORTHODOX & 174 & 0,02 & 33 & 667,42 \\
\hline 236 & FLUSHES & 94 & 0,01 & 4 & 665,42 \\
\hline 237 & CLINICIANS & 110 & 0,01 & 28 & 662,59 \\
\hline 238 & INTEGRATED & 230 & 0,03 & 48 & 661,81 \\
\hline 239 & WEBSITE & 68 & & 18 & 658,50 \\
\hline 240 & VITAMIN & 156 & 0,02 & 27 & 656,50 \\
\hline 241 & PARKINSON & 120 & 0,02 & 4 & 640,59 \\
\hline 242 & CONDUCTED & 234 & 0,03 & 72 & 638,64 \\
\hline 243 & SAFETY & 369 & 0,05 & 61 & 637,20 \\
\hline 244 & PANAX & 67 & & 7 & 630,74 \\
\hline 245 & GPS & 140 & 0,02 & 23 & 629,46 \\
\hline 246 & DOSAGE & 97 & 0,01 & 8 & 627,18 \\
\hline 247 & ALLERGIC & 108 & 0,01 & 10 & 612,84 \\
\hline 248 & SYNDROME & 162 & 0,02 & 27 & 608,43 \\
\hline 249 & GOOGLE & 64 & & 9 & 601,87 \\
\hline 250 & ECHINACEA & 64 & & 12 & 601,87 \\
\hline 251 & MUSCULAR & 133 & 0,02 & 8 & 600,90 \\
\hline 252 & $\mathrm{COHOSH}$ & 62 & & 5 & 600,40 \\
\hline
\end{tabular}




\begin{tabular}{|c|c|c|c|c|c|}
\hline 253 & MENOPAUSAL & 78 & & 9 & 596,51 \\
\hline 254 & ACCESSED & 115 & 0,01 & 45 & 592,99 \\
\hline 255 & $\mathrm{C}$ & 734 & 0,09 & 93 & 592,56 \\
\hline 256 & PRACT & 61 & & 35 & 590,71 \\
\hline 257 & FURNHAM & 62 & & 21 & 590,14 \\
\hline 258 & CONSULT & 159 & 0,02 & 17 & 585,39 \\
\hline 259 & $\mathrm{~L}$ & 396 & 0,05 & 78 & 581,37 \\
\hline 260 & CLINICS & 138 & 0,02 & 36 & 581,08 \\
\hline 261 & PHARMACOL & 60 & & 21 & 581,03 \\
\hline 262 & LEWITH & 60 & & 26 & 581,03 \\
\hline 263 & RHEUMATOID & 91 & 0,01 & 11 & 578,69 \\
\hline 264 & FLAVONOIDS & 67 & & 3 & 574,46 \\
\hline 265 & DRUGS & 279 & 0,04 & 54 & 571,72 \\
\hline 266 & EMETOGENIC & 59 & & 1 & 571,35 \\
\hline 267 & AYURVEDIC & 67 & & 20 & 567,69 \\
\hline 268 & LIFESTYLE & 152 & 0,02 & 22 & 567,29 \\
\hline 269 & CRITERIA & 243 & 0,03 & 54 & 566,57 \\
\hline 270 & MEDICATIONS & 77 & & 29 & 565,50 \\
\hline 271 & LANCET & 92 & 0,01 & 42 & 561,79 \\
\hline 272 & KINESIOLOGY & 59 & & 14 & 561,19 \\
\hline 273 & QUESTIONNAIRES & 118 & 0,02 & 34 & 552,09 \\
\hline 274 & BENEFIT & 385 & 0,05 & 51 & 547,15 \\
\hline 275 & CHIROPRACTORS & 62 & & 19 & 546,55 \\
\hline 276 & SEROTONIN & 82 & 0,01 & 5 & 546,32 \\
\hline 277 & $\mathrm{COM}$ & 103 & 0,01 & 48 & 544,65 \\
\hline 278 & METHODOLOGICAL & 113 & 0,01 & 24 & 543,44 \\
\hline 279 & CROSSREFMEDLINEWEB & 56 & & 4 & 542,29 \\
\hline 280 & INHIBITORS & 97 & 0,01 & 5 & 537,28 \\
\hline 281 & GENERAL & 816 & 0,10 & 87 & 535,60 \\
\hline 282 & HOMEOPATHS & 57 & & 11 & 534,54 \\
\hline 283 & PROFILE & 193 & 0,02 & 23 & 532,85 \\
\hline 284 & WEBSITES & 55 & & 9 & 532,61 \\
\hline 285 & EUR & 61 & & 29 & 529,33 \\
\hline 286 & FACTORS & 337 & 0,04 & 65 & 528,59 \\
\hline 287 & INCLUDED & 403 & 0,05 & 75 & 527,43 \\
\hline 288 & CLOVER & 93 & 0,01 & 4 & 525,30 \\
\hline 289 & FINDINGS & 215 & 0,03 & 51 & 519,73 \\
\hline 290 & HOSPITAL & 442 & 0,06 & 59 & 519,65 \\
\hline 291 & SCORES & 172 & 0,02 & 21 & 519,09 \\
\hline 292 & CAS & 78 & & 5 & 518,69 \\
\hline 293 & ADRS & 56 & & 3 & 518,62 \\
\hline 294 & ANTIEMETIC & 56 & & 2 & 518,62 \\
\hline 295 & CONDITION & 327 & 0,04 & 40 & 518,02 \\
\hline 296 & HARMFUL & 130 & 0,02 & 20 & 516,53 \\
\hline 297 & STANDARDS & 348 & 0,04 & 33 & 512,34 \\
\hline 298 & WARNINGS & 127 & 0,02 & 6 & 511,58 \\
\hline 299 & $\mathrm{OF}$ & 27755 & 3,54 & 110 & 510,09 \\
\hline 300 & METHODOLOGICALLY & 65 & & 9 & 509,16 \\
\hline 301 & PAEDIATRIC & 80 & 0,01 & 15 & 507,40 \\
\hline 302 & RELATED & 356 & 0,05 & 68 & 504,16 \\
\hline 303 & PRECAUTIONS & 115 & 0,01 & 2 & 501,68 \\
\hline 304 & ALZHEIMER & 58 & & 3 & 501,29 \\
\hline
\end{tabular}




\begin{tabular}{|c|c|c|c|c|c|}
\hline 305 & ANALYSES & 148 & 0,02 & 30 & 500,20 \\
\hline 306 & AND & 24027 & 3,06 & 110 & 499,33 \\
\hline 307 & CONSULTATION & 190 & 0,02 & 30 & 497,07 \\
\hline 308 & SHARAN & 58 & & 2 & 494,27 \\
\hline 309 & PREPARATIONS & 134 & 0,02 & 28 & 493,91 \\
\hline 310 & EMOTIONAL & 216 & 0,03 & 30 & 493,86 \\
\hline 311 & $\mathrm{Q}$ & 281 & 0,04 & 15 & 493,01 \\
\hline 312 & POPULATION & 403 & 0,05 & 67 & 492,49 \\
\hline 313 & CLINIC & 150 & 0,02 & 41 & 487,30 \\
\hline 314 & HYPNOSIS & 91 & 0,01 & 20 & 487,15 \\
\hline 315 & DIETS & 109 & 0,01 & 15 & 486,70 \\
\hline 316 & SINENSIS & 56 & & 6 & 486,31 \\
\hline 317 & AUTHORS & 185 & 0,02 & 58 & 485,18 \\
\hline 318 & SIGNI & 51 & & 6 & 484,01 \\
\hline 319 & DEPRESSION & 176 & 0,02 & 30 & 481,99 \\
\hline 320 & HEALERS & 69 & & 18 & 480,74 \\
\hline 321 & NATUROPATHIC & 52 & & 15 & 480,32 \\
\hline 322 & SYST & 52 & & 15 & 480,32 \\
\hline 323 & WRISTBAND & 54 & & 2 & 479,56 \\
\hline 324 & BASELINE & 108 & 0,01 & 14 & 476,51 \\
\hline 325 & $\mathrm{R}$ & 454 & 0,06 & 84 & 475,15 \\
\hline 326 & INTERN & 59 & & 27 & 469,46 \\
\hline 327 & FUNDING & 229 & 0,03 & 48 & 469,22 \\
\hline 328 & OUTPATIENT & 91 & 0,01 & 31 & 468,52 \\
\hline 329 & IMMERSION & 86 & 0,01 & 6 & 468,36 \\
\hline 330 & EVALUATION & 194 & 0,02 & 46 & 466,37 \\
\hline 331 & BOTANICALS & 53 & & 10 & 465,96 \\
\hline 332 & PITTLER & 48 & & 20 & 464,82 \\
\hline 333 & MIDWIVES & 81 & 0,01 & 11 & 459,63 \\
\hline 334 & DEMOGRAPHIC & 117 & 0,01 & 37 & 459,60 \\
\hline 335 & PHYSICIAN & 103 & 0,01 & 43 & 457,63 \\
\hline 336 & TREAT & 209 & 0,03 & 47 & 456,59 \\
\hline 337 & IDENTIFIED & 268 & 0,03 & 53 & 456,39 \\
\hline 338 & NUTRITIONAL & 99 & 0,01 & 32 & 456,30 \\
\hline 339 & OUTCOME & 209 & 0,03 & 34 & 455,83 \\
\hline 340 & HOMOEOPATHIC & 83 & 0,01 & 16 & 455,24 \\
\hline 341 & $\mathrm{DM}$ & 83 & 0,01 & 43 & 448,97 \\
\hline 342 & ACUPUNCTURISTS & 52 & & 19 & 448,93 \\
\hline 343 & KNOWLEDGE & 408 & 0,05 & 79 & 448,83 \\
\hline 344 & COMPARED & 312 & 0,04 & 64 & 446,03 \\
\hline 345 & INTERVIEWS & 172 & 0,02 & 30 & 445,88 \\
\hline 346 & ONCOL & 46 & & 21 & 445,46 \\
\hline 347 & ANTIEMETICS & 47 & & 3 & 445,43 \\
\hline 348 & METHYSTICUM & 47 & & 5 & 445,43 \\
\hline 349 & $\mathrm{MG}$ & 139 & 0,02 & 13 & 445,42 \\
\hline 350 & PREDICTORS & 63 & & 24 & 444,93 \\
\hline 351 & CONSIDERED & 390 & 0,05 & 66 & 443,46 \\
\hline 352 & OMEGA & 73 & & 6 & 442,91 \\
\hline 353 & ADVICE & 338 & 0,04 & 46 & 442,49 \\
\hline 354 & CLICK & 110 & 0,01 & 12 & 441,78 \\
\hline 355 & AUTOGENIC & 49 & & 5 & 441,27 \\
\hline 356 & DIABETES & 109 & 0,01 & 16 & 441,24 \\
\hline
\end{tabular}




\begin{tabular}{|c|c|c|c|c|c|}
\hline 357 & PRESCRIBED & 133 & 0,02 & 45 & 439,49 \\
\hline 358 & GINGKO & 47 & & 8 & 438,46 \\
\hline 359 & TRAINED & 212 & 0,03 & 34 & 437,79 \\
\hline 360 & OIL & 344 & 0,04 & 33 & 437,20 \\
\hline 361 & FREE & 541 & 0,07 & 73 & 436,97 \\
\hline 362 & PHARMACOLOGICAL & 64 & & 27 & 436,67 \\
\hline 363 & PROVIDERS & 114 & 0,01 & 33 & 436,54 \\
\hline 364 & ARV & 46 & & 1 & 435,79 \\
\hline 365 & STATUTORY & 208 & 0,03 & 13 & 434,67 \\
\hline 366 & REFERRAL & 109 & 0,01 & 23 & 433,46 \\
\hline 367 & REASONS & 341 & 0,04 & 65 & 432,67 \\
\hline 368 & MEDITATION & 98 & 0,01 & 25 & 431,52 \\
\hline 369 & $\mathrm{~T}$ & 380 & 0,05 & 81 & 430,75 \\
\hline 370 & $\mathrm{CHI}$ & 89 & 0,01 & 29 & 428,29 \\
\hline 371 & $\mathrm{H}$ & 327 & 0,04 & 74 & 427,33 \\
\hline 372 & DISORDERS & 115 & 0,01 & 31 & 427,20 \\
\hline 373 & EVALUATIONS & 79 & 0,01 & 14 & 426,23 \\
\hline 374 & BIENNIS & 44 & & 3 & 426,09 \\
\hline 375 & ACUTE & 165 & 0,02 & 35 & 424,38 \\
\hline 376 & SCIENTIFIC & 246 & 0,03 & 48 & 421,49 \\
\hline 377 & REMEDY & 144 & 0,02 & 35 & 420,04 \\
\hline 378 & PRIMROSE & 76 & & 14 & 419,40 \\
\hline 379 & OTC & 70 & & 7 & 419,27 \\
\hline 380 & MANIPULATION & 114 & 0,01 & 24 & 417,67 \\
\hline 381 & KAMPO & 43 & & 3 & 416,40 \\
\hline 382 & MH & 57 & & 27 & 416,00 \\
\hline 383 & QI & 52 & & 9 & 413,84 \\
\hline 384 & PROFESSIONALLY & 97 & 0,01 & 4 & 412,07 \\
\hline 385 & SPORTS & 215 & 0,03 & 9 & 412,04 \\
\hline 386 & NURSES & 166 & 0,02 & 29 & 408,39 \\
\hline 387 & FIM & 45 & & 4 & 408,13 \\
\hline 388 & SCIENCEGOOGLE & 42 & & 2 & 406,72 \\
\hline 389 & PHYSICAL & 311 & 0,04 & 43 & 406,05 \\
\hline 390 & CARDIOVASCULAR & 78 & & 12 & 405,93 \\
\hline 391 & UPTAKE & 87 & 0,01 & 13 & 404,68 \\
\hline 392 & OENOTHERA & 44 & & 3 & 403,82 \\
\hline 393 & APPROACHES & 185 & 0,02 & 52 & 403,49 \\
\hline 394 & MEDLINE & 49 & & 23 & 402,21 \\
\hline 395 & BALANCE & 299 & 0,04 & 25 & 400,44 \\
\hline 396 & AYURVEDA & 43 & & 14 & 400,07 \\
\hline 397 & ABSTRACT & 155 & 0,02 & 69 & 399,29 \\
\hline 398 & GOV & 47 & & 22 & 398,97 \\
\hline 399 & PERCEIVED & 162 & 0,02 & 45 & 397,60 \\
\hline 400 & ACTAEA & 41 & & 2 & 397,04 \\
\hline 401 & CYCLE & 189 & 0,02 & 8 & 396,20 \\
\hline 402 & BR & 122 & 0,02 & 51 & 395,74 \\
\hline 403 & APPROPRIATE & 339 & 0,04 & 54 & 395,43 \\
\hline 404 & MJ & 45 & & 28 & 394,80 \\
\hline 405 & OSTEOPATHIC & 43 & & 12 & 394,27 \\
\hline 406 & GENDER & 150 & 0,02 & 30 & 392,13 \\
\hline 407 & VITAMINS & 92 & 0,01 & 36 & 391,95 \\
\hline 408 & SOC & 75 & & 32 & 391,34 \\
\hline
\end{tabular}




\begin{tabular}{|c|c|c|c|c|c|}
\hline 409 & PRACTICES & 210 & 0,03 & 48 & 390,83 \\
\hline 410 & STANDARD & 363 & 0,05 & 44 & 390,76 \\
\hline 411 & SMEDLEY & 52 & & 1 & 390,53 \\
\hline 412 & RACEMOSA & 42 & & 3 & 390,48 \\
\hline 413 & CONSTITUENTS & 108 & 0,01 & 12 & 389,50 \\
\hline 414 & ALTMED & 40 & & 1 & 387,35 \\
\hline 415 & EBSCOHOST & 40 & & 1 & 387,35 \\
\hline 416 & RES & 82 & 0,01 & 30 & 384,70 \\
\hline 417 & CLONIDINE & 43 & & 3 & 384,41 \\
\hline 418 & ETHICS & 107 & 0,01 & 45 & 384,37 \\
\hline 419 & $\mathrm{JA}$ & 62 & & 36 & 382,66 \\
\hline 420 & FUTON & 47 & & 1 & 381,31 \\
\hline 421 & NATUROPATHS & 41 & & 9 & 380,89 \\
\hline 422 & SIGNIFICANT & 343 & 0,04 & 71 & 380,55 \\
\hline 423 & HYPERTENSION & 83 & 0,01 & 8 & 379,71 \\
\hline 424 & UNKNOWN & 201 & 0,03 & 15 & 379,12 \\
\hline 425 & BELIEFS & 156 & 0,02 & 38 & 378,54 \\
\hline 426 & DULCIS & 40 & & 1 & 377,97 \\
\hline 427 & JADAD & 39 & & 3 & 377,67 \\
\hline 428 & MASSAGING & 60 & & 3 & 377,57 \\
\hline 429 & PCT & 53 & & 4 & 377,22 \\
\hline 430 & LEVODOPA & 43 & & 2 & 376,02 \\
\hline 431 & TRANSDERMAL & 41 & & 1 & 375,18 \\
\hline 432 & $\mathrm{SCI}$ & 64 & & 25 & 372,69 \\
\hline 433 & MENTAL & 230 & 0,03 & 36 & 371,49 \\
\hline 434 & GROUPS & 450 & 0,06 & 65 & 370,97 \\
\hline 435 & HOMEOPATH & 41 & & 15 & 370,10 \\
\hline 436 & MEDICALLY & 65 & & 21 & 365,53 \\
\hline 437 & REGRESSION & 96 & 0,01 & 20 & 363,86 \\
\hline 438 & ASSOCIATION & 328 & 0,04 & 59 & 362,66 \\
\hline 439 & HERBALISM & 44 & & 18 & 362,20 \\
\hline 440 & GLUCOSAMINE & 40 & & 9 & 360,61 \\
\hline 441 & DIPLOMA & 103 & 0,01 & 8 & 360,06 \\
\hline 442 & QUAI & 44 & & 3 & 359,43 \\
\hline 443 & MONNIERI & 38 & & 2 & 358,70 \\
\hline 444 & GABAPENTIN & 37 & & 1 & 358,30 \\
\hline 445 & UNCONVENTIONAL & 65 & & 30 & 357,53 \\
\hline 446 & CONTRADICTORY & 97 & 0,01 & 7 & 356,30 \\
\hline 447 & ESSENCES & 61 & & 9 & 355,77 \\
\hline 448 & LITERATURE & 211 & 0,03 & 67 & 355,59 \\
\hline 449 & EFFECT & 495 & 0,06 & 65 & 354,73 \\
\hline 450 & ATTITUDES & 204 & 0,03 & 56 & 353,85 \\
\hline 451 & RA & 80 & 0,01 & 20 & 353,47 \\
\hline 452 & PREVENTION & 126 & 0,02 & 41 & 352,71 \\
\hline 453 & RECOMMEND & 133 & 0,02 & 26 & 350,84 \\
\hline 454 & OBSERVATIONAL & 66 & & 16 & 347,05 \\
\hline 455 & BOWEL & 116 & 0,01 & 20 & 346,91 \\
\hline 456 & ENGL & 38 & & 27 & 346,57 \\
\hline 457 & BMC & 59 & & 29 & 344,75 \\
\hline 458 & INCLUDING & 501 & 0,06 & 83 & 344,32 \\
\hline 459 & CHELATION & 38 & & 6 & 341,63 \\
\hline 460 & BIOMEDICAL & 54 & & 23 & 339,52 \\
\hline
\end{tabular}




\begin{tabular}{|c|c|c|c|c|c|}
\hline 461 & FOR & 8567 & 1,09 & 110 & 338,25 \\
\hline 462 & INSOMNIA & 57 & & 4 & 336,89 \\
\hline 463 & DYSFUNCTION & 59 & & 11 & 335,84 \\
\hline 464 & $\mathrm{SD}$ & 74 & & 15 & 334,78 \\
\hline 465 & FATTY & 87 & 0,01 & 6 & 334,36 \\
\hline 466 & GASTROINTESTINAL & 84 & 0,01 & 14 & 333,11 \\
\hline 467 & NURSING & 159 & 0,02 & 32 & 332,82 \\
\hline 468 & SPINAL & 78 & & 20 & 331,66 \\
\hline 469 & EVECT & 34 & & 2 & 329,25 \\
\hline 470 & PROBIOTICS & 34 & & 4 & 329,25 \\
\hline 471 & QIGONG & 34 & & 6 & 329,25 \\
\hline 472 & CLIENTS & 198 & 0,03 & 14 & 329,22 \\
\hline 473 & PEER & 101 & 0,01 & 25 & 329,12 \\
\hline 474 & OSTEOPATHS & 40 & & 12 & 328,51 \\
\hline 475 & REGARDING & 146 & 0,02 & 54 & 328,33 \\
\hline 476 & RIGOROUS & 89 & 0,01 & 28 & 327,85 \\
\hline 477 & PHYTO & 37 & & 1 & 327,72 \\
\hline 478 & ERECTILE & 37 & & 2 & 327,72 \\
\hline 479 & IRRITABLE & 72 & & 13 & 326,85 \\
\hline 480 & DATABASE & 166 & 0,02 & 40 & 326,78 \\
\hline 481 & INSURED & 95 & 0,01 & 4 & 326,32 \\
\hline 482 & ENHANCE & 116 & 0,01 & 23 & 325,90 \\
\hline 483 & PROGESTERONE & 46 & & 1 & 325,78 \\
\hline 484 & UNIVERSITY & 379 & 0,05 & 70 & 325,29 \\
\hline 485 & CHARACTERISTICS & 175 & 0,02 & 55 & 325,15 \\
\hline 486 & ALLERGY & 65 & & 10 & 321,96 \\
\hline 487 & OESTROGEN & 55 & & 5 & 321,95 \\
\hline 488 & MANUAL & 147 & 0,02 & 23 & 320,80 \\
\hline 489 & EPHEDRA & 34 & & 5 & 320,18 \\
\hline 490 & $\mathrm{~A} ß$ & 33 & & 1 & 319,57 \\
\hline 491 & AMED & 33 & & 11 & 319,57 \\
\hline 492 & REDUCE & 238 & 0,03 & 33 & 319,01 \\
\hline 493 & DIARRHOEA & 91 & 0,01 & 9 & 318,55 \\
\hline 494 & STRATEGIES & 149 & 0,02 & 33 & 317,57 \\
\hline 495 & GUIDELINES & 139 & 0,02 & 28 & 317,17 \\
\hline 496 & INDIVIDUALIZED & 46 & & 9 & 315,95 \\
\hline 497 & ASSESSMENT & 232 & 0,03 & 52 & 315,50 \\
\hline 498 & OVID & 43 & & 3 & 314,56 \\
\hline 499 & CMS & 52 & & 1 & 314,04 \\
\hline 500 & YOHIMBINE & 34 & & 2 & 313,83 \\
\hline
\end{tabular}

